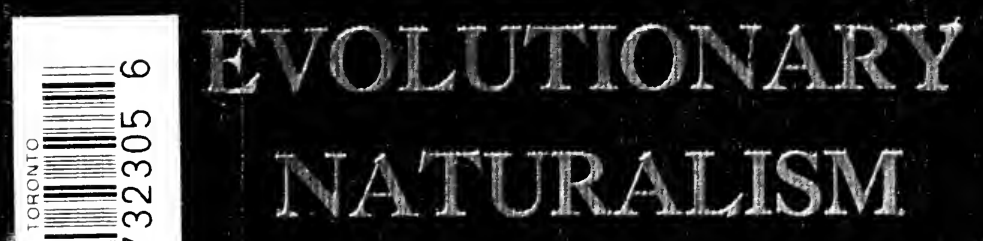

FOY WOOD SELLARS 


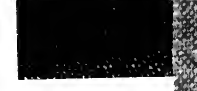
(7)

s.
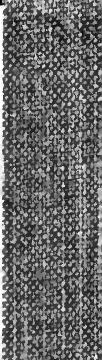



$$
\text { - }
$$




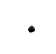




\section{Evolutionary Naturalism}


. 


\section{Evolutionary Naturalism}

By ROY WOOD SELLARS, Ph. D.

ASSOCIATE PROFESSOR OF PHILOSOPHY IN THE UNIVERSITY OF MICHIGAN Author of "Critical Realism," "The Next Step In Religion," "The Essentials of Philosophy," Etc.

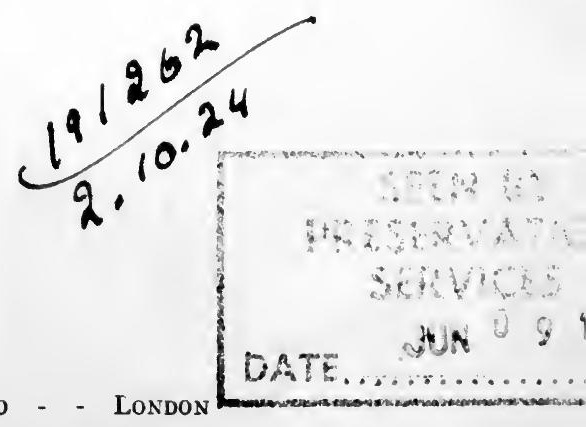

THE OPEN COUR'T PUBLISHING COMPANY 
Copyright, 1922

\section{THE OPEN COURT PUBLISHING COMPANY}

\section{Chicago}




\section{TO HELEN}




\section{PREFACE.}

T $O$ paraphrase a saying which gained considerable notoriety a 1 decade ago in the field of politics, we are all naturalists now. But, even so, this common naturalism is of a very vague and general sort, capable of covering an immense diversity of opinion. It is an admission of a direction more than a clearly formulated belief. It is less a philosophical system than a recognition of the impressive implications of the physical and the biological sciences. And, not to be outdone, psychology has swelled the chorus by pointing out the organic roots of behavior and of consciousness.

But just because an adequate naturalism has never been formulated and defended, we find that many who are naturalistic in their general outlook are yet sharp in their criticism of naturalism as a philosophy Why is there this apparent contradiction? Why is there this conservative withholding of allegiance to naturalism on the part of the majority of philosophers? Why is naturalism insistently defined in so narrow a way that it becomes a thing of straw easily torn to pieces? This situation has awakened my interest and I wish to say a few words about it.

To define naturalism in a narrow and indefensible way and then to tear it to pieces may be a pleasant enough dialectical exercise, but surely it is not consonant with the serious aim of philosophy to discover the truth about nature and ourselves as children of nature. There is something childish, rhetorical and merely verbal in this procedure, something which smacks of the lecture-room instead of the laboratory. Such lecturers are in the habit of making remarks such as the following: "No philosopher to-day is a materialist," "Atheism has been completely discredited," "No one to-day knows what life is," etc. The vicious effect of such dicta is the encouragement of obscurantism.

But among the more serious and competent thinkers there is the effort to work out exact definitions and to do justice to the actual content of both science and philosophy. Why, then, do so many of these, also, attack naturalism? The reason is, I think, twofold. First in order comes the recognition of the crying defects lism of a few decades ago. Second may be placed the momentum of ideal- 
ism. Clearly, there is need for a new naturalism which has avoided the pitfalls into which the old naturalism fell. In this book I have put forward what I call evolutionary naturalism, as able to meet the objections of the past and to challenge acceptance. It is, I maintain, free from the defects of the old naturalisms which founded themselves upon the results of the exact sciences alone, leaving out the levels of organic and social behavior. And it meets the momentum of spiritualism by the counter energy of the modern realistic movement. Evolutionary naturalism is the reflection into a focal system and the interpretation of the general results of all the sciences. It is a system of philosophy. Nor would evolutionary naturalism stress science alone. All valid human experience can find a place in the Weltanschaunng thus outlined.

Those who desire to do justice to evolutionary naturalism must be on their guard against identifying it with some special meaning current in the past. Let it be understood that $\mathrm{I}$ am not defending the naturalistic ethics of three decades ago, nor associational psychology, nor the naive philosophizings of Haeckel, Huxley and Spencer. These past naturalisms were products of their period, which is not ours. Evolutionary naturalism is the contemporary of pragmatism, genetic psychology, behaviorism, electronic physics, social ethics and epistemological realism. I pray that this be noted. Thus when G. P. Adams writes that "The very essence of naturalism lies in withdrawing ideas and loyalties from objective significant structures in which they may participate, and in viewing them as the fruition of natural life processes and interests," 1 he clearly has in mind the naturalistic ethics of the first flush of Darwinism. Surely ideas must make good in the world and they must be prospective just as the organism is. Pragmatism has had many relevant things to say upon this point; and yet American pragmatism is strongly biological and naturalistic in its outlook. But I feel certain that Professor Adams would not contest my interpretation.

Again, when Balfour asserts that "The very essence of the physical order of things is that it creates nothing new. Change is never more than a redistribution of that which never changes," 2 he is assuming a degree of Eleaticism in the outlook of science that I doubt is there. Modern science is beginning to accept the notion of creative synthesis. If naturalism founded itself upon a denial of novelty, it would condemn itself to be a philosophy which could not account for experience as it is. Much theism has taken its leap with an outworn science as a springboard.

It would be easy to find other illustrations of the identification of naturalism with past formulations. Ward, Perry and Spaulding occur to one. In the case of Ward, the motives are obvious. He was fight-

${ }^{1}$ G. P. Adams, Idealism and the Modern Age, p. 133.

2 Balfour, Theism and Humanism, p. 39. 
ing free from the grip of an inadequate naturalism. And as 2 thinker I owe him much. The neo-realists are influenced in part by the limitations of a naturalism founded on the exact sciences only and in part by their theory of knowledge. They wish to make logical being and values coordinate with physical being, whereas I wish to include them in a concrete and evolutionary way. The chapters in the book dealing with the epistemology of evolutionary naturalism will attack this Platonic extension of being.

I cannot close without a word as to the situation in philosophy to-day. The critical realist is of the opinion that there is far more agreement in the ranks than is realized. It is not his purpose to found a new philosophical sect. Let me take this opportunity to say that it is his opinion that critical realism does justice to the insights of both pragmatism and neo-realism. I have tried to develop this thesis in Chapter IV. I have hopes that Evolutionary Naturalism will be taken by pragmatists and neo-realists, alike, as a constructive attempt at the metaphysical development of that "new pluralism," as Professor Woodbridge calls it, toward which they are both working.

The present work is the fulfilment of the promise made in my first book some five years ago that I would subsequently deal with the categories. Perhaps I did not fully realize then how much I was undertaking. This book was in substance completed two years ago, though there have since been minor alterations. I take this opportunity of promising a third book to deal with human life, that is, with values and institutions.

I wish to make acknowledgment to my wife for her helpfulness and loyalty; also, to the Open Court Publishing Company for their courtesy and careful attention to all those details which fall upon the broad shoulders of publishers.

AnN Arbor, December, 1920.

Roy Wood Sellars. 


\section{CONTENTS}

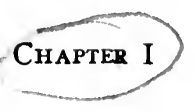

The Requirements of An Adequate Naturalism..............

The Aim of a More Flexible Naturalism-The Spirit of Naturalism and Modern Science-Two Common Forms of Speculative Naturalism-The Situation in Philosophy-The Idealistic Criticism of Naturalism-The Inadequacy of Past Naturalism-Evolutionary Naturalism.

\section{Chapter II}

The Epistemology of Evolutionary Naturalism.............

The Common-Sense View of Knowledge-Difficulties Confronting Naive Realism-The Nature of Knowledge a Problem-An Explanation of Terms.

\section{Chapter III}

The Epistemology of Evolutionary Naturalism (Continued)....

A Critical View of Knowledge-Different Meanings of Consciousness-The Grasp of Knowledge-Knowledge of Other Minds-The Question of Truth-Subsistence and Existence.

\section{Chapter IV}

The Status of the Categories.........................

Traditional Views-The Pattern of Experience-Kantianism -Objective Idealism-Pragmatism and Neo-Realism-Critical Realism-The Status of the Categories.

\section{Chapter V}

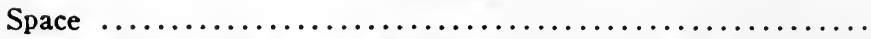

Space a Strategic Category for Realism-A Genetic Approach-Sensational Space-Perceptual Space-Empiricism vs. Nativism-The Truth of Preceptual Spatial JudgmentsConceptual Empirical Space-Mathematical Space-Space as a Category-An Historical Retrospect-Kant's AntinomiesIs Nature Infinitely Divisible?

\section{Chapter VI}

The Elementary Experience of Time-The Specious Present -The Addition of Memory and Expectation-Common or Standardized Time-Mathematical Time-Kant's Antinomy -Time As a Scientific Category-Temporal DistinctionsChange the Objective Basis of Scientific Time-A Return to Kant's Antinomy. 
Things and Their Properties....................... 124

Natural Pluralism-Realistic Meanings-The Rise of These Meanings-The Interpretation of the Not-Self in Terms of the Self-The Interpretation of the Self in Terms of the Not-Self-The Aspects and Properties of Things-The Paradox of Common-Sense Realism-Lockian RealismBerkeley's Idealism-Properties Are Cases of KnowledgeConstant Properties and Powers-Reflections and Suggestions.

\section{Chapter VIII}

Change, Identity and Conservation................... 145

Two Sets of Problems-Identity and Change-Changes of Things-The Fluctuating Boundaries of Thinghood-Things As Physical Systems-Change for Science-Can We Think Change Without. Contradiction?-The One and the ManyThe Meaning of Individuality-Self-Identity and Change.

ChAPTER IX

Quantities and Qualities............................

The Qualitative View of the World-The Quantitative View of the World-Eleaticism Versus Dynamism-The Primary and the Secondary Qualities-The Extra-Organic Foundation of the Scientific Properties-The Correlation Between Scientific Properties and Sensations-All Sensational Qualities Are Subjective and None Are Unreal-The Quantitative View of the World Only a Quantitative Study of the World.

\section{ChAPTER X}

Physical Connections and Relations...

Variety of Relations-The Category of Relation and the Method of Knowledge-The Connections of Things-Traditional Metaphysical Terms-Logical Considerations-A Summary.

\section{Chapter XI}

Motion, Force and Activity...................... 216

Preliminary Distinctions-An Application of the Genetic Method-A Return to Space and Time-Zeno's Paradoxes - The Movement versus the Path Traversed-Typical Problems-Motion and Force-The Dynamic versus the InertThe Significance of Activity-Experiences. 
associated with science, while supernaturalism finds expression in an ethical metaphysics, the rule of the Good.

The great difficulty confronting naturalism has been the inclusion of man in nature, an inclusion that would do justice to all his distinguishing characteristics. An adequate naturalism must not belittle man in order to press him into some rigid scheme. It must not be a priori in its methods and assumptions, but work creatively upon all that can be known about all phases of nature. To-day the naturalist has no excuse for little faith.

We have suggested that supernaturalism is the antithesis of naturalism. If naturalism stresses the self-sufficiency and intelligibility of nature, it can be defeated only by demonstrating the insufficiency of nature. In the past, theological speculation sought to prove the rational need for some primal source beyond nature, for a Necessary Being upon which the contingent world could be grounded. As is well known, the analyses of Hume and Kant gave pause to this direct and assured refutation of naturalism. The three proofs of scholasticism, the cosmological, the ontological and the teleological, were shown to contain assumptions which had small measure of plausibility when critically examined.

But Kant himself suggested a more subtle and indirect way of approach than that of the confident scholasticism of the precritical period, namely, an appeal to inner convictions or demands of the moral and religious self. But can man's life be divided by a hatchet into two compartments in this easy fashion? Any semblance of plausibility in such a division was due to the Kantian disposal of the physical world as phenomenal. Only because nature was more or less illusory could beliefs conflicting with the tide of natural fact retain their prestige.

Now as time passed, ethics and, with it, the theory of values were swept into the current of empirical investigation. English utilitarianism, evolutionism, a broader study of social facts, a more adequate psychology, all these new elements undermined the innate practical reason on its own 
ground. Psychologically and ethically, man was becoming a part of nature, comprehensible only genetically and biologically. The Kantian dualism between the theoretical and the practical reason no longer sounded relevant to the facts of human life. Man was a very complex whole immersed and functioning in nature.

The strength of this more subtle attack upon naturalism lay, then, in two things: (1) its denial of physical realism, and (2) its assertion of a contradiction between determinism and empirical freedom. These two motives run through the opposition to naturalism characteristic of the nineteenth century. Idealism maintains, on the one hand, that physical natıre is a realm of causal determinism and so contradicts man's freedom; on the other hand, that nature is a construction and not an independent reality. An adequate naturalism must meet both of these contentions. It must demonstrate the validity of physical realism as an epistemology and point out the possibility of reconciling determinism with empirical freedom.

Naturalism has been given many meanings in the course of this age-long controversy. Most of these meanings have been slightly derogatory. The reader must, therefore, be on his guard against the application to the evolutionary naturalism forming to-day of interpretations which were in a measure those of the older, less adequate naturalism of the past. The ethics of modern naturalism, for instance, are by no means those of a crude Darwinism. Wé belong to a generation which has realized that while man is an animal he is not a brute.

Those who attack naturalism usually forget its larger setting and significance. They are not trying to save naturalism from injustice to itself but to destroy it for the greater glory of some view more kindly to supernaturalistic beliefs. Hence, we find naturalism identified without a remainder with naive materialism, positivism, agnosticism, the mechanical view of nature, etc. The weaknesses of past formulations were taken as conclusive for the basic fallacy of naturalism itself. But were anti-naturalistic positions 
any less open to criticism? The truth is that a secret animus was at work. But cannot the thinker examine these fundamental questions with the candor and objectivity of the best type of scientist?

In my own thinking, I have always hesitated to identify naturalism with naive materialism, positivism, the mechanical vicw of nature, or the bias of the physicist to reduce the whole world to facts of physics and nothing more. Has not the time come for the attempted formulation of a more adequate naturalism than those of the past? For a philosophy giving due weight to all the sciences and to the various sides of man's actual nature? The formulations of naturalism have often been narrow and harsh, while the demands of supernaturalism have been sentimental and exaggerated. The warfare between naturalist and antinaturalist has resembled that between mechanist and vitalist in biology. While vitalism has gained little headway as a doctrine, it has prevented scientists from falling too completely into dogmatic slumber. But surely the time is becoming ripe for a step beyond the sharp contrasts of the past, into a broad and sympathetic empiricism.

The Spirit of Naturalism and Modern Science.-The following characterization of naturalism is true to its spirit: "At first tentative, but becoming ever more distinctly conscious of its real motive, naturalism has always arisen in opposition to what we may call 'supernatural' propositions, whether these be the naive mythological explanations of world-phenomena found in primitive religions, or the supernatural popular metaphysics which usually accompanies the higher forms. It is actuated at the same time by one of the most admirable impulses in human nature-the impulse to explain and understand, and to explain, if possible, through simple, familiar and ordinary causes." 1 The spirit of naturalism would seem to be one with the spirit of science itself. And many formulations of naturalism have been the products of the speculatively inclined scientist in his moment of indulgence in far-reaching generalization,

1 Oțto, Naturalism and Religion, p. 18. 
The specialist works in his own field in accordance with the technique which he has inherited and refined. His is the task to secure data that will help to solve specific problems; and his views are often the reflections of his methods and habits. Yet, if he is a man of keen curiosity with some natural bent for wider thought, he will sooner or later formulate views concerning the larger relations of things. In short, he will assume the role of philosopher and interpret fundamental questions in the light of the concepts and data with which he is familiar.

But these concepts and data are not necessarily sufficient for the foundation of an adequate naturalism. How could the physicist expect to do justice to chemical processes? Or the chemist to biological phenomena? Or the biologist to social institutions? Yet the specialist on his philosophical adventures is only too prone to postulate not only the truth of his categories but their sole sufficiency for all the problems confronting the mind. As against such an assumption, we shall argue that all the sciences contribute to the solution of ultimate problems. To attempt to solve the basic queries as to the nature of life in the light of physics alone is to challenge failure or a resort to sophistry.

Modern science has worked in favor of naturalism more successfully through the implications of its results than by means of wide-reaching speculation. It is the direction of the drift of the complex movement that is sensed. Hence, I shall be compelled to be rather hard upon the inadequate speculations of the older generation of thinkers even while sympathetic with their purpose. The time was not ripe for a philosophy of nature.

Tzwo Common Forms of Speculative Naturalism.-Let it be borne in mind that we are not denying that science leads, inevitably, to some critical form of naturalism. The arguments of this book will show, clearly enough, that I believe that an adequate naturalism can be worked out. What we are suggesting is that the interpretation of the results of science is a far more difficult undertaking than has at times been realized. Consciousness, for instance, must be gotten 
into nature in a specific way in connection with the mindbody problem and not thrown into nature in a lavish and wholesale fashion. The two common forms of naturalism which we shall briefly discuss represent two stages which do not seem to come up to this critical level. The second form, positivism, comes nearer to this ideal than does naive materialism, the first form.

Naive materialism is a form of naturalism which has played a very important part in the history of thought. It is now often carelessly thrown aside with the remark that we know too much about matter now to take it seriously. I am not so sure of the truth of this statement. The newer views of matter are far more subtle than the views of a few generations ago. But I must admit that it is seldom easy to know the exact idea of the physical world held by either materialists or anti-materialists. Both are stronger on assertion than on exposition.

The older materialism declared that physical reality consists of matter and motion. The notion of matter was probably that of the science of the period-hard particles affecting one another by contact. Just what the stuff of these particles was conceived as being I cannot make out. In short, it seems to me that this older materialism was largely the generalization in an uncritical fashion of the dominant mechanical view of the world. And just because it belittled such grave questions as those presented by life and mind or else had inadequate conceptions of these realities, it did not fulfil the conditions of an adequate naturalism. Naive materialism never realized the importance of epistemology. How do we come to know matter? The world we see is clearly a sensuous world; the world of matter in motion is an abstract, conceptual world. By what right do we pass from the one to the other and declare its superior validity? It would seem that the materialist of the uncritical type passes to a schematized vision of the physical world much as the interested reader uses words as mere symbols of meanings. He tends to give scientific concepts a vague ontological existence as intuitions of the very stuff of physical 
being. I frankly confess that it is not always easy to do justice to naive materialism, just because it is not philosophically articulate. I think that it was Royce who said that the materialist was the thinker who believed that all phenomena could be expressed in terms of differential equations of the second degree. There is a large measure of truth in this characterization. The scientist is only too apt to exalt his science's formulas and to make them universal. The materialist is the naturalist who reads nature in a limited way and believes that he has exhausted its possibilities.

I frankly recognize that there is a measure of arbitrariness in this description of materialism. It is a term which, after all, has no univocal meaning. For some, it means little more than naturalism as a sort of faith. They would reject any but the most modern ideas of matter and energy. Yet I think that materialism can rightly be associated with a certain degree of epistemological simplicity and with a tendency to reduce higher natural processes to lower without a remainder.

Scientists who have given themselves to speculation often temper their physical realism with agnosticism and animism. Thus Büchner argues that matter and force are inseparable. "There is no force without matter-and no matter without force." The stuff of the universe is dynamic. Matter is that which manifests itself in the various energies of light, heat and motion. These energies are measurable, but that which lies back of them is unknowable. But just because matter is unknowable, it can be endowed with all sorts of potentialities. It can be endowed with intellectual force as well as with physical force. It is noticeable that Spencer, although far more sophisticated, argues in much the same fashion that force is an unknowable source for all the phenomenal effects we experience. "By the Persistence of Force, we really mean the persistence of some Cause which transcends our knowledge and conception." Mr. Spencer's looseness of thought has been so unsparingly exposed by Ward that it is hardly necessary to go over the ground again. It should be noted that there is an unbridgeable gulf between 
our experiences and this unknowable, and that persistence means alternately quantitative constancy and permanence of being. $^{2}$ Haeckel is another example of the militant scientist on speculation bent. The following quotations give some idea of his daring generalizations. "The two fundamental forms of substance, ponderable matter and ether, are not dead and moved only by extrinsic force, but they are endowed with sensation and will (though, naturally, of the lowest grade) ; they experience an inclination for condensation, a dislike of strain; they strive after the one and struggle against the other." "Attraction and repulsion seem to be the sources of will-that momentous element of the soul which determines the character of the individual." Haeckel is obviously fighting for continuity. But is continuity of an cvolutionary type opposed to novelties? There is another feature of this naive naturalism to which attention must be called. The experts in other fields are rather despised. Thus he pays his respects to psychologists after this fashion: "Most of our so-called 'psychologists' have little or no knowledge of these indispensable foundations of anthropologyanatomy, histology, ontogeny and physiology.... Hence it is that most of the psychological literature of the day is so much waste-paper."

What shall be our comment upon these analogous forms of materialism? I think that our chief criticism must be that matter and energy become unknowables to which are assigned in a verbal way just those capacities which are necessary to meet unpleasant problems. What explains everything in this enigmatic fashion explains nothing. The intention is in a way commendable. Reality must be of a sort to account for the world as we experience it. Yet the connection between reality and experience is of the slightest. Philosophy becomes unanalytic and vague, a series of assertions which are not explanatory because knowledge of the unknowable is contradictory. Can the unknowable evolve and acquire new properties? Or is it always and everywhere

2 Cf. Spencer, First Principles, sec. 191, stereo. ed., p. 552; and James Ward, Naturalism and Agnosticism, 4th ed., p. 213. 
alike in a static and dead-level way? The familiarity of the terms used suggests a directness and specificity which they do not possess as metaphysical symbols. We swing back and forth between scientific realism, for which matter and energy are determinate entities, and a vague agnosticism in which they are postulated as sufficient reasons for whatever occurs in the phenomenal realm.

The shortcomings of these uncritical forms of naturalism has led scientists, better acquainted with the history of speculation, to develop various forms of positivism. There may, or may not, be a reality outside the reach of experience; but science affords us the only valid knowledge we can attain. The methods of the physical sciences have justified themselves by their results. Here are data cooperatively found and recoverable; here are empirical laws stating invariable relations between terms. This information satisfies the intellect and guides human behavior in successful ways. What more can be desired? The aims of metaphysicians are illusory. There are no things-in-themselves, no substantial reality of a transcendental kind. Terms like matter and energy and force should be kept to their analyzed, empirical meaning, for they are merely concepts descriptively useful in the organization of experience.

These positivistic forms of naturalism, when examined in detail in the writings of Pearson, Mach and Poincaré, show how dependent a naturalistic philosophy is upon theory of knowledge. Although securing much of their prestige from their standing as scientists, they plunge immediately into psychology and logic. Pearson becomes a Humean sensationalist. Mach seeks to establish neutral entities or elements which are physical and psychical according to their relations. Poincaré attempts to justify science by demonstrating the exactness of its results and the control exercised by the facts of observation. Thus they write, not so much as scientists indicating the reality of the physical world and the validity of our knowledge of it, as like descendants of Hume and Kant. They succeed in showing the naiveté of old-fashioned materialism and the uncritical use of scien- 
tific concepts by speculative naturalists, but they cannot be said to prove the sufficiency of their own positivism. In short, they are philosophers whose training has been in science rather than in philosophy. Consequently, they possess the defects as well as the merits of their training and outlook.

Is it too much to assert that the speculations of scientists turned philosophers have demonstrated the necessity of theory of knowledge as a condition of an adequate naturalism? The need naturalism has for a well-founded epistemology has thus been made clear by both its exponents and its critics. It is, as James Ward points out, a tentative philosophy, and yet a philosophy which has not taken advantage of the critical analyses offered by experts in the field. But why has it neglected these offerings? For two reasons, in the main. In the first place, the scientist has become a specialist seldom acquainted with the situation in philosophy, and, what is more, inclined to be contemptuous of it. Hence, when he starts to speculate, he does it boldly from his own stock-in-trade. In the second place, ninteenthcentury philosophy was largely romantic in its bias and itself inclined to be condescending to science. Instead of cooperating, science and philosophy went their separate ways. But this cooperation is an essential condition of the discovery of a true naturalism.

The Situation in Philosophy.-Above the technical differences between the various schools of philosophy, and to a certain degree determinative of them, worked the opposition between naturalism and romanticism. Idealism has always been anti-naturalistic and favorable to what-for lack of a better term-may be called a religious view of the world. Naturalism, as we have already noted, represented the drift toward a lawful and, so far as possible, physical explanation of events.

While naturalism swung between materialism and positivism, idealism was able for a long time to present a uni- fied front to its opponent. Especially was this the case in the English-speaking countries. Objective idealism was the 
dominant academic philosophy in England and the United States during the latter half of the nineteenth century. And idealism worked hand in glove with romanticism. It is not strange that the half-articulate naturalism of the time found it hard to cope with such an enthusiastic combination. Yet, on its side, it felt the comfort and support of the vigorous sciences springing up around it. The prestige of science confronted the prestige of religion. The tactical skirmishes between naturalism and idealism were practically always in favor of the latter, but the pressure of numbers on the other side made these victories Pyrrhic.

But the end of this period found new movements in philosophy. The ascendancy of objective idealism was rudely challenged by pragmatism and later by realism. Pragmatism sharply criticized the constant appeal made by transcendental idealism to absolute and virtually non-human standards. It opposed the too-facile monism and dialectical temper of approach of its opponent. The banner of empiricism was again raised and in a more critical form. The fruit of this new spirit is an alliance with the social and biological sciences and a flirtation with naturalism. Perhaps its weakness has been an unwillingness to develop a systematic metaphysics. And yet in its latest manifestations there can be no doubt of the sympathy of an instrumentalist pragmatism with a more broadly conceived naturalism. ${ }^{3}$

Realism is in deadly opposition to the cherished assumptions of idealism. While idealism has always maintained that the physical world as common sense and science conceive it is illusory if taken as more than phenomenal, realism accepts the independence of the known and the objective status of nature. Idealism is being driven more and more to take the defensive. As we should expect, realism finds itself in sympathy with the temper and ideals of science. Accordingly, the rise of realism makes possible that cooperative supplementation and interpretation of science by phi-

${ }^{3}$ This drift of pragmatism toward naturalism comes out quite noticeably in Creative Intelligence, a series of essays by American pragmatists. In his review of the last edition of Ward's book, McGilvary points out this fact. 
losophy in which alone lies the hope of an adequate naturalism. Since the whole argument of the present work will concern itself with the pregnant union of science and realism, we need not stress the point farther at present. In short, the situation in philosophy has ceased to be unfavorable to naturalism.

The Idealistic Criticism of Naturalism.-The current criticism of naturalism deserves attention, for those who desire to establish an adequate naturalism must heed the objections in the controversial literature. The whole truth was by no means on the side of the older naturalism, even though it did not reside in the camp of idealism (spiritualism) either. What is desirable is not eclecticism but a thorough overhauling of assumptions.

In the main, the chief objections to naturalism of the traditional sort fall under four headings: (1) the denial that the higher can be reduced to the lower without a remainder of supreme importance; (2) the claim that description is not explanation; (3) the existence of gaps in nature disastrous to naturalism; and (4) the refutation of realism, or, as it was usually called, dualism. Let us glance at these objections. We shall see that they need careful interpretation to separate what is true in them from what is false.

We shall admit that there is much truth in the contention that the older naturalism sought to oversimplify by reduction, and we shall try to indicate the historical reasons for this mistake. Probably they reduce to two: the nonage of the biological sciences and the continued dominance of the kinetic conception of all physical processes. The idea of evolution was either unknown or its full implications unappreciated. The first tentative efforts at the application of the idea of evolution were wooden in the extreme. The fact of the matter was that the various connective sciences between physics and politics had not yet sufficiently developed to reach hands across to one another. Naturalism desired continuity between the various apparent levels of nature, but at first could conceive it only as meaning that the higher is nothing but the lower. But supernaturalism-and 
idealism was often ready to give it comfort-was friendly to the idea of discontinuity. The one wished to achieve continuity by a rough and dogmatic reduction; the other to establish discontinuity. The conditions of an adequate naturalism had not yet been reached.

The claim that description is not explanation itself needs explanation. To explain an occurrence is to give its why, the cause or conditions out of which it sprung. Such explanation is in logic contrasted with mere empiricism. To explain is to solve problems by the discovery of laws and relations, which are, to my way of thinking, cases of wellformulated knowledge about nature. Wrongly, I think, explanation is frequently thought of as a reference of events to an unseen essence or productive activity. When explanation is so conceived, the work of science is said to be detailed description of things and events as research presents them to our minds. It is what I would call knowledge about the physical world. Explanation of events must rest for us in such descriptive knowledge about their conditions and setting; and the logic of investigation must convince us that there is an essential fidelity to reality in such descriptive explanation. The assumption that such description as characterizes modern science is arbitrary in anything else than the symbols used is agnostic and unjustified. There are different logical levels of description.

What these critics of scientific explanation have in mind is, so far as I can make out, something as follows. We cannot intuit nature so as to appreciate the inner necessity which moves things to act as they do. Perhaps it would be better to speak of the inner expression of things of which their behavior is a function. Laws give knowledge about things in relation but no living glimpse into their counsels. To say that $A$ attracts $B$ is to say that $B$ approaches $A$. But can we sense this attraction, this dynamic continuity which has this result?. Assuredly not. Hence science does not really explain.

But can any other discipline penetrate to the veritable process of change? Only the idealist makes this assump- 
tion, and he claims to achieve this ideal by analogy. Cause is desire and will. That may be, yet the scientist may well reply that what explains every event explains none. Scientific explanation with its specificity and genuine knowledge about things is as necessary and as valid as ever. The critics of science believe that they can supplement science and, I suppose, hope to clear the way for some mysterious teleology more harmonious with idealistic hopes than the matter-of-fact results of science. I must admit that I can see no escape along this path. There is a discoverable orderliness, massiveness and immanent executiveness about nature.

The frequent emphasis laid by idealists upon supposed gaps in nature cannot be regarded as an attack upon naturalism alone. On this point, naturalism and science are in the firmest alliance. Religious idealism displays a disposition to belittle science itself and to build upon the fact that its tremendous tasks have not yet been completed. But those who comfort themselves in this way are like squatters who fear that the rightful owner may at any time appear and claim his property. The history of the struggle betweeri vitalism and the physicochemical view of life illustrates this situation very well. As long as vitalism stood for a protest against too easy solutions, it was justified by the prodding it gave to facile dogmatism. But when it represented an appeal to some factor out of physical nature, it hampered research. Advances were achieved in spite of it instead of by it. Let us admit that the conception of evolution is an hypothesis. What better systematizing theory is there to put in its place?

But the strategic attack upon naturalism made by spiritualism has always involved the supposed proof that physical realism is epistemologically faulty. We shall have much to say of this in the next two chapters, but we have already paid our respects to the contention elsewhere. Spiritualism has been avid to prove that science deals only with phenomena. Granted this by bewildered science, it has gone on to argue that orderliness and intelligibility of phenomenal ar- 
rangements implied an orderer. We might well ask it to supply the major premise of this argument. May not our own intelligence be an expression of this innate orderliness of nature? But the assumption which modern realism will not admit is that nature is phenomenal. We know nature through the data it controls in our minds. The data, not, nature, can be called appearances.

The Inadequacy of Past Naturalism.-Aside from its philosophical immaturity, past naturalism had three main weaknesses. These we have in a measure already rehearsed, but a degree of repetition from another angle may be of advantage. Naturalism sought too blindly to reduce or disintegrate, as though novelty could not arise, as though the organic could be only the inorganic. It was dominated almost entirely by the exact sciences with their stress upon quantities. And it did not enough recognize the reality of mind and of those human organizations and events for which mind is pivotal. In brief, past naturalism did not take evolution seriously nor did it take mind seriously. As we shall try to show in the course of our general argument. these two shortcomings are very closely connected. An adequate naturalism must reckon without condescension with biology, psychology and sociology.

To explain by means of analysis is an ideal native to science. Only by tracing strands of dependency in the physical sciences, only by abstraction and selection in the logical sciences was knowledge able to advance. Experience comes to us too complex and interwoven for comprehension. Hence the early history of science is an account of the successful reduction of the complex to its elements. Movements are clearly the resultant of components; optical processes contain vibratory factors ; heredity is carried by correlated unitcharacters; character is in some measure an organization of acquired habits; and chemical compounds are recoverable elements.

But in its zeal for analysis, science often forgot the fact of synthesis. Because it could disintegrate and identify, it tended to ignore the organization which had been dissolved. 
In other words, the temptation was to level down, to say that chemical compounds are nothing but the atoms into which they can be disintegrated, to refuse to see the significance of the dynamic whole upon which operations had been performed. The result was a naturalism of reduction. The following quotation from James is a relevant criticism of this reductive naturalism: "The mention of material substance naturally suggests the doctrine of 'materialism,' but philosophical materialism is not necessarily knit up with belief in 'matter' as a metaphysical principle. One may deny matter in that sense, as strongly as Berkeley did, one may be a phenomenalist like Huxley, and yet one may still be a materialist in the wider sense, of explaining higher phenomena by lower ones, and leaving the destinies of the world at the mercy of its blinder parts and forces." ${ }^{4}$ The old naturalism ignored novelty and evolutionary synthesis. An adequate naturalism must not make this mistake.

Was there not a tendency in the past to confuse conceptual analysis with physical analysis? The anti-intellectualist of to-day complains that analysis changes the facts or ignores relations. To assert that an organism has parts seems to him to deny that these parts are interdependent. To this complaint the realist can only reply that he does not see the necessity. But physical analysis, actual dissection, does destroy the whole. And there can be little doubt that kinetic theories favored the identification of physical and conceptual analysis.

This brings us to a consideration of the second source of weakness of past naturalism. It moved within the circle of ideas and facts native to the exact sciences. The consequence was an incompleteness of which thinkers interested in biological and mental facts rightly complained. The world tended to lose space-and-time-filling content and to assume a purely mathematical character. The evolutionary differences in nature were ignored as irrelevant. We shall have more to say of this situation when we come to treat of the mind-body problem. Recent discoveries in physics

4 Jámes, Pragmatism, p. 92. 
have, however, put a stop to this abstractive tendency. The physical atom has come to its own once more. And, what is even more significant, the category of organization and the idea of evolution are moving downward.

That the naturalism of the nineteenth century did not do justice to "mind" is pretty generally acknowledged. But we must remember that psychology was hardly a science as yet and that biology was largely natural history.

It is not surprising that little agreement could be found between such extremes as physics and introspective psychology. The idea of intermediate levels genetically connected had not arisen. And yet the fearless naturalist of the day sought to maintain that the laws of mental operations are similar to those found in mass movements. Thus this stage of naturalism appears in psychology as associationism of a sensationalistic type. Mental atomism corresponded to physical atomism. The aim of this associationism is apparent. If mental events are governed by laws similar to those found in physics, the disparity between the physical and the mental was surmountable. The older forms of psychophysical parallelism reflected this manner of approach to the mindbody problem.

But instead of bringing mind down to the brain as kinetically conceived, why may we not bring the brain up to the mind as empirically analyzed? Such is the endeavor of evolutionary naturalism. We shall hold that even psychophysiological parallelism does not do justice to the empirical facts.

Evolutionary Naturalism.-If naturalism is the view of the world which founds itself upon the results of science, it follows-does it not? - that the texture and breadth of naturalism will alter as the sciences alter and as science is enlarged by the frank admission of new sciences into the commonwealth of tested knowledge. So long as mechanics was the master science to which the other sciences were ideally reducible, naturalism, was simplicity itself. It was a dogmatic metaphysics for which all occurrences could be adequately described in terms of equations. But its very 
simplicity was, as we have seen, against it as soon as reflection upon all features of the world attained maturity.

It was the growth of science, itself, that undermined the older naturalism. Philosophy could only have held naive naturalism at bay had this not been the case. It is, therefore. evolutionary naturalism that I shall seek to develop and defend. Chemistry, biology and psychology have become autonomous, concrete and profoundly expressive of evolutionary ideas. It is no longer possible for a fair critic to identify naturalism with the mechanical view of the world. Scientists are tentatively reaching out for more flexible and less dead-level ways of approach. Evolutionary naturalism is not a reductive naturalism.

While naturalism could plausibly be linked with mechanism and be called "physics treated as metaphysics," philosophy could make a dialectic use of sharp contrasts, such as blind necessity and human freedom, fixed law and purpose, chance and design, matter and spirit, etc. No one can deny the rhetorical effectiveness of these contrasts; nor, I think, can it be doubted that effective use of them has been made by idealistic writers. But it is time to lift the controversy above this dialectical level which, after all, got no one any great distance, and to live critically into the knowledge we actually possess to-day. And yet I would not be understood as refusing to recognize the truth of much of that for which idealism stood in opposition to the older naturalism. But has not the time come for a thorough overhauling of the epistemology and Kategorienlehre of the past? It is something of this sort that I hope-however imperfectly-to accomplish.

If, as even its opponents admit, naturalism is a view of the world which flows by inner necessity from the accomplishments of science, the philosopher can pride himself that his function is like that of an artist who adds finishing touches here and there to some massive, cooperative work. The evolutionary naturalism which the keen eye can discern is like the statue hidden in the marble. Much must be done before it can be released. Just because the common result 
of all the sciences is the concern of no one science, there is need of a discipline of a comprehensive nature.

As we have constantly suggested, the cooperative assistance open to philosophy takes two lines: epistemology and the analysis of the categories. Seldom is science aware of the need of a theory of knowledge, yet the scientist who attempts to speculate stumbles around rather blindly for lack of it. On the other hand, science begins to make use of new concepts or categories long before it has clearly formulated them. We should expect this "lag" if we bear in mind the fact that categories have their birth in experience and that experience comes bit by bit in new fields. A critical eye, not concerned primarily with specific problems, can note changes of ideas and methods of interpretation that the busy specialist will overlook. To analyze and comprehend these large "forms" of cognitive experience is the - selfappointed task of the philosopher.

If naturalism is usually an implicit system of philosophy, let the philosopher who is in sympathy with science make it explicit. Let him honestly, face all difficulties and at least show how they can probably be met. His can be no narrow naturalism limited to the physical sciences. The whole of man must be included in nature, and nature so conceived that his inclusion is possible.

Without further parley, I shall now proceed to the exposition and defense of the epistemology which in my view justifies evolutionary naturalism as a metaphysics. The technical name for this interpretation of the nature and conditions of knowledge is critical realism. It is realism because it maintains that the human mind can build up knowledge about extramental realites; and it is critical realism because it holds that these realities cannot be presented to an immediate awareness, as naive realism inclines to assert. Assuredly, it will be interesting to discover what form naturalism will take when it makes an alliance with critical realism. What will be the product of this cooperation? I prophesy that it will not easily be labeled with the conventional names. 


\section{CHAPTER II.}

THE EPISTEMOLOGY OF EVOLUTIONARY NATURALISM.

WHAT I wish to do in this chapter is to make reasonably clear just what the nature of human knowledge of the physical world is and what are its conditions. Knowing is surely a natural operation resting upon evolved abilities. To give a naturalistic explanation of it is, as we have already suggested, to give a crowning touch to science itself. Nature is a world in which knowing occurs, just as surely as it is a world in which coal burns and dynamite explodes. We may rightly think of epistemology as a special science concerned with the fact of knowing.

It is particularly desirable that the naturalist should gain a clear insight into knowledge. Otherwise, he may fall into naive notions of the reach and directness of his knowledge and suppose that the very stuff and labor of the physical world is open to his penetrating gaze. The mistake of physical realism in the past has lain largely in this impatient passage from knowledge to reality. Knowledge is, of course, a fact: but it behooves us to discover what kind of fact it is, what its materials are, and what processes are involved. A measure of brooding upon this field will make us less likely to adopt simple ideas of substances whether material or spiritual.

Critical realism is an epistemology that accepts physical realism. Like common sense, it holds to the belief that there are physical things; and, like enlightened common sense, its idea of physical things is moulded by the conclusions of science. 
But its acquaintance with the process-side of knowledge may make it very critical of any remnant of intuitionism in the thought of the stuff of the physical world. While the critical realist is convinced of the existence of physical things and considers his own organism in which his knowing takes place as one of them, he may have views as to what sort of information knowledge can convey that will sharply differentiate his physical realism from ordinary physical realism with its associations of metaphysical dualism. It will be well that the reader bear this suggestion in mind.

The common character of all modern realisms is the principle that the objects of knowledge do not depend for either their being or nature upon our knowledge of them. To know is not to form the reality known out of a priori and $a$ posteriori material of a mental provenance, as Kant held, but to gain information about it as it exists in its own circle of being. Being is one thing, and knowledge is quite another sort of thing, a function of the mind resting upon a causal relation with that which is known as one of its essential conditions.

Our position, which we call epistemological dualism, agrees, then, with the so-called "axiom of independent reality." Prichard's formulation of this axiom is as follows: "Knowledge unconditionally presupposes that the reality known exists independently of the knowledge of it, and that we know it as it exists in this independence." The idealist, perforce, denies this axiom and asserts that we have no such conviction. Thus Bosanquet substitutes the following formulation which is more harmonious with his epistemology: "Knowledge presupposes that the system of judgments in which it consists can maintain itself against any contradiction, and that the reality known is unmodified by knowledge except in the direction of being revealed as more completely itself." 1 Now I think that it is obvious that this qualification is simply the expression of his idealism. And it is clearly a very sophisticated and artificial qualification. Yet, as against naive realism, it receives the support that

1 Bosanquet, Logic, Vol. 2, p. 305. 
consideration of the experiential character of the content of perception yields. "The nature of reals," argues Bosanquet, "is fatal to the axiom that we know things as they are apart from cognition.” But the epistemological dualist comes to the rescue of the realist and points out that the object of knowledge is never given in knowledge but only the content of knowledge.

We shall concern ourselves very little with the refutation of idealism. The development of a coherent realistic system is of far more value, even from an argumentative point of view, than a continuation of the more or less dialectical struggle between idealism and realism. The strength of idealism has always lain more in the weakness of past realisms than in its own plausibility.

We shall be compelled to make many distinctions to meet the complexities of actual knowing. There are different kinds of objects of knowledge and, corresponding to them, different kinds of knowing. We shall indicate the status of these various classes of objects and adopt a terminology which will make their epistemological ordering clear. Our basic principle will be, that an entity is madc an object by the knower, that it is not an object in its own right. It is, however, an existent of its own peculiar kind in its own right. Being known, that is, being an object, happens to entities and does not affect them, for it is a function of the knower. Now there are different kinds of entities, and these are known differently according to their status. One large class can be given in consciousness and to awareness, while physical things cannot be so given. The chief epistemological puzzle has been with physical things which cannot be given to awareness and which yet are known and are, therefore, objects of knowledge. In introspection, on the contrary, we note psychical contents while, in reflective thought, we examine entities such as mathematical characters and relations. It is becoming customary to speak of this latter class of entities as subsistents. It seems clear that we experience them, or they are given to inspection, in a way that does not hold of physical things. At this point, we shall content our- 
selves with calling attention to the fact that it is generally admitted that it is only for physical objects that a casual relation is implied in the possession of knowledge. In the major part of this chapter, we shall concern ourselves with physical things as objects of knowledge.

Common-sense View of Knowledge.-At the stage of common sense, knowledge is on the whole regarded as an intuition by the percipient of the things about him. $\mathrm{He}$ is aware of them; they are open to his inspection; they enter and pass from his field of experience. These given objects are regarded as things independent of this awareness. They are thought of as relatively permanent and executive. They are co-real with him, the organic individual who perceives them. It is within this setting and in relation to these meanings that the idea of knowledge is formed.

This structure of the field of experience, this sense of intuition and these realistic meanings are not mere accidents. They have their import and deep-lying causes. If physical realism is correct and there are physical existents affecting the percipient organism, we can readily understand why these realistic meanings have developed within experience. Realism and realistic meanings imply each other. Modern psychology works on this assumption and is increasingly correlating mental processes with the adaptive behavior of the organism. For instance, the unit of psychophysics is the sensori-motor arc. What critical realism seeks to do is patiently and persistently to develop an idea of knowledge which fits in with the obvious position and circumstances of human beings.

It seems to me, therefore, the best policy to see what the plain man instinctively takes knowledge to be. We can then go on to modify it and improve it as a wider reflection demands. Logic and psychology can be called to our aid in this task of interpretation and refinement.

The assumption that knowledge is an awareness of objects independent of this awareness is an inevitable reflection of the structure of the individual's field of experience. 
The fact is that the objects of awareness have these realistic meanings attached to them. The boy whom another boy is trying to catch grimly feels the co-reality of this pursuer. His instincts and his motor adjustments are clamant of the fact. But if things are external and co-real and I am able to perceive them, my perceiving them makes no difference to them and is primarily an event which happens to me. Perceiving is taken most naturally to be a sort of intuition in which the object to which I am adjusting myself is revealed. Vision leaps across space.

Now perception is usually taken to be a primary kind of knowledge, whereas thoughts, images and ideas-it matters little just here what term we employ-are secondary. In other words, the natural bias is to take the content of perception as the surface of the object affirmed and adjusted to. And it is this appearance of the object in a literal relation to the act of perception that is thought of as the most satisfactory type of knowledge. And for ordinary purposes for which perceptual data are sufficient guides to behavior, there is no practical reason to go back of this outlook.

Thus the plain man would, I think, hold that I perceive this brown-covered book on my desk just as it is, although not exhaustively. There is more to the book than I perceive at any one time, yet in veridical perception I do intuit the book itself. The content of perception is merged with the object of perception, that to which I am adjusting myself. The independence of the object of perception, the physical thing co-real with my organic self, is carried to the content of perception, the datum of which I am aware. This natural objectification of the content of perception by means of instincts and motor attitudes is the cause of naive realism. The psychology of it is pretty obvious, and there is no motive at this level to inhibit the identification of the object toward which we are reacting and the content of which we are aware.

For the naive realism of common sense, therefore, primary knowledge is the intuition of the physical object more or less adequately, while secondary knowledge is the recall 
of this object by means of representative images and ideas. The mechanism of neither type of knowledge is understood.

Difficulties Confronting Naive Realism.-But as soon as reflection enters, difficulties of an empirical and specific sort confront this identification of the object of perception with the content of perception. These are in the main so familiar that they will scarcely stand repetition. ${ }^{2}$ The upshot of the matter is that it seems impossible to continue to hold that the object of perception is intuited. The datum of perception must be separated from the object of perception and given a subjective status. Other thinkers are beginning to realize the need for this separation and express it by calling the content of perception a given essence.

Now when we call logic and psychology to our aid, we find that they supplement the teaching of science. Science convinces us that the content of perception is an intra-organic response to the stimulation of the sense-organs. These mental sciences add the conclusion that perception is not the simple awareness of a passively given datum. The more sensuous part of the content is penetrated by meanings and even interpreted by concepts. I perceive this particular object as a book. Significant perception involves judgment, for universals are being used. Is psychology wrong when it asserts that perception requires mental activities and a synthetic unity of sense datum and meaning? The complex experience called "perceiving a book" can be analyzed into a more or less discriminated datum interpreted by concepts as being an external, permanent thing of the book type, a whole of which I am aware. What the "I" or subject-self is we shall later discuss. We shall find it quite empirical and unmysterious.

One of the points the critical realist wishes to make is that there is a profound truth in the outlook of commonsense realism despite its inadequacy. The plain man is outward-looking and accepts results at their face value. The sense of thinghood dominates his perception. He is react-

2 Cf. The Essentials of Philosophy, Ch. 3. 
ing toward his environment, making all sorts of ordered motor adjustments. Now in our opinion he is completely justified in so doing and in the realistic affirmations implied. His mistake lies in the identification of the content of his perception with the object toward which he is reacting.

The justified function of idealism, so far as it speaks for real physiological, psychological and logical facts, is a war against the simplicity of common sense, its ignorance of processes, its belief in an abrupt presentation of physical things to the apprehending subject-self.

Unfortunately, idealism has always gone beyond this critical analysis to a denial of the independent existence of the object of perception. To my way of thinking, it has made about as bad an identification of the content and the object of perception as has naive realism. Only, in this swing of the pendulum, the object is identified with the content and declared to be mental because the content is. The result is a denial that there is an independent physical existent and the associated remark that, if there were, it could not be known. Wasting no time upon Berkeley's rather unhappy phrase, esse est percipi, we may say that modern idealism maintains that subject and object fall within experience. But this "object" of the idealist is really the content of perception, the datum or essence. I do not think that my statement is too strong when I assert that the refusal to distinguish between datum and object is at the foundation of all the vagaries of modern philosophy.

We may summarize our preliminary results as follows: No motive has entered to cause us to doubt the existence of physical things co-real with the percipient, but reflection has discovered that the objective content with which we at first clothe these acknowledged realities is intra-organic. In other words, we can no longer believe that we can literally inspect, or intuit, the very external existent itself. The content of which we are aware is clearly distinct from the physical existent with which it was erstwhile identified. though it is in causal relation with it. 
The Nature of Knowledge a Problem.-Historically, epistemological dualism was shipwrecked on the puzzle of the status of ideas in knowledge. Attention swung to the ideas, and the query arose, Is it not possible that in all cognition that which is known is never the physical thing but only an idea representing that thing? But how representing? And how can you be certain that there is a thing to represent? When epistemological dualism had once allowed itself to be formulated thus, its fate was settled. Radical empiricism, or epistemological monism, seemed so much more simple. The idea is given: why not call the idea the object of knowledge? Representing an unknown which you only infer does not sound plausible. So thought Berkeley and Hume; and the majority of philosophers, including Mach, Avenarius and the American neo-realists, have followed them.

But, in the first place, mere subjective occurrences, call them sensations and images or sense-data, are not ideas in the cognitive sense. It is the cognitive use of these subjective events which makes them ideas. The fact is that attention swung from the cognitive use of mental contents to their mere givenness as subjective events. Logic and epistemology were virtually shoved aside in favor of the elements of physiological psychology. In the second place, this first burst of empiricism was not empirical enough. It did not realize the significance of the fact that we have such distinctions as that between consciousness and the external world and that we make cognitive claims to know this external world. The modern epistemological dualist recognizes these distinctions, shows that they are justified. and points out what knowledge actually is. ${ }^{3}$

Radical empiricism, or the way of ideas, did not win historically without a protest. Thomas Reid attempted to carry through a distinction between sensation and perception. Unfortunately, he was unable to analyze this distinc-

${ }^{3}$ Professor Dewey has attained a more adequate empiricism than has been common. But even he is too afraid of the category of the subjective. See his essay in Creative Intelligence called "The Need for a Recovery of Philosophy." 
tion and fell back upon common sense as a court of appeal -a refuge denied to one who sets out to be a philosopher and, so, reflective and analytic. "We are so constituted," argues Reid, "that, on the occasion of sensation, we perceive material objects and their qualities existing independently of the percipient mind....Grasping a ball, we perceive it at once to be hard, figured, and extended; moving the hand along the table, the qualities of hardness, smoothness, extension, and motion are at once suggested to the mind."

Can the modern thinker with the help of psychology explain the distinction between sensation and perception and indicate genetically the factors in the process by which we build up the category of thinghood? If so, he can explain what to Reid was inexplicable. Puzzled though he was, Reid held obstinately to the fact that in knowledge we claim to know external things and not ideas. But how we could know external things he really did not see. He balked when philosophers turned to radical empiricism, but he could not find the opening into the path he desired to take.

It is interesting to note that Hodgson, who is generally acknowledged to be the father of the English realistic movement, makes a demand, or postulate, very similar to Reid's. $\mathrm{He}$ asserts that a thing is what it is known as, a reality independent of the existence of a perceiving consciousness. But neither was he able to carry this postulate through successfully.

Now the modern epistemological dualist attempts to give a solution of the problem of knowledge in terms of two things: (1) a re-interpretation of knowledge, and (2) a more complete analysis of perception and thence of all cognition. $\mathrm{He}$ is dissatisfied with the traditional formulation of representative realism, that ideas are known and that inferred objects are represented in terms of these ideas.

Let us stress this important point, that we will not allow our opponents to interpret the term, dualism, in accordance with the usual formulation of the representative theory of knowledge. For the modern epistemological dualist, the knowledge-claim is directed, from the first, to the thing- 
object and not to the content, or datum, as such. Knowledge of the object is direct though mediated. Thus, as I said above, modern epistemological dualism re-interprets knowledge. It is epistemological dualism only in opposition to the false empiricism of epistemological monism. The prime doctrine is this, that, in the knowledge-claim, reflection forces us to distinguish between the object of knowledge and the content of knowledge.

It is at this point that the critical realist believes that he can better the analyses of Reid and Hodgson. In the first place, why is it wrong to identify sensation with perception? Because a sense datum is only an elementary part of the total experience of perceiving. There are many meanings and images on the content side of perception which raise it above the purely sensational level, and there is an act of affirmation directed toward this content. We perceive things and not sense-data. The category of thinghood, which is a very empirical category, has arrived and, with its arrival, sense-data have been interpreted into the sensuous qualities of things. Perception involves (1) a coordinating and interpretative response to a complex of stimuli, and (2) a sense of contrast between my bodily self and the things surrounding it to which it is responding or tending to respond. To remove sense-data from this context is to be unempirical. ${ }^{4}$

It is clear that, if the critical realist's doctrine is true, we must find in the perceptual experience something corresponding to an affirmation of an object as well as to the percept-datum. It is not difficult to do so. The attitude, or set, of the organism in perception floods consciousness with a sense of the presence of something co-real to which the self is attending. The motor impulses to reach out to, or to flee from, this something carry out this feeling and develop it. And I think that there can be no doubt that additional meanings, such as externality, independence of control, and persistence, all add themselves to this nucleus to constitute the belief in a co-real object. Professor Strong

4 Russell's Scientific Method in Philosophy is by all odds the ablest attempt to do this. See p. $107 \mathrm{f}$. 
calls this affirmation of an object instinctive. It is quite clearly expressive of the nature and situation of the organism. The structure of consciousness reflects the situation of the organism.

I would suggest that the flaw in Berkeley's analysis of perception was due to his lack of attention to the psychological factors mediating the affirmation of an object and to his neglect of realistic meanings. In common with the traditional empiricists, he did not do justice to the category of thinghood.

But the sensuous thing which is given in perception as the object has tended to suggest an impossible view of our knowledge of physical existents. Since these sensuous things are open to inspection, we assume that physical things, with which they are confused through lack of reflective discrimination, are open to this intuitive type of inspection. Primary knowledge is thus taken to be an apprehension of physical reality, and physical reality is thought to be of this sensuous character. These correlative beliefs are equally significant, for they have made their influence felt everywhere in epistemology. Thinkers who relinquish naive realism are yet apt to fall back upon the copy-theory, that is, the assumption that physical things are sensuous in nature and can be pictured more or less adequately by means of the sensible things apprehended in experience. This position is called representative perception. Knowledge is still taken to be an intuition; only now it is an intuition of a reproduction of the physical existent or of its qualities.

But it must seem quite obvious to us now that knowledge of physical existents cannot be either a direct or an indirect intuition of them. In fact representative perception sounds like a clumsy makeshift. Rather should we ask ourselves the searching question whether the whole ideal of intuition is not an illusion due to the fusion, in common-sense perception, of the object of perception with the content of perception. ${ }^{5}$ What should we mean by knowledge?

5 We shall combat this intuitional ideal of knowledge in more detail in the chapter devoted to Things and Their Properties. 
We have seen nothing in our method of empirical advance that justifies either idealism or agnosticism. And I hope that philosophy has passed beyond the stage of jumping at hasty conclusions. What is needed is a patient analysis which goes forward step by step under the guidance of the facts until it reaches new insights. We have seen that the facts which break down common-sense realism work within a realistic set of affirmations and meanings. Hence there is no movement in the direction of subjective idealism. On the other hand, only if knowledge must be an awareness of the physical existent, itself, is agnosticism implied. But what right has a thinker to shut out other possibilities by such a dogmatic assumption! Agnosticism is a counsel of despair. The agnostic is one who sees that some naive notion of knowledge cannot maintain itself before criticism. He does not take the further step of reconstructing his idea of the nature of knowledge. We may say, therefore, that a critical epistemology concerns itself not so much with the question whether there is knowledge as with its nature and conditions.

Who can deny that reflection partly finds present, partly extends, the distinction between the realm of consciousness as a field of contents and processes somehow connected with the organism, and the acknowledged world of which any such organism is only a part? And patient reflection only develops this contrast. ${ }^{6}$ The actual content of all intuited objects turns out to be subjective. It is personal, bound up with a particular organism. In a word, it is what we are accustomed to call psychical.

The paradox of the situation is that what is apprehended discovers itself to consist of characters which have no substantiality. Discriminate as we will, we find only characters and meanings; and yet we feel that the reality which surrounds us cannot be any sum or organization of such elements. Where is the executive push of things which makes them have effective consequences? The psychical characters do not consume wood or-shatter fortresses into fragments.

${ }^{\circ}$ Cf. Critical Realism, Ch. 3. 
We tend to believe that we grasp an external reality in an intuitive way so that its councils and pulsating energy are open to us, and the tragedy is that what we grasp has no such dynamic power. In a sense, being escapes us. And what is true of common-sense realism is equally true of scientific realism. What are mass and energy but quantities? And are quantities self-sufficient realities? The very stuff and being of the physical world again eludes us, while we are left with contents hanging in the air, as it were, and yet masquerading at the least excuse as self-existent and substantial. ${ }^{7}$ We are led to ask ourselves whether being can be given. Is not the sensuous content of perception a peculiar substitute for the object of perception? The object of common sense breaks down for reflection into a selfexistent reality, which cannot be given to awareness, and a complex datum which is so given.

But this discovery that only subjective contents are given is a fairly common possession of modern philosophy. It must be remembered, however, that these subjective contents of perception are objective within consciousness, that they are subjective only in the sense that they are in the individual percipient and not a part of the physical environment to which the conscious individual is reacting. Nor within consciousness need these contents be regarded as dependent upon the conscious self's awareness of them. Self-aware-of-content is a complex of a unique sort the parts of which are together; and, as these parts are contents, they do not modify one another. At any one time, I am in the field of what is given together. The being of the content is not its being perceived, and yet the content is psychical and within consciousness. But this conclusion excludes only naive realism. It proves that only mental contents can be given in consciousness; it does not prove that we can know only phenomena. The mistake of philosophy has been to confuse these two principles; or, rather. to deduce the second from the first. Yet, unless givenness

7 The old-fashioned forms of materialism were cases of this mistaking of concepts for things. 
is clearly the only kind of knowledge, such deduction is unjustified. Uncritical as such a dogmatic assumption is, it has been at work in modern philosophy to a disastrous extent. Kant indicates-in this following in essentials Locke and Hume-that only phenomena can be given, and interprets this fact as meaning that only phenomena can be known. The whole setting he gives to epistemology is a subtle begging of the question.

But when we recoil from the agnosticism of Kantianism. "camouflaged" by the substitution of experience-in-general for the structure and demands of the consciousness of individual knowers and the identification of the physical world with constructs within this blanket experience, and return to a critical development of the leadings within common sense, we soon see that we humans do possess information about the physical existents we affirm. Within consciousness, we are acquainted only with contents; but what is to prevent us from regarding these contents as material for the knowledge about the physical existents which we continue to affirm? What necessity is there for holding that all knowledge terminates on sensory contents? That is a sophisticated view which results from analysis and the abstraction from the meanings and attitudes of common sense.

Now, as I understand it, critical realism stands for the reality and fundamental significance of another kind of knowledge, a knowledge which presupposes this interpretative awareness of the data of observation as a foundation; and yet goes beyond it in the reference of propositions, built upon these data, to affirmed physical existents, as knowledge about them. The propositions are within consciousness, the reference is an act in consciousness; but the existent, which is the object of such knowledge, is not in consciousness. The object of knowledge is identical with the object of perception; but, whereas in perception we tend to clothe the object in the apprehended content, we now think of the content as material for obtaining knowledge about the object. We use the content in the critical knowledge-claim. 
An Explanation of Terms.-To get a suitable terminology to express the nature of our knowledge of the physical world is a rather difficult task. One way is to give a negative definition. Knowledge of the physical world is nonapprehensional; that is, we must give up, once for all, the ideal of intuiting the physical realm. Let me now offer a positive notion. Knozoledge of the physical world is a comprehension of the characteristics of things by means of subjective contents. An idea, or judgment, is said to be a case of knowledge when it makes a claim to reveal something about things, and its claim is granted. This definition permits the usual belief that there are degrees in the completeness of our knowledge of things as we pass from ordinary perception to science. It is not that careful perception is wrong-for it is the right sort of response to the stimuli -but that the methods of science use perception, that is, observation to carry us further in our comprehension of things.

The distinctive feature of our most finished knowledge of the physical world, scientific knowledge, is that it consists of understood propositions regarded as information about an independent realm of existence. Since this content is entirely empirical, its character can be studied. Factors of the following sort appear to me to be the characteristics of things which we comprehend: comparative size, texture, constituents, relations to other things, the ways they affect other things and are affected, processes of change, functional capacities, behavior. This information about things involving these categories can clearly be mediated by sense-data when these are properly handled by the mind of the individual. To assert that all this is not knowledge is to possess some a priori concept of knowledge and to apply it dogmatically.

Let me now try to exclude a misunderstanding. When I say "knowledge about" the physical world, I do not have in mind the psychological contrast between primary and secondary cognition, presentation and representation. What I call knowledge about the physical world is critical knowl- 
edge of it which has used both presentation and representation. Presence, or absence, of the object to perception is irrelevant. Observation is simply a primary condition of such knowledge. Knowledge is a saltatory claim, though to its making you may have any number of ambulatory experiences. All this follows, I take it, as soon as you rise above both naive realism and radical empiricism.

This saltatory claim of knowledge is what has usually been called transcendence. The subjective content, which is used in knowledge, is separate from the affirmed object. We shall see that, when properly understood, there is no mystery in such transcendence or extramental reference. And knowledge of the physical world is not the only instance of this type of reference. As we shall see, memory and knowledge of the contents of other minds are also striking and undeniable instances. We should try to understand the structure and the elements of such a knowledge-claim.

The Conditions of Knowledge of the Physical World.I think that it must be granted that the very possibility of true knowledge implies some sort of correspondence between the subjective datum, used in knowledge, and the object. And this correspondence rests ultimately upon perception. Of course, the fact of error shows that we may think that we have knowledge when we actually do not have it. But there is no contradiction here if we but bear in mind that a false claim to knowledge has the same structure as a true claim.

We have no good reason to regard the character of the sense-datum as arbitrary; quite the contrary is the fact. If, under apparently the same conditions, the datum changed in a capricious way, it would be impossible to regard data as material which could mediate knowledge of their control. We would have to accept the view-now championed by Bergson-that the world is a flux. But our experience indicates an actual, causally-based correlation between the physical existent and the datum. One flower is white. another blue, and so on. These contentual differences are 
rightly taken by all to point to differences in the physical objects.

But what is the exact nature of this correspondence? We should realize that no dialectical answer will do justice to the problem. We must appreciate the psychophysical situation. A determinate existent is the object of the organism's nervous attention, and so controls the rise in the brain of a content of which the subject-self is aware. The character of the stimulus complex must be correlated with the datum aroused. But I would not suggest any mechanical view of their connection. The datum is a correlated response to the stimulus. And it is this differential correlation that makes the present content valid material for knowledge of the physical world. Knowledge must be quarried out of it by patient comparison and ingenious experimental control. But is not this precisely what science effects?

The value of sense-data as material for knowledge rests, therefore, upon this responsible, differential correlation between them and things. An element in the one does not need to be like an element in the other as representative perception supposes. The revelatory identity between the content of knowledge and the object of knowledge concerns the characteristics of things. It is this that is reproducible in another medium. Things must have structure and connections. In knowledge, our universals are contents which partly symbolize, partly reproduce this structure and these connections. The content of knowledge is, as it were, a translation of the characteristics of the thing; and, as in all translation, there is reproduction and yet difference. Working, as it does, with sense-data as its materials, the mind does exceedingly well. It grasps much about things, and this can be empirically stated. Yet knowledge can never be anything but a pale reflection of the object. Knowledge should not claim to be being.

The undesirable assumption of the copy-theory was that the physical existent is like what may be called the "sensible thing" of naive realism. Instead of a deeper analysis of our knowledge of the physical world, we were simply given 
a retreat of the sensible thing into an imperceptible realm. Awareness was supposed to terminate on a mental object, and this mental object was then asserted to resemble an extramental thing. The tendency of the mind to maintain the copy-view is easily appreciated. Just because common sense clothes the object of perception with sensuous qualities, it doggedly retains this sort of imagination of it even after it is forced to admit that it cannot be intuited.

The usual criticism of representative perception is interrogatory: How can you know the physical thing to be like the sensible thing if you are limited to the latter? The criticism which I have offered is, I think, a far deeper one. It points out the cause of the illusion and how to master it.

Critical realism, then, uses the data of observation as material for making judgments about the nature and connections of things. It relinquishes any desire to clothe things with sensuous qualities. To this extent, it may be said to break with perception as naive realism conceives it. It is confirmed in this position by an analysis of science. And, in this connection, it may be well to call attention to the difference between the Greek and the modern view of knowledge. The Greek view took knowledge as giving the defining essence of a thing. This outlook is apt to nourish the assumption that things have a sort of form, or defining essence, which the mind grasps. Medieval realism made this assumption. Now I am convinced that we must relinquish this view because it is a tantalizing mixture of truth and error. The physical world must have structure and its parts must have connections with one another. It is a knowledge of this character of things and of their connections which is mediated by data. The critical realist must, therefore, hold that universals are post rem. But they are used as revelations of what is in re and inter res. I presume that it is this position which differentiates modern science from Greek science and modern epistemological realism from medieval realism.

Let me explain the status of the universal in knowledge by a simple example. When I assert critically that this 
penny is round, I do not mean to assert that there is an entity, called the quality round, which is possessed by the penny; nor do I mean that the penny is composed, among other things, of the universal round. Rather it seems to me that I mean that the shape of the penny is best understood by means of this universal round. And this shape is the formation of its parts. Universals are means for thinking truly about things and their connections; they are not parts of things, nor peculiar adjectives of things.

How, then, must we adjudge the status of the presented content in perception? Existentially, as an intracortical occurrence to be correlated with the perceived object; epistemologically, as the contentual material out of which knowledge of the object can be gleaned. And one of my main contentions has been the desirability of setting up a critical notion of what knowledge of the physical world actually is.

The general conditions of knowledge are twofold: (1) the presence of data, which are adaptive and (potentially) revelatory responses to things, and (2) the intelligent use and interrogation of these data in the way of analysis and synthesis, the formation of hypotheses, the construction of concepts, etc. In the chapter on the mind-body problem, I shall attempt to show that the capacity for both these conditions is to be assigned to the brain; the brain, however, risen to the level of conscious functioning. What we are permitted to accept is a complex stimulation of the brain which is welcomed and furthered by it in accordance with its own nature and interests. The conscious brain-mind is interested in things for good biological reasons and, like a skilled lawyer, draws out their story bit by bit and puts it together in its own language. The physical world must be assisted toward its unintentional self-revelation by such an organ as the brain-mind if knowledge is to arise.

And this setting of the content of knowledge allows us to claim a genuine conformity between it and the physical existents known. The situation is, of course, unique, and metaphors will not much help us. We are confined to the 
subjective side and can never have in consciousness the existent known, though we can literally grasp it with our hands. Penetrative intuition of the physical world is impossible just because we are what we are, organisms stimulated by external things. Physical being is determinate, and knowledge patterns after it in accordance with its own medium. 


\section{CHAPTER III.}

THE EPISTEMOLOGY OF EVOLUTIONARY NATURALISM.

\section{(CONTINUED.)}

I AVING laid and defended a critical foundation for physical realism, let us now proceed to develop its implications.

We have decided that knowledge of the physical world is just the tested propositions achieved by the intelligent use of the data of observation. These propositions are referrcd to the physical world as their object of judgment. We come to the decision that physical things have size, exclude one another, are massive, have structure and organization, have capacities for action, behave in certain describable ways. In the most natural fashion, we make claims to a valid knowledge of this sort, and, so far as I can see, skepticism has no logical basis against it. The foundation of modern idealistic skepticism is the refusal to distinguish between the datum of perception and the object of perception.

We think physical reality in terms of our knowledge of it. It is this thinking physical reality in terms of our knowledge which the reference of our knowledge to reality means. We are confined to knowledge since we cannot intuit physical reality; but we have given concrete reasons for our belief in the correspondence of datum and object.

The tests of conformity are internal or experiential, and are the tests applied to particular judgments from the perceptual to the conceptual level. But we have given the whole resultant construction its ultimate foundation by pointing 
out the responsible conformity of perceptual data to the physical existents which are the objects of perception. These latter we have been accustomed to call the controls. When this situation is once clearly understood, it will be realized that the validity of knowledge of the physical world is its conformity to reality.

In the light of this interpretation we can examine the structure of our critical knowledge about physical things. An explicit act of knowledge seems to involve at least three factors: (1) the affirmed existent with its determinate nature and continuities; (2) the propositional content within consciousness; and (3) the act of reference of the second to the first as informative of it. This analysis separates what is given together in a complex act of judgment, and yet it does not falsify the facts of the case. It appears that these factors are distinguishable in any judgment concerned with physical things. The physical existent is the subject of the judgment, and its name or symbol is the subject of the proposition; the predicate is the information about it; and the copula indicates the reference or relevance of the two. We think the existent affirmed in terms of the "objectives" - to use a word of Meinong - that it has a particular structure, size, position, powers, etc. It should be noted, however, that critical realism differs from common sense in that it does not suppose the subject of the judgment to be literally presented, nor does it assign to the subject any sensuous content. We mean the thing rather than see it, and our knowledge is a series of abstract statements for which data are merely the cues.

The easy way in which the realistic judgments of common sense can be developed into the framework of critical realism drives home the point I made earlier, that critical realism can retain the truth of common sense while passing beyond its naiveté. It also accounts for the fact that the critical judgments of science attach themselves to the matrix of common sense with such readiness. All the time, however, we know that science deals with the imperceptible. The object of perception is idențical with the object of knowl- 
edge, and so the subject of judgment is the same; but the interpretation of this object is different in the two cases. ${ }^{1}$ For the one, it coincides with the content of perception; for the other, this content is a mental datum correlative with the object. It is an appearance of the object.

In this setting, it may be worth while to point out the ambiguity of the term imperceptible. Distinguished philosophers have written to me saying that they could not believe in imperceptibles. But do they not ignore the distinction which the critical realist makes between the content and the object of perception? The physical existent is not an imperceptible if you mean object of perception; it is an imperceptible if you mean content of perception.

And this distinction rests upon the nature of the act of perception itself. The percipient organism attends to the object of perception. We can see the focusing of the eyes, the tension of the head, the directive set of the body. The psychologist knows that the instincts and interests of the organism are aroused and are finding expression in this behavior. We have a behavior-attitude. And correlative with this is the content of perception, which is to the subjectself within consciousness as the object of perception is to the behavior-attitude of the organism. It is this parallelism which leads common sense to merge the correlatives and so identify content of perception with object of perception. All that critical realism does is to distinguish what is distinguishable, and so prepare the way for a satisfactory synthesis which will cover the facts which break down naive realism. ${ }^{2}$

Another implication needing stress is the absence of any cognitive relation between the physical existent known and the propositional knowledge about it. Past philosophy made much use in its dialectic of the subject-object relation. Idealists held that the object is internally bound up with the sub-

1 Those who wish a more detailed comparison of the judgment of naive realism with that of critical realism will find it in my Essentials of Philosophy, Ch. XI.

2 The chapter on the mind-body problem will perform this synthesis. See, however, an article of mine in the Philosophical Review, March, 1918. 
ject or knower, while the neo-realists countered with the idea of external, or non-modifying, relations which left the reality the same whether being known or temporarily outside the cognitive relation. The ideal of knowledge certainly favored the realistic plea; and yet the battle was drawn. What critical realism does is completely to change the problem from dialectic to fact. If the physical existent is extramental, it is nonsense to speak of a cognitive relation between it and the act of referred knowledge. Such a relation could only be transcendental and non-natural. And like all transcendental relations we soon find that it is absolutely unnecessary.

The physical existent is not an object in its own right. It is made an object by the selective activity of the percipient organism. And this selection is behavior on the part of the organism, preliminary, usually, to overt action upon the existent selected as object. It is an adjustmental activity of the sort described above. The relation of the existent to the organism is causal; it is the source of stimuli. But the selection of one existent rather than another as object is due to the interest of the organism. ${ }^{3}$ At the level of perception, therefore, we have the following correlation: objectively, or physically, an organism focusing upon one of many stimulating existents and making this existent its object, an action to which the existent is quite indifferent; subjectively, or in consciousness, a content growing in clearness as the self attends to it and initiates those adjustments felt as movements of the eye and head, etc. There is a togetherness of the content and the self in the unity of consciousness. Back of this togetherness is a functional activity of the organism, but there is no causal relation between content and self in consciousness. Between existent, selected by the organism as object, and the organism there is, on the other hand, a causal relation but in the direction from existent to organism. This factual analysis shows that there

${ }^{3}$ The critical realist and the neo-realist have much in common here, but the neo-realist has confused the content with the object of perception. 
is no peculiar cognitive relation between the object and the percipient organism.

And what is true of perception is equally true of critical knowledge. The act of reference is a selection of an existent as object of the knowledge-claim. This selection is an internal process mediated by spatial and temporal distinctions. Thus I mean (select) the house five blocks from me on the right-hand side of the street. Instead of speaking of a cognitive relation, it would be far less ambiguous to speak of a cognitive selection. ${ }^{4}$ But as soon as we do so the dialectic controversies fade into their proper nothingness. The traditional maxim, "No subject without an object, and no object without a subject," can only mean that in perception and cognition the organism selects an existent as object, that is, as what it focuses itself upon. But philosophers have not well enough noted this relativity of objectness to the organism, and have interpreted the maxim as meaning no existent without a subject, which is untrue.

Physical realism must also defend itself against the phrase "transcendence of experience." Experience is one of those blanket terms which have made epistemological analysis difficult. It seems nonsense to say that I can transcend experience. But as soon as I realize that experience means both consciousness and knowledge, the situation begins to clear up. I can transcend my consciousness, not in the sense that I can get outside of it in any literal way, but in the sense that the knowledge I build up in it can by an act in consciousness be thought of as interpretative of an existent affirmed by the self as co-real.

Different Meanings of Consciousness.-There are two current uses of the term consciousness which must be sharply distinguished. Fortunately, there are synonyms for each usage.

The psychological usage most general is the "stream of consciousness," the changing field of the individual's experience. - Whatever is felt or given to awareness is a bit of

4 See Critical Realism, Ch. 8, for a fuller development of this point. 
consciousness in this sense. Consciousness is a term for what is experienced as well as for the experiencing self. While the field of attention is clearly given, the background needs introspection for its analysis. We may say that consciousness in this sense is composed of the psychical. Bits of color, sounds, concepts, feelings, emotions, all these are psychical. They are given to the individual in a way nothing else can be given. Such terms as subjective, psychical and mental are denotative as well as connotative. The members of the class are given to each experiencer.

If, then, any psychologist comes to me and says that there is no such thing as consciousness, I simply reply that he does not know what he is saying. He may be a very good student of animal behavior. But behavior is not a premise from which the denial of consciousness can be deduced. There is cloudy thinking somewhere or else a love of paradox. I admit that the rôle of consciousness in behavior is a moot point and of that I shall have more to say in a later chapter.

All the parts of the field of consciousness are compresent in a distinctive way, and so are spoken of as in consciousness. There is an analogy with space in this mode of expression, but this analogy must not be taken too seriously. It is simply an empirical case of the whole and part: The field has its continuity which undoubtedly has a functional foundation.

Traditional psychology, which was not behavioristic enough, abstracted from the situation of the organism and studied psychical content as such. This narrowness played into the hands of the idealists.

The critical realist desires to point to the fact that idealism has given this concentration by psychology upon the psychical a false interpretation. While the psychologist of to-day is a realist and believes in the physical realm and uses the results of the physical sciences, the idealist is persuaded that the content of perception is the object of perception. The psychologist consciously makes the abstraction from cognitive reference, while the idealist asserts that 
there is no need of such an abstraction because experience is an ultimate: "Etwas Wirklicheres als das Erleben gibt es nicht." But all modern realists are protesting against this bland assumption that the content of knowledge is the object of knowledge. Unfortunately, many realists thought that the only way of escape from idealism was to give up this comprehensive use of consciousness as the psychical and to build on consciousness as awareness.

Epistemology is interested primarily in cognition. It will not, therefore, make the abstraction that psychology makes. In a very real way, epistemology only supplements psychology since cognition is a function within consciousness. It cannot be too much stressed that consciousness is simply a term for the field of experience with its empirical structure. This structure is far more important than psychology has in the past realized. The field of consciousness is a psychical complex in which the self, which identifies itself with the organism, is set over against the perceptual contents regarded as objects perceived. The affirmation of these contents is essentially a motor response, although it is suffused and furthered by what I have elsewhere called realistic meanings. The affirmation of both self and these not-selves is an experience within consciousness. On both sides there is only the psychical, but psychical contents arising in a peculiar functional relation which seems to me explicable only in the light of the instinctive needs of the organism in behavior. This large structural duality reflects the interplay in behavior of percipient organism and physical thing.

We are now ready to examine the other meaning of consciousness. It is that of awareness, that of "conscious of." It is quite obvious that this meaning reflects a relationship within consciousness of the previous usage. It seems to me best to designate it awareness.

Awareness is, then, a functional character in consciousness (the field of experience) which accompanies the attention-process. The self attends to its contentual objects. Such objects of attention are clear and are set over against the interested self. This whole of subject-aware-of-object 
seems to me to be structural unity which rests upon a processunity. When I come to consider the English neo-realists I shall lay some stress upon this analysis. Needless to say that my position is neither that of the idealists nor that of the neo-realists. The idealists were right in holding that we have in awareness only a functional relation within consciousness, but they were wrong in limiting cognition to this elementary relation upon which cognition really only builds. The neo-realists were right in their attack upon the assumed dependence of the contentual object of awareness on the subject-self; they were wrong in their mythical notion of awareness and in their refusal to consider contentual objects mental.

This analysis of consciousness, brief as it has necessarily been, enables us to bring out the ambiguity in the current notions of transcendence. It is an empirical fact that I do affirm the existence of things and persons other than myself. I affirm them in the attitude I take toward them, an attitude guided by a content with which they are ordinarily simply identified. To affirm them is, accordingly, not to intuit them. We symbolize them and respond realistically to this symbolization. It is clear, then, that affirmation of other realities involves no transcendence.

But if affirmation involves no transcendence, it follows equally that knowledge, also, requires no mysterious transcendence. And yet we do both affirm and know existents which are not literal elements in our consciousness. The riddle is surely clear by now and finds its solution in the fact that knowledge involves a content of which we are aware and the claim that this content is interpretative of an entity affirmed as the object of this content. The object is selected and affirmed but is not within consciousness; the content, however, is within consciousness and is a datum of awareness. The illusion of transcendence is due to the intuitional prejudice which common-sense realism has nourished. All knowledge is thought of as an awareness of an object. And how can we be aware of an object which is not given to awareness? It has seemed to me pathetic to 
find naive realists giving consciousness the ability to reach through time and space to its objects. But some such mysterious power must be assigned to consciousness as a referential awareness if the triad of critical realism, subject-self, content and object, is denied for the duad of awareness and object.

The critical realist prefers such terms as "selective reference" and "internal pointing" to transcendence with its spatial associations. Objectness is a character assigned to an existent by this reference and yet a character never literally attached to the existent. The existent is in the situation of a person for whom some honor has been designed by others without his knowledge. Knowledge is a function in consciousness played by means of substitutes. No physical existent is given. Even the percipient and knowing organism is not given. The subject-self is the substitute for that organism and is, as we shall see in later chapters, a peculiar part of the organism. But the subjectself is taken to be the organism because there is nothing given to invalidate this working assumption by an appearance of greater existential solidity. We must not forget that existentially we are confined to consciousness. We can have knowledge of our own organism as of other physical things, but we can $b e$ it only to the extent that our own consciousness is the organism. What extent that is, is, of course, the consciousness-brain problem.

But I think that Kant's experience-in-general in which physical things are constructions and so phenomena, while things-in-themselves are unknowables, has had much to do with this bogy of transcending experience. For the Kantian, knowledge terminates within experience upon objects; for us, knowledge of a critical sort is a claim and content within experience concerning existences, outside of experience, mentally selected as objects. But I shall say no more about this aspect of the controversy, "for, if my mode of approach has not already undermined Kantianism, I cannot hope to do It $i n$ a few words at this point. Kantianism and critical real- 
ism are incompatibles. The two have entirely different notions of knowledge.

The Grasp of Knowledge.-In the argument of the book I shall constantly make the assertion that we do not intuit physical reality but only have knowledge of it. What does this distinction mean? What does knowledge reveal? Can we know in any sense the limitations of our human knowledge of nature? It is the contention of the critical realist that a careful study of the conditions and content of knowledge of the physical world gives us the conviction that this knowledge falls far short of that intimate insight into the stuff and labor of the world that the idea of intuition conveys. It is knowledge of the relative positions of things, their internal structure, their effects on other things, etc. It is information of the sort that sense-data can mediate. It is knowledge, but a far more modest knowledge than mankind has in its pride sometimes dreamed of.

The assumption that we can "know" the stuff of the physical world gets its measure of apparent plausibility from two really opposed approaches: naive realism and idealism. The critical realist asserts the falsity of both of these naive theories.

The naive realist supposes that he intuits the physical thing itself. For him, knowledge is an awareness of the very inherent and essential qualities of physical substance. The stuff of the world is open to inspection. There may be more to it than is revealed, yet this more is sampled by what is given. Traditional materialism is, I presume, simply a refinement of naive realism in which secondary qualities are removed, and master concepts, like mass and motion, developed in the place of the more sensuous primary qualities. Many idealists think of matter in this way although they have the refuge of denying its external reality.

The idealist holds that the psychical is a stuff, that it is meaningless to assert the reality of anything outside of experience. The panpsychist has usually been an idealist in his epistemology. But the realistic panpsychist is certain 
that in introspection he knows a psychical reality which is substantial and is actually the substance of the brain. We are at present concerned primarily with the grasp of knowledge based upon perception and will postpone consideration of introspective knowledge until we come to the treatment of the mind-body problem. To the idealistic panpsychist, we reply that consciousness does not equate with the physical world as known by means of science. What the idealist does is to identify the object of knowledge with the content of knowledge and so escape the weight of the problem. By analogy, he passes to the stuff of other things, assuming that in experience he has first-hand acquaintance with himself of an exhaustive sort. The point here to bear in mind is that it is only by analogy that he believes himself to have insight into the stuff of the physical world.

If sense-data and the propositions built upon them are mental contents, they cannot be supposed to reproduce the stuff of the physical world. It does not seem to me that we should expect being to be reproduced in knowledge. Knowledge is different from being, and in its way and for its purpose a substitute for being. Let us remember that perception is largely for the sake of guidance. Let us remember the practical situation of the organism and the fact that perceptual data arise in the organism. Bearing these facts in mind, we should not expect of knowledge what it cannot do. To put it bluntly, by the very situation of the knowing organism and the very nature of the psychical, physical being must escape us. To have knowledge of a physical existent is not to grasp the very stuff of that existent. To have knowledge is not to be the thing known. Knowledge supervenes upon the thing known and is external to it. It is the sort of information which the organism can achieve under stimulation from the existent. It is this knowledge of knowledge which a sane epistemology seeks to achieve. There is nothing self-contradictory in the idea. We first have knowledge of the physical world, and then we try to gain knowledge of the nature and conditions of that knowledge. 
If this be agnosticism, it is at least of a peculiar kind. It is agnosticism only in contrast to an uncritical idea of the nature and reach of knowledge. There is nothing in it of the traditional contrast between knowable phenomena and unknowable noumena. It is physical reality, itself, that is the object of specific human knowledge. But we do not have a penetrative intuition of physical reality. Let him who is a realist and claims to have it tell science what electricity is and not merely what it does under different conditions. I am strongly inclined to maintain that the intuitional notion of knowledge as an ideal is incapable of bearing reflection of an analytic sort. A concrete knowledge of the biopsychological setting of human knowledge lays bare its impossibility and its consequent absurdity. Knowledge has its place in consciousness, which is, itself, in an organism reacting to its environment. Such knowledge necessarily has its inherent limitations. But because it is knowledge, conformable to physical reality, it guides the human organism in its perilous effort at adaptation to, and control of, the parts of the universe in which it finds itself.

Knowledge of Other Minds.-Knowledge of other consciousnesses is different from knowledge of the physical world. It is a knowledge through asserted identity of content, whereas knowledge of the physical world is information about its object with no assertion of identity of content. Thus, when I interpret an expression on the face of my friend as meaning amusement, I use the expression as a symbol of an experience which I regard as in its essentials contentually the same for him as for me. Words which he uses are likewise admitted symbols of contents sufficiently identical in character. Such identity of character does not conflict with the numerical difference of existence of the two states implied.

Other consciousnesses are, therefore, objects of my knowledge. They are affirmed to exist and cannot be intuited, but they are interpreted by means of contents present in the knower's consciousness. For this reason, it is usually 
said that they are inferred by analogy. There are decided objections to such an explanation if it is taken in a technical way. The passage from behavior to the assumption of an idea back of it corresponding to the idea back of similar behavior on my part is instinctive and is confirmed by language and tested conduct. It is better to call it a natural assumption or postulate rather than an inference.

Of the general assurance that this instinctive postulate is justified by a careful study of communication and cooperative behavior connected therewith there can be no doubt. It is only the idealistic tradition which assumes that the object of knowledge must be something given in the knower's consciousness that casts skeptical shadows upon this knowledge of the content of other minds. And this very implication of idealism, far from raising any effective doubt as to the existence of other minds and our knowledge of their contents, should cast doubt upon the validity of the idealistic theory of knowledge itself. The critical realist finds that the demands of the situation fit in with what he is prepared to admit.

That we have knowledge of other minds and that this knowledge influences our own ideas in complex ways is a set of facts we are prepared to admit. Science is a cooperative achievement, and so are literature and law and custom. Men do have knowledge of the same objects and know that they agree or disagree, as the case may be, in regard to their ideas of these objects. The mechanism, so to speak, of this mutual understanding is a recognized knowledge of one another's opinions and beliefs founded upon the data of perception and judgment. We must remember, however, that such accordant beliefs involve no literal overlapping of the respective consciousnesses of the participating individuals.

The striking difference between knowledge of the physical world and knowledge of the contents of other minds requires emphasis. Both are cases of claims to knowledge of something extramental, that is, something outside of the particular knowing mind. In both instances, again, this 
claim is attached to an idea in the mind of the knower. At this point, however, a marked difference enters. In the case of knowing the idea in the mind of another, we carefully build up an idea which we take to be sufficiently identical in its meaning to the postulated idea and then regard it as the content of the knowledge-claim whose object is this selected external idea. When we think of the two ideational contents as separate existences in the minds of two individuals, we are apt to speak of them as similar just as we speak of two physical things as similar in this regard or that. When we think only of the characteristic content, we can speak of the two ideas as identical or largely identical. The object and the knowledge-content are, then, similar or identical, as we wish to phrase it, in this kind of knowledge. In the case of knowledge of the physical world, on the other hand, there is no claim that the idea as such is either like or identical with the object. The idea is not an object considered for its own sake and then asserted to be identical with a similar kind of object. That was the mistake of representative perception. To it Berkeley replied that an idea can be like only an idea. In knowledge of the physical world, therefore, we really have understood propositions which make definite statements about the physical realm, such as that an object has a specific kind of structure, that it is the cause of certain effects in other objects, etc. For the one kind of knowledge, the data (expressions, gestures and words) are instinctive or arbitrary symbols of mental contents supposedly occurring in two minds; for the other kind, the data are not symbols but foundations for the construction of information about objects.

It is the claim of critical realism that it can suggest an evolutionary naturalism for which consciousness and the functioning brain can be thought of as continuous and one natural whole by reason of this difference in our knowledge of them. Mental contents are intuited, the brain is not. Obviously, two unity theories open up: panpsychism says that the non-intuited brain is consciousness, the psychical; 
evolutionary naturalism suggests that the brain may include consciousness in a unique way because consciousness is a novel quality of the tensionally functioning brain. But we must leave these questions for a thorough examination in another chapter.

The Question of Truth.-Critical realism has little difficulty in formulating the meaning of truth implied in its epistemology. Trueness and falsity are terms of critical approval and disapproval applied to judgments or claims to knowledge. We know that many past judgments have turned out to be mistaken, and therefore the claim of a belief is theoretically disputable. Specific, or motived, doubt is the expression of some fact which apparently conflicts with the accepted judgment. For the judgment to survive, this conflicting fact must either be discredited or be so interpreted that it no longer conflicts with the judgment. When, with this possibility of error in mind, we continue to assert that an idea is true, we mean that it is a case of knowledge as it claims to be. It follows that the knowledge-claim is logically prior and is the important element in the meaning of truth; and, as we have already seen, knowledge demands the correspondence or conformity of the knowledge-content with the selected object.

But when the idea of trueness is merged in the definite body of truths accepted by the individuals of a social group, truth is certain to contain other elements of meaning of an historical and an instrumental character. Truth is something that grows and increases in volume and significance. Old beliefs are reinterpreted and new facts assimilated. I presume that all thinkers would now admit the historical development of the accepted beliefs of the present. Knowledge is not something machine-made. Parts of it are more or less adequate, more or less undergoing change.

That ideas are historical products and that they have instrumental worth the critical realist would proclaim as fervently as does the pragmatist. In fact, he is very sympathetic with the position of the pragmatist, albeit he thinks 
that many pragmatists are too utilitarian and do not value enough, or sufficiently admit, a theoretical interest in knowledge as such.

We shall have something more to say in the next chapter concerning the agreements and disagreements of pragmatism and critical realism. At present, it must suffice to state that the critical realist has only welcome to give to the instrumentalist's analysis of reflective thought and of the place therein of ideas. The critical realist is a mediatist and thinks of knowledge as an achievement and not as an intuition. Of course, we must be capable of being aware of data which are the material and means of knowledge. But this awareness of data and their careful discrimination is a feature of the process of achieving critical knowledge.

But knowing as a process ends in knowledge as a product. It is at this point that the critical realist is unwillingly forced to part company with the pragmatist, while hoping that the pragmatist will sooner or later realize the necessity of following the realist. Because of his idealistic antecedents, the pragmatist still thinks of knowledge as an intraexperiential affair. Pragmatism seems to me at present in unstable equilibrium. The American branch, at least, is naturalistic and realistic in its tendencies. I am inclined to believe that the blanket term "experience" still hides the genuine problem of knowledge from these would-be realists' eyes.

We must distinguish the criteria of truth from the meaning of truth. The criteria of trueness are intra-experiential or empirical. These criteria and their application come out clearly enough in the working of science. Science lays almost equal stress upon fidelity to the carefully discriminated data of controlled observation and upon coherence with other theories. Those ideas tend to establish themselves as true which agree with facts and show a capacity, due to their content, of organizing these facts in an explanatory way.

Scientific knowing is social in the sense that it is cooperative. There is endorsement of conclusions by many workers 
and there is agreement upon the methods employed. The product of scientific knowing is scientific knowledge of the world. The knowledge is not the world, but propositions informative about the world. Let it always be borne in mind that the critical realist does not hypostatize concepts.

Brief as this discussion of truth is, it must suffice. It will be noted that realists and pragmatists have much in common and that both are opposed to the outlook of absolute idealism. For instance, both would hold that particular judgments may be true by themselves without regard to some hypothetical whole of experience. When I assert that Columbus discovered America in 1492, this judgment is either true or false as it agrees or does not agree with the tested facts relevant to it. Judgments may supplement each other and so form a system, but the individual judgments need not depend upon the system. Is it necessary to add that truth must not be used as a term synonymous with reality, as many idealists have been inclined to use it? Trueness is a critical approval passed upon a judgmental idea concerned with an object. Idea and object are distinct. Truth is a human and mental affair. It is, however, not arbitrary, but, like knowledge of which it is the confirmation. strictly controlled by responsible and relevant data.

Subsistence and Existence.-A few words must be said concerning the distinction between subsistent and existent. While I am not particularly fond of a multiplication of terms, new terms at least indicate a valuable distinction or disclose a misunderstanding. So is it with this term subsistent. The neo-realists make much appeal to the subsistent as something equally real with the existent and yet not reducible to it. Of late, the medieval term essence is coming into use as meaning much the same thing as subsistent. The physical world exists, it is said, while geometrical objects, numbers, space, time, universals, facts, ideals, subsist. Sometimes we hear mention of three kinds of being: the mental, the logical or subsistent, and the physical.

Frankly, I do not like, nor see the need for, this use of 
the term, being. The very abstractness of the term is apt to induce unreal puzzles. To admit coordinate kinds of being is to proclaim species of a genus; and what is more natural than to be challenged for both the differentia of each species and the common character which makes them belong to a genus? Is it the assumption that three kinds of substances can be intuited and known to be different? If so, the critical realist challenges any such assumption.

We have already hinted our belief that consciousness as the psychical can be assigned to the brain when this part of the physical world is properly interpreted. Consciousness as awareness is, on the other hand, simply a function within the psychical due to its structure. We have also argued that physical being cannot be grasped by consciousness, because data and knowledge-content are not literal reproductions of physical existents. What we can attain to is a knowledge of what may be called the "form" of the physical world if this term be not taken in too literal a fashion.

So far as the psychical does not fit the knowledge of the physical world which science has acquired, the physical world cannot be identified with the psychical without a remainder. And a little reflection has shown us that we are acquainted with the psychical as we are not with the physical. Hence, the exclusion cannot be one of inspection as naive dualists have supposed. Moreover, the existential relation between them need not be one of identity. Because the terms are unique, we must be on our guard against the application of such relations as beg the question of unity.

To anticipate our later, more detailed argument, we shall hold that consciousness is a functional expression of the brain and so internal to, and continuous with, physical reality. And this location of consciousness admits its uniqueness and primacy for us while asserting that an existential dualism of the traditional type is not justified by this contentual complexity of the brain. Only he who supposes that he can so intuit the whole being of the brain as to be certain that the psychical is not there, has the logical right to reject this hypothesis to which all the empirical facts point. 
In short, we are dualists as against the extreme position of behaviorists and neo-realists, who do not admit a difference between datum and object, but we are not dualists in the Cartesian sense.

I presume that Bergson in his repeated declarations that consciousness cannot be in the brain is building upon his assumption that the material world is really space. Descartes still pursues the anti-intellectualist. To grasp time as the characteristic dimension of consciousness and throw it as a fourth dimension into the face of space is dialectical and not empirical. May not time be a character of the physical realm as well? And why are people so certain that the brain cannot engender representations? What inside information have they that excludes this possibility? We cannot at present do much more than suggest our own position and cast doubt upon the facile assumptions so often made.

To regard the logical or subsistent as a part of the mental realm used to be the unfailing course of philosophy. Such apprehended contents are, for Locke, ideas. They have logical characters which can be analyzed and judged. Both Locke and Hume realized that mathematics is a non-existential science dealing with essences or conceptual data of the nature of ideas. It is true that they often introduced the irrelevant question of place and time of the existence of these conceptual data. But we can clearly distinguish this existential question from the actual discrimination of logical characters in the given contents and the consequent discovery of relations. It is the contents that exist and existence does not add any peculiar property to the data which are being studied. The triangle which I now hold before my mind's eye has certain characteristics about which judgments may be made. The psychological judgment that it is a mental occurrence is only added information not at all affecting these characteristics and these geometrical judgments.

Reasoning, as I understand it, is a process of dealing with contents by way of noting their identities and differences in order to solve particular problems. Such assertion of 
existence as is in the mind at the time is more apt to be that of naive realism than that of psychological reflection. But this fact does not invalidate the truth of psychological reflection when it comes. For the critical realist, there is no contradiction between the fact that these contents are mental and the fact that they are the kind of contents they are. The term mental does not seem to me to be more than a critical mode of classification and means non-physical,, bound up with the organism, open to inspection. The contents which are so classed are increased as naive realism breaks down. We may speak of sensory contents and imaginal contents, the latter shading into meanings and what is frequently called imageless thought.

Much of neo-realism seeks to identify consciousness (the mental) with a reference to a contentual object or with a transparent awareness. It seems to the critical realist that the analysis has not been accurately made. What we have in awareness is a structural contrast within the whole mental field. Introspective psychology suggests such factors as a complex motor attitude set over against and qualifying the content of perception or an image, bodily feelings of an organic type, a sense of familiarity, the purpose controlling perception. There is a duality in the field of consciousness corresponding to the distinction between organism and object. A sense of attending to, of being interested in, an object accompanies the object.

Thus there would seem to be no need for the rather mystical notions of awareness that some realists cherish. So far as content is concerned, both sides of cognition are mental. The difference is one of function. In perception, the content of perception is identified with the object of perception and is, accordingly, set sharply over against the subject side. In critical knowledge, the triad we have acknowledged comes into being. The subject-self is aware of propositional content as knowledge of an extramental

5 Non-physical, here, means not a substantial physical object. That it is a peculiar contentual character of the functioning brain and, in that sense, physical will be one of our theses, 
object. The reference to, and affirmation of, an object is filled out by the knowledge-content. The mental has a complex structure and a complex content.

Cognition is never a mere immediacy. The self-complex is present and is joined with concepts interpretative of the given data. My argument is that the complex "self aware of objective content" is a characteristic structure of the field of experience. It is carried over from perception to conception, and from the perception of objects to the awareness of contents. All that is needed is a loosening of the content from the meaning of thinghood; the content then stands out in its own right.

Such mental contents, when abstract, are what are called subsistents. Abstract space, time, number, ideals are not physical things and yet they are contentual objects of thought. They can be analyzed and synthetized. Did not the mind have this capacity, there could be no science. But I see no good reason to believe that these contentual objects are non-mental existences. The ordinary tradition in psychology and logic seems to me quite satisfactory.

Let me connect this structure of cognition with the situation of the percipient organism. It will be remembered that I was led to place stress on the parallelism between the behavior-attitude of the organism and the thing which it focuses upon (the object of perception), on the one side, and the two poles of consciousness, the subject-self and the content of perception, on the other. There is a duality on both sides that cannot be ignored. The content presented to, and interpreted by, the subject-self is to this self much as the thing is to the interested organism. The realist believes that this structure within consciousness is no accident. It is surely a functional reflection of the situation of the organism. The perceptual datum is a mental substitute for the thing to which the organism is reacting, and the conscious self is interested in it for that reason. The situation of the organism is projected into consciousness. The subjectself as the representative and conscious expression of the instincts and purposes of the organism is to the organism 
as the sense-data are to the thing. The independence of the two terms which are extramental is reflected in the independence of the two poles of consciousness, the self aware and the contentual object of its awareness. And, if I am not mistaken, psychology admits that the presentational side of consciousness, connected as it largely is with special areas of the brain, has this sort of independence of subjective interest. Of course, the two poles are inseparable, yet there is no causal relation between them. The subject-self selects, ${ }^{6}$ it does not create or change data.

It follows that I agree with much of the analysis of the English neo-realists in regard to awareness and its contentual object. Yet I am convinced that they have robbed awareness of its actual content by separating it from the interested and interpretative subject-self. Their other mistake was to regard the contentual element, or ideas in the Lockean sense, as non-mental. As I have already argued in my Critical Realism, this total structure is an affair of consciousness in the psychological sense of that term.

Now as the practical attitude demanding action becomes less dominant, this perceptual structure remains but is transformed. The very personal, active self becomes more the thinking subject, while the perceived thing becomes more a content of which the subject is aware, one of his thoughts. This content or idea may be a sense-datum or a very abstract complex symbolized by words. But if my argument above is correct, this idea is mental and dependent upon the brain. The subject is just as mental, but is the center of control and organization. These ideas are what it is now the fashion to call subsistents. Their coming and going are events indifferent to their nature. What is given to the subject is the content and not the content's existence as a mental event.

Yet genetic analysis soon convinces the unprejudiced thinker that all ideas, even the most abstract, have their roots in sense-experience and so are continuous with presentations. Universals are not fictions, but they have the same existential status as sense-data.

- It selects largely through its control of behavior. 
But the ideas in terms of which we possess knowledge about the physical world are understood propositions. Knowledge has its internal structure as well as its reference. Data of awareness are the servants of propositional knowledge about things.

The essentials of the epistemology underlying evolutionary naturalism have now been explained. The necessity for this rather full treatment will become increasingly apparent as we proceed to examine the categories.

It may be well to take note of Professor Perry's recent review of Essays in Critical Realism in the Philosophical Review, July, 1921. I can speak authoritatively only for my own position which belongs to the so-called "minority report." Since I published its first systematic exposition in my Critical Realism I believe that I have the right so to do.

There are clearly two different uses of the term meaning, one for content and one for function. Meaning as content is any ouale, any bit of significance, which can be held before the attention. It is usually thought of as additional to sense-data and more conceptual. Meaning as a function is a complex, active experience. It is to mean. It is a selecting of an object of any kind, (a) presentatively, (b) representatively. I mean an object. This is a complex experience which involves two factors, reference and identification. Reference is an attitude plus an identification. To mean an object is to select it, pick it out. Critical Realism, p. 192. I mean an object representatively by means of an idea of an object. There is the same attitude of reference and the same content of identification, but a sense of the absence of the actual object qualifies the complex. Representative meaning develops out of, and rests on, presentative meaning.

All this can be found by retrospective analysis in consciousness. May I register a protest against the dogma, which seems to me to underlie the notion of essence, that introspection gives only a hodgepodge of images? Consciousness has a structure which expresses the situation of the organism. 


\section{CHAPTER IV.}

THE STATUS OF THE CATEGORIES.

CINCE I shall have much to say of the various categories $D$ in the succeeding chapters, it is only right that I should state as succinctly as possible my idea of their status and origin. Such a statement is especially imperative because the nature of the categories has been much obscured in the past by the efforts of Kant to meet Hume's sensationalism. Both Kant and Hume were geniuses of the first water and did in the way of analysis all, and more than all, that could rightly be expected of them by their most fervent admirers ; and yet they could not go beyond their time.

Traditional $V$ iews.-I am compelled to criticize the tendency of this eighteenth-century movement as in many ways perverse. The story is an old one, and I shall refer only to essential points. Hume reduced reality to a manifold of passing elements having no permanence or sameness. In other words, he clearly saw that data are not physical things; and yet he was so much influenced by Berkeley's idealism that he was unable to work out a theory of knowledge of a realistic sort. To a Humean, we can only offer our own critical theory of knowledge, which is neither naive realism nor a naive copy-theory. I presume that Hume would have admitted our possession of such categories as identity and permanence but would have denied their applicability to anything in human experience. The assumption that there was anything validly to apply them to was an illusion. But the critical realist would retort that we clearly apply 
them to objects of perception, and logical identity to the contents of perception, Hume's impressions.

Kant started from the fact of knowledge and proceeded to analyze the contents and implications of scientific knowledge. This was an excellent method of approach to the problem; but, unfortunately, Kant had not achieved an adequate epistemology and so was led to distinguish between phenomena present to, and formed by, a universal, logical mind and the inner flow of sensations in an individual mind. This logical mind supposedly forms its objects, and so knowledge finds what mind has already contributed. As is well known, Kant postulated an original manifold of sensations somehow passively given to the mind. The logical mind was thereupon regarded as a machine which actively wove these sensations into an ordered pattern. The pattern was contributed by the ego and was subjective.

Kant's phenomena are really contents and not objects. Although he is an empirical realist, he is not a physical realist. Or, to put it otherwise, these phenomenal contents which he takes to be objects are constructs related to the postulated synthetic ego and dependent on it. Kant is an idealistic realist, that is, he does not want to drop back into psychologism with Hume, and yet he is convinced that what is given is mental. To put it frankly, he was puzzled. No one can read the Critique of Pure Reason without feeling this. He tries to keep the realism as regards the percipient, while admitting the idealism in relation to a logical ego. It is this "objective" idealism which modern idealism takes refuge in. Unlike Hume's sensations, the Kantian phenomenon is thought of as permanent and identical. It is in this similar to the thing of naive realism, and yet it differs in that it is relative to a logical ego.

In accord with most critical thinkers to-day, I would disavow both Hume's atomism and Kant's logical machinery. As James Ward puts it, "Thinking is doing, and like all doing has a motive and has an end. Kant's logical ego functioning spontaneously out of time is but a chimera buzz- 
ing in a vacuum and feeding on second intentions; that it is the thinnest of abstractions, he himself allows." 1

What we must commence with is the field of the individual's experience as it is concretely given with its structure and empirical content full upon it. Genetic logic and genetic psychology can study the growth of this complex experience from humbler stages, but they find no reason to assume either a disconnected manifold or a spider-like ego, however far back they go. What they will discover is greater simplicity of structure and fewer distinctions.

Strictly speaking, epistemology is a critical science which studies the meaning and claim of knowledge at the level of adult experience, in the light of what are decided to be inevitable and well-grounded distinctions. Hence, this genetic approach is not absolutely necessary to it. Yet it is confirmatory and suggestive, and enables the thinker to throw off the incubus of the old controversies. I would not be understood to belittle the value of a keen insight into the logical development of modern philosophy. I do not believe that any one can go far toward the solution of these problems unless he appreciates the formulations, rejections, successes, and failures of past thinkers. He must have the ability to hold past and present together in a synoptic way, and yet possess the vitality that is not overwhelmed by erudition. In other words, he must be able to put his finger upon the genuine problems and grasp the best setting for them that philosophy and science have made possible by their growth.

The individual's field of experience is, I take it, but ancther name for what the psychologist calls consciousness. The common thesis of critical realist and psychologist is that this changing field of experience is a structural whole which is a function of the organic individual in active relation with his environment which consists of inorganic things and other persons. It is within this organic individual as an expressive part of it that consciousness arises. Per-

1 Ward, Naturalism and Agnosticism, 4th ed., p. 481. I am glad that I can agree so largely with Ward on these points. 
sonally, I do not care whether this organic individual be called a subject, or a self, or what you will, as long as no unempirical notions are surreptitiously introduced. I prefer to call it an organic individual or a psycho-physical organism because these terms correspond to our knowledge of it and do not preclude the intussusception of all that the terms subject or self can justly add. Let me admit that idealistic philosophy was far from wrong in its protests against associational psychology and against the reductive mechanistic views of biology. It was right in its empiricism; it was wrong in its transcendentalism. But is not this old battle a thing of the past whose fruits have been appropriated by the younger generation? The sharp contrasts of the past have given way to a deeper outlook. The time is ripe for the interpretation of this massive growth. It is my contention that evolutionary naturalism, on the metaphysical side, and critical realism, on the epistemological side, are the logical philosophical formulations of the actual Weltanschauung of the present.

The Pattern of Experience.-Epistemology stresses what psychology has neglected, viz., the structural or formal side of consciousness. I presume that it puts its finger on a common weakness of past science, its neglect of pattern or organization. Psychology has been largely reductive and analytic. It may be that psychology can thus best meet the special problems in which it is interested. Nevertheless, philosophy must examine the structure and important distinctions of the individual's field of experience. These are facts as real as any to be found in biology. This descriptive empiricism, dealing with the structure of the whole of consciousness as it is concretely given rather than with the hypothetical elements into which abstracted parts like ideas and perceptual complexes can be analyzed, is the true foundation of epistemology. ${ }^{2}$ Such descriptive empiricism has nothing in common with what continental thinkers call psychologism. It does what psychology has neglected to do:

${ }^{2}$ Cf. The Essentials of Philosophy, Ch. 8. 
it enlarges psychology, if you will. And I take it that this is what modern philosophy has really accomplished. Unfortunately, the Kantian tradition with its consciousnessin-general and its neglect of the individual was often too strong for it.

This large structure of concrete consciousness is just as common to various individuals as is the structure which the biologist finds in an animal species. This commonness of structure, however, no more conflicts with mental pluralism than does the common structure of individuals of a species conflict with the numerical distinctness of the individual organisms.

Now, with the addition of this descriptive enlargement of psychology, critical realism reaffirms the belief of both common sense and psychology that consciousness is a function of the organic individual in interaction with its environment. But against naive realism it holds that this environment is not apprehended. The knowledge situation is more complex than naive realism supposes. New distinctions must be added. In other words, knowledge is not conceived as an act of awareness of an object literally presented but as a structural system of contents and affirmations. In the preceding chapter, we have, I hope, made sufficiently clear the interpretation of knowledge involved logically in this conception of consciousness. Knowledge of physical existents can be only grounded information assigned to affirmed objects as revealing something about them. ${ }^{3}$

If the individual's field of experience is a growth which reflects-if it does not do more-the active interplay of organism and environment, we need not be surprised to find that it contains distinctions of significance. Let us mention a few such distinctions which we shall later analyze.

There is, for instance, the idea of particular physical things. These things are qualified as permanent and self-

${ }^{3}$ Cf. an article in the Philosophical Review, September, 1918. This interpretation of knowledge does not conflict with the existence of less critical views. 
identical. These are the categories which we saw puzzled Hume who could not find anything which justified their application. We know that they apply to existences which cannot be literally given but which are represented in a way by data. The origin of these categories is fairly clear to the psychologist of to-day. They are quite obviously not contributions of a logical ego but meanings which reflect concrete experiences. The individual senses his own permanence and recognizes the same content again and again which he instinctively treats as the object to which he is reacting. Thus the sensible things of naive realism are complexes of contents which move together and behave in describable ways. Their self-existence is partly modeled on that of the self and their independence means that they are things to be reckoned with. Thus these preliminary categories grow up in a natural and empirical way.

These things are perceived as in spatial relations with one another; they "act" upon one another; they change in various ways. The bodily self reacting to them is considered one of them, and its experiences of willed action and passive influence are the material for much of the first idea of these categories. It is only later that such categories are critically examined and adjusted to what is actually known about physical existents. Probably the critical refinement of the category of causality illustrates the status of the categories as well as any. Much of the feeling content has had to be elided.

How natural these distinctions built around "things" sound! How inevitable they seem to us to be! And yet they are growths whose psychological basis and stages we can in a measure trace. They are expressions of the interpretative drift of consciousness under the play of organic instincts and external stimuli. The presentational content -itself a growth of sensori-motor processes-is seized, as it were, by interests focalized in the self. This presented field suggests a division into complexes which hold together, move together, and threaten or entice the self. Thus are empirical things differentiated and interrelated. 
Within the field of the given, therefore, the growth of a clear pattern appears to be the function of a process in which two complementary factors work: change of position of complexes on their own initiative, and the attention to these complexes in a unitary way as a result of interests such as desire, curiosity, and fear. Because these complexes are not under the individual's direct control, they are regarded as external things and secure motor meanings. They are co-real with the self; things to be reckoned with; objects which have consequences for weal and woe. Thus this empirical structure of consciousness has an origin of the most natural sort. It rests, on the one side, upon characteristics of presentational complexes, their groupings and changes, their independence of direct control; on the other side, upon selective interests of the self.

Philosophy has laid great stress upon this distinction between the self and the not-self. Yet it has failed to give it the concrete setting which is desirable. ${ }^{4}$ It must be remembered that the not-self is a term for a plurality of things not felt to be essentially different in kind from the self. The contrast held in mind is self as a conscious center of action; and this self is from the first a bodily self. What we should stress is the fact that we have here a pattern within the consciousness of each individual. The self notes factors in their relation within consciousness and so achieves the category of thinghood. It notes sequential changes in one complex after another has moved toward it and come in "contact" with it, and soon arrives at the idea of causal interaction. The setting of these primary or common-sense categories is very concrete. The active self selects and seeks to control; it notices alterations of position; it re-

4 Cf. Ward's quotation from Ferrier, Naturalism and Agnosticism, pp. 491-92. Ward tries to kill dualism in this fashion. But this pattern within the individual's consciousness has nothing to do with dualism; it has to do with the indication of pluralism. Each self feels itself confronted with many co-real things. I am inclined to think that the inability to distinguish between content and object of perception together with that abstraction, consciousness-in-general, accounts for much idealism. 
marks changes. It is one thing among others, intensely interested in them and their possibilities.

Of course, the development of these primary categories takes time. They are growths; and yet, I think, inevitable growths. It is absurd to attempt to deduce them from an abstract understanding. They are products of the character and behavior of the sense-continuum in relation to the self as active and interpretative. Spatial and temporal order are features of the complexes which are given thinghood: and causality is the spatio-temporal interaction of these things. The framework is objective, and, if the self introjectively gives a tang and affective atmosphere to it, this subjective coloring can be withdrawn without injury to what is cognitively essential. The conscious self does not spin the categories from itself.

But it is time that we gave this development within experience its realistic setting. The parallelism between the object of perception and the interested organism, on the one hand, and the content of perception and the conscious self, on the other hand, needs to be borne in mind. The following diagram may suggest the situation:

Consciousness

(conscious self $\longleftrightarrow$-IIt selects $\nrightarrow$ m $\rightarrow$ contents of perception)

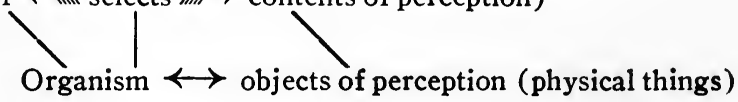

The foundation of the growth of the field of experience is the interaction of organism and environment. This situation is symbolized in the diagram by the double-headed arrow. Corresponding to this active relationship, and expressive of it, is the structure of consciousness indicated above the organism. While the relation between the organism and its environment is causal, the relation between the conscious self and the contents of perception is not overtly causal in the same sense. Yet it is an undoubted fact that the conscious self is influenced by the contents of perception and that the contents of perception are selected more or less in accordance with the interests of the conscious self. 
Overt changes in the content of perception (an empirical thing) can be brought about only by action of the organism. This diagram illustrates the control of the contents of perception by the objects of perception. It also makes clear the basis for the conformity of data and objects. It is just because objects are organized wholes which move as one that contents of perception behave in a corresponding way in consciousness. It is just because the relations of objects are spatial and temporal that the relations of contentcomplexes are likewise spatial and temporal. The whole situation suggests that controlled correspondence of order which critical realism affirms.

Kantianism.-Let us now contrast this analysis with Kant's schema. As nearly as I can make out the main drift of Kant's outlook-every one acknowledges that he hesitated-it is as follows:

Transcendental
ego $\rightarrow H \rightarrow$$\rightarrow\left\{\begin{array}{c}\text { forms of the } \\ \text { understanding } \\ \text { forms of } \\ \text { perception }\end{array}\right\}$ sense-manifold $\mid$ thing-in-itself

Now it is evident that there can be no correspondence of order between the thing-in-itself and the objects of experience whose order is subjectively assigned. Kant shut himself into agnosticism by his very approach. Kant's schema suggests the working of a machine into which raw material is fed and there worked up. But is not the analogy completely false? We have to do with an organism with remarkable capacities under complex stimulation.

The need of the organism is to achieve a presentational pattern corresponding to the physical environment to which it must adapt itself. I do not think that it is far-fetched to suggest that consciousness is an instrument of that adaptiveness or Zweckmässigkeit which characterizes all organic life. (We shall develop this point further in Chapter 15.) The facts indicate that the organism selectively receives stimuli in their real order and transmutes them into sensedata of a corresponding order. Association by contiguity 
assists the construction of this internal pattern, but the method is not entirely passive. Recognition of the same objects of perception enables the organism to test its constructions again and again. There is nothing of the pure machine in all this. It is more like the fulfilment of a set task. It is the effort of the organism for its own safety to shut out the arbitrary and purely subjective. As I put it in an article, "The brain is sympathetic with reality, and, like a skilled lawyer, draws out its story and puts it into its own language." ${ }_{5}$ It is the actual situation of the organic individual which leads to the conformity of the pattern of empirical contents with physical things. It is the need of the organism which makes it objective in its methods.

The higher levels in consciousness bear witness to the same aim. The conscious self identifies, discriminates, analyzes, compares, notes implications, traces relations, etc. What it does is to bring out the pattern in all its complexity. It does not change its material; it studies it, and it finds assistance in repetition, experimentation, a larger experience. The activities of the mind are like ingenious tools, they further the aim of the organism. Not by passivity but by the right sort of activity is the correct pattern reached. Realizing this, we stand on the shoulders of Hume and Kant. We have risen above the yearning for a passive transmission of the world into consciousness. But in so doing we have risen above both naive realism and the naive type of copy-theory. We can be realists and yet appreciate what idealism felt to be a truth, the part played by mind in knowledge.

Yet this mind is not a disembodied mind. It is not a logical ego nor a transcendental self. It is the mind of psychology and logic; it is the brain-mind sensitive to stimuli and transmuting them into presentations which arouse in the same brain-mind interests, focused in the conscious self, and operations of both an analytic and a synthetic character. This brain-mind is an instrument of the organism and it employs consciousness as a medium and means

- The Philosophical Review, September, 1918. 
for the transmutation of the macrocosm into a correspondent microcosm. And this cognitive side of the mind is, as we all realize to-day, an organon of the affective-volitional tendencies of the organic individual. But we must not forget that what is at first almost entirely a means can become an end desired for its own sake. The desire to know is now a prime desire of civilized man.

Knowledge is, then, a function of the capacities of the organism, many of which are experienced in consciousness, and the physical things the organism selects as objects and therefore controls. These are the ultimate conditions of knowledge. And it must not be forgotten that knowledge has two distinguishable levels: (1) of contents correlated and identified with objects of perception, and so cues for conduct; and (2) propositional contents, developed upon these, yet held to be mental and distinct from the objects of perception and thought, and informative of them. Naive realism tries to carry through the first outlook; critical realism to explain the first and advance to the second.

Objective Idealism.-Because much of objective idealism took its departure from the Kantian tradition, it tended to think of the categories as conditions of knowledge in the sense that a non-natural mind must contribute forms and relations from itself. We see now that it confused mental capacities, as instrumental to perceptual and judgmental content, with a contribution of forms from a hidden ego. In contrast, the critical realist asserts a bio-psychological process.

Hegelianism tried to escape that inner dualism which Kant has adopted as a way of escape from Hume. So far, so good. But this immanent deduction of the categories from one another by the dialectical method has never been successfully carried through. The categories are actually discriminations expressive of the situation of the psychophysical organism. They are distinctions to be discovered within the individual's experience in an empirical fashion. The whole ideal of deduction seems to me fundamentally 
mistaken. We must add that Hegel, no more than Kant, solved the epistemological problem. He rejected Kantian agnosticism but never gained the insight that we can possess knowledge of that which is not an element within experience as a consequence. The Hegelian has always shown a timidity in facing the problem of perception.

In its actual working, objective idealism-whether neoKantian or Hegelian-has discovered the categories in the object of thought instead of in the subject. Why? Because that is where they develop. A careful student of idealism writes as follows: "As a matter of fact, objective idealism has deduced the categories from the object and not from the subject. To deduce the categories from the subject, it would have been necessary to define the subject-which the idealist has consistently omitted to do. The subject has been a bystander, whose familiar presence has gradually assumed the appearance of indispensable necessity.... The idealist deduces the categories from subject in so far as conformed to the objective nature of things, and thus, in the last analysis, from the objective nature of things. The actual subject, then, does not impose necessities on nature, but yields to necessities which are dictated to it by something beyond itself."' In its actual implications, therefore, much of idealism is idealism only in name. It is for this reason that many religiously inclined thinkers speak of objective idealism as closely allied to naturalism. And so it $i$. It is a naturalism manqué. It is this because it never conquered its Kantian beginnings, the idea of constitutive thought, a universal mind, the object of knowledge as given in experience, etc. In short, it was reared on an inadequate epistemology. We shall see that even the pragmatists have not escaped from that magic circle called experience.

It is not too much to say that modern philosophy shows an unsettled view of the nature and function of mind. And yet the growth of philosophy, in the light of modern biology, psychology, and logic, is bringing a remedy to the vague

- Perry, Present Philosophical Tendencies, p. 160. 
ideas of the past which repeated such terms as relations, synthetic unity, and coherence in a semi-ecstatic way.

Pragmatism and Neo-Realism.-Pragmatism and neorealism have supplemented one another in this advance, pragmatism showing the concrete setting of thought in the position and capacities of the human organism, while neo-realism stressed the actual operations of analysis and synthesis which are performed in consciousness. It is now seen that reflective thought follows "leads" in presented material, that reasoning is a purposive solution of problems by means of ideas and that it involves the noticing of identities and differences. Neo-realism supplements pragmatism by its intellectualism, by its stress upon order, by its anti-romanticism. It adds the iron which pragmatism has at times decidedly needed. Both movements have turned their backs on Kantianism. The actual process of thought is being located. The individual is coming to his own. The natural is seen to include mind. Thought is not a vague creative ferment, but a highly structural process which we can empirically analyze.

But this result confirms the outlook of critical realism. The neo-realist is right in his contention that knowledge must conform to reality, but he wants an identity of idea and thing. He makes thought into a literal presence or a selective apprehension of non-mental entities. He does not see, or will not admit, that thought as a structural process ends in thoughts or ideas which conform to reality as an independent control. He thinks of consciousness as either an act of apprehension or a peculiar inclusion of objects. $\mathrm{He}$ would not admit the distinction between the mental content of perception and the physical object of perception. Hence he is compelled to leave the organic basis of knowledge in the capacities of the organism unexplored. Like all naive realists, he is unable to do justice to all the facts of consciousness and is puzzled to account for error and illusion. ${ }^{7}$

${ }^{7}$ Neo-realism seems to be working away from its pan-objectivism. This comes out in Spaulding's The New Rationalism. But critical realism will be the logical terminus of such a movement. 
Pragmatism, on the other hand, has worked out a more empirical idea of the structure of thought as a process. It has removed logic from the rather stiff philosophical setting which it retained even with such a critical thinker as Bosanquet. Whether it has added much logic in the process is a question over which there might well be dispute. But pragmatism never conquered the epistemological problem which it had inherited. Instead, it felt the strength of the drift toward realism and sought more and more to be realistic in a pragmatic sort of way, that is, by ignoring patient analysis and trusting to the right postulates. While valuable as a dissolvent of absolute idealism it would have accomplished far more, and accomplished it more quickly, if it had frankly faced the questions realists propounded. Still, this must be said in its favor, that much of this realism was of the immediatist type and conflicted flatly with the pragmatist's analysis of thought as a process. But in so doing, pragmatism was compelled to develop a doctrine as conflicting with common sense as that of the change of physical things by thought. It has always seemed to me that this implication should have given them pause. But if experience is to be equated with reality without remainder, what can one do? Pragmatism drifted toward realism from its reaction against absolutism; it never earned the right to realism.

Critical Realism. - Now critical realism is a mediate realism which seeks to do justice both to reflective thought as a process and to the claims of knowledge. In it-if I may permit myself a prophecy-both pragmatism of a chastened sort and neo-realism of a less doctrinaire type may ultimately find the satisfaction of their insights. The neorealist must cease to take contents for objects, and the pragmatist must stop juggling with the terms of experience and admit a reference beyond the contents of experience. I am inclined to think that the root-fallacy is the same for both, the inability to distinguish between content and object.

There has been too much eristic in philosophy. For 
instance, both pragmatist and neo-realist must realize that words are equivocal, that there are several equally valid meanings for terms. There has been too much of a tendency to oversimplify.

It seems to me that a true empiricist can easily note that we use "thought" in four distinct ways. First, thought is a term for a reflective process; second, it is a term for data, the contentual entities which are objects of awareness; third, it is a term for the act of awareness ; fourth, it is a term for an idea of an object, for the contentual thought of an object of reference, for a specific knowledge-claim. It is too bad, perhaps, that there are all these four uses of the one term; and yet a little patience will keep them apart. I have no doubt that the use of the one common term implies the recognition that the individual mind is always involved.

Another example of an equivocal term which has always led to ambiguity is "idea." Eristic has thrived on this word. It has been a case of "either-or." But an idea is a term for an instrument within reflective thought (pragmatism) and a term for critically conceived data and ideata as contentual entities (use number two above). The two uses do not conflict. But is there not a third use, the mental idea of an affirmed existent? An object of thought may function in the process of thought as an instrument in the solution of a problem, and in the cognitive attitude as the content of the specific knowledge-claim. It is to this third use that neo-realism has not done justice because of its immediatism. I am inclined to suggest that neo-realism was led to ignore this third possibility as a result of its stress upon subsistents, be these mathematical objects, universals or ideals.

The Status of the Categories.-Having gained a better knowledge of the structure of consciousness and a clearer idea of mind as a condition of knowledge, we can now perceive the status of the categories. We can repeat our statement that primary knowledge is a function of the capacities of the organism under stimulation by its environment. These 
capacities correspond to different levels, and their operation finally results in cognitive ideas directed toward affirmed existents. The standard elements and distinctions of this knowledge are the categories. Thus physical things are conceived as in a spatial order and as measurable. What direction they are from one another, what distance lies between them, what their size is-all these are specific bits of knowledge that come under the spatial form as such. Space as an abstract universal is exemplified by the specific instances. It is the common form or order. Events, or changes in physical things, happen in a peculiar order, the temporal. This order can be abstracted from its instances and studied as a universal. It is the common character of events, and, since physical things change, our knowledge about them contains this order as an internal form. Thus space and time are categories in that they are characteristic elements of the content of our knowledge about the physical world. They are not a peculiar logical type of being which somewhat underlies the physical world. Once abstracted, however, they can become subsistential contents of awareness; they are, then, thoughts, not thoughts of.

Space and time illustrate very well this empirical doctrine of the categories. They are not physical things; they are not even peculiar elements of the physical world. They are characters of our knowledge about things. It follows that the validity of the categories is bound $u p$ with the validity of knowledge. They are not forms to be deduced from the self in some peculiar fashion; they are features to be discovered in objective knowledge, abstracted, and analyzed. Thus the objective idealist was right in his practical procedure. Unfortunately, the constitutive notion of the self vitiated his final interpretation. It is true, also, that he did not take some of the categories seriously enough. This depreciation is especially true of space and time. He wished to introduce the idea of value into the categories and to speak of higher categories and lower categories, degrees of reality, etc. Besides, the Kantian tradition that space and time are self-contradictory lingered in philosophy 
long after proper analyses of these categories had been made.

We have made it a fundamental principle that the valid. ity of the categories is bound up with the validity of critical knowledge about reality. But it would also be true to say that the categories are themselves instances of the most general knowledge about the physical realm. That things are in the spatial order is a knowledge-claim. And knowledge seeks to conform to that about which it is knowledge, to reflect in its own medium that which is reproducible about existence. But we have examined knowledge enough, already, to realize that it plays over existence, connecting the past with the present, comparing things which have no very direct continuity, and in general probing nature. Knowledge conforms to reality in an active way much as an investigator conforms to his material. We shall see that the categories follow knowledge in this regard. They give, as it were, the structure of nature as this is projected into consciousness.

The categories appear first in experience as general characters of its pattern. This pattern is a growth which expresses a necessity to which the would-be adaptive organism is exposed. It is not a blind necessity in the mechanical sense; rather is it a necessity which is freely admitted as means to end. The mind of the organism must produce a pattern in consciousness correspondent to physical reality if it is to further the organism's safety. The result is apparent in what I have called the primary categories, viz., space, time, thinghood, and causality.

These primary categories arise at first in an uncritical form. It has taken much reflection on the part of both philosophy and the sciences to separate the objective essentials from the more subjective ingredients and so to achieve categories which are cases of general knowledge about the physical world. The history of causality is, perhaps, the most instructive example of this clarification.

Other categories arise in connection with these primary categories as knowledge is enlarged. Mass and energy as quantities, conservation as a character of these quantities in 
nature, and evolution as the genetic side of many empirical substances are examples of later categories which develop and amplify the preliminary categories. These new categories are at once the general features and the signs of a fuller knowledge of the world. Their history can be completely investigated since they arose in modern times. Their origin in the data of experience can readily be traced. They are discoveries and not deductions; and yet they are discoveries which require reasoning and precise reflection.

Like all universals, the categories are at once discoveries and standards. Our past experience assumed the temporal and spatial pattern and fell into things causally interacting. Whereupon science marked these features for her domain and formulated her laws in terms of such universal characters. Any thing or any event is expected to obey this framework which has been built up from a wide experience. A thing is assumed to have mass and to be in a definite position or in motion from one position to another; an event is assumed to be a function of antecedent conditions. In this sense, the categories are postulated to apply to all possible experience. They are guides for the mastery of new instances, of complex and tangled fields. Particular laws cannot be deduced beforehand, but it can be maintained that these laws will come under the categories. In this sense, they apply to all possible experience.

The question has at times been raised as to what guaranty there is that nature will recognize the categories. Kant, it will be remembered, tried to meet this difficulty by having the categories make nature. But he could give no guaranty that the ego and its forms would not change. The critical realist meets the difficulty in a different way. The categories are cases of general knowledge about nature resting upon the control by nature of the objective data of consciousness, a control actively furthered by the organism. Hence, nature itself would need to change before they would become invalid. And while we must admit that we cannot demonstrate that nature may not abruptly change its objective order, this thought is essentially unmotived and can hardly 
be entertained seriously by any one who realizes the massiveness of nature and the fact that particular changes are expressions of that which changes. This hypothetical catastrophe assumes an uncaused change and so conflicts with our actual knowledge of nature. It should be noted that any gradual change in nature would be reflected in the categories.

In conclusion, attention must be called to the two general classes of categories, the epistemological and the metaphysical. Space, time, causality, organization, conservation, energy, etc., are metaphysical categories, that is, fundamental concepts characteristic of our knowledge about nature. In the following chapters we shall deal chiefly with this class of categories; but, if we are to secure mastery in philosophy, we must also bear in mind those categories which concern knowledge. We must be able to get the correct interpretation for such terms as subject, object, idea, awareness, datum, phenomenon, consciousness, etc. We must be able to appreciate the structure of consciousness, its distinctions, claims, and affirmations. It is this that critical realism claims to do. It is a realism which stresses mental process, which regards the mind as an organ of the psychophysical individual, which relinquishes the myth of a mysterious act of apprehension overleaping the boundaries of space and time, which realizes that knowledge is resident in consciousness. In this way, the epistemological categories harmonize with the metaphysical categories. Critical realism of this naturalistic type has no room for a disembodied knower. 


\section{CHAP'TER V.}

\section{SPACE.}

E EW categories have aroused more controversy than has 1 space. The reason for this divergence of opinion lies. in part, in its basic character; in part, in its various forms and implications. Let the reader ask himself whether he can conceive the physical world apart from space? Does he not even locate-vaguely enough it may be-his own sensations and emotions? Again, how many perplexing problems cluster around space as a center! Is the world infinite in extent or finite? Is it infinitely divisible? Is space a receptacle in which things somehow exist, or is it simply a term for the peculiar order of things? What is the relation between space and time? Are they absolutely antithetical as Bergson holds? Or are they supplementary and in a way correspondent? Is space reducible to time as some empiricists have held? Has each of us a private space? And, if so, is there a common space? Is space an entity, or subsistent, as neo-realists maintain? It is evident that enough questions can be, and have been, asked about this category. It would be easy to find material to write a weighty tome upon this category alone.

The consequence of this varied approach is that the field has become very complex; and so the unwary thinker is apt to become confused as he attempts to find his way about in the heaped-up literature. Each specialist envisages the topic from his own angle, and, in trying to be thorough, succeeds in making a treatise. In such a situation, it re- 
quires some temerity to attempt to cover the philosophical essentials in a brief chapter. And yet this is our task. But we can pluck hope from the fact that process and result are in a way incommensurable. Just as years of experimentation can be condensed into a single formula, so years of reflection and persistent pushing-through of a point of view can find relatively brief expression.

Space is a strategic category. The physical realist is called upon to defend its validity and self-consistency against the attacks of idealists. Important as this task is, I do not think that it is very difficult. Mathematicians have of late aided the philosopher by their very able analysis of space as a subsistential content involving position, order and distance. The majority of neo-realists have followed them in this work. But the critical realist has the further task of appreciating space as a category concerned with the physical world. The physical world is not simply subsistential space, and yet it has a "form" to which the character of such space is applicable." Scientific knowledge about nature contains spatial order as a primary ingredient. Physical existents can be located with reference to one another.

When the critical realist thinks of space as a category, he does not mean that space is a physical reality. He means only that valid knowledge of physical reality contains elements which can be universalized under such headings as distance, position, size, etc. We shall treat the category of quantity as intimately bound up with space, while fully admitting that there are quantities which are intensive rather than extensive. Knowledge of the physical world, then, contains such judgments as that this thing is to the right of that, this thing is ninety million miles from the earth, that these things are measurable in terms of an arbitrary unit adopted as a standard. All this is preliminary knowledge, if you will, but it is none the less valid.

This defense of space as a valid category marks one of the essential differences between a realistic naturalism and all forms of spiritualism. - The antipathy of spiritualism to space is well known. Leibniz, its first protagonist, attacked 
the objective validity of space and maintained that reality consists of spaceless points which are in themselves immanently evolving spirits. For Schopenhauer, also, space is phenomenal and has not objective validity. Reality is of the nature of will. This agreement is no accident, for we find in Bergson, likewise, a tendency to belittle space at the expense of duration in consciousness. Space is stated to be homogeneity and simultaneity, while the self reveals itself to intuition as an interpenetrating flow of qualities. Space is here a sort of pièce de résistance, and the exact status of space and matter is not very clear; yet it seems certain that for him the higher levels of reality are nonspatial.

With the general attitude of neo-realism toward science the critical realist is in the heartiest sympathy. Still, the profound difference in epistemology has its necessary consequences.

The neo-realist is nearer naive realism than is the critical realist, yet he champions the non-mental reality of such entities as space, time and number. When he includes values of all sorts, he is led to attack naturalism with the fervor of the Platonist. ${ }^{1}$ Neo-realism and Platonism have much in common; critical realism and Platonism have little in common. Of course, values are real just as sentiments, desires and judgments are. But they are entirely human responses.

Evolutionary naturalism is a critical naturalism. It distinguishes between objective contents in the individual's experience and the physical objects of his knowledge. Thus critical naturalism can do as full justice to mathematics and logic as Kant and Locke tried to do. The weakness of the older naturalism was its unreadiness to do justice to the significance of mind, mental entities and values.

A Genetic Approach.-We shall find it true of spaceas of the other categories-that it has different levels and contexts. Therefore, our first task must be the separation

${ }^{1}$ Cf. Spaulding, The New Rationalism, p. 498. (Why not a "new naturalism" as well as a "new rationalism"?) 
of these levels and a relation of them to their proper universe of discourse.

The more highly developed kinds of space, while not simply reducible to the more primitive types, cannot be understood apart from them. They are a development, a clarification, of them. The categories which we apply to the physical world have their birth in the field of perception. It is this point which I wish to emphasize by this genetic approach. Discrimination and reflection play their part, but they must have material on which to work. This material consists of sensible characters given in consciousness.

Sensational Space.-The philosopher does not feel it his task to trace the spatial experience of the adult to its beginnings. It is for the psychologist to discover the various factors whose active synthesis leads somehow to the perceptual level at which we all naturally live. Enough along this line of investigation has been done to convince the thinker that the process of fusion and development has been both a gradual and a progressive one. But the fact remains that we are not ordinarily aware of anything but the result. We live on the crest of the wave of experience and profit by all that has gone before; or, to vary the simile, we are like spectators in the theater who see the finished play and do not know what goes on behind the scenes. Assuredly, the adult's ability to distinguish position, distance and size is an accomplishment. "For those who are born blind," writes Bourdon, "space is a synthesis of tactile, muscular and joint sensations, and particularly of the tactile, muscular and joint sensations of the fingers, of the hand, of the arm and of the lips; for the normal man. on the contrary, space is essentially a synthesis of retinal sensations with tactile, muscular and joint sensations of the eyes and of the head. Now a long time after sight has been given to one born blind, he will still keep his old way of representing space." 2

2 Bourdon, La perception visuelle de l'espace, p. 362. 
Before passing to the level of normal perception as dominated by sight, touch and movement, it will be well for us to note certain data which are calculated to restrain us from dropping into the dead-level view of space which has so often appeared in philosophy and mathematics. Had Kant meditated on these facts, his theory of space could not have been so neat and simple. It is a well-known fact to-day that the spatial extensities primitive to different senses are not correspondent, that there is something of qualitative incommensurability about them. "The interior of one's mouth-cavity feels larger when explored by the tongue than when looked at. The crater of a newly extracted tooth, and the movements of a loose tooth in its socket feel quite monstrous.... If two points kept equidistant be drawn across the skin so as really to describe a pair of parallel lines, the lines will appear farther apart in some spots than in others." ${ }_{3}$ Of course, very few of these and similar facts are noted in every-day life because the interest of the individual is not directed toward them. We live in a space which has gradually been standardized because of our need to adapt ourselves to our environment, physical and social.

Perceptual Space.-Perceptual space arises at a level in which the synthesis of the various sources has been pushed a long way. The rôle played by meanings and cues is the evidence of this fact. Visual and tactile space have so intimately been brought together that we pass from one to the other without any sense of difference. The one has come to mean the other in our spatial interpretations of things and distances and positions. But the part played by movement in the growth of perceptual space, as a sort of continuum of things in which we experience ourselves as living, can hardly be overestimated. Motor experiences organize, suffuse and knit together interpretatively the material contributed by sight and sound. Our vital interests are always forcing us to note positions and to estimate distances and directions, sizes and contours. Space becomes an affair

${ }^{3}$ James, Psychology, Vol. II, p. 139. 
of discriminations and estimations within a realm of apparently given things.

Now the perceptual level is likewise the level of things, their qualities and relations; it is the stage of common-sense realism. As we should expect, perceptual space reflects this situation and appears in completest harmony with it. Things have size, shape, position; they are at certain distances and in certain directions from one another. Space is not a thing, rather is it the complex of these characters. The whole perceptual field arises together as both quality and structure. The older philosophers and psychologists used to speak of an act of objectification by means of which the self passed from sensations to things. A little reflection should convince us, however, that objectification is a growth and not an act. It represents the passage from the vague and inchoate to the relatively clear and structural. Sensations are not first experienced in the headhow could they be?-and then extruded in some mysterious fashion. Objectification is a functional growth rather than a unique act.

Perceptual space is, then, the spatial character of the field of the individual's experience. It is a character which ministers to all the meanings of thinghood and independence. The book which I see in front of me is appreciated by me as at once self-existent, perdurable, composed of printed paper, of a certain size and shape, so far distant and in such a direction.

But this spatial order of perceptual things has three main characteristics which each one can verify for himself, and which are of considerable philosophical interest. It is, first. limited in extent. Our horizon always has a boundary, and near objects are more distinct and better defined spatially than are far ones. In short, each one perceives a concrete manifold of objects which is limited on both sides and also in the third dimension. I can see only so far in front of me and am compelled to turn my head in order to see objects too much to one side. In the second place, perceptual space is sensibly continuous, or unbroken by that which is non- 
spatial. It is obviously impossible to escape the presence of space in perception for it suffuses and relates the content of the field. All things have position. What we perceive in vision has one character so far as extensiveness is concerned. Spatial material is genetically the nucleus of it. If the term be not misunderstood, space can be called a form of things, that is, an omnipresent character with which we can contrast other, more variable features like color and odor. Space is a constant character of the field, while other characters undergo successive change. These elements vary independently. A thing may change its color while not changing its place; and, again, it may change its place without changing its color.

Empiricism vs. Nativism.-Psychologists and philosophers were long divided upon the question of the comparative innateness of space-perception. This problem is more a psychobiological than a philosophical question, that is, it is a question of genesis rather than a question of content and validity. But I do not think that it is going too far to assert that the historical controversy between those who believed space to be an innate possession of the "mind" and those who sought to derive it from elements essentially non-spatial in character has ceased in large measure to be a real one. The original antithesis has been outgrown in these evolutionary days. The Kantian form of nativism, called by Stumpf the psychic-stimulus theory, asserts that space is an innate form of the "mind" in which the chaotic manifold of qualitative sensations is arranged. Kant assumes that form and qualitative content are derived from different sources. The Humean type of empiricism sought to derive space from the arrangement (?) of qualitative points.

Kant's schema has many obvious weaknesses: it has a view of the mind which we would hardly accept to-day, and assumes that all connectedness is contributed by the agency of a transcendental ego of apperception. As a matter of fact, relations appear to be as sensuous in the first place and as naturally given as any other features of the perceptuai 
field. The Kantian machinery strikes the present thinker as extra-natural and uninforming; and Kant's formulation is, historically, an attempt to supplement Hume rather than to make a thoroughly new analysis. ${ }^{4}$

That all perception rests upon, and involves, processes of discrimination and interpretation is a commonplace of to-day, but it was not so in Kant's day. That much should be pointed out in apology for Kant's formal intellectualism. Where we see genetic process, Kant saw a formal operation. It was this formal operation which involved the coming together of two unlike mental factors, the a priori and the $a$ posteriori, the one contributed by the mind in a free way, the other caused by something outside of the mind. We cannot permit a nativism which assumes an a priori element of this sort. All elements are innate in the sense that they are functions of the brain-mind under stimulation. The following quotation is, I think, a fair statement of contemporaneous psychological opinion: "We hold that the crude, vague feeling of extension, of volume, is a genuinely innate experience, unlike any other experience, and underived by mere experience from non-spatial psychical elements. So far we are nativists. On the other hand, we are confident that all accurate knowledge of the meaning of the space relations in our space world, all practically precise perception of direction, position, contour, size, etc., is a result of experience, and could never be gained without it. So far we are empiricists, holding to a genetic point of view regarding the development of our adult space-consciousness." The spatial character of the field of objects which we suppose ourselves to perceive is a discrimination gradually achieved through material lending itself to the distinctions.

The Truth of Perceptual Spatial Judgments.-We have already suggested that judgments usually imply the setting

${ }^{4}$ Cf. Critical Realism, Ch. 6. William James and James Wardamong others-have subjected the Kantian psychology to severe criticism. I hardly feel that there is need to kill the already slain.

5 Angell, Psychology, p. 141. 
of common-sense realism. That is, the judging individual is convinced that he perceives self-existent things which are the sources and centers of such executive agency as finds place in his world. He, himself, is only one-though a unique case-of these manfold things. In veridical perception, he becomes aware of such things and passes judgment upon their characters and relations. His sense of things does not always appear in explicitly judgmental form, but it can easily be so analyzed; and the judgments resulting will be considered true. Thus this red book in front of me is oblong in shape, quite thick, medium octavo in size, two feet from me and toward the right. These spatial predicates can be tested by renewed perception and then accepted as finally valid-their exactness being adequate to my purpose. What shall we say of them?

It is evident that, within this setting of realism, I assume that I can note these features, or characters, and can subsume them under conceptual characters which I possess. The book is of this size. That is, I can discriminate its size and identify it just as I discriminate its color and identify it. And so with the other predicates. There is, so far as I can see, nothing mysterious in this process as long as it is kept within its setting and continues to be empirical. We have simply that interpretative interplay of perception and conception which is the heart of judgment. Relative positiòns, sizes, contours, distances, are distinguished and interpreted by means of concepts already in our possession as a result of past experience. Such judgments are as true as any other judgments directed upon sensible things. That this book before me is oblong is just as true as that it is red; that it is to the left of my typewriter is as certain as that it is cloth-bound. Yet, as we have already pointed out in the introductory chapter, such judgments are the material of our critical knowledge about the physical world.

Conceptual Empirical Space.-One further development of our spatial experience, which is at the same time a development of our idea of the physical world, deserves notice. 
Perceptual space is dominated by a perspective. It is the sensuously given expanse of things that stretches out from the percipient organism. Now empirical space is a development of this space somewhat as perceptual space is a growth out of sensational space. Empirical space is a conceptual combination and modification of the various perceptual spaces into the thought of a continuous world spread out in every direction. The vague apprehension of this larger, more inclusive world spread out in every direction floats in the background of our consciousness to qualify what we perceive at any one time. Thus there is no break between perceptual and conceptual space. One point of interest is, however, that we assume that things we perceive are in relation with things we do not perceive but acknowledge to exist. Moreover, these things are taken to be common to all people. Commonness is a meaning which suffuses things and, therefore, the spatial form and relations of things.

We need hardly linger upon the genesis of empirical space. Movement from place to place, with the areas combined by thought, reading, intersubjective intercourse, etc., all these factors assist in our conception of the world as a spatial expanse in which positions, distances, contours, sizes, directions can be distinguished. Direction is now referred to the sun and the points of the compass rather than to the body of the percipient ; size and distance to units of measurement upon which agreement has been reached. It follows that we have here only a development of perceptual space. The setting is essentially the same-a common world of things open to discriminative apprehension. Measurement and a useful axis of reference introduce the chief changes in the field of objects. Another point should, however, be noted: most of the physical expanse is absent so far as perception is concerned. It is chiefly present in thought though absent in reality. Let us remember that, for common sense, experience supervenes upon things which are self-existent. We perceive things which are present and think of things which are absent.

This spatial, physical world has no apparent limits. 
Astronomy tells its marvels of constellations beyond constellations in pathless space, and the imagination grows weary in continuing a process to which there seems no necessary end. But it is important to note that space is still neither a thing nor a semi-reality, for it is inseparably intertwined with bodies. It is not a receptacle into which things are put but a distinguishable character of related things. The world is not so much in space as it is spatial or extended.

Science deepens our appreciation of the spatial character of bodies. Common sense, being limited to surface views, misses the knowledge which comes from the combination of cross-sections. Mechanics with its study of stresses and strains, physics with its appreciation of interdependence, chemistry with its theory of rings and stereo-isomeric substances, biology with its discovery of structure, all deepen the spatial aspect of things. He who has studied the detailed structure of the nervous tracts can hardly deny the reality of position.

Mathematical Space. - But the observational and experimental sciences are not the only sources of our deepened knowledge of space. They are the only basis of actual knowledge of the spatial nature of particular objects, it is true, but they are assisted by an abstract science which studies spatial characters as such, viz., mathematics. It is this non-physical science which assists the physical sciences through the setting-up of correspondences between their contents. The position we shall adopt is, that mathematical space is an abstractive construction resting ultimately upon characters gotten in perception. Mathematics is an intense study of the nature of spatial relations. The information it acquires is, therefore, interpretative of physical relations. If a body is a sphere, the results deduced mathematically about a sphere are relevant to my thought of this body.

The empirical basis of the ultimate material of mathematics is indicated by the history of the subject. But this material is conceptualized and studied intensively and in the light of all sorts of methods. Analytic geometry and cal- 
culus are examples of what I mean by this inventive, intensive study. The results are, however, applicable to the material to which they are relevant. It is for this reason that calculus is as instrumental to the physical sciences as is geometry, which is far more directly related to perception. In other words, the material of physical science overlaps in part the material of mathematics. I agree, then, with James Ward in his criticism of Kant: "Given only the pure space of Kant and the geometers, it is impossible to deduce the actual space of experience; but, given this, the deduction of that is intelligible."

Now how does this construction arise? We have already seen it well under way in our examination of common, empirical space. We learn to abstract the spatial features of bodies. In this way is obtained the concept of an empty space homogeneous in all directions. There can be no doubt that this process of abstraction is aided by the fact that bodies change their places, that is, their relative positions, while retaining their forms. This experience of rigid bodies which move from place to place enables the mind to advance to the conception of space as such, to spatial characters as such. This genesis has left its trace upon the geometrical concept. Just because rigid bodies have dominated our experience, we tend to think of the parts of empty space as immovable and exclusive of one another. What we do is to remove thinghood and nonspatial characters from the empirical expanse of ordinary perception. It is for this reason that I affirmed that content is emphasized in mathematical space and reference omitted. Mathematics is a nonexistential science; it is not a science directly concerned with the physical world, even though its information is valuable for the physical sciences.

There are to-day both metrical and non-metrical geometries. So soon as geometrical objects are thought of as having size, we enter the domain of metrical geometry, which is decidedly the more primitive type. But how is it possible to measure the magnitude of a geometrical quan- 
tity? Primitively by superpositions. ${ }^{6}$ The geometrician must be able to distinguish the two elements of position and form; and he determines equality by such a relative displacement as results in coincidence. "The figures are equal," writes M. Poincaré, "when one is able to superpose them; in order to superpose them, it is necessary to displace one of them until it coincides with the other: but how can one displace it? If we ask this question, it will be replied without doubt that one ought to do it without deformation and after the fashion of an invariable solid." It is from this situation that the geometrical axiom of free mobility arises: Spatial magnitudes can be displaced without deformation. Now this axiom bears witness to the origin of mathematical space.

But mathematics has recently passed through a stage of reflective analysis in which search has been made for the smallest number of axioms which could bear the weight of a rational construction of different mathematical systems. For all the elements and processes involved, definitions are sought. There is, however, no real conflict between this demand and the acknowledgment of the genetic origin of the construction which is thus being rationalized. Reflection clarifies, discriminates, abstracts, defines, and logically relates elements of content, but it has its cues and suggestions in the material which has first been intuited. Mathematical space is, in other words, a development of the characteristics of empirical space, such as order, direction, distance and area.

Perhaps the contrast between empirical space and mathematical space can best be brought out by an examination of the idea of space held by prominent mathematicians. This method of approach will also give us the basis for a better understanding of the ideality or non-existential status of mathematical space.

Newcomb defines space as the totality of all positions into which a body could possibly be moved, were no impediment to motion in existence. "This totality." he writes,

- Cf. G. Lechalas, Etude sur l'espace et le temps, p. 31. 
"forms a continuum, the conception of which is so elementary and fundamental that no definition can materially aid in its formation. To us the parts of space are all those places, infinite in number, to which or in which a body can be conceived to move or exist, and vice versa, we can conceive any body to move into a part of the infinite continuum which is formed by the totality of those places. Space is continuous not only in the sense that every part joins to the parts around it, but that every part is susceptible of indefinite subdivision."7

What I have said of the empirical source of mathematical space stands out clearly in every sentence of this chapter. Spatial characters are enriched by operations, potential and actual, to which there are no assignable limits. Let us now turn to Russell. In his Scientific Method in Philosophy he makes the following remarks: "I do not see any reason to suppose that the points and instants which mathematicians introduce in dealing with space and time are actual physically existing entities, but I do see reason to suppose that the continuity of actual space and time may be more or less analogous to mathematical continuity. The theory of mathematical continuity is an abstract, logical theory, not dependent for its validity upon any properties of actual space and time. What is claimed for it is that, when it is understood, certain characteristics of space and time, previously very hard to analyze, are found not to present any logical difficulty." Continuity and infinity are, then, logical concepts which are applicable to space and time as derived from experience and which enable us to analyze and handle these characters. In accordance with this logical effort, point, instant, continuum and infinite are assumed or defined. Continuity is a property of series, and a series is continuous when between any two terms whatever, however near, another one can be placed. Again, infinite numbers cannot be reached by counting : they are a class quite distinct from finite numbers and have properties peculiar to them-

7 Newcomb, art. on "Space," Dictionary of Philosophy. 
selves. It should be noted what a part number-theory has played in the formation of these concepts.

Mathematical space is, then, continuous and infinite, and there is no self-contradiction in these concepts. But mathematical space is more a system of operations and elements than a given expanse. For instance, for mathematical purposes, any object may be taken as a point or position. Again. when a mathematician speaks of an infinite number of points between any two positions on a straight line, what does he mean? He means that this portion, like any other portion, is a continuum. In a continuum there is no next position but always one between, and so on indefinitely. Thus we achieve the conception of a compact series. To assert that a line is infinitely divisible is not to regard it as made up of self-existent entities which are discrete and distant but to indicate a process which has no limit. Positions are foci of a conceptualized attention. They are the homologues in abstract space of things in perceptual space. Positions imply other elements because they are inseparable from distance and direction. Or we may put the same conclusion in the following way; if points were spatial, they could be further divided; if they were spaceless, they could not make up a piece of line-room. Infinite divisibility is the expression of this relativity of position in the total character of space.

In his treatment of space, Bergson often seems to confuse this abstractive space of mathematics with something purely external. He does not do justice to the subsistential status of mathematical space. Time, or duration, is internal and pure heterogeneity, while space is external and pure homogeneity. Besides, I do not think that many mathematicians would agree with him that number is inseparable from space. ${ }^{8}$ These abrupt antitheses are not empirical: they are dialectical-just the sort of method that Bergson claims to avoid. Even abstract space is not mere simultaneity; it is position, direction and distance. And are

8 I believe that it is generally held to-day that numbers are concepts. Cf. Shearman, The Scope of Formal Logic, Ch. 6. 
not these elements qualitative characters? But we shall be obliged to reexamine Bergson's doctrines when we come to treat of time.

It is also necessary to say a few words about the theory that space is reducible to time. This theory has taken two forms. First may be mentioned the older associationist stress upon the succession of sensations in the formation of tactual space. But it was forgotten that this succession was accompanied by the character of coexistence in the complex of sensations in the resting hand, and that this latter character dominated the interpretation of the total experience. Positionness and extensity are characters which function actively in the construction of space. An element in the process, such as the temporal succession of new experiences, can be used in the making of a product in which temporal succession is not an element.

The second form of the temporal theory of space asserts that space is but a reversible time-order. We can pass from $a$ to $b, c$ and $d$ and then back again. Of course we can. Space permits the passage of our attention or of our overt action back and forth over things. But the temporal order is that of events; in this case, our acts. Action implies space and space lends itself to action. To reach a distant object, I must pass by intermediate objects. But this does not contradict the fact that these objects were, all the time, in the relation of coexistence in the order of side-by-sideness, the basis of direction. And, by the way, is not the very expression "a reversible time-order" a contradiction in terms? It is an attempt to combine the different qualitative orders of space and time. Our actions are reversible, but the timeorder is not.

Space as a Category.-Having now gained a fair idea of the genetic basis of conceptual space and also some insight into its character as a subsistent content, we are ready to consider the validity and meaning of this content when used as a category of knowledge about the physical world. That world is for us reality, the very substance of being. 
And it is by an irresistible pressure of the material of knowledge that we think of it as extended. Some thinkers, it is true, hold that this pressure of our objective experience to consider reality spatial in its character, that is, to hold spatial predicates applicable to it, leads to a disastrous conflict between reason and instinct. But I think that even they must concede that the burden of proof rests upon them. ${ }^{9}$

Space claims, then, to be a cognitively objective category, to mediate knowledge about reality. Judgments of position, relative size, contour, distance and direction are, therefore, referable to the physical world. To say that these judgments are valid and contain information referable to an independent realm is to think this realm spatial, for these elements give the very meaning of space as a category. Space as a category is not an external reality. To assert that the physical world is spatial, means, not that the physical world is in a non-dynamic receptaculum analogous to mathematical space, but that certain predicates are interpretative of its actual constitution and nature. While we need not exaggerate the amount of information given by spatial judgments nor the depth of insight contributed by them, it is likewise unnecessary to deny their significance. The morphologist has his work to perform as well as the physiologist. An organism has structure as well as function. We shall learn, as we proceed, that the categories supplement one another and are intertwined in adequate knowledge.

An Historical Retrospect.-Science always acts as a stimulus to the active thinker, and he who does without this stimulus is apt to swing around in a dialectical circle, trusting all the time to the advent of some pictorial intuition. The first philosophical view of real space identified it with a void in which atoms somehow exist. This void, the $\mu \grave{\eta} \stackrel{o}{o} v$ of Greek philosophy, was a sort of semi-reality

${ }^{\circ} \mathrm{Cf}$. Bradley, Appearance and Reality, Ch. 4. We shall examine the logic of these contentions in the chapter on "Physical Continuities and Relations" (Chapter X). For another reason, Bergson, also, attacks the validity of space as a category. 
which could be filled and which could also remain empty. The fact to note about this outlook is its failure clearly to distinguish between mathematical space and the void. Physical reality is thought of as passively dispersed.

Plato identified matter and extension-just as Descartes did after him-and was led to reject the void of the atomists. But, here again, mathematical space tends to be reified. When Descartes asserts that the defining essence of matter is extension, he is in the hands of a mathematical rationalism which pretends to intuit reality rather than to gain an elementary knowledge applicable to it. He does not realize that mathematics is a non-existential science which can be developed for its own sake as well as be used as instrumental to the various physical sciences.

The development of mechanics gave rise to the Newtonian conception of nature which gave a semi-reality to space as such. For Newton, space is as a whole hyperphysical-an independent, fundamental variable in relation to which the world directs itself. We are led to think of it as a connecting continuum in which things are. Thus its unity gives unity to the world of things in space. This means that the unity was not so much held to arise out of the nature of the physical world as out of this menstruum. It is only fair to Newton to point out that there have been different interpretations of his system, especially in regard to such a problem as action at a distance. Yet, when all is said, absolute space is for him a receptaculum. His system is impregnated with what may be called mathematical realism. Space as a category of our knowledge of the physical world is confused with a blank expanse.

To make Newton's position somewhat clearer to the reader, let us glance at the teaching of a contemporary mathematician. In The Problems of Philosophy Mr. Bertrand Russell writes as follows: "Thus we may assume that there is a physical space in which physical objects have spatial relations corresponding to those which the corresponding sense-data have in our private spaces. It is this 
physical space which is dealt with in geometry and assumed in physics and astronomy." I interpret this position as similar to Newton's, although I must confess that Mr. Russell's philosophy is fundamentally unclear to me. What is this physical space? Is it the physical world conceived as spatial, that is, in terms of spatial predicates? Or is it a second kind of reality, a receptacle?

Faraday inaugurated another movement which may be regarded as a reaction against a conventionalized Newtonianism. His experiments led him to adopt the view that all physical action is mediated by intervening physical conditions. The physical world, in other words, has its own dynamic continuity and does not need to borrow it from a real, hyperphysical, absolute space. The whole drift of modern science has continued in this direction. It is time that mathematical objects and content be separated from physical reality.

When I assert that a physical thing is extended, I mean that it is measurable in terms of units superposed directly or indirectly upon it, that it actively excludes other things, that its parts have a characteristic external order of position in relation to each other, and that these facts can be related to other facts which can be brought out by experiment. In this sense, I have the right to say that physical things are extended without meaning that they are in an absolute space as a sort of receptacle or that they possess an attribute of which I can gain an idea of a copy sort. Hence, to assert that nature is extended is to maintain that human knowledge about nature contains elements of a certain type. Physical space is, then, the physical world known as spatial. The more we know about the intimate structure of the physical world, the more we know about real space. So far as mathematics is of assistance to science, it does not come between nature and our knowledge as a disturbing factor, and the thinker must rid himself of the habit of assuming that physical things are in a homogeneous medium made of positions, an absolute space. 
Kant's Antinomies.-Kant sought to prove that the assumption that reality is spatial lands us in certain contradictions which can be avoided if we once admit that space is phenomenal and holds only of phenomena. His argument has played such a rôle in the history of philosophy and is still taken so seriously that it must be examined.

Kant's thesis is that the world is limited with regard to space, that is, that it has a determinate and finite size. His method is to point out the contradiction in the opposite assumption. "In that case," he asserts, "the world would be given as an infinite whole of coexisting things." But to the realist the expression "given" is ambiguous. Does it mean "exist"? Either we can have a conception of an infinite totality of things (or had we better say, an infinite extent?), or we cannot. If we can, such an infinite totality may exist. If we cannot, there is no reason to assert what is meaningless to us. Now Kant seems to suppose that, in order to conceive an infinite world, a successive synthesis-presumably by human minds-would have to be looked upon as completed. But is this necessary? A standing infinite would rather be one which was thought of as inexhaustible by enumeration or measurement. For Kant, it is one which should, but cannot, be enumerated.

$\mathrm{His}$ antithesis is, that the world is infinite in respect to space. Here, again, he works by disproof of the contradictory. If the world be finite, it would exist in an empty space without limits. We should, therefore, have not only a relation of things in space, but also of things to space. But such a relation would be a relation to no object and therefore it is nothing. Hence, the world is not limited with regard to space, that is, it is infinite in extension.

Let us look at this strange argument. In the first place, it assumes that a finite world must exist in empty space. We, however, have shown that such a space does not exist, since it is the mere reification of an abstraction. Kant then argues that, because such an empty space cannot limit the physical world, this latter must be infinite. But this argu- 
ment makes the assumption that what is not limited from outside is infinite-an unwarrantable assumption. ${ }^{\mathbf{1 0}}$

We are forced to conclude that Kant disproves neither his thesis nor his antithesis. We are left, therefore, with a choice to be determined on other grounds. And Kant's purpose is defeated.

What must be our own conclusion in regard to this ageold question? We may put it in this fashion: If the terms, finite and infinite, are contradictory adjectives applicable to the physical world, no a priori reasoning can decide for one as against the other. Inductive science, alone, with its superstructure of tested theory, is potentially able to decide the question, and the day has not come when this can be done with any certainty. I would, however, like to call attention to certain points sometimes misunderstood.

The principle of the conservation of energy does not by itself point in either direction. It simply maintains that energy is not lost or gained; it does not inform us how much energy there is in the universe. Again, the second law of thermo-dynamics, popularly known as the law of the dissipation of energy, sets a problem for the course of nature, but does not inform us whether nature avoids it by being infinite or by being able to reverse the process. The truth is that these principles are more intimately bound up with the category of time than with space.

If nature be finite and thus of a determinate size, as many facts seem to attest, this character does not necessitate it to have a smooth boundary beyond which electrons could not dash. The boundary needs must be dynamic and one of varying equilibrium. If gravitation have significance for the minutest portions of physical reality, its internal pull will determine the "flaming boundaries" of the world. The void is perfectly thinkable, for it is purely a condensed negative proposition and not a thing. It is nonsense to assert that the void is-if this expression be interpreted as an existential proposition. It really means that not one of

10 For the quotations from Kant see Müller's translation of the Critique of Pure Reason, pp. 344ff. 
the things we are accustomed to find is present. But, it will be demanded, can we not ask the question, What lies beyond? Certainly we can; and the void is the denial that anything lies beyond. ${ }^{11}$

Is Nature Infinitely Divisible?-Mathematical space is infinitely divisible. But it does not follow that a physical thing is infinitely divisible. In the case of the one, we are concerned with an operation of thought correspondent with the nature of the material operated upon. In the case of the other, we are confronted with a problem of fact. Certainly, human beings cannot divide a physical thing into an infinite number of parts. The structure of things seems to be atomic. Of late, theories of energy have drifted in the same direction-as comes out clearly in the quantum-theory of Planck. Nature-to use James's expression-seems to bud off drop by drop. Infinite divisibility would seem to involve a passive sort of homogeneity; and this is alien to the dynamic, structural character of the world as revealed in experience. To substitute mathematical space and its characters for reality-however valuable instrumentally at times-is to beg the question. ${ }^{12}$

11 If I may judge from various discussions of the Einstein theories, scientific opinion is increasingly in favor of a finite universe.

12 On the discontinuity-theory, time, change, etc., would grow by finite buds or drops, either nothing coming at all, or certain units of amount bursting into being 'at a stroke.' Every feature of the universe would on this view have a finite numerical constitution. Just as atoms, not half or quarter atoms, are the minimum of matter that can be, and every finite amount of matter contains a finite number of atoms, so any amounts of time, space, change, etc., which we might assume would be composed of a finite number of minimal amounts of time, space and change." James, Some Problems of Philosophy, Ch. 10, p. 154. 


\section{CHAPTER VI.}

\section{TIME.}

T

HE usual feeling in regard to time has been expressed by no one better than by Saint Augustine: Quid est tempus? Si nemo ex me quaerat, scio; si quaerenti explicare velim, nescio. No concept is more baffling nor has more subtle apparent contradictions than has time. As another writer has put it: "All things live in time and it lives in nothing; all things die in time and death is not able to attain - it." But may it not be that it is this very mystical tendency to substantialize time that leads us into our difficulties? Because we have not sufficiently distinguished the various meanings and contexts which the term has, we are the more easily led to regard time as a mysterious form or receptacle in which events somehow happen. Let us seee whether we can treat this concept in a genetic fashion as we did space, and in this way succeed in relating each level to a context in which it becomes significant. We shall, I think, find that the preceding examination of space will aid us-especially in the study of kinetic and mathematical time. But there will also be important differences between space and time to note, due to the fact that each is sui generis. Each bears upon and introduces us to fundamentally distinct characteristics of reality.

The elementary experience which is at the foundation of what we roughly call time is the immediate feeling of change. "The mere fact that $B$ follows $A$ in consciousness does not of itself constitute the consciousness of $B$ as fol- 
lowing A. On the other hand, we must not jump to the conclusion that, because the sequence $\mathrm{AB}$ is not in itself the cognition of that sequence, it is therefore not experienced at all in any way. We must distinguish between consciousness of change or duration and change-consciousness or duration-consciousness. Change in consciousness may be felt without being cognized as change, and duration may also be felt without being cognized as duration."' What Professor Stout refers to here is the distinction between two mental levels. For instance, we can feel that there is a similarity between two objects long before we are able to analyze out the element which is essentially common to both. Cognition is a more reflective attitude which supervenes upon the relatively unreflective flow of experience. Probably no writer has brought out the significance of these feelings of change, these transitive experiences, better than William James; at the same time, James emphasized the difficult problem with which introspection is confronted in its search

- for them. "Let any one try to cut a thought across in the middle," he writes, "and get a look at its section, and he will see how difficult the introspective observation of the transitive tracts is. As a snowflake crystal caught in the warm hand is no longer a crystal but a drop, so, instead of catching the feeling of relation moving to its term, we find we have caught some substantive thing, usually the last word we are pronouncing, statically taken and with its function, tendency and particular meaning in the sentence quite evaporated." As this writer points out, the denial that these transitive feelings or experiences exist has led to absurd mistakes in theory of knowledge. Sensationalism of the associational type was tempted into asserting that consciousness consists of sensations and their copies and derivatives "juxtaposed like dominoes in a game, but really separate." In other words, these early empiricists mistook the results of a partial analysis at a reflective level for the actual flow of experience and thus reached a false idea of the immediate data of ex-

1 Stout, Manual of Psychology, pp. 384-85.

2 Principles of Psychology, Vol. I, p. 244, 
perience. They reached such a false idea, not because reflective analysis is unveracious or falsifying, but because it was in their case controlled by preconceptions. They did not introspect delicately enough; they were too rough-andready and too biased. To-day, however, there is fairly general agreement that we feel change long before we analyze out the factors and think of them as in a sequence.

But the sense of change is only one of the elements which reflective analysis can note in perceptual time. Just as important is the feeling of duration or lapse of time. All individuals have an ability to estimate roughly the extent of duration of a process or activity. It is the task of the psychologist to explain the conditions of this sensing of duration. The indication is that it is connected, in part, with certain recurring activities which help to give a rhythm to consciousness, and, in part, with what may be called the cumulative effect of the process of attending. "When we are listening to a sound," writes Stout, "our experience is different at the end of one minute from what it is at the end of two minutes, although the sound itself may not have altered in quality."' There is a qualitative difference in the experience, as time passes, which adds an experiential differentia to the sense of change and complicates it. The more we penetrate to the experience itself and remove, as it were, the images with which habit has veiled this experience, the more we realize its unique qualitative nature. If the aim is to be true to the experience itself, the picture of a stream or a line is totally inadequate. Let us call this interwoven sensing of change and duration the basic time-experience.

In personal time, we have, then, the immediate experience of both change and duration. These characters are data for the philosopher, although the psychologist may recognize it as his task to find their conditions. Moreover, we must admit that, as experienced characters, there is no contradiction between change and duration. A sense of the lapse of time fits in with the sense of change as its complement. While we cannot infer the one from the other, they har-

Stout, op. cit., p. 386. 
monize so completely that there is reason to think of them as supplementary aspects of one complex experience. Both bear witness to the unity in diversity of consciousness.

The Specious Present.-The actual span of consciousness gives the experienced, or specious, present. This empirical present is not an indivisible instant of time but a changing span of some dimension. What its exact dimension is must be left to experimental technique to discover. The point to note is, that perceptual experience knows nothing of mathematical instants. ${ }^{4}$ To assume them as is implied in the query, whether the felt present is made up of moments and is infinitely divisible, is to confuse levels and standpoints. It is the great advantage of the genetic method that it prevents the occurrence of such pseudo-problems.

The present is not an arrested span of consciousness but rather all the consciousness there is. It is a flow whose cont is always changing. "If the present thought is of A. B C D E F G, the next one will be of B C D E F G H, and the one after that of C D E F G H I-the lingerings of the past dropping successively away, and the incomings of the future making up the loss. These lingerings of old objects, these incomings of new, are the germs of memory and expectation, the retrospective and the prospective sense of time. They give that continuity to consciousness without which it could be called a stream." If we disregard the complications introduced by memory and expectation, which represent an additional story added, as it were, to the current of perceptual happening, we are in a better position to gain clear ideas of the basic elements of the time-experi-

4 "In short, the practically cognized present is no knife-edge, but a saddle-back, with a certain breadth of its own on which we sit perched, and from which we look in two directions into time. The units of composition of our perception of time is a duration, with a bow and a stern, as it were-a rearward and a forward-looking end. It is only as parts of this duration-block that the relation of succession of one end to the other is perceived.... The experience is from the outset a synthetic datum, not a simple one; and to sensible perception its members are inseparable, although attention looking back may easily decompose the experience, and distinguish its beginning from its end." James, Principles of Psychology, Vol. I, p. 609.

5 Ibid., p. 606. 
ence. These are developed and amplified by conception rather than changed.

The specious present is the moving content of the stream of consciousness. This span contains change of content, transitive feelings of a temporal sort, and felt distinctions which join with, and develop, the sense of change. In a chord of music played arpeggio, the various notes can be distinguished as both simultaneous and successive. They are heard together yet in the order of succession.

Thus our perceptual experience presents us with four characters relevant to our idea of time, viz., change of content, sense of dduration with a feeling of more or less, order of succession, and simultaneity. Along with these characters there is often another-the sense of growth or summation. This last character appears prominently in the experience of directed activity which has a goal. A more passive form appears in music. Heard melodies consist of tones which shade transitively into one another and yet mass together into a whole whose richness depends upon the musical capacity of the listener.

In the analysis of perceptual time, emphasis has usually been placed upon the irreversible order of succession characteristic of events. And yet, significant as this feature is, attention to it alone is apt to encourage a linear notion of time. It will be well for us to note the aspect of simultaneity of events as well as their succession. Simultaneity is the order of co-occurrence which characterizes many events. Consciousness is not thin and merely linear; instead, it is complex in content. I can hear the peal of thunder at the same time that I see a man scurrying across the street. In the busy streets of a city how many distinct actions can be noticed practically at once! We shall find that this order of events opens up a tremendous field for the imagination and lends itself to a significant development in science. Simultaneity will enable us to link time with space and give it a depth of location it otherwise is apt to lack.

The Addition of Memory and Expectation.-The "just 
past" and "not yet" of perceptual time are, it has been suggested, the germs of expectation and memory. But the expansion of time which accompanies the growth of these attitudes and contents is critical, for it gives a reach and reference which is basic for time as a cognitive category of knowledge. The stability of our time-meanings-the past, the present and the future-depends upon this supplementation by a larger range of events than the"specious present" can offer. We are lifted to, and live in, a wider temporal horizon than perception permits. The events which are marshaled in order are ideas and not sensations. There is, in this freedom from the original limitations, something analogous to the movement from perceptual space to common, or empirical, space. Conception is, here, not something opposed to the nature of perception, but rather something which develops and ripens the potentiality of the latter. The train of successions opened to the mind by memories and expectations is held together in one massive series and touched by the vivifying flow of life; and the whole is suffused by that sense of change and of duration which we have seen to be so basic and primitive. Due to this contact, the higher level of personal time retains an individual flavor and reference. It has a direction, is never empty, and has the uniqueness of the stream of consciousness of which it is a part.

Common, or Standardized, Time.-This higher level of personal time shades insensibly into common, or standardized, time. What should particularly be noted is the infusion of a spatial framework through various needs, among which is that of interpersonal intercourse. We must not, however, jump to the conclusion that such intercourse is, alone, responsible for this introduction of space. The more subjective estimates of duration are found by the individual to be too dependent on emotions and bodily conditions to be trustworthy as standards guiding the phases of behavior. For these various reasons which reenforce one another, the individual is led to resort to changes in things conceived to 
be indifferent to these more fluctuating personal factors. Of course, this acceptance of the neutrality of processes in nature is confirmed and, in large measure, caused by the testimony of others who are not at the same time subject to our hopes and fears. It is, therefore, in the attempt to get beyond the personal equation in duration-estimation that stress is laid upon features of the physical world--the standpoint being here that of common-sense realism-which correspond to temporal order and harmonize with the sense of duration. Does this standardization affect any of the timecharacters? When rightly understood-as it not always isit does not.

We have already emphasized an analogy between the conceptual development of time and the conceptual development of space. Another analogy is in order. Just as measurement by superposition is an advance upon measurement by the eye, because harmonizable with the latter and yet more exact and certain, so measurement of duration by motion is an advance upon a more intra-organic estimation. It must not be forgotten that the essential elements of change, order and duration, remain unaltered.

Thus empirical time moves outward to nature. And this movement works in favor of the cognitive use of time in our knowledge of nature. Time becomes differentiated and, in one of its forms, fitter to become a category of the physical sciences. It is easy to understand how a chronology for the external world arose. A uniformly recurrent process wquld best serve as the standard, and, accordingly, the daily and yearly movements of the sun were adopted-with the historical result that history, or the process of the world, was reckoned by years, days, hours, etc. We are all of us familiar with this system, but we are not so familiar with the shift in time-estimation which occurs as we pass from personal time to this standardized time. "Shakespeare tells us that time travels 'in divers paces with divers persons'; Newton tells us that time moves at a constant rate. Shakespeare's time is evidently subjective time, and Newton's 
objective time."' The contrast is between intraorganic time-estimation and measurement of events by commonly appreciated standards based on processes outside of the organism. No intuition of a literally objective time is demanded.

Mathematical Time.-Common time very easily links itself with mathematical space to become mathematical time, infinitely divisible and potentially infinite in extent. Hobbes has expressed this transformation so clearly and, withal, so naively that it will be well to quote him: "As a body leaves a phantasm of its magnitude in the mind, so also a moved body leaves a phantasm of its motion, namely an idea of that body passing out of one space into another by continual succession. And this idea, or phantasm, is that which (without receding much from the common opinion, or from Aristotle's definition) I call time.... And yet, when I say time is a phantasm of motion, I do not say this is sufficient to define it by ; for this word time comprehends the notion of former and latter or of succession in the motion of a body, in as much as it is first here and then there. Wherefore a complete definition of time is such as this, time is the phantasm of before and after in motion." Motion is one case of perceived change, a case for which measurement can easily be devised.

Movements are best represented symbolically by a line with a direction, thus $\longrightarrow$ : in such a symbol, there is a quantitative character and also the characters of order and direction. Hence, the line symbolizes duration and succession. The minimal elements of the construction are, measurable line-room to represent the relative duration, and positions, apprehended together and yet thought of as successive to correspond to temporal order. Mathematical time, then, uses space as its measurable basis and superposes upon this a different kind of order, that of succession instead of coexistence.

Now, in our study of space, we saw that the more devel-

- Stout, op. cit., p. 498. 
oped levels must not be substituted in a literal way for the lower levels. To think of perceptual space as really mathematical space disguised is to lay oneself open to all sorts of pseudo-problems. Mathematical space is, in part, a selfsufficient conceptual realm; in part, instrumental to knowledge about the physical world. There is continuity in spatial characters and also difference in their setting and use. In the same way, to seek to reduce personal time as an experience to mathematical time is absurd. The time characters are present in both, but their setting is different. Mathematical time is conceived by us to be infinitely divisible, infinite in extent homogeneous and empty. The characters are abstracted from their plangent source. It is against the identification of personal time, as the interwoven flow of conscious life, with space-time that Bergson rightly objects. ${ }^{7}$ But the flow of life is not time as a category of knowledge.

Kant's Antinomy.-Mathematical time is, as it were, the abstracted order of common time thrown upon the background of space. It is a conceptual construction reflecting essential characters, and yet characters here loosened from their normal content, which is events and changes. We can note the order in which all events do come and consider it apart from any particular events. The order is, in this sense, the form of all possible events which must be simultaneous and successive with respect to other events. Thus there is a fundamental continuity between the genetic levels of the time-experience, what may be called an identity of essence. Mathematical time can, therefore, be instrumental to knowledge of the physical world much as the space of mathe-

7 "Were I to look at it closely, I should see that this abstract time is as immobile for me as the state which I localize in it, that it could flow only by a continual change of quality, and that if it is without quality, merely the theater of the change, it thus becomes an immobile medium. I should see that the construction of this homogeneous time is simply designed to facilitate the comparison between the different concrete durations, to permit us to count simultaneities, and to measure one flux of duration in relation to another." An Introduction to Metaphysics, p. 46. I fear, however, that Bergson forgets that temporal order is qualitative. 
matics is. The material of knowledge is given in perceptual experience; and yet the more conceptual stages, which mental operations produce, develop and employ this material for conscious ends.

This identity between the essential characters of common and mathematical time being granted, we can proceed to discuss Kant's famous antinomy. We shall see reason to believe that it is as much of an error as that which was directed against the validity of space. Naturally, we shall grant to Kant that neither space nor time is a thing-in-itself. Our different epistemology sets a new formulation. We ask, Is time a category potentially or actively interpretative of the character of reality?

Kant seeks to prove the thesis that the world has a be. ginning in time by showing the absurdity of the opposite proposition. "For if we assumed that the world had no beginning in time, then an eternity must have elapsed up to every given point of time, and therefore an infinite series of successive stages of things must have passed in the world. The infinity of a series, however, consists in this, that it never can be completed by means of a successive synthesis. Hence an infinite past series of worlds is impossible and the beginning of the world is a necessary condition of its existence."

What we are here really dealing with is our conception of time. Time is an order of successive events. Let us take a line and consider any arbitrary point as the present. Does it follow that I must think of the portion of the line, which extends to the left and symbolizes the past, as finite? Assuredly not. One of the initial mistakes of Kant was to start with an assumed past moment and work toward the present instead of with the present and working backward. So far as our thought follows the method of synthesis, we begin with the present; and the infinity of time means that there is no conceivable end to the movement into the past. Kant speaks as though time were a stream flowing into the present. There is a double danger in this approach: the image suggests a source, and we confuse our thought with 
the flow of things. An infinite flow does not involve a human synthesis of an infinite collection of events. The critical realist does not demand too close a parallelism between the process of thought and the process of reality. Thought is retrospective and supervenes upon reality. Hence, to think of the world-process as without a beginning is an empirical affair of which we find ourselves quite capable.

Time as a Scientific Category.-What kind of knowledge of the physical world does time cover? We shall realize in the case of time, even more clearly than in that of space, that human knowledge is not an intuition of the physical world. Knowledge implies intuited material and the use of that material in a cognitive way, but what is intuited is subjective and not the physical object.

The first point to note is the character of the measurements upon which science builds its facts. Scientific time is at once a measurable quantity and an order of succession. Some process-preferably a movement-is taken as a standard, and other processes are referred to this unit. If two processes begin and end at the same time, they "occupy" the same time. Let us take an example to make this method of measurement clear. Suppose that we wish to know how long a certain chemical process takes. We note the positions of the hands of a watch at the moment we put the chemicals together and also at the exact moment the reaction ceases. We measure the one process in terms of the other standardized one to which we relate all other processes. This measurable correspondence is the type of scientific time-quantity, and it is for temporal knowledge what the superposition of things is for the spatial knowledge of nature. In both cases, our knowledge consists of ratios, not of intuitions of inherent properties. Perception is a means to knowledge.

The standard process which science has adopted is, we have said, movement. It might have been other processes like the loss of heat by bodies, but practical conveniences led to the selection of movement. The point to stress is, 
that the prime requisite of the reference-process is its capacity for exact measurement. That processes, as we say, occupy time means two things: first, they are experienced by us as corresponding to an immediately estimated duration; second, that there are changes of a successive order. The scientist undertakes to measure these aspects and relate them to one another. What process is selected as a standard of reference and what unit is adopted are arbitrary so far as nature is concerned-a fact that makes us realize that knowledge is a human affair and is knowledge about nature rather than a reproduction of something external to man. But the ratios secured are not at all arbitrary. Given the method and the unit, the result is determined by reality itself. Nature dictates a response to man's questions. But the questions and the language of the response are human.

When the thinker reaches this conclusion, he is led to seek confirmation in the more theoretical reflections of scientists themselves. And it is interesting to find that scientists are more alive to such questions to-day than ever before. In every field there is an increasing demand for exact definition and discriminating analysis. In regard to space and time, the theory of relativity has produced a marked degree of reflection. Thus, in his examination of the theory of relativity, Dr. Silberstein treats of the "definition of physical time or the selection of a clock or timekeeper, to be employed for the quantitative determination of a succession of physical events."8 Let us consider his summary of the method adopted by science to work out a suitable standard.

"Suppose," he writes, "we do not limit ourselves to the investigation of motion only, but are concerned with every possible kind of physical phenomena, such as conduction of heat or electricity, diffusion of gases or liquids, melting of ice, evaporation of a liquid, etc., and that we propose to describe the progress of these phenomena in time, to trace their history, past and future. How are we, then, to select our time-quantity $t$ ?" Newton's absolute time flowing at

- Silberstein, The Theory of Relativity, Ch. 1. 
a constant rate-whatever that may mean-could not help us since we have no clock to measure this absolute time. The result is that science selects some standard process like the rotation of the earth and adheres to it so long as it can relate other processes to it. When this cannot be done with ease, the standard process is examined more thoroughly to see if it is variable. "Thus astronomers have come to the conclusion that the earth as a clock is losing at the rate of 8.3 seconds per century and they have given up the earth as their time-keeper and substituted for the sidereal time $t$ a certain function $\mathrm{T}=\phi(t)$, slightly differing from $t$, as their new 'kinetic time.'"

It is obvious that science has relinquished that naively realistic attitude toward kinetic time which still lingered in the mind of Newton. The above analysis of scientific time fits in exactly with the position which our own critical analysis forced us to take. The universality of scientific time follows from the identity of the reference made. We may say that the whole physical world is in one time: when properly analyzed, this means only that any one process can be brought into correlation with all the physical processes which we know. ${ }^{9}$ Hence the oneness of the world's time is expressive of the fact that all processes in nature can be compared and measured by human ingenuity. The world is spatially one, and so it lends itself to these comparisons.

An interesting result, which we might otherwise have missed, now stares us in the face. The unity of scientific time really rests upon the spatial unity of the physical world. The processes of change which are measured are changes in the physical world, localizable with respect to each other. We move our eyes hither and thither to note the changes which are. running their course and keep tab of them in the light of the movements on the clock's face. It is obvious that the unity of scientific time implies the spatial character

9 The modern theory of relativity deals with the assumptions underlying measurement. It has led to an analysis of scientific space and time long needed. For a fuller discussion, see Ch. XI. 
of nature. These two fundamental, and yet elementary, quantities hold of the same world. The elements of the two quantities are, however, essentially different. Space signifies order of coexistence in distance: its character comes out best in the experience of solidity. The idea of change is alien to its content. When we think of nature in terms of it, we think of coexistent bodies whose parts exist alongside of one another. Time, on the other hand, signifies an order of change qualified by duration. Such change we think of as in bodies. The distinctness of the two categories can be brought out in this fashion: Conceive of the physical world as inert and changeless. Would time have any meaning for such a world? But our world is different. It is both spatial and temporal. Only when we think of it in terms of both do we grasp it properly. Thus they are co-valid of nature. Physics recognizes this correlation in the acceptance of the four-dimensional manifold of space-time.

Temporal Distinctions.-Let us next glance at certain distinctions characteristic of personal time in order to see whether we should carry them over to time as a category of scientific knowledge about nature. I refer to the timemeanings, the past, the present and the future. In personal time we distinguish the now from the past and the not-yet. It will be remembered that in perceptual space we distinguish the here from the there, chiefly with reference to the organism. What becomes of the temporal contrasts at other levels?

The present of common time is clearly a construction of arbitrary limits. It may be a minute, a day, a year, according to the context and interest. This relative character of the present holds also for mathematical time, for in it there is nothing to distinguish one moment from another except their order. The present of such a time is an arbitrary portion of time-room which can be made as small or as large as desired. There is no present in its own right in mathematical time. The situation is analogous to the arbitrariness of any "here" in mathematical space. 
But what shall we say of the present for kinetic, or scientific, time? Does our knowledge of nature reveal a present which stands out in an absolute sense and can be measured? Obviously not. What science offers us consists of processes which can be correlated with the accepted time-intervals. Theoretically, such an interval can be made smaller and smaller; practically, this process of comminution has a limit set by technique. The general measurements which are obtained in science give quantities which can be treated as infinitely divisible. Whether the natural process itself is of this type remains, however, to be seen. ${ }^{10}$ The preliminary knowledge which gross measurement contributes is incapable of answering such a penetrative question. Be that as it may, it follows that kinetic time offers no natural present in any way analogous to the specious present of consciousness. Let us not, however, condemn science for giving only the sort of knowledge it can obtain.

Change, the Objective Basis of Scientific Time.-If time is an order, it must be an order of something. In our own consciousness, it is an order of experience. What do we think of as in an order of succession in nature? The answer which leaps to our minds is change. Real time is change, or, to put it the other way round, change, as cognitively conceived, always involves an order of succession.

But the character of real change is, itself, a problem. Is change continuous or discontinuous? Again, does change involve an order in nature? We must postpone the detailed consideration of these questions to another chapter, but certain points may be noted now. In the first place, change in consciousness seems to involve both continuity and discontinuity. There is often no preparation for what happens. Thunder breaks in upon silence in a cataclysmic way. The principle of the threshold, likewise, suggests abrupt transitions. But it may be retorted that the nervous system carries the increasing strain cumulatively. To this it may be replied that there are different rates of change, and that

10 We shall examine the question of continuity in another chapter. 
nature often works like a gasoline engine by a series of quick explosions. At other times, change seems to be progressive and continuous.

When we ask ourselves whether change involves an order of time, the answer seems clear. Change in consciousness does so, for that is the exemplar from which the category of time is derived. But when we think of changes in systems independent of consciousness, a difficulty arises. The past ceases to exist, and there seems to be no natural present. Knowledge about nature is not the same as nature, and we have a right to expect a divergence between the form of knowledge and reality. Let me illustrate the point. The scientist furnishes us with knowledge about a motion by describing the path traversed and the time-rate of the motion. But the body moving does not carry its path with it. Only man with his memory is able to connect a past position with a present one. The moving body has no such coordinating memory. When this difference is once grasped, we realize that knowledge about a motion is not the sam $\epsilon$ as the actual motion. Paradoxical as it may sound at first, we must admit that nature produces events according to an order and that man arranges them in an order. The stretched-out order of past and present is founded upon nature and agrees with nature but does not exist in nature. Knowledge and reality are not identical.

The "now" is present experience in contrast to past experience, which is remembered, and future experience which is anticipated. The remembering and the anticipating are present, while what is remembered is dated as past and what is anticipated dated as future. A little care would avoid all difficulty here. We should say that events are past rather than in the past. What we mean is, that certain processes or activities have ceased, though they once did occur. Their existence was their presentness. The "now" of nature is what is going on there.

It follows that temporal contrasts should not be read too naively into nature. When we come to consider the category of causality, the importance of this warning will appear in 
all its force. Can the cause, which is past, produce the effect which is present? Our analysis of time will enable us to meet such questions with assurance.

Real time is change: but what is change? What is its setting. Consciousness is a stream whose content is changing, that is, old content lapsing and new content coming. It is not a thing which changes so much as a series of changes. But when we think of the physical world, we conceive of it as that which changes or in which changes occur and not as a series of changes. If we can master a metaphor, we can say that the present of nature is the reality of the things of which it is composed. In our thought of reality, we get rid of that threat of transiency which qualifies consciousness and gives much of its sadness to the present moment. It is evident that we are here on the track of the category of substance, of that which is the seat, source and center of change but whose existence is not imperiled by change. It is reality which changes and at the same time persists.

A Return to Kant's Antinomy.-To those who have grasped the implications of the above analysis, it will be clear that the usual view has been reversed. Instead of nature being in time, time (change) is in nature. So understood, time suggests neither beginning nor end to the world.

Had the world a beginning? We do not ask whether it had a beginning in time. Now, if the world had a beginning, it must have been because it was created, or because it arose out of nothing. But is there any good empirical reason which suggests creation? Is not the burden of proof on those who assert it? Science possesses no data which lead in that direction. To those who protest that they are forced to think of a beginning, it may be pointed out that they concede that God is eternal. It is evident that the thought of an eternally existing reality is a common possession. Let us pass to the other alternative. While I can't absolutely disprove that the world arose out of nothing, I find the idea opposed to all the tendencies of my thought 
which urge me to seek a cause for what comes to be. We are here face to face with the so-called problem of being. ${ }^{11}$ As James has so well said, "Not only that anything should be, but that this very thing should be, is mysterious! Philosophy stares, but brings no reasoned solution, for from nothing to being there is no logical bridge." ${ }_{12}$ But philosophy is essentially an attempt to understand the world as it exists. And, besides, not-being is a concept founded upon being by negation.

The complementary problem-Is the physical world eternal? - can be discussed in a few words. The position taken toward the previous question implies the answer to this one. The facts are in favor of conservation of some kind. What it is that is conserved is another matter and will demand consideration later. If the universe be a spatial system, what holds of subsystems can be applied to reality as a whole. The more science secures data in favor of conservation, the more it urges on us the view that nature is eternal. And by eternal I mean, not changeless, but never ceasing to exist.

Summary and Suggestions.-In the previous chapter on Space, we were led to the conclusion that spatial judgments are valid of nature and that the elements of the spatial category, such as distance, position and order, correspond to, and reveal, the structural character of the world. But we also realized that these elements appeared in those innumerable detailed judgments which constitute science. It was their commonness which constituted space a genuine category of knowledge. What is true of space is also true of time. Temporal order and measurements give us knowledge about nature. Yet these categories require development and deepening: they are apt to be conceived in too passive and mathematical a form. While space blossoms out, with the increase of knowledge, into the categories of dynamic

11 Cf. Schopenhauer, The World as Will and Representation, Appendix 17.

12 James, Some Problems of Philosophy, p. 39. 
relation and internal organization, time deepens into the idea of processes of cumulative change. Dynamic elements enter to give body and energy to our concept of nature. Into the framework furnished by space and time all the other categories fit. No valid predicate can conflict with them. Reality is spatial, and this spatial reality changes. 


\section{CHAPTER VII.}

\section{THINGS AND THEIR PROPERTIES.}

THE foregoing consideration of space and time has 1 surely convinced the reader that philosophy can set the categories in their true light only by studying them both genetically and analytically. To introduce a view which belongs to one level of outlook into another can only work confusion. But along with a correct mode of approach must go a correct theory of knowledge. The theory of knowledge will, of course, be deepened by the clarification of the metaphysical categories; yet some measure of epistemological perspective is needed in the field from the start.

In the present chapter, it will be our purpose to apply this method of systematic reflection to the distinction between a thing and its properties. What is a thing? What are properties? What is the relation between them? We shall study these terms at the level of common sense. Then, after a consideration of the new meanings brought in, or emphasized, by science, we shall finally ask ourselves what interpretation philosophy must give to these relative categories.

At the level of common sense, the world is taken to be a more or less interdependent collection of bodies of different kinds. These heterogeneous things are open to perception. They are there before us as real as our organic selves and to be reckoned with in our actions and plans. These recognitions or assumptions are of the very heart of natural realism. The unsophisticated man, largely unaware, and wholly negligent, of the conditions which control his per-. 
ceptions, divides the field of his experience into physical things and his own more private, mental experiences-his thoughts and feelings. ${ }^{1}$ That we all perceive objects which we interpret and classify as physical things there can be not the least doubt, and so far the plain man is right. No philosopher would be foolish enough to assert that the pedestrian does not see a diversified landscape.

Realistic Meanings.-The correct setting for an analysis is very important. We will be excused, therefore, if we try to summarize the meanings which characterize natural realism. The essential meanings which qualify and surround the heterogeneous things of common sense are roughly as follows: $(a)$ co-reality with the percipient, $(b)$ independence, $(c)$ commonness, $(d)$ occupation of space, $(e)$ high degree of permanence, $(f)$ possession of dynamic capacities. All these empirical predicates must be true of an object before it can be regarded as a physical thing.

It will be noticed that three of these predicates involve a reference to the human observer. Just as I recognize that I exist, so I admit the existence of these surrounding things. Such as they are, they are co-real with me. It is not necessary that I read into them any sense of life like my own. It is, rather, that I know myself to be one among many, a part of nature, a living organism adjusting itself to its environment. It is this free admission of my place as a particular reality along with others, founded upon my specific knowledge of the world, that I mean by co-reality. Independence is a predicate closely bound up with co-reality. Things are independent of me in the same sense that I am independent of them. I can use them for my purposes but, in so doing, I acknowledge that I handle them from outside and by force. My will works only through my body. Again, independence may have an epistemological significance. It means that my perception and knowledge aims at things from within my consciousness. Their esse is quite untouched by percipi. It was this common-sense realism which

${ }^{1}$ Cf, Critical Realism, Ch. 3. 
Berkeley was forced to attack almost against his will. Perception and knowledge are supposed to supervene upon these co-real things to light them up or reveal them. Commonness is another predicate which involves a human reference and perspective. Physical things are perceivable by all alike. That is, in fact, one of the tests which things must measure up to. An object which only one person can perceive is ghostlike and unreal. It doesn't really exist ; that is, it isn't the sort of an object we have taken it to be. It must be reclassified and put in the class of illusions.

These predicates are fundamentally veracious and represent the insight of long and constant experience. He who would challenge their essential truth must have strong evidence at his back. All that critical realism purports to do is to give them a more critical setting.

The other three predicates concern themselves more with the nature of physical things. Let us examine these characteristics a little more fully.

Physical things occupy space. Recalling to mind our analysis of space, we know what this assertion means. Things are bodies which have position, are measureable in three dimensions, have shape and size. Such classes of judgments are referable to them as giving knowledge about them. Whatever is a physical thing is the potential subject of such judgments. This universal proposition is not the expression of any a priori mental necessity but of an empirical classification. Spatial character is one of the defining marks of the class.

Physical things have a high degree of permanence. The degree of permanence in any case is a matter to be dis. covered by experience. Rocks perdure in spite of the flow of time, while flowers blossom and fade in the space of a few hours. The physical world is not a flux and yet it changes. In the inorganic realm, forms shift under the play of weather, of frost and erosion: in the organic domain, the cycle of life and death proceeds in a routine way after the nature of each kind. All this is a matter of unimpugn- 
able knowledge. These are the things which are co-real with ourselves.

Physical things possess dynamic capacities. They are centers of produced change. This book can be used as a weight under which to press flowers; this typewriter writes the letters on the paper as I press the keys; this chemical substance has the property of attacking iron. Science is full of this sort of knowledge about things and the substances which compose them. Invention has made fertile use of these capacities to force them to minister to human needs. Real processes occur all around us of prime importance for our welfare. The physical world is the seat of activities whose drift and course it is to our advantage to learn.

The Rise of These Meanings. - It is the task of the psychologist to discover the factors which in combination account for these realistic meanings. But a brief summary of his conclusions will be helpful in giving the genetic background of the categories which we must analyze.

The first point to bear in mind is that groups of sensational experiences which are under complete command of the individual do not suggest something external. They naturally integrate with, and become a part of, his personal activity. Such is the case, for example, with the experiences which flow in from the movement of the arm: they continue, express, and join with the purposes with which the individual is identifying himself at the moment. Sensational experiences, again, which are completely out of immediate control, just as little suggest an external reality. Thus, those feelings in the organism which accompany the individual and give the atmosphere of his activity and general life as naturally merge with the self as do the kinesthetic sensations. "What is required is a motor command of the flow of senseexperience which has to be acquired by a process of adjustment to conditions which are themselves uncontrollable. This is what I have called motor adaptation. It is present wherever we have to find out by trial the motor activity requisite for getting certain sense-presentations in a certain order."2

${ }^{2}$ Stout, The Groundwork of Psychology, p. 93. 
The individual soon learns that those sense-contents which he calls his body are under his control in a way that other sense-contents of the same type are not. He can move his hand while he cannot move the book in front of him until he grasps it. Hence, the delimitation between himself -a concrete being, replete with feelings, ideas and motor sensations-and other things arises in the field of spatial perception under these differences of motor control. This cue is deepened by the experience of resistance. When he approaches those visual contents which are given as at a distance from his body, he sooner or later finds that his path is barred. He has met an obstacle. This meeting of an obstacle is a vivid experience of tensions and strains. Sometimes the obstacle can be removed by an effort, sometimes it cannot be. We can remove a chair: we cannot remove the wall.

In these various ways, the body as a perceived and felt object, under direct control, becomes contrasted with the contents (objects) given by the eye and ear, the distancereceptors for man. The point to grasp is, that this division into the self and the not-self is natural and inevitable. The whole process is one of growth in which trial and error play an important part. I am also inclined to think that a social factor enters in to develop the division. One individual can note another reaching for an object which is beyond his grasp. The not-self becomes a realm of common objects, external to others as well as to oneself. ${ }^{3}$

It should be borne in mind that all these cues coexist and reenforce one another. It is absurd to take only one of them - the experience of resistance, for example-and throw all the burden upon it. Many of the older thinkers made this mistake.

It is probable also that desires and instincts play their part in the growth of the sense of something independent. Fear and hope attach themselves to objects in the perceptual field. We desire what we have not: we fear what is out-

8 "The skin and what lies inside it is apprehended as belonging to the self; what lies outside it is apprehended as not-self." Ibid., p. 102. 
side us and which we reflectively, or instinctively, believe will harm us. The very structure of our mind thus harmonizes with the idea of an external reality.

Thus the peculiar attachments of kinesthetic experiences, the motor adjustments required, the experience of resistance, the urge of instincts, etc., all play into one another to produce that recognition of external reality which is at the basis of common-sense realism. And reflective experience finds no reason to reject this realistic structure and the meanings which give it fuller interpretation.

The Interpretation of the Not-Self in Terms of the Self. - Both anthropology and child psychology inform us that physical bodies are primitively interpreted in terms of the self. And it must be remembered that the self of this early period is chiefly the willing, acting, desiring self. It is the self of the flow of immediate, direct experience rather than the self of knowledge. It is the enjoyed self which inhabits the body and uses it as its subservient instrument.

Now the child thinks of things as like itself. They are hungry, sleepy, angry, playful. This is called interpretation by analogy. It is also called the projection of the self and the introjection of the self. Similarly applied terms are: sympathy and Einfühlung. What they indicate is a natural association or movement of interpretation to regard these co-real things as centers of conscious life like himself. Thus the sensible surface of things is filled out in his thoughts by an inner source of reality which seems to the child selfsufficient and adequate. The nature of this embodiment is not a problem to child or savage because the presence of his own flow of conscious life in his body is not a problem. The sensible appearance of his own body goes along with willed movements, feelings and ideas. The relation is one of merged compresence. It is not a theory but a fact. I presume that other things are vaguely apprehended in the same fashion.

When we come to the category of causality, we shall again meet with this situation. Hume was one of the first 
to point out that the popular idea of force and energy consists in the experiences of strain and effort which we ourselves have while making exertions. We read them vaguely into things in similar situations-the horse pulling the cart up hill, the locomotive panting before the long train of cars, the pillar supporting the heavy ceiling. The history of science has been the rejection of this naive projection in favor of quantitative knowledge about what bodies can do in the way of lifting, pulling and pushing. As scientific terms, force and energy are quantities.

But the point to bear in mind just now is that things are often thought of as sensible objects whose inner core of being is like that which forms the active and flowing nucleus of the percipient individual. I sometimes imagine that the body is experienced as a shell filled on the inside with consciousness. But is not all this an illusion? Does it not represent a natural, and yet naive, substantialization of consciousness, simply because it is the only reality which we intuit and enjoy? We shall see that there is both illusion and truth in this hylopsychism.

The Interpretation of the Self in Terms of the Not-Self. -As we have already suggested, the movement of science was in the direction inverse to the primitive one. While primitive man interpreted nature in terms of the self, science has increasingly interpreted the self in terms of nature. The gist of this movement was the growth of the mechanical view of nature. The two general aspects of this movement which are relevant to the present context are: (1) the discovery of definite laws in the occurrences around us, and (2) the formulation of nature in terms of spatial and temporal characters. Questions concerning the exact reach, implications and significance of the mechanical view of the world may be dismissed for the present. What it is of importance to note is the entrance of a new framework for which the projection of the self is essentially beside the mark. Let it be granted to the psychologist that we still have the tendency to read into the processes and relations around us some echo 
of our motor feelings: still, our intellectual idea of these processes and relations is analyzable into observed facts formulated under categories suggested by, and developed in harmony with, the content of human perceptions. The interpretation of the not-self in terms of the self assumes an analogical intuition into the very heart of nature; and the significant, and yet unconscious, postulate is that conscious processes are the strategic core of the self. There has yet been no clear break between the body and consciousness. As we pointed out, the sensible appearance of the body goes along with willed movements, feelings and ideas. The outline of the body is experienced as filled out on the inside with the passionate flow of consciousness.

Now the interpretation of the not-self in intellectual terms resting upon the characteristic content of perception leads to a conception of the world antagonistic to this naive compresence of sensible appearance and inner consciousness. The physical sciences state the not-self in terms of mass, movement, energy, position, distance, etc. These elements fit into the context of realistic meanings whose genesis we have studied to give the thought of the physical world dominant in science. ${ }^{4}$ The projection of kinesthetic sensations is regarded as unwarranted and irrelevant to the problems at hand.

Two epistemological comments may be made at this point: (1) The scientist is too often inclined to hold that his knowledge is an intuition of an intellectual sort able to present the very stuff of nature and to exhaust its potentialities. Of such a kind was the mistake made by Descartes; (2) The philosopher has the right to raise the further question whether there are any of the elements of real activity in the scientist's thought of the world. Pondering upon this latter question, he who is idealistically inclined may wish to return to a slightly purified projection of the self. But may not activity, itself, be a category of knowledge which demands critical use? A category, moreover, which is very fundamental for our ultimate conception of reality.

4 Cf. Critical Realism. Ch. 2. 
But we must return to the effect upon the self of this development of descriptive scientific thought of the not-self. Historically, it led to the attack upon the animistic view of the self. The self became two things: the body and consciousness. Anatomy and physiology concerned themselves with a study of the body in accordance with the methods and ideas of the other physical sciences. The not-self thus became a source of interpretation for the self. On the other hand, conscious experiences were conceptually separated from the bodily movements into which, according to the older view, they flowed in a creative way. The mind-body problem became full-fledged. Is consciousness merely an epiphenomenon? Is the interpretation of the not-self by the self entirely illusory because the naive view of the self is erroneous ?5

The Aspects and Properties of Things.-We have seen that, for common sense, a perceived thing is a reality co-real with the percipient. The percipient has the unique capacity to apprehend it-a capacity connected with the sense-organs and mind-and apprehends it more or less as it is. But he is seldom supposed to apprehend all of it. Experience leads him to admit that he sees things from angles and distances. The datum he apprehends is determined by many factors and conditions, and yet he holds that it is always the actual thing, itself, that is the object of his perception. The basic belief is that there is an actual physical reality occupying space, relatively permanent and having executive capacities, and that this reality is to some extent open to the mind. This basic belief is, at the most naive level, scarcely separable from the idea that the objects given in the field of experience are, just as they appear, these physical things. That is, the distinction between appearance and reality has hardly made its advent. But this distinction may arise and attain considerable strength along with the confidence that the physical thing is somehow apprehended in and through the appearing datum.

5 These questions will be taken up and answered in the chapter dealing with the mind-body problem (Chapter XIV), 
We may say, then, that common-sense realism always contains a firm faith in the realistic meanings enumerated above, while swinging from the uncritical level of immediate apprehension to a more or less conscious admission of knowledge through appearance.

No one, I believe, has put the difficulties confronting naive realism more strikingly than has $G$. E. Moore. And this is particularly interesting because his sympathies are with naive realism. His argument may be summarized as follows : ${ }^{6}$

1. Let us assume that we are perceiving an inkstand and judging, "This is an inkstand." What factors are involved? Clearly, we are not perceiving the whole of the inkstand. Very rarely, if ever, do we perceive the whole of the object which we judge ourselves to be perceiving. Our judgment, in such cases, is on the one hand about "this"- the datum, the item in the total field of presentation at the moment, about which, as distinct from every other simultaneous datum, the judgment is being made. On the other hand, the judgment is also about the "inkstand" which we certainly believe ourselves to be perceiving. Now, whilst the datum is thus "the real or ultimate subject" of every judgment of perception, yet, clearly, it is not, in general, the kind of a thing for which the predicate term (here "inkstand") is a name. The "this" may be a color, or a sound, or any other sort of sense-datum; it will not be what we mean by a physical or material thing. If "this" is all we perceive, then we are not perceiving an inkstand, and the judgment "this is an inkstand" will be false.

Here the critical realist uses his distinction between the content and the object of perception. The content is the "this." The object is the inkstand. Thus the object is interpreted through the datum though it is never given as the datum is.

2. If "this" is all that is strictly perceived, then the whole

- I shall follow Hoernlé's excellent summary, particularly since I wish to criticize his solution of "Saving the Appearances." See his Studies, p. 127. 
object is only "known by description" as "the object which stands to this in a certain relation? Suppose we say, in examples drawn from sight, that "this" is a part of the surface of the thing. But we encounter insurmountable difficulties. When we look, for instance, at the "same" inkstand from different distances, or from different angles of perspective, or when we perceive it by touch rather than by sight, the sense-data differ perceptibly throughout, yet we do not judge the inkstand to have perceptibly changed. The "this" cannot be a literal part of the object.

What, then, must be our conclusion? Let us bring it out by contrast with Hoernle's. This writer, who is one of the champions of objective idealism, concludes that we perceive "things" only by interpreting data to mean wholes which, as wholes, are not data. There is in this process of interpretation something of the nature of transcendence. But the transcendence which he has in mind is that of supplementation. He accepts the construction and concludes that "Reality reveals itself in what, on the basis of perception and feeling, we are obliged to think it to be."

There is so much in this position that I agree with, as against Russell and Moore, that I regret its vagueness. Is reality the physical object? Or must we conclude that all of reality is always the object of our perceptual judgments? The critical realist holds that we know a specific affirmed object in terms of this developed content. And this position implies just that saving of the appearances which Hoernle desiderates. Data are not absolute or inherent qualities of the physical thing; they are only relative to conditions. Each datum in order to be properly understood must be generalized by stating its condition. But granted that the thing must be interpreted in terms of its appearances, has it a determinate nature of its own? The critical realist argues that it has. It is next to impossible to discover exactly what position the objective idealist adopts. Both the distribution of knowledge and its reference are too vaguely treated.

Bosanquet and Bradley, who are the recognized leaders 
of objective idealism in England, frankly admit that their outlook founds itself in a measure upon subjective idealism. Subjective idealism is used to break down naive realism. Thus Bosanquet writes as follows: "I understand it (subjective idealism) to mean that we know nothing but states of our own minds. It is not actually true, but it is truth of a higher order than that of naive realism." 7 The critical realist would challenge this statement. It is not of a higher order of truth to assert that we know nothing but states of our own minds. Instead, it is a fundamental mistake. Thus the critical realist holds himself to be freer from subjective idealism than is the objective idealist. His quarrel with naive realism is not about the realism but about the assumption that the physical thing is intuited. For him as for the naive realist, the physical thing is from the first, and always, the object of knowledge.

Since objective idealism builds upon the entire rejection of naive realism, it is naturally forced to get what objectivism it can through a sort of cooperative synthesis. "It follows," writes Bosanquet, "that the nature of external objects is continuous with that of the stuff of mind, and is physical, i. e., has variations relative to those of other objects, as well as psychical. Physical or spatial objects are just as we know them, and truly have the characters which our knowledge (so far as it is knowledge, i.e. so far as it is consistent with itself and with experience) attributes to them." And again, "The stuff of mental states enters into them, and though the stuff of each particular mind is only a very small contribution to the real world, yet it is a contribution, and is capable in principle of furnishing some element which no other particular mind supplies."8

We are now in a position to formulate characteristic positions with regard to things and their qualities. Naive realism holds that data are aspects of things and so qualities. Mill, the empirical idealist, held that things are permanent possibilities of sensation. What qualities are on such a view

' Bosanquet, Logic, 2d ed., Vol. II, p. 311.

8 Ibid., p. 310. 
it is difficult to see. And is not a permanent possibility an actuality? Russell changes things into logical constructs of actual and ideal sense-data. But the critical realist holds that data are responses of the organism which are correlated with external things and regarded, first, naively as their qualities or aspects, and, then, critically as material for knowledge of them.

Man grasps objects as complex. An apple, for instance, has a definite size, a particular shape, a specific odor, a characteristic taste, a definite weight, etc. It is one thing and yet has these discriminable elements. Not all of these are experienced in a sensational way at any one time; most of them are given as images and concepts. Yet they are organized together as the apple. They are qualities of the apple. How shall we explain the situation?

Our general approach makes an analysis easy. The elements given in the field in union with the perceptual attitude are fused and are intimately qualified as an external thing by the aforesaid realistic meanings. Thus is the category of thinghood achieved. And relative to this category is that of qualities. The qualities of things at this level are the discriminable features of the contentual object. The nucleus of things is for man their spatial position and contour. This is filled in by all other quales, sensational or conceptual, which fuse with the nucleus.

In such a context, what things are good for, what they cause in ourselves and other things-their powers and capacities-easily and naturally introduces itself as an essential part of the content. And this whole content is grasped in the setting of thinghood.

It is worth noting that both common sense and science are inclined to distinguish between the sensible aspects of things and their properties or powers. In general, properties are statements of what things do under certain circumstances. Aspects are, roughly speaking, the more sensuous characters; properties express physical connections. The distinction is suggestive. 
The Paradox of Common-Sense Realism.-Things are granted a being subtly and unconsciously modeled after our own sense of life. But the sensible exterior of things alone is turned toward us. What is apprehended discovers itself to be content, characters which are potential universals; and these cannot stand alone and yet are given alone. Take any physical object as empirically given and analyze it, and what do you have? Conditioned data. And these data have no substantiality. We always add to them their reference. They are characters of this thing. But what is the thing itself? Is it anything apart from these characters? We have here the baffling relativity which forces us beyond naive realism. The external things stand for the conviction of something to which these characters and our bodily posture point. So closely are the characters identified with this object and so automatically are they fused into a working unity by the mind that their apprehension is assumed to be the apprehension of the thing. In short, the paradox of common-sense realism is that physical things seem to be apprehended, and yet what is apprehended turns out to be relative and unsubstantial. Discriminate as we will, we discover only characters; and yet we feel that the object cannot be any combination of characters.

And what is true of common-sense realism holds also of scientific realism. What are mass and energy but quantities? And are quantities self-existent realities? The very stuff and being of the world here again appears to elude us, while we are left with contentual objects hanging in the void and yet claiming a connection with that which is self-existent and substantial.

According to critical realism, the key to this paradox lies in the nature of knowledge. We cannot apprehend physical things themselves, for what we take to be such are really mental substitutes. Knowledge is the nearest to things that we can consciously attain ; and knowledge is based upon perceptual and conceptual characters existent only in experience. 
Lockian Realism.-Our position may so readily be confused with Locke's by those who have not seen its more critical character that it may be well to indicate the difference. Locke was very uncritical when he had to do with metaphysical categories and, through that negligence, weakened his theory of knowledge. I shall quote in this connection from the latest and best analysis of Locke's position. Under Locke's hands, substance became an unknown $x$ to which we refer the contents of experience. "In order to appreciate what seemed to Locke the startling nature of this result, we must bear in mind the position assigned to substance in the metaphysics which he inherited, and from which he never succeeded in entirely breaking away. For it substance, and substance alone, possessed an absolute and indefeasible reality. While reality was held to consist of substances and their qualities, the former were thought to possess an ontological superiority, since qualities depend upon substances for their existence, and indeed 'flow' from them in some mysterious way. A substance must, therefore, be thought of as possessing a being of its own, apart from, and prior to, the qualities which we refer to it." 9 This support and source of accidents remains an unknowable, while the primary accidents are somehow copied in experience.

But a modern thinker is not attracted to this metaphysical interpretation of substance and qualities. It is the physical reality with its specific nature which he knows, and he does not conceive this specific nature as a complex of qualities unified by an underlying substance. The physical thing, itself, is a substance in the sense that it is a relatively permanent portion of the world. Its determinate nature is not external to itself in the way of supported qualities but is intrinsic. The unity of any substance is the organization of its parts into a definite whole, and thus is an expression of the concrete nature of the substance. We must be on our guard in this field against the fallacies of "pseudosimplicity" and "indefinite potentiality," as Perry has named them. We must not take such terms as essence and sub-

- Gibson, Locke's Theory of Knozvledge, pp. 95-96. 
stance as indicative of something mysterious and fundamental. Actual knowledge always has definite things for its objects.

If we disintegrate the more complex things into their component parts and so secure atoms and even electrons, these, also, are not substances in the Lockian sense. They are specific realities about which we can gain knowledge. The matter of the physicist has nothing in common with the substance of medieval thought. Substances are specific things which exist and which we wish to know. Any particular substance has its own nature, its structure and its typical modes of behavior. Thus form is a product of creative synthesis. The particular substances are the formed stuff of the past in a further integration.

$\mathrm{My}$ argument is that particular things are complex, but that this complexity does not require a unifier because it is not a pluralistic complexity of a logical sort. It is a complexity which corresponds to our idea of system. In other words, the physical thing unifies itself, much as our minds do, through immanent processes. The identity, or unity, of a thing does not conflict with its complexity.

Berkeley's Idealism.-We have seen that Locke's terminology was unfortunate. His position was a blending of medievalism and Newtonian atomism. He was clearly bewildered and hovered between the thought of the primary qualities as somehow inherent in a possessive $x$ and a view of them as powers of matter to affect us in certain ways. His copy idea of knowledge played the traitor and made him more susceptible than he would otherwise have been to the medieval schema.

For Berkeley, a thing is simply a complex of sensations. A thing is an idea, a collection of its apparent qualities. The realistic meanings of thinghood are largely belittled or ignored. We have argued that this thinness of his view of perception was due largely to his refusal to make the distinction between the content of perception and the object of perception. 
Berkeley had little difficulty in showing that the Lockian type of substance is essentially unintelligible. It performs no actual function. How can qualities inhere in something distinct from themselves? Are not inherence and support mere metaphors? The relative categories of substance and qualities did not have a satisfactory metaphysical status; and yet representative realism of the Lockian type seemed to demand the metaphysical validity of this disjunction. I mean that the primary qualities had to exist in order to be copied in the mind. But, since they were unsubstantial and passive, they must be owned by something more vigorous and self-sufficient. What we have called the paradox of common-sense realism is transferred to the world outside experience. There can be no doubt that Berkeley is effective against Locke. But his acosmism ignored other possibilities. Critical realism attempts to offer another possibility through its reinterpretation of knowledge and its identification of substance with thing. The thesis we have in mind may be stated thus: The specific nature of a thing does not conflict with its unity. But this specific nature is known in terms of a logical complex whose only unity lies in the common reference. Any lapse into an intuitional view of knowledge, therefore, creates an insoluble problem.

Properties Are Cases of Knowledge.-Let us call the physical existent which controls data in our consciousness an instance of being or a substance. It should be clear by now that sensuous qualities cannot be literal attributes of such a substance. Yet it is in terms of the definite propositions built up by the mind upon the foundation of perceptual data that the physical existent is known. What, then, are properties? Simply the elements of our tested thought of the thing. The remarkable fact is that the distinction between substance and properties is an epistemological rather than an ontological one. In a very real sense, properties as we formulate them are cases of knowledge about the existent. And yet, since knowledge must give insight into reality, the existent can rightly be said to possess 
these properties; its determinate nature must be such that these propositions conform to it.

This epistemological approach to the idea of property suggests the mistake made in the past in regard to the category of substance. A substance was the subject of predication. The simplicity of the subject apart from the predicate was easily mistaken for real simplicity. The naive hypostatization of this logical relation led to the schema of a unitary and unknowable substance supporting properties. But we now see that the subject of the proposition merely means the physical existent and that there is no justification for the assumption of the simplicity of this existent. In fact, it must be complex in its nature if the various elements of knowledge hold of it.

But a complex nature does not require something external to it to hold it together. And yet this assumption was back of the traditional interpretation of substance. Properties were thought of as disconnected entities which needed a transcendental unifier. But a particular substance which becomes the object of knowledge has its nature and inner unity. We must not project into the particular substance the atomistically conceived properties which we have formulated. To do so is to misunderstand knowledge.

Being, or physical reality, is concrete; it is all that there is; it is nature with its immense fulness. And being ${ }^{10}$ is one thing, while knowledge is another, and quite different, thing. Yet, if knowledge is knowledge and veracious, it must give us insight into reality. When we once grasp this situation, we see why properties are at once contents of knowledge and revelations of nature. Nature is such that these predicates hold of it. Things are extended, of certain shapes, massive, energy-containing, etc. But such judgments must be removed from any danger of the old substance-qualities schema of interpretation.

${ }^{10}$ Such being is not mere being and indeterminate. It is not a that apart from a what. Knowledge supervenes upon what is determinate. 
Constant Properties and Powers.-When we come to analyze our thought of physical things at the scientific level, we note that they tend to fall into divisions which may be called, respectively, constant properties and powers. Much of our knowledge of a thing consists of well-founded belief as to what the thing will do under certain conditions. These conditions are supposedly reproducible. The behavior of the physical system is a function of the nature of the particular thing and its surroundings. The properties of chemical substances are, for example, largely a statement of their reactions with other elements and compounds under fixed conditions of temperature and pressure. We should say that a body has such a nature that it does so and so under such and such conditions. These powers, or properties, are hypothetical rather than innate possessions which can be intuited in the thing by itself. They are to be connected with processes and activities. But who is bold enough to deny that the information about things, which we thus gather, is revelatory of their nature? A moment's reflection leads us to realize that our knowledge of human beingseven of ourselves-is predominantly of this sort. We judge people by what they do under trying circumstances. It is, however, obvious that such knowledge of the nature of things is not the reproduction of passive aspects. We must work ourselves free from the suggestions encouraged by the givenness of sensible appearances in perception.

Constant properties are less relative than powers. Powers are correlative to change and process. They are prospective and potential. Constant properties, on the other hand, assert information about what is present all the time. When the category of space is interpreted critically, as we have interpreted it, it may be said that powers express the time-dimension of reality, while constant properties express the spacedimension. Thus things have size, shape, position, internal organization and structure, energy-capacity, mass. There are certain classes of judgments which are always valid of physical systems and which, therefore, give an essential part of the defining concept of the physical world. A body always 
possesses mass, size and internal structure, even though it is not always active in this or that particular way.

But it must not be forgotten that powers and constant properties are ultimately inseparable in our thought of the physical world. The behavior of things throws light upon their constant nature. The color of an object is becoming a clue to its internal structure, physical and chemical. Structure and function are intimately connected.

Reflections and Suggestions. - The critical realist endeavors to make a thorough analysis of the distinction between a thing and its qualities, or properties, in the light of the actual epistemological pressure within experience. While admitting and doing justice to the realistic meanings which make the category of thinghood, he is led to break with natural realism, on the one hand, and with psychological idealism on the other. Things are not apprehended in whole or in part. Yet, if they were, the qualities of things would be discriminable aspects. And the idealist is wrong when he proclaims that things are complexes of sense-qualities. $\mathrm{He}$ is wrong, in the first place, because only a few sensations are given at any one time, so that the apprehended thing is a construction of sensations and memories; in the second place, because qualities are thought of as correlated with sensations rather than identifiable with them. Idealism does not meet the demands of experience. It is a protest against natural realism rather than a well-thought-out solution.

John Stuart Mill sought to correct Berkeley by certain amendments. The physical thing is the permanent possibility of the various types of sensations. Sensations come and go, they vary with physiological conditions and position, but the thing does not vary in the same way. Again, the uniformity of nature cannot be identified with the uniformity of our sensations, for there is not much law or order in the advent of sensations. The realistic trend is conspicuous, but the agnostic note is just as evident. What is a permanent possibility? It means either that the physical thing is a fiction 
or that sensations are caused by something self-existent. If the latter be the meaning taken, it stresses the fact that a manifold of sensations of all sorts and degrees can be correlated with this independent reality.

Let it be granted that all the sensational material which we directly apprehend is the response in our organisms to the powers of self-existent things, does it follow that we can have no knowledge about these independent realities? The idealist has been too prone to work in one direction, that is, causally from the thing, and to forget to work cognitively in the other direction and ask himself why this material, given to the organism, cannot be used as the material of knowledge about the physical world. The critical realist holds that the elements of this achieved knowledge give insight into the nature of the physical world and, in so doing present us with what we call its properties. In $r e$, attributes are the complex determinate nature of the thing. The thing is formed, is structural, is capable of various responses. The attributes are the character of the thing. In cognition, attributes are the elements of our knowledge of the thing. Locke read the attributes in cognition into nature and attached them externally to an unknowable substance. This mistake we have avoided. 


\section{CHAPTER VIII.}

\section{CHANGE, IDENTITY AND CONSERVATION.}

THE physical world is composed of relatively independ$I$ ent things which we know in terms of their properties and which are dynamically connected with each other. Thus far, we have held ourselves to the endeavor to get clear preliminary meanings for certain terms. We have sought to answer such questions as the following: What in a general way are things? And how shall we conceive their properties? We found ourselves compelled to pass from commonsense realism to critical realism or epistemological dualism. Thinghood became a category consisting of meanings divisible into two groups: predicates stressing externality and predicates descriptive of the nature of these external realities. We allowed the further questions of individuality, physical continuity and discontinuity, and identity-in other words, the more specific, sequent problems-to be inhibited for the time being, and busied ourselves with the general context of physical realism, the outline which would later need filling in.

When we assert that physical things are, we simply acknowledge that we are led unavoidably by our experience to admit known realities as real as our own organic selves. We do not, however, slur over the problem of the one and the many, nor beg the question of the intimate connections of realities in that sum total and union of things which we call nature. Reflective thought must move step by step, especially in exposition. 
Two Sets of Problems. - The category of thinghood gives off two sets of problems, according to whether stress is laid on the time or the space dimension of the physical world. If we approach things from the angle of time, we meet the question of change versus identity and conservation. If we approach from the angle of space, we are confronted with the problem of the one and the many. And yet these two types of problems are not ultimately separable any more than are space and time themselves as valid categories. It will be remembered that we concluded that reality is spatial and that this spatial reality changes. Things are differentiated spatially, and yet these differentiated things change. There is no conflict between these dimensions of reality. Both must be combined in a synthetic outlook if an adequate conception of reality is to be attained. What we shall seek to do, then, is to study things in the light of each dimension and then to unite the results. Nature will be grasped as a differentiated, stereometrical process, that is, time will become immanent in space. Individuality in space must be supplemented by identity in time.

Identity and Change.-The physical world contains both sameness and change. In perception, these two aspects are equally apparent. We recognize objects as essentially the same as they were years before. On the other hand, we can note slight differences intervening to mark the teeth of time. Familiar types of objects are, again, all around us, and their variety seems to have a limit in nature itself. Thus we are witnesses of repetition, novelty, persistence and change. The world is not a mere flux, and yet it is not static and frozen. How can these aspects be combined?

Take, again, the self. It is surely an indisputable fact that the self changes, and yet it has enough identity in spite of this change to be called and to feel itself the same self. There have been many theories with respect to this identity, to some of which we shall pay our respects. Obviously, identity is a category whose meaning we must discover if we are to apply it correctly. It may be misleading to assume 
that identity must mean this or this. We may demand too much or too little as the case may be. Let us be empirical rather than dogmatic.

The qualitative view of the world-which was an attempt at a naive empiricism-combined change and repetition by appeal to the persistence of qualities differently distributed at different times. The same matter, it was supposed, could embody distinct qualities so long as these were not contradictory. For example, red could give place to yellow, orange to green. The same succession could occur in flavors, odors, sizes and shapes. Were these not eternal essences which, in themselves changeless, gave place to each other in the physical world as they secured or lost foothold? Such was the logic of Aristotelianism.

We need not linger upon this interpretation which we have already rejected because of epistemological difficulties. So far as it is a mere description of empirical facts, it is true; but as a metaphysical theory it must be rejected. It conflicts both with the causal foundation of perception and with the correct view of properties. It is impossible to accept the scheme of qualities inhering in a substance. We must have another view of both substance and qualities.

It is a fact that we intuit a limited number of sensuous characters; and the sensuous world, which we commonly identify with the physical world, is but the interwoven complex of such characters shot through and sustained in our minds by realistic meanings until they seem to stand on their own bottom as physical and self-sufficient things. Sensuous change is, then, an alteration in the given complex by the addition or removal of some character. One color gives place to another, one shape passes either abruptly or insensibly into another. The apple grows and ripens, the log of wood decays and crumbles to pieces or burns on the hearth to become smoke and ashes. If things are only sensible things, Berkeley was right in maintaining that identity is more verbal and pragmatic than real. Is the object I see under the microscope the same object that I see with the naked eye? How can it be since its characters are different 
and it is nothing but its characters? Thus the thing dissolves into complexes of characters, and these are coming and going, shifting and recombining. The best that can be done is to form genera for these qualities and to achieve abstract nouns to denote them.

The quantitative view of the world stressed properties of a measurable sort and, by its adherence to the realistic idea of bodies, laid the foundation for a less kaleidoscopic view of things. Gradually, things were interrogated by a manipulative technique until man's knowledge of them had for its content elements of a less fitful and lawless kind than those given in sense. The burning log changes its sensuous appearance completely, but the physicist discovers that there has been a conservation of mass and energy. The two gases, hydrogen and oxygen, combine to form water. What a qualitative change in sensuous experience! And yet, research has shown that the original bodies are somehow there all the time. The weight of the water is the sum of the weights of the two gases; the gases are recoverable, etc. Bodies can be known in terms of additive properties as well as in terms of variant properties.

But we need not thresh over again the distinction between material realities and their properties. Suffice it to recall that the non-apprehensional realist affirms that we know material realities in terms of the critical ideas which arise within experience. Properties are our empirically derived modes of cognitively grappling with the physical world. We do not intuit the physical reality itself, but only data which can be employed by the mind as material for knowledge. In such employment, man learns to separate changes in the given data, due to his own motions and physiological processes, from changes which must be correlated with objective alterations. The color of a solution may vary as I move away from it, but, if those who have not changed position inform me that it has not altered, I conclude that there has been no change in the solution itself. But we have done 
justice to these distinctions in the more epistemological part of our treatise. ${ }^{1}$

Changes of Things.-Many of the problems which confront us are more dialectical than real. No confusion of points of view must be allowed to lead us astray. At the level of natural realism, things are taken to be essentially intuitable. Hence, change is simply an alteration of aspect or property, an alteration which must be accepted as an empirical fact, even though its cause cannot be assigned. A thing changes when one or more of its perceivable aspects has either disappeared or given place to new ones. Such modifications are compatible with our idea of a thing because it is the way we experience things that determines our ideas. This approach enables us to show the absurdity of the old query, How can a thing change and yet remain the same thing? It is the recognized nature of the thing to change. But it is obvious that such bafflement as remains turns on the ambiguity of the adjective "same."

Those who deny that a thing is the same after it changes in some aspect evidently think of sameness as excluding change. To say that a thing changes is, therefore, a contradiction in terms. But this situation really turns on a confusion of content with existence. Same may mean exactly similar to. If a thing is recognized although it has altered in various ways, we call it the same thing even though we would no longer say that it is the same as it was. ${ }^{2}$ There can be no doubt, then, that common-sense realism thinks of things as alterable bodies. A thing may remain the same thing while it is no longer the same, to put our conclusion in a paradoxical form. The first sameness is to be connected with the outlook of natural realism and with those meanings which we have frequently stressed. So long as these co-real things are not annihilated, they have a continuity of existence which change does not destroy. In part there is a reflection of the self into the not-self in this feeling

${ }^{1}$ See Critical Realism, Chs. 1 and 3; and The Essentials of Phillosophy, Ch. 3.

${ }^{2}$ Cf. Hume, Treatise, Selby-Bigge's edition, pp. 256ff. 
of identity. Just as we can change while still feeling ourselves to be the same, so can the things which surround us. And it must be remembered that spatial solidity and dynamic capacity are fundamental in our thought of physical things. While there is a continuity in these characters of the thing similar to the continuity in the sensible character of our bodies, identity will not be withdrawn. What the exact nature of this identity is remains to be determined. The second sameness is the result of comparison. Just as we can compare two bodies which are both present and declare that they are as like as two peas, so we can compare the same object as seen at different times. Often we find that the contentual aspects of the object have not changed. We make what we regard as a correct reference to existent realities and discover no change in the selected existence. We refer to the same object-is there not the idea of a selection from independent realities?-and find that it has not changed. The context of these meanings does not seem at all recondite. It is that of the essentially pluralistic realism of common sense and of science. Things are spatially delimited, recoverable objects. But such objects are admittedly only relatively permanent. There is a wear and tear upon them which gradually dissolves them. How few things endure. And yet we who know them feel that they are the same up almost to the moment of their disappearance. There is a continuity in their successive appearances which enables us to trace the thing from its fresh newness to its disintegration.

The Fluctuating Boundaries of Thinghood.-Having given this empirical description of identity and change, let us try to meet the age-old problems about identity and difference. We shall interpret our results in terms of critical realism. At the end of the chapter, we shall correlate the principles we have found valid for physical things with the principles which stand out for personal identity.

There are three pretty distinct classes of things. These are organisms, artifacts like chairs and dishes, and huge 
objects like mountains. In the first two cases, the boundaries of the thing stand out clearly. In the third type, we must not take the delimitation from the general bosom of nature too seriously. The objective marks which guide our delimitation are, however, there. In general, things stand out from their surroundings by means of an internal structure and indicated boundaries. Organisms move about and are thus actually separable from their surroundings. Artificial things can be moved and the same distinction is obtained. We are not arguing for discontinuity but for distinctness and differentiation.

I understand that Bergson admits that organisms are things in their own right, but holds that the other types are made by a practical human selection. In so far as this suggests that demarcations are arbitrary and are not guided by objective marks it is misleading. But, assuredly, organisms are highly developed individuals in a way that no other gross things are. This is the problem of evolution and life. My chief objection to Bergson's doctrine is his apparent neglect of spatial structure in favor of flux or mobility. Time is put in flat opposition to space whereas I regard them, not as antagonistic, but as supplementary.

How can a physical thing change and remain the same thing? Are there definite bounds which it cannot transgress without ceasing to be the thing it once was? I take it as pretty obvious that our empirical approach has enabled us to see that these bounds are quite pragmatic and human. As we examine the varying standards we shall realize that identity is a preliminary, largely subjective category.

At any one time, one thing is distinguished from other things by spatial position as well as by characteristic possession of structure and qualities. We must, I think, admit the primacy of position as a means of distinguishing one thing from others. This is the spatial angle of thinghood. We must know what thing we are thinking of in contrast to others before we can raise the question of its identity through change. Position is a mark which at any one time can be employed as a principle of distinction when all other 
marks fail. It gives us the difference of what were otherwise indiscernibles, of things as like as two peas.

Again, a thing is a solid with some internal structure and external outline or form. We must be able to act toward it as a whole. It must have a cohesive unity so that it can be handled as a practical unit. I think that these are demands which objects of perception must fulfil before they are called things.

We have been speaking of physical things, for these have a sort of spatial demarcation and independence. There are also purposive demarcations made by human beings, such as a country or a township. Again, there are things which are products of human capacity for association, as political parties, religious sects, etc. The principles applicable to these objects are not essentially different from the ones we shall study in connection with strictly physical things. Moreover, it may be remarked in passing that these social objects are natural products of those peculiar physical things called human beings. The integrative relations involved are mental rather than dynamic. But more of that anon.

Let us take an organic thing-a tree, for instance. Next let us introduce the time dimension. No matter how large a tree grows, we regard it as the same tree because we know that it is the nature of a tree to grow. There is spatial position; the known existent has not been replaced by another in any abrupt fashion. The various stages of the tree are continuous. It can be traced from a seedling to its present towering state. We are tolerant of change in this case. It is the same thing so long as there is continuity and a certain measure of identity in its appearance. If the seedling is an oak, the old tree must have oak leaves. Thus even between the temporal extremes we expect some identity, while, as the temporal difference decreases, we expect the amount of identity to increase.

Suppose the tree to fall. We still regard it as the same object because the change has not been great enough to justify another classification. But, as it decays, a time 
comes when we feel that it is a tree no longer. Our concept no longer applies to the object we now perceive. The concept contains those marks which must be present if sameness is to be affirmed.

Perhaps our problem can be best brought out by contrasting a hypothetically changeless thing with a changing thing. Both will have in common an independence of other things. When I assert that I am handling the same object that I did before, I have this type of separation in mind. Usually the space dimension of reality is relevant to this distinction. Accordingly the changeless thing is independent of other things and distinguishable from them. It is always just itself. The knowledge applicable to it ane time is always applicable to it. There is by hypothesis no question of identity in spite of change. But a thing which changes has a history. There must be connection between its various states if they are to be states of one thing. Our problem is to determine the nature of this connection.

The facile answer of the past was to regard these various temporal states as possessed somehow by something above time and change. It was the assertion of something changeless through change and yet synthetic of changes. But is this answer really a valid answer? How could this changeless substance possess the various states and give them unity? I do not see that the solution solves, and I believe that this feeling is to-day shared by the majority of thinkers.

What is needed is a sane approach to the problem. First, it must be granted that a thing can be allowed to change and be the same thing. Otherwise, there could be no search for continuity. Of course, if a thing changes, it is not the same in character in all points. But, second, if this view is allowed. the identity must be one of reference. As realists, we believe that there is an existent which persists, though not unchanged, through time. Hence, at various intervals in time we can make a reference to this existent and assign it different characters. That which persists is the physical existent and not an unchangeable substance. We conceive the physical existent to be capable of change. 
But I will be told that this is no answer. How can the physical existent be the subject of change? Does it not stretch out in time and lose its identity? These changes must be states of one thing, and so this thing must be above time.

To those who have followed my analysis of time the answer is comparatively easy. Real time is change in the particular substance or thing. Hence, the particular thing does not combine the past changes with its present condition. There are in physical reality, itself, no states of one thing, somehow coexistent though temporally separated. The physical thing is the resultant of its history, but it does not attempt to combine its past, as past, with its present. That is man's necessary view-point and manner of approach. In short, man synthesizes by a common reference while nature synthesizes by growth. Man's temporal distinctions are valid for knowledge about nature, but they must not naively be reified in nature. The past does not exist for nature, yet nature was as that past tells us. Things have a history, but they are products of that history, not literal possessors of it.

What I am now going to point out is an obvious deduction from my treatment of the category of time. Since the physical existent changes but is not annihilated, it is permanent. It carries its own continuity by being itself. This fact is the justification of the common-sense qualification of things as permanent. It is the thing, itself, which is permanent, and not a hypothetical substance threading states in some mysterious way and giving them unity. There is no question for the thing, itself, of its identity. It is for us who have knowledge about it that the question arises.

The empirical question thus becomes that of the conditions of an identical reference for various experiences of the thing; or, to put it a little more carefully, how long do we continue to call it the same thing? The answer is plain: So long as there is enough contentual identity to satisfy us. And we should note that we might deny identity if we considered temporal extremes, while we would not if we con- 
sidered phases nearer together. The thing is no longer the sort of thing it was, yet we can trace it from stage to stage. It is many things as well as one thing. Many concepts apply to it, and yet there is continuity. The same person is a baby, a youth, an adult and an old man. $\mathrm{He}$ is all of these things if he is one and the same person, and yet at any time he is only one of them. Man unites the no longer existent state of a thing with its present phase and so creates his own problem. But his assertion of continuity is valid. The history of a thing is genuine knowledge about the thing, even though the thing is the product of its past and contains this history in no other way.

A thing which changes is no longer the same. When we call it the same thing we do so for the sake of classification. It has not changed enough to fall into another of our very inclusive classes which admit differences so long as there are common features. It is only after it has changed a great deal that we say that it is no longer the same (sort of) thing.

To summarize: ontologically, or in nature, the physical existent changes, yet so long as it holds together as a particular substance it is the same. In our human experience, we recognize this permanence of the particular substance and try so to combine its changes as to refer them to one thing. We mean that these states are the successive states of the permanent, though changing, existent. And permanence means continuance in existence and not changelessness. The degree a thing may be allowed to change with the same classification varies and is more or less arbitrary. A particular substance may be destroyed quickly, as when a block of wood is burned, or it may be changed very gradually.

Let us apply this interpretation to the famous case of the stockings darned until no part of the original material remains. It should be noted, first of all, that we have to do with a manufactured thing in which form and material are clearly distinguishable. If the form is uppermost in our minds, we may be inclined to call them the same stockings; 
if the material, no. And yet, even here, if we consider intermediate phases and not the two extremes, we may call them the same. Again, if our interest is purely personal, that of use, we may call them the same after many changes. But if it is economic, we may refuse them identity after the slightest change. The standards are human and pragmatic.

Things as Physical Systems. - Thus far in our examination of things we have kept pretty closely to the pluralistic realism of common sense. Let us pass next to the outlook of science. The chief differences are, I presume, that science agrees with critical realism that things are not intuited and are composite, and that change is more constant than common sense supposes.

Science achieves systematic knowledge of inorganic things by studying their structure and breaking them down into their components. The mineralogist, for example, analyzes rocks into distinct minerals whose chemical formulas and genetic conditions he seeks to know. Such minerals are called chemical substances, and their formation and intimate union can be studied. In short, an inorganic thing becomes a material body which persists. Abrasion or chemical disintegration, alone, destroys this type of thing. To the scientist, external shape is a very superficial character of such a body, important as it may be to the artist. It is the same piece of marble whether in the rough or chiseled into a statue. And rightly approached, there is no conflict between scientist and artist. The scientist would not deny the new shape given to the material body; as scientist, he would not be interested in it. It is only because this kind of shape awakens an esthetic reverberation in the spectator that it is so much stressed in the artist's idea of the material body. To mar it would be to change the thing abruptly, to make it lose its identity.

Much of scientific knowledge is knowledge of classes of substances and of the most general properties of bodies rather than knowledge of this or that particular body. The boundaries of common sense are relatively unimportant for 
science, for they concern accidental distributions and exaggerate independence. But this general knowledge can be modified into specific knowledge of any one particular thing through special investigation. Such a thing is regarded as the function of a more or less temporary equilibrium of favoring energies.

Physical changes concern the distribution of matter and energy. Changes of physical state and change of position of the whole or of its parts are studied. Erosions, torsions, liquefaction, etc., have their laws.

Chemical processes are clear instances of more internal changes. What takes place? Seemingly new linkages and combinations between elementary substances in accordance with the favoring influence of temperature and pressure. The biologist must consider these processes as foundations for organic life. The environment - to use a cleverly adapted expression - must be fit. Chemical processes are cases of changing equilibria and of changing internal relations. Synthetic bodies arise with new properties. The chemist studies behavior and structure. $\mathrm{He}$ is unable to intuit objective activities, that is, he is unable to apprehend the very being of the physical process, but he is able to gain information of the steps, their conditions and their results. The information illumines reality and presents its structure and changes in another medium.

A physical system is, then, some portion of the material world taken for study because of its relative isolation. Preferably this is done in the laboratory under conditions of control. The scientist wishes to discover laws of change, constituents, structure, energy-content, conditions of equilibrium. A single thing is seldom of importance to the scientist. He deals in the general. Could the scientist reach single molecules, he would regard them as systems which he could study to discover such features as those enumerated above.

Change for Science. - A double knowledge is the condition of the judgment of change. We compare a physical 
system as known at one time with the same system as known at another time. The identity is in the identity of reference; the change is in the difference of content. Thus science sets change in the framework of scientific time. Knowledge of change is not the same as change itself. Yet if our knowledge is true, the judgment of change must correspond to what occurs in nature itself. We are again confronted with the difference between knowledge and being.

Various types of change in nature can be specified. Thus most changes involve motion, increase or decrease of tension, adjustment, fusion, etc. A change of physical state is known as a change in the position of the molecules in relation to each other. A solid differs in this way from a liquid, and a liquid from a gas. A chemical change involves active processes of internal adjustment, an adjustment reflected in energy-measurement, structure, properties, etc. All this is delicate knowledge about the change, its methods, laws and results. But the process of change is in the system itself. Real change is dynamic while knowledge can never be dynamic. In a very true sense, science is a reflection of nature rather than a reproduction of nature. In every field, we can achieve true description of what takes place and descriptions of preceding conditions, but we must not take such descriptions as literal participations in the drive, tension and urgency of being. It was because he expected science to lay bare the very springs of activity in nature that Berkeley turned from it in disgust to the will. He demanded from knowledge more than knowledge can give.

And it seems that Bergson is committing a similar mistake. Surely modern science does not deny mobility. It is true that an element of Eleaticism lingers here and there; but increased knowledge has been the chief means to its overthrow. Bergson seems to admit as much when he writes: "Modern mathematics is precisely an effort to substitute the being made for the ready made, to follow the generation of magnitudes, to grasp motion no longer from without and in its displayed result, but from within and in 
its tendency to change; in short, to adopt the mobile continuity of things." 3 I would suggest the following criticisms of Bergson: (1) He asks that concepts be fluid. Does this mean that a concept of change must be, itself, a case of change? Or does it mean that we must make our concepts more and more correspondent to the data whose essence they give? (2) $\mathrm{He}$ assumes that we must be capable of penetrating the actual process in nature. "There is a reality that is external and yet given immediately to the mind." The epistemological dualist would deny the second part of this thesis. (3) He assumes that we should interpret all other realities upon the model of the self. "The consciousness we have of our own self in its continual flux introduces us to the interior of a reality, on the model of which we must represent other realities." The evolutionary naturalist admits the value of the analogy but would use it very critically. It supplements knowledge and does not replace it. But our aim does not permit a study of Bergson's attack upon concepts and his romantic mistrust of analysis.

Can We Think Change Without Contradiction?-The position I have been defending is clearly halfway between Eleaticism and the structureless flux. Against Bergson I would defend a conceptual formulation of change, holding that it harmonizes with our experience of change. Against the Eleatics, ancient and modern, I would maintain that there is no self-contradiction in the thought of change.

Let us take an instance of change. At the level of science, change is the reference of new elements of knowledge to the same system. A system has at one moment the temperature of $50^{\circ}$ centrigrade, at another moment that of $60^{\circ}$. It is the same physical system in the two cases, thought of as real, independent and spatially localizable. Yet these conflicting predicates are assigned to it as knowledge of it. We escape the contradiction by appeal to the time-order. It is the very nature of physical systems to change. And sensuous changes and numerically graded changes in our

3 Bergson, An Introduction to Metaphysics, p. 70. 
thought of a material system are correlated with those characteristic modes of real change indicated above. The system is a process in unstable equilibrium. Objective change may be defined as an active process in being which is known in terms of a succession of specific characters put in the time order and referable to the one system. If we are asked what changes, we must answer, "Reality itself in this particular part." Material reality is rightly conceivable in terms of both space and time.

But change must not be conceived as absolute origination and annihilation. It is reality that changes. It is this relativity of change to something which changes that gives significance to the numerical indentity demanded. This is so in the case of the self as well. We shall hold that the stream of consciousness is a case of change in the organism which is the ultimate self. We shall maintain that this which changes is yet permanent. It is permanent in the sense that it is that which changes, not in the sense that it is alien to change. The subject of change is the object that changes. Reality is the very seat, source and agent of change.

In change we are concerned with particular substances, that is, specific material systems. Evolution seems to mean that the higher is built on the lower or is an integration of the lower. Thus there is a natural order of substances. It seems also to be a rule that the more complex substance is more mobile and, at the same time, less stable than the more elementary substances. Living substances are peculiarly interesting cases of mobile equilibrium. In all this there is no question of the annihilation of physical being but only of special integrations with their peculiar properties.

The modern idea of conservation involves this distinction. It is not that specific substances are conserved. We all know that to be untrue. Science has discovered invariant features in physical systems. The conservation of mass and of energy are principles of constancy in nature. Recent investigations seem to show that mass is conserved only under certain general conditions which are pretty typical of the present stage of evolution. Of course, we have here, also, 
the distinction between mechanical mass and electrical mass. But no matter how much physical systems change in structure and in the relations of their parts, there is good reason to believe that this change is never destructive of that which changes. Empirical substances alter and disintegrate, yet there is conservation of the elements. Scientists are just beginning to realize how far down this process can go. Is there a limit to it? It seems to me exceedingly probable. But facts will decide the validity of any quantum theory.

Evolution implies novelty. Conservation implies constancy. We have argued that these two demands do not conflict when rightly applied. When we come to reflect deeply, we realize that there is no good reason why change should involve loss or gain of capacity to do work. Why should activity be thought to cause a waste of the power to act? Any tendency to think thus expresses an anthropomorphic prejudice. The individual who uses his store of energy too carelessly may find that his particular stock has been depleted, and he may leap to the conclusion that this energy has been lost, whereas it has simply been lost to him. Frankly, I can see no logical connection between activity and either destruction or conservation. It is an empirical question. As I see the situation, persistence is a trait, not of particular substances, but of that out of which these are formed and to which they return. As a property, it applies to all systems. We shall have more to say of this distinction in a later chapter. ${ }^{4}$

Changes in sensuous characters are, then, signs and clues to those processes in nature of which they are the surrogates in consciousness. Since sensible things are but the organized complex of characters to which realistic meanings are attached, naive realism is easily induced to believe that change is a literal coming and going of aspects of things. The critical realist, on the contrary, having relinquished any hope of an intuition of the physical world, realizes that he has specific knowledge of change in terms of position, order, structure, behavior and novelty of properties, but that the

${ }^{4}$ Chapter XI. 
inner life, as it were, of these adjustments and creative fusions in a measure escape him. It is maintained by many idealists that to rob the physical world of the sensuous is to make it arid. I do not so hold. The world becomes nonsensuous but remains intelligible. It is a tremendous expanse of heaving, self-organizing, self-differentiating being whose varying form we can grasp.

The One and the Many.-The problem of "the One and the Many" has been in many ways the most distinguished metaphysical problem. It had its origin in Greek philosophy and has intermittently appeared ever since. In our own day, many thinkers have honored it with their constant interest. As a problem it naturally comes up for consideration in this chapter.

The phase of the problem which we shall examine most carefully at this point is the status of concepts. Empiricists have often been extreme nominalists and held that only percepts are real. Rationalists, on the other hand, have not infrequently maintained that the field of sense is unreal as compared with the realm of ideas. What does the epistemological dualist of to-day hold?

I think that it is obvious that he denies the validity of these old contrasts. Sense-data and propositions are related as foundation to superstructure. They are not rivals in any sense for each has its locus and peculiar function. But the empiricist is wrong if he maintains that in knowledge concepts must necessarily terminate upon sense-data. All knowledge of the physical world is directed toward extramental objects. It is only in verification that concepts are in touch with sense-data. Both concepts and sense-data are in the epistemological sense subjective. Moreover, concepts are subjective creations and not changeless entities of a Platonic sort. They are always in some measure responsible to sensedata. Are not the old contrasts of nominalistic empiricism and rationalistic realism outworn?

Let us consider the logical context of the problem of the one and the many. A class-concept is one and yet it covers 
the membership of the class. Do we have here a vicious problem? I must confess that I cannot see that there is the semblance of a difficulty. What is a class? It is a logical, not a real, collection of things called members. We assume that we can distinguish objects from one another and yet note that certain of these objects can be taken together in our mind as possessing certain marks in common. Leaving to one side the genetic question, we find that the idea of a class analyzes into the two inseparable factors: denotation and connotation, the membership and the marks. Any classterm calls up these two aspects; there must be marks and there must be objects which have these marks.

Now it is obvious that the epistemological dualist must hold that the objects which are taken as the members of a class are ordinarily extramental; the idea, or that way of taking them, is mental, and the marks are properties which are cases of knowledge of the objects. Classifying things is, like comparing them, a mental operation. It rests upon knowledge and is, like knowledge, objective in its reference. Classes do not exist in nature but that upon which we found classes does. It is clear that to the modern critical realist the very setting of traditional contrasts is no longer existent.

Plato held that sensible things are unreal in the main. What reality they possess is a reflection of ideal types which are changeless and intuited by the reason. Every ideal type has its several copies. And the ideal types are arranged in a hierarchy with the Good at its summit. This ethical metaphysics reifies human concepts. It does not realize the proper and relevant place of ethical ideas. Surely these have significance only in human affairs as changing ideals of the good life. It seems to me that evolutionism and pragmatism have given the death blow to a Platonic metaphysics. Whether pragmatism has always done the justice it could and should have done to concepts is another question.

It has frequently been suggested that the modern thinker must interpret Plato's types as laws. But what are laws? They are not entities which can be reified. They are human 
formulations of relations between the properties of a system in change. They give knowledge about physical systems and are products of careful investigation. Laws are instances not of being but of knowledge. Laws do not govern nature. Nature governs itself according to its nature. The very idea of governance has no strict relevance here but only in society.

The Meaning of Individuality. - The categories of change and identity suggest a discussion of individuality. We have concerned ourselves with the changes of physical systems and have looked upon the majority of things as only partially delimited portions of a larger and restless whole. We have tried to be empirical and to guard against the extremes of flux and permanence, continuity and discontinuity. But individuality implies a more distinct separation than the gross inorganic things of the human environment possess. There is in the idea the element of relative independence and self-sufficiency. The individual appeals to us as a center of activity and of origination.

Idealists have had much difficulty with this category, some maintaining that only the Absolute can be regarded as a true individual, while the more empirically-minded have argued that individuality can be the possession of parts as well as of wholes. In a later chapter we shall discuss this difference as regards its logical aspect. ${ }^{5}$ At present we wish to develop the standpoint of the evolutionary naturalist. But, in passing, it should be noted that idealists speak of subjects or selves rather than of things. For the realist, subjects or selves are kinds of things and must somehow be absorbed in this larger category.

The older naturalism did not do justice to the organic individual and assuredly not to the human individual. Therein lay its weakness and its limitation. It leveled down because it did not appreciate biology and psychology. It was a product of physics and chemistry alone. Much of the fear of naturalism, of its fatalism and bleakness, was due

5 Chapter X. 
to this prime disregard of human characteristics. In a word, it was unempirical. The evolutionary naturalist tries to understand the actual world in all its complexity and differentiation.

It seems to me that the evolutionary realist can, as usual, take the current use of the category and work up to a more critical employment of it. In the section entitled "The Fluctuating Boundaries of Things," we saw that thinghood was a rough, general category. And organisms are the kind of things which we shall most carefully study. Their unity is clearly of a higher and more mobile sort than is the case with solid inorganic things. They constitute a peculiar kind of things. There is a unitary, internal organization as well as a cohesion of parts and the possession of boundaries.

Empirically, we find no justification for Herbartian or for Leibnizian individuality. There is no evidence for discontinuous monads or for absolutely simple substances. Actual individuality does not conflict with relations more or less modifying. But it should be noted that the higher organisms do not combine into new individuals in the way that atoms and molecules do. Human beings enter into what we call social relations, and these social relations modify them. But we have here a nezv method of organization made possible by the properties of human beings, such as the capacity for communication. The relation between citizen and society is physically conditioned, but is neither a chemical nor a biological type of relation. In other words, relations are relevant to and expressive of the character of the terms. It is the recognition that both terms and relations change with evolution that distinguishes modern evolutionary naturalism from the mechanical type.

We may say, then, that organisms have more in common with atoms and molecules and chemical substances than with inorganic masses whose boundaries are accidental and fixed, as it were, from the outside rather than from the inside. The difference between this first valid type of thing as an individual and an inorganic mass is empirically clear. Our knowledge of them enables us to differentiate them. 
There are those who, being mystically inclined, suggest large individuals whose outlines are not perceivable by us; demi-gods, powers and principalities, as it were, whose titanic loves and hates surround us but to which we are as blind as are the unicellular organisms to our feverish activities. But where are the data upon which to found such imaginary creatures? The Fechnerian panpsychist can envisage souls of all dimensions, but the critical realist, who takes sense-data and the categories which grow therefrom seriously, must relinquish this flirtation with mythology. It is man's fate that he, alone, on the face of this broadbosomed earth has reached self-consciousness and the knowledge of good and evil. Insignificant dimensionally, he yet towers above aught else in capacity. This is at once the terror and the sublimity of his situation.

The difference between the higher and lower levels of individuality can be best brought out by studying the subordinate category of uniqueness. Uniqueness is more than numerical difference although it involves that. Two things may be individuals in a numerical sense and yet not possess uniqueness. Even human beings seem to merge into a dull mass of indistinguishable individuals. We think of them as types, so little does any unique feature come to the front. But, of course, this is an exaggeration due to our lack of knowledge and to the relative unimportance of such differences as exist. To the scientist, I presume, there is a specificity or uniqueness about every organism. ${ }^{6}$

What we desire in individuality is uniqueness and not mere numerical separateness. A unique individual is more than a member of a class with common attributes. $\mathrm{He}$ is that and yet always more than that. He is sui generis; and yet his uniqueness rises upon, and does not conflict with; his membership. He has the common properties, but they are common only through a disregard of their special flavoring, through an emphasis upon their identity rather than their

- Since writing this chapter I have become acquainted with the work of Ritter on the organismal theory of life. His Unity of the Organism is an extremely suggestive piece of work. 
difference. The more we know about human individuals, the more apt are we to find this touch of uniqueness. But there are degrees even here. The great figures of history stand out clearly from their contemporaries through a heightening of traits. We have no difficulty in distinguishing Aristotle, Cæsar, Goethe, Napoleon and Lincoln from other men.

Our query is this, How far down in the scale of organization does such specificity descend? The answer cannot be given in an a priori fashion. A critical empiricism must lead us. If capacities are functions of complex integrations, we should expect the possibilities of novel permutations to increase with the number of elements and sub-individuals integrated. Conversely, with the decrease of complexity, the chance of variation would also decrease. Even if the relative units were identical, this principle would hold. Creative synthesis would produce all sorts of new properties which would find varying expression in different situations. Only to the extent that this is so does the history of an individual count in its comprehension. Now human beings are notoriously functions of their history. This is true both phylogenetically and ontogenetically.

Does this principle hold for atoms, molecules and chemical substances? Only if these units are growths with specific properties. To the extent that they are growths you may have specificity. But the history of elementary units is undoubtedly brief. Yet, even so, the individuals may differ slightly from one another. I believe that chemists and physicists are discovering that there are distinguishable kinds of lead, chlorine, etc. Now at this lowest level the possibilities of variation are very limited. Still it cannot be proved that all units are alike as though turned out in some cosmic factory by some standardized machine. The approach of physical science to these elementary substances is as yet statistical. So far as I can judge, the range of specificity at this level cannot be determined. It is probably so small as to be practically negligible. Assuredly, I would not connect individuality with indeterminism. 
The being of an organism is a becoming. At any one time, the organism is the resultant of its history. It is for this reason that the category of time is so fundamental for human beings and for society. Memory, habits, character, trained abilities are growths due to functional adjustments which we can think of as spread out in time. Apart from these slowly acquired possessions, the behavior of individual men and women is inconceivable. The actions studied by mechanics and physics do not involve time as a growth but only time as a measurable lapse. The reason for this difference is, I presume, the fact that the types of behavior stressed in mechanics have no apparent history. It is within this apparently ready-made world that organic evolution arises. Probably the advances of physics will make the contrast less sharp, yet it will retain a relative force. Mechanics does not concern itself with individuals and their life-history.

Self-Identity and Change.-We have thus far treated what may be called objective identity in relation to change. Particular substances change, though in varying degrees. Organisms develop in a continuous way. They change and yet are rightly called the same. In our knowledge about them, there is a large measure of identity from time to time. This is added to the fact that they can be traced temporally back to specific beginnings.

But this identity is one of forms, organization, capacities, and is, besides, inclusive of change. I have about the same capacities that I had ten years ago, yet there have been changes. What the normal personality possesses is a sort of cumulative continuity in its expression. And it seems to be the very nature of the organism that this relative identity of form and capacity does not demand the presence of numerically the same elementary substances. Substitutions are continually being made. The process is one of mobile equilibrium. This does not mean that form is independent of elementary substances but that it is independent of any particular examples of elementary substances. One 
chemical molecule is as good as another for the needs of the organism.

But we humans are able to approach the problem of identity from another angle than that of external knowledge. There is the "me" or the self along with other selves as object of knowledge. There is also the "I" or subject-self which is experienced rather than known. The self as object is identical through change much as other things are. We can trace this object through the lapse of time and find that there are elements of identity in our knowledge of it. There is never any complete break in the continuity and, even when a man is the wreck of his former self, there is yet some recognizable element such as the outline of the face, some characteristic liking, some trick of behavior. But in the case of the "I" the man is on the inside as it were. He feels his identity as well as knows it. And in this feeling there is a tang and familiarity which is basic. Our problem is, What are the factors in this sense of identity?

First of all, it is clear that it does not consist in some one permanent element of a changeless sort. Hume, I believe, drove this lesson home to the Western mind. Some hold that Gautama had grasped it ages before in his denial of a soul. The problem formulates itself thus: There is an empirical sense of identity or sameness; in what does it consist, and how is it compatible with the ceaseless coming and going of the contents of the stream of consciousness? We are reality only from moment to moment and only in our waking life so far as the " $I$ " is concerned; and yet we experience ourselves as in large measure identical with the self of the past and therefore as the same person.

Since I have discussed the question in some detail elsewhere, ${ }^{7}$ I shall note in this place only the principles involved. These are, first, the recognized sameness of the self does not preclude difference and newness; second, there must be a recurrence of elements which are recognized as the same. This recognition may not be more overt than a feeling of

${ }^{7}$ Critical Realism, pp. $94 \mathrm{f}$. 
familiarity. In short, there must be contentual sameness along with difference. The question now takes the following form: How can contentual sameness be reconciled with numerical difference? Can I have literally the same idea to-day that I had yesterday? The answer is, "yes and no." Yes, so far as content is concerned or, to be extremely exact, identical in many points and recognized to be identical; no, so far as existence is in question. Clearly, I do have in one sense the very same ideas, sensations, aims and situations to-day that I have had off and on for weeks. These elements are recognizable and familiar. The organic feeling of self is based upon this massive recurrence. Continuity of purpose is, likewise, founded upon it.

The solution of this mystery lies in the insight that contentual or logical identity, whether overt or felt, has nothing to do with existence. Ordinarily, the question of existence is not raised. We live and move in contents qualified as novel or old and familiar. The recognized recurrence is an - experience, and it antedates the highly reflective question of numerical existence of states of consciousness. I presume that this is what Bergson has in mind when he speaks of the intuition of the unity and identity of the self. Bergson is an excellent descriptive psychologist who tells us what we experience, but he is not so good a logician. Perhaps this is because he misunderstands the function of analysis and seems to identify it with a literal dissection rather than with a knowledge which does not claim to be the thing known. Analysis illumines, it does not alter. To decide after due reflection that the self through time consists of an interwoven and overlapping flow of elements fused temporarily and coexistentially in characteristic ways, is not to change the actual experience but to know it.

We speak of similarity when we are reflectively concerned with two or more objects. Such objects may be physical things, minds, or mental contents thought of as specific events. As objects they must be numerable. In order to be objects there must be a difference in space or 
time or both to differentiate them as existents. Objects can be only similar, not identical. Contents can be identical as contents. In other words, identity is a category which is used in two different, though related, senses: (1) as applied to objects, (2) as applied to characters. Thus self-identity through change involves distinction from other existents and the continuation in being in spite of change. It is this kind of identity which we have been analyzing in this chapter. Logical identity, on the other hand, disregards existence and stresses empirical character. That is why we experience ourselves at various moments as having the same idea and why we speak of different people as having the same idea.

The form of logical identity which plays the important part in the sense of self-identity is that of familiarity. It is an experienced identity rather than a product of a judgment of comparison. Back of it, there must be something of a nascent revival of past contents, a revival which is a recurrence of content and not of existence. The point is that recurrence of content is able to perform the same function that the past existent, if reborn, could perform. Thus empirical sameness of the self is quite compatible with the ceaseless coming and going of the contents of the stream of consciousness.

Since Locke's time it has generally been recognized that an identity of soul-substance or of the brain would be no pleasing substitute for felt identity within consciousness. Let this be admitted once for all. Yet it does not follow that consciousness is self-sufficient and exists $a$ se. It may still be that the cumulative growth of the brain, its structural, functional and fundamental identity, is the condition of self-identity within consciousness. Time as a growth rather than time as a mere measurable lapse-the two do not conflict though the first involves deeper insight-is the important interpretation of the brain-mind. And it is this character of the brain which finds its translation in the cumulative deepening of consciousness. 
We may conclude, then, by pointing out that the objective meaning and standards of identity as applied to things are harmonizable with felt self-identity. If the brain achieves a certain set as a consequence of its functioning, it is not surprising that identical contents arise again and again into consciousness. But the ultimate and inclusive ego is the organism with its inherited instincts, trained character and capacities-a very complex thing. 


\section{CHAPTER IX.}

\section{QUANTITIES AND QUALITIES.}

T $\mathrm{N}$ many ways, the most important struggle in the history 1 of science was the struggle between the advocates of the quantitative view of the world and the advocates of the qualitative view of the world. And, contrary to the general opinion, this conflict is not entirely a thing of the past. During the Middle Ages, the strict Aristotelian theory of change dominated thought and found its expression in such experiments as were performed. Then came the mechanical interpretation of things and processes and the attempt to treat qualities as essentially subjective. In its classical form, the mechanical theory of nature postulated the hidden, and only inferred, notion of small particles as the ultimate cause of all changes. All change in the physical domain is the motion of substantial entities which remain otherwise unchanged. Such was the Eleatic form of atomism which roughly attacked the Aristotelian recognition of empirical qualities.

It will be our purpose to examine this early conflict and to point out why mechanical atomism won. We shall then attempt to show why mechanical atomism has since been vigorously attacked as concealing a faulty metaphysics and why a more empirical outlook, different from both Aristotelianism and mechanical atomism, has of late years won its way. Finally, we shall endeavor to indicate that science is an orderly description of the world in terms of knowledge. In short, we shall in this chapter seek to demonstrate that 
the development of science has quite unconsciously been in the direction of critical realism as against the naive realism of Aristotelianism and the rationalistic realism of Democritus and Descartes. The critical realist does not believe in an abstract monism of motion, ${ }^{1}$ nor does he tend to hypostatize concepts such as mass, force and energy. These are for him clearly terms of knowledge and not entities.

The Qualitative View of the World.-It is well known that the view of the physical world held during the Middle Ages was qualitative and naive. Alchemy, for example, rested upon the assumption that qualities are easily discriminable objective characters or essences which can be combined by manipulation in various ways to constitute recognizable empirical substances. The zealous searcher after the secret of the transmutation of the baser metals into gold hoped to find some method by which to bring the qualities of gold together. The philosophical theory at the base of alchemy was Aristotelian.

The qualitative view of the world believed that it could explain the particular qualities of things by a manipulation of certain fundamental, or principal, properties. A distinguished German chemist describes the Aristotelian outlook as follows: "Aristotle, who possessed an intuitive knowledge of great scope, pointed out that the most general properties of things ought to be regarded as their principles or elements. He remarked that it is by their properties that we know things and that it is by them that we differentiate things from one another. He sought accordingly the properties that are common to all things and believed that he had found them in the warm, the cold, the dry and the wet. Cold and wet gives water; cold and dry gives earth; wet and hot gives air; dry and hot gives fire." 2 Now these are not elements in our modern sense. They are not bodies from which other bodies can be formed. Rather are they

1 This is Morris Cohen's expression. See his excellent article entitled "Mechanism and Causality in Physics" in the Journal of Philosophy, Vol. 15.

${ }^{2}$ Ostwald, L'evolution d'une science-la chimie, p. 5. 
determinate and fundamental properties or conditions. The so-called four elements-water, earth, air, fire-were only representatives of these properties in their simplest combinations. The problem was, How could the immense variety of nature be explained by different proportions of these properties? The Arabs found the four Aristotelian elements insufficient. Hence they added mercury to symbolize the metals and sulphur for combustibility, etc.

Theoretically, there was nothing impossible in this qualitative view. But the empirical fact remains that it did not lead to the discovery of clear chemical and physical laws. Probably the philosophical idea at the basis was misleading, viz., that the underlying stuff, or substance, was indifferent to the properties or forms it received. Such a schema suggested stiff exchanges rather than processes. It is hard to see how dynamic ideas could develop in such a context.

The Quantitative View of the World.-The other path of theorizing and investigation is commonly called the quantitative view. Yet, as we shall see, this expression is only partially indicative of the outlook. The fundamental postulate was the acceptance of bodies which could in some degree be measured. It is not the quantities which are real but the bodies.

The atomic view of nature goes back to the teachings of Democritus. Vigorous as the movement was, it was for a long time overshadowed by the Aristotelian interpretation of nature. Perhaps the backwardness of mathematics and the lack of scientific technique account for the stationary condition of the atomic theory. The alliance of Aristotelianism with theology also had something to do with the situation. Be that as it may, the atomic outlook remained only a vague, general scheme until the seventeenth century.

With the rise of modern science and the accompanying increase of knowledge the atomic idea came to the front. The information acquired led to the belief that it would be necessary to seek in the bodies themselves those elements on which the properties of the bodies depend. It is thus 
that the concept of an element evolved more and more from an abstract property to concrete matter. Robert Boyle (162791) wrote as follows: "It is not right to regard the elements as properties but as bodies, and the elements are the bodies which cannot be decomposed and which by their combinations give the other bodies." It is evident that we have here a realistic view which has turned its back upon the Aristotelian outlook.

Given this change of outlook, the adoption of mechanical and geometrical analogies was inevitable. The idea of mass was clearly formulated by Newton. On the chemical side, it was realized that corpuscular motions made possible a comprehension of the conservation and reappearance of substances after they had from the qualitative side apparently disappeared. Hence the attempt was made to find constant properties as against the more variable qualitative properties. Mass and combining weight were just such properties. The data of measurement turned out to be more constant and reducible to law than the odor, color and taste of sensible things.

What is the significance of this greater objectivity of the data of measurement? It has been much misunderstood. In a later section to deal with the distinction between the so-called primary and the secondary qualities, we shall examine the problem in more detail; but it is worth comment at this point. It is clear that all the data of sense are subjective and, in the historical sense, equally secondary. Measurement gives judgments about things. In it we employ data but do not rest in these sense-data for their own sake. Thus the scientific movement was experimental and its implications possessed a genuine significance which has not always been understood. The sensations underlying the estimation of the size and the weight of objects are no more reducible to law than the color or odor of things are.

But we can handle pure elements. Hence the philosophical situation is somewhat different for the atom, the concept of which was next developed in chemistry. Atoms are by hypothesis so small as to be invisible. Certainly our most 
delicate instruments cannot enable us to see them. ${ }^{3}$ It is not surprising to find that the arguments of John Dalton, the originator of the atomic theory in its application to chemistry, were mainly deductive. If the elements are composed of atoms, all of them of the same mass for each element, he reasoned, their combinations with each other must be in definite proportions and in the quantitative relation which may be called that of their atomic weights.

The importance of the atomic theory for chemistry consists in the fact that it was a powerful agent in putting chemistry on a quantitative and spatial basis. It rendered clear relations and facts which had before been but vaguely grasped. Probably the tabulation of combining weights would have made predictions possible, but the atomic theory allowed modifications and changes which would express clearly new facts such as those of isomerism.

What, then, is an atom? We must not take the etymology of the word too seriously. It has empirically developed to mean a small body which acts under certain physical and chemical conditions as a unit. Atoms are now known to be decomposable to a greater or less degree. They are wellknit physical organizations which function in known ways. The development of our knowledge about the atom has been very striking of recent years. It is known to have an internal structure and to be capable of shifting dynamic relations with other atoms. As this knowledge is firmly grasped, it is realized that any picture of the atom in terms of senseobjects is misleading. The hard, passive surface of the old naive view has gone forever. It is a dynamic center of definite structure and spatially localizable. We have knowledge about it, not a sensible image of it. Such symbols as we use must not be taken as pictures.

Eleaticism vs. Dynamism. - The growth of modern science has been visible, as much in the changed idea of the

3 In terms of critical realism this means that they are not able to produce a single distinct effect on the eye and so indicate an outline. I am aware that Brownian movements and electronic experiments reveal pretty direct dynamic effects. 
physical world as in the vast accumulation of detail. Certain somewhat conventionalized, and yet significant, terms are evidence of this deeper transformation of outlook. The battle is not over and the smoke of the conflict still obscures the field; yet the drift of thought can be discerned. The younger generation of thinkers proclaims that the earlier views were too static and geometrical and that dynamic ideas alone are valid. Let us try to see what this contrast means.

Philosophers have been accustomed to call any view which denies change as basic and intrinsic an instance of Eleaticism. And sometimes they have believed that science unanimously held such a view. The truth is that the science of many philosophers has been the science of a previous decade.

The Eleatics maintained that being is homogeneous, unitary and eternally the same. The Greek atomists compromised by assigning these predicates to the hypothetical atoms as bits of being, while admitting that the atoms were redistributed in various ways. Thus change was reduced to a minimum and concerned arrangement and order rather than that which was ordered. I presume that the idea at the heart of this form of Eleaticism is that spatial position is external to the terms and non-modifying. The physical world is simply a complex of atoms and a void. Each atom is a sterile and unanalyzable microcosm.

Now clearly all this was mere speculation. And it was, quite obviously, an hypothesis which took its departure from the images aroused by the behavior of gross masses toward one another. But, natural as it is, what logical right have we to build our idea of the character of the microscopic parts of the world upon analogy in this speculative way? The advance of science since the discovery of radioactivity has involved the correction of this first analogical imaging of the world. New data have come to the front, data with which only the scientist in the laboratory comes in touch; and these data have enabled him to analyze the atom. reconceive mass in electrical terms, and explain what seemed to the 
older physicist final properties as functions of activities. The new knowledge has lighted up the interior of the atom.

The dynamic interpretation of the physical world founds itself on the very fact of change. All is in motion, and this motion involves tension and shifting equilibria. Both within and without the atom, there are linkages making systems and sub-systems. This active connection seems to be the work of the electrons, which are the most mobile part of the atom. For instance, chemical valence is thus explained. And the atoms, though recoverable, yet enter into novel systems with new properties in chemical combination. The physicist will draw for you a diagram of the helium atom, showing the positive core, which has the mass of the atom, and the electron revolving around it as a center. And he will tell you that Rutherford has been able to bombard the center of a heavy gas and thus reduce it to a lighter kind. And, by so doing, intraatomic energy has been released. How different all this is from the older atomism with its blank assertion of impenetrability and hardness! The inherent properties of Lockian metaphysics have become functions of spatially organized electrical charges. They can no longer be considered surfaces to be copied by our sense-data.

Let us admit frankly that our terms are only cognitive. In such terms as position, mass and energy we describe the measurable behavior and order of the parts and do not intuit more penetratively the stuff and connections of these intense particles. It is knowledge and revelatory, and yet pale beside what we feel that being must be.

It is notorious that chemical processes are now regarded less as fixed changes running their course in one direction and resulting in firm couplings than as cases of shifting equilibria responsive to conditions of temperature and of pressure. A reaction is a temporary balance of conditions ready to move in the opposite direction as conditions vary. Physical systems are phases instead of finalities.

It would be easy to indicate the growth of this dynamic outlook in the more concrete sciences. The biologist is aware that function is intimately creative of structure. 
Physiology stresses metabolism and points out the delicate interdependence of processes and conditions in all the parts of the body. Regulatory processes of the greatest fineness of adjustment are constantly in operation in the body. ${ }^{4}$ In the following passage from Roux, the priority of dynamic ideas is obvious: "The fully formed blood-vessels are no static structures, such as they appear to be according to the teaching of normal histology, and such as they have long been taken to be. Observation and description of normal development never shows us anything but the visible side of organic happenings, the products of activity, and leaves us ignorant of the real processes of form development and form conservation, and of their causes."

Let us see whether we can summarize the differences between the static and the dynamic as opposed tendencies of interpretation. The static suggests rest, position, firm outline, inertness. The dynamic, on the contrary, emphasizes process, interdependence, activity, cumulation, changing and measurable tensions. We see now that these views supplement each other. The truth is that much error has resulted from ignoring the time dimension of nature. Thus the modern physicist will tell you that the only place he can ignore the results of time is in the quick reaction of two free electrons to each other. In all other instances, we must study to see how structures are produced and maintained. It seems clear, therefore, that the classic mechanical theory of nature started too much from results and supposed that all we have is a mechanical alteration of positions. It ignored the influence at each step of the cumulative effects of organization. The classic mechanical theory of the world was too hypothetical and deductive. The world is as it is empirically and experimentally known as. To consider nature as merely a complex of atoms in mechanical motion

4 "It is hard to realize," writes Haldane (Mechanism, Life ana Personality, p. 51). "that something which looks under the microscope like nothing more that a somewhat indefinite gelatinous material can react, and continue to react, true as the finest mechanism of highly tempered steel, to the minutest changes in its environment."

${ }^{5}$ Quoted from Russell, Form and Function, p. 329. 
is altogether too thin a conception to mean very much. No scientist can deduce the empirical laws of chemistry and of biology from the laws of mechanics.

The Primary and the Secondary Qualities.-The distinction between the primary and the secondary qualities has played such a puzzling rôle in both the history of philosophy and the theory of science that it demands critical examination. By uniting our theory of knowledge with the outlook of modern science, we ought to be able to give an unambiguous answer to this problem.

First, then, it is clear that we must relinquish in every way, shape and manner, the metaphysical position that qualities inhere in a substance. To strip this substance of secondary qualities is not enough, for we are shown that all sense-data are subjective. Such was the position of Hume. The $x$ left was a mere nothing which it was not worth while either to affirm or to deny.

Since this point is basic for critical realism as I understand it, I shall take the time to make it as clear as I am able. Critical realism puts knowledge in the place of intuition where the external world is concerned. It is a nonapprehensional realism. ${ }^{\circ}$ All sense-data are equally subjective, and yet all sense-data are equally means to knowledge. In both common sense and science, knowledge is fused with sense-data in our outlook upon nature. There is not the sharp logical distinction between knowledge and sense-data as means to knowledge which philosophy must make as a result of reflection. This confusion of knowledge and intuition is rendered almost inevitable by ordinary perception, which is partly intuition, partly judgmental knowledge. The psychologist tells us how much inference and interpretation there is in perception. The logician does the same. Yet this interpretation and judgment never detaches itself logically from the data upon which it is founded. The consequence is naive realism and the assumption that physical things are substances possessing sensuous qualities.

- Cf. The Essentials of Philosophy, p. 151. 
We see and know things at the same time. The awareness of the sense-data makes for intuitionalism; the inferential ingredient for critical realism.

The aim of critical realism is to make the thinker realize that knowledge is neither a direct nor an indirect intuition of the physical world. The critical realist rejects both naive realism and the naive copy view. I hope that the present discussion will bring out his logical separation of knowledge from intuition.

Let me use Fullerton's treatment of the distinction between appearance and reality as my object lesson. He sees the logical futility of Locke's position and yet realizes the strength of the scientist's argument. He then endeavors to escape by means of the tactual nucleus which is for him somehow reality in a way that the data of vision and hearing cannot be. He comes near the truth but always misses it because he does not realize that knowledge is different from the awareness of data. Let me quote. After pointing out that Locke never gives a sufficient reason why color must be denied to things while extension is not, he adds: "And every modern Lockian, whether scientific or non-scientific, sticks in the same difficulty. If the sounds and colors that I perceive do not exist in a world beyond us, but come into being in me when my body is acted upon in certain ways, why may not the same be true of the resistance, the extension, the motion, that I seem to perceive in things? Can I perceive bodies to be resisting, extended, or in motion, unless they act upon my body? May not the resulting complex of sensations in this case, too, be wholly different from the external cause? Perhaps the real world is not, then, the extended and imaginable thing that $I$ have thought it. Perhaps it is only a name for the unknown, a something that I cannot more clearly define."7

Thus Fullerton argues that "In so far as the man of science distinguishes between appearance and reality by placing the former in consciousness and the latter without it, his position may be justly criticized by the metaphysi-

${ }^{7}$ Fullerton, $A$ System of Metaphysics, p. 147. 
cian." But the critical realist denies this. Of course, he does not accept the Lockian view that the atoms are endowed with primary qualities or that we rightly attribute qualities to them. Instead, he maintains that the so-called primary qualities are judgments about the physical world having a foundation in the inferential use of sense-data. That things are extended means that they are superposable and measurable, that the parts are in the order of side-by-sideness; that things are solid means that they exclude other things in measurable ways; that they are at rest or in motion means that they change position with respect to some standard coordinate or do not; that they are numerable means that they can be numbered; that they have figure means that the parts are in a definite order on the surface, etc. Now all these statements, while mediated by the pattern of sensible appearance and deepened by manipulation of things, are in no sense assignments of sensible qualities of any kind. They are intellectual graspings of the determinate nature of things through use of the sense-data they arouse in us. Thus we return to the point we made in Chapter II, that the spatial and temporal order of things in all their variety is reproducible through the correspondent correlation of data and the nature of things. The pattern of nature can be worked out through an inferential study of the pattern of appearance. The sensible appearance is a qualified, or differentiated, order; and every datum has meaning for the inquiring mind. It indicates something about the object of knowledge. It is these leads that science rightly follows.

Our epistemological argument is that, because common sense interweaves data and inferential knowledge about things, the real nature of knowledge has been hidden. Both Aristotelianism and Lockianism have failed to attain the proper logical view ; and of course, the ordinary scientist does not know whether he is a naive realist, a representative realist or a critical realist. But let the thinker once follow our argument and he will realize that the substance-qualities

8 Ibid., p. 147. 
schema is invalid for metaphysics, that properties are merely elements of our knowledge of things with their determinate nature and connections, that all sense-data are equally subjective and equally means to knowledge.

While I would not go as far as Singer in the stress upon measurement, there is much truth in his contention that "a physical science is one which employs in its description of nature only such terms as can adequately be defined by the use of the measuring rod." I would say that all the exact sciences are of this sort, and that all physical objects can be treated-though not exhaustively-in this fashion.

Measurement is a method of handling things so as to get data which can be used inferentially to determine quantities. There is never a conflict between critical perception and the results of such measurement, but the one process is more dependable and exact than the other. I say that this room looks to be fifteen feet wide. I measure it and say that it is fourteen feet six inches and a half. And perception halts on the threshold of what measurement technique can determine. But every one to-day knows this though he may not have realized what it meant. Any one who has followed in detail the determination of the atomic weight of an element knows that observation is merely an element in a process of technical inference. In the case of antimony, whose atomic weight has recently been redetermined in the laboratory of the University of Michigan, the process involved the possession of pure antimony and pure bromine, then pure bromide of antimony free from water vapor. At each stage data of observation were taken as tests. Finally the comparative weights of pure silver bromide and pure antimony bromide were compared and the atomic weight of antimony calculated with silver known. Take mass again. The felt weight of an object varies from time to time. It grows heavier the longer it is carried. The weight as measured on a scale does not vary. The information mediated by sense-data is not identifiable with sense-data. Another

- Singer, The Physical World-Order, appendix to Fullerton's Metaphysics, p. 609. 
point to note is that such knowledge always founds itself upon the study of things in relation to one another and not of the human organism. The organism is a condition of the data of observation and the organism's mind is an essential instrument in the use of these data but the organism is not the object of knowledge. It is an omnipresent condition but it is not that toward which knowledge is directed. Idealism has always misunderstood this situation. And, until a non-apprehensional view of our knowledge of the physical world is achieved, this situation will remain misunderstood. The awareness of data is confused with the giveness of the object of knowledge. The conditions of knowledge, physical, physiological and psychological, must not be put in the place of the nature and claim of knowledge as an act of the conscious organism.

It is characteristic of science that all the data must be brought into one system. The physical world must be such that it is the source of sound, color, kinesthetic sensations, tactual sensations, odor, etc. No one datum is extruded and considered unreal. Philosophers who have not understood science have talked much nonsense at this point. And there is not a sense datum which cannot be used as a source of knowledge about the object which the scientist is studying. Both chemists and physicists use color as a means of studying substances. Take the colorimeter and the spectroscope as examples of this technique.

I find a rather interesting fact here. The data of the distance-receptors usually are excellent means of getting information about the minute parts and processes of things. Thus color has been correlated with the vibrations of electrons and sound with the vibration of bodies in a wave-like fashion. This correlation is inferential but it is not arbitrary. I want it noted, however, that there is no attempt here to reduce secondary qualities to primary qualities as generations of philosophers have asserted. Auditory sensedata and visual sense-data are not identified with tactual data at all. 
The Extra-Organic Foundation of the Scientific Properties.-Before we advance farther, it may be well to develop a point that we have already mentioned and have not applied in its full significance. We said that scientific knowledge founds itself upon the study of things in relation to one another and not merely to the human organism. The human organism is a constant condition which as constant is eliminated. Examine the content of the exact sciences, mass, size, position, motion, energy, acceleration, momentum, etc. In final form, they are all delivered as ratios. The technique of such information should have been more studied by thinkers. The manipulation of things and instrumentation are basic. Observation merely gives readings. It is the human organism that knows, and this knowledge is an inferential product, but the content of knowledge and the act make no reference to the organism except as knower. The scientist seeks to make nature speak in terms of itself. And I think it is quite obvious that he succeeds, that a reference to the organism does not intervene like an undesirable third party in his knowledge of the physical world. The subjectivity of his data and of his content does not vitiate the claim of knowledge and its reference, unless you make some $a$ priori assumption as to what the nature of knowledge must be, probably based upon the ideal of intuition which the mixed character of ordinary perception nourishes in the human mind.

The Correlation Between Scientific Properties and Sensations.-One of the chief causes of confusion in the treatment of the comparative standing of the so-called primary and secondary qualities has been the inadequate analysis of the correlation between properties and sensations. The reason for this lack of analysis was undoubtedly the lack of such a contrast between data and knowledge as I have made. Added to this absence of the proper distinction between properties as elements of knowledge and sensedata was the confusion of sensation and perception. It was not realized how much knowledge there was in the content of perception. 
The correlation between length as a case of knowledge of a physical thing and perceptual length is logically very close. Yet we are prone to misinterpret it because we confuse sense-data of an atomic sort with the content of perception. Reflection would show us how much comparison there is in our apparently immediate intuition of the spatial character of a particular thing. And in the content of perception there is quite a pattern. But take any sensation which can be analyzed out by itself and the correlation is merely one of correspondence. Spatial character is a sensuous correlation of sense-data of a peculiar kind, a correlation which corresponds to the correlation of things and their parts in nature. It is this correlation, or pattern, which is revelatory of nature. Measurement develops and deepens this correlation so that knowledge can use better data.

The correlation between weight as a quantity and weight as a kinesthetic feeling is similar. Probably for most of us the comparative element enters less than in the perception of size. Yet it is there. And it is very obvious that the sense of weight must not be objectified. Nor must the ratio for that matter. But both can be used as cases of knowledge. The correspondence, then, consists of the double fact that things feel heavy, and that our comparisons between the feelings caused in us by physical things give an order of heavier and lighter, agreeing with the ratios found by weighing things in scales in terms of accepted physical units.

The correlation between mass and the kinesthetic sensations is similar in character. The order of one corresponds to the order of the other. But the knowledge obtained according to the technique of science is more easily quantifiable and constant.

We have in an earlier chapter noted why mankind passed from personal time estimations to the employment of clocks and other mechanical means of registering intervals. And it will also be remembered that we distinguished between time in this sense and time as internal, cumulative growth. 
What holds of the fundamental physical units of the exact sciences is true of the derived units and their application. What sensation corresponds as such to density, or to acceleration, or to energy? Sense-data are means to this level. The correspondence is clearly indirect.

But these correlations between knowledge and sensation and between the physical object and sensation as studied in the exact sciences have to do in the main with the object as a whole. The primary properties give what may be called a thin, general knowledge of bodies en gros. My whole organism must exert itself against an obstacle to give me the feeling correlative to mass. In size, again, I deal with the object as a whole. But propositions which may be true of bodies taken as wholes may not be true of the parts as these are carefully studied. Thus mass was once thought of as an innate property which things somehow passively possessed; it is now regarded as a variable function of electrical conditions. The mass of an electronic particle may increase and decrease.

While the so-called primary properties concern our knowledge of bodies as wholes, the secondary qualities are found to be correlative to activities of the minute parts of bodies. Thus taste is a chemical sense. The same is true of odor. Vision and hearing are correlative to vibrations emitted by the bodies. These vibrations can be studied quantitatively by means of a delicate technique. The point to bear in mind is that the data of the distance-receptors are not reduced to tactual and kinesthetic sensations. They are correlated with their external causes as these are studied inferentially by all the means at hand. In no case is there assumed to be a resemblance between a sense-datum and its external cause. What does hold is an ordered correlation so that to every difference in the one there is a difference in the other manifold. It is because of this ordered correlation that we are able to infer the size, structure, behavior, position and internal constitution of physical objects. No category of science demands resemblance between the physical object and any one sense-datum. It is the recogni- 
tion of this fact that differentiates critical realism from the traditional type of representative realism.

All Sensational Qualities are Subjective and None are Unreal.-We have maintained that all sensible characters can be used as material for knowledge of the physical world. But this material must be used judgmentally and in relation to significant questions. A difference between the sensible appearances of two physical things, when the conditions of perception are the same, indicates a difference in the actual nature of the two objects. Perceptual judgments of size and shape are genuine cases of knowledge so far as they go. They are clearly based on correlations and comparisons, partly automatic, partly conscious. The case is the same for judgments of weight and of velocity. Different colors, tastes and odors are also indicative of physical conditions. And, obviously, different senses may be brought to bear upon the same external process by a little ingenuity.

The point which I wish to reenforce, however, is that there is no need to reify any of the sense-data of any of the senses. They are all equally subjective and all equally means for knowledge. Unfortunately, it requires a high degree of reflective ability to transcend the natural fusion of knowledge and the data of knowledge and to overcome the tendency to clothe objects with sense-data. The flaw in all radical empiricism lies here. It is so dominated by that hybrid, perception, that it is unable to grasp the logical situation. The physical thing remains for it a complex of sensedata.

It may be of interest to mention the theory of M. Bergson that colors are condensations of the qualitatively heterogeneous movements which we call waves of light. As I understand him, this condensation is accomplished by memory which works in time, and the result is the specific quality which appears as given to the conscious self. The critical realist does not need the identity between the stimulation and the datum which Bergson as an intuitionalist desiderates, nor does he see what exactly can be meant by condensation 
in this case nor how memory accomplishes it. The fact is that there is a qualitative novelty in color and that it is a function of stimulated nervous conditions. It clearly arises in the brain as an internal feature of its response to excitation. The critical realist accepts this situation as a fact though he would welcome further neurological and functional analysis of it. Bergson is a dualist and regards the brain simply as a system of lines of transmission; whereas the evolutionary naturalist considers the brain a unified functional system which interprets and responds to stimuli and is the seat of consciousness which is an essential ingredient of this interpretation and response. ${ }^{10}$

To the critical realist, then, the physical world is not intuited directly or representatively. Instead, it is known by means of the revelatory value of the data as they come in differential patterns. At the level of common sense, where the chief need is action, the correspondence of data to their external causes enables them to be used as guiding symbols. The use value of objects for the individual is the only concern. It is for this reason that perception combines use knowledge with data and the object is apparently intuited. But science has frankly turned its back upon this practical purpose and desires to have knowledge of the thing and not merely to think of the thing in terms of perceptually correlative symbols. It has been our purpose to show what kind of knowledge data in their continuities and patterns can be made to mediate. It is knowledge of size, position, structure, behavior, relative changes.

The Quantitative View of the World Only a Quantitative Study of the World.-We are at last in a position to show that modern science is turning its back upon the classic mechanical view of nature as well as upon the sensuous qualitative empiricism of the medieval outlook.

Sciences are physical so far as they concern themselves with physical things. I would say that, in a very real sense, all sciences are physical. But since we have not yet shown

10 This point will be discussed more fully in Chapter XIV. 
that mind is a physical category, we shall not strain the reader's patience. Let us, therefore, hold to the milder definition. Biology is as much a physical science as is physics. It studies the structure and behavior of organic bodies which are evolved bodies with specific properties not found at the inorganic level.

The exact sciences study the general properties common to all bodies, and they study them quantitatively. Thus quantities are relative to properties, that is, to determinate characteristics of nature. Mass, temperature, acceleration, momentum, pressure, force, saturation, all these distinguishable characteristics can be examined by measurement. The result is a descriptive knowledge of nature.

As we pass from physics and physical chemistry to inorganic and organic chemistry and thence to biology, we note the same relationship. Structure and composition, reactive capacities, etc. are studied and, so far as possible, quantitatively. But it must be remembered that we have qualitative analysis as well as quantitative analysis. In biology, quantity has played a lesser role than in the inorganic sciences. The distinguishing features of organisms, their color, scale formation, skeletal structure, their habitat, behavior, food, these are the elements of our knowledge. We are again dealing with bodies of conspicuous dimensions and using all that is discernible as means to knowledge. It is not, as some have supposed, that we are not able to break down the organism into its physical and chemical parts but that wholes have new properties as real as the properties of the parts. To call physics the basic science should not mean that it is the only science theoretically, but that the material it deals with underlies and helps to constitute the organic whole. But this whole has a nature which is not reducible to the nature of its parts. We must avoid what a very able biologist has called elementalism. His remarks on the theory of knowledge essential to biology are so relevant that I quote: "To gain understanding of the behavior of living beings is admitted by everybody to be the chief reason for investigating such activities. Due consideration of the nature of the 
activities and of the nature of understanding makes it certain that the phenomena themselves are highly integrative and integrated, or synthetic, and that understanding of them depends as much on synthetic knowledge-getting as on analytic knowledge-getting." 11

Thus there is no such conflict between quantity and quality as thinkers have been induced to suppose. A mere monism of motion is absurd. We must think nature in terms of our concrete and differentiated knowledge. To remove the gauds of sensible color and perfume from nature is not to leave it a mathematical skeleton. Mathematics and measurement are instruments for the specification of certain types of knowledge of things. But this knowledge is not exhaustive and not exclusive. It exists in a matrix which may rightly be called qualitative in a logical sense. Being has its determinate structure and activities with which we humans must cognitively grapple as best we may with the resources at our command. We may say, then, that science has passed through three philosophical interpretations and, with critical realism, is entering a fourth. These are the substratumqualities stage, the classic mechanical view of intuitionalistic rationalism, phenomenalism, and the position that determinate reality is known in terms of analytic and synthetic inferences built up on the foundation of patterned sensedata.

I hope that the arguments of this chapter have made the epistemology underlying evolutionary naturalism clearer and more concrete. We have relinquished the ideal of intuiting the stuff of the physical world either directly (naive realism) or indirectly through a copy (Lockian realism). The physical world has order, and this order is reproducible in the pattern of appearance by correspondent correlations. Moreover, every feature of the sensuous pattern has significance for science and is interrogated to see what it can contribute to knowledge. But however specific the knowledge of things we may attain, it must be covered by such categories as position, structure, composition, growth, behavior, no one of

11 Ritter, The Unity of the Organism, p. 213. 
which assumes an intuition of the stuff of reality. This position is agnostic only to those who have an uncritical view of the nature of knowledge. Let us remember that we are organisms existentially external to the things in our environment and that mind is primarily an organ aiming at adjustment. The data aroused in the organism are obviously differential clues rightly referred to things in perception. But this very reference fosters an illusion which only the severest reflection can overcome. No datum is like its external cause. Knowing the psychological processes involved, we are more than ever convinced that stimulus is not like the effect. But, just because of the responsible correlations involved, knowledge of the physical world can be quarried out of the data. To the intelligent mind, the physical world reveals itself by these clues, which are put together and interpreted by science. Critical realism is to be distinguished from traditional representative realism by its more critical idea of knowledge. In this way, it has outflanked Berkeley, while admitting all that is valid in his attack upon Locke. It is the physical thing which we gain knowledge of by a study of appearance, and we discard the notion of a substratum in which copiable qualities inhere. 


\section{CHAPTER X.}

\section{PHYSICAL CONNECTIONS AND RELATIONS.}

$\mathrm{T}$ is impossible to pick up a modern book on technical 1 philosophy without running across the controversy as to the nature of relations. The present form of the dispute concerns itself with the bitterly fought issue whether relations are external or internal. It appears that the idealists-so far as they believe in relations at all-contend for the internality of relations, while the majority of the realists follow the lead of Mr. Russell and as loudly proclaim the externality of relations. It will be our endeavor to explain this controversy and to make the distinctions which follow very naturally from the outlook of critical realism. Here, as elsewhere, we shall, I think, find that thinkers are apt to be right in what they affirm and wrong in what they deny. The locus of their judgments is not sufficiently defined. We shall be led to ask such questions as the following: Are physical things separable from their connections? Are mathematical objects modified by the relations into which they are put? Does the part survive in a whole? Is order or continuity given with that which is ordered? Are all judgments concerned with the assignment of a predicate to a subject? By stepping warily and using the distinctions which critical realism suggests we shall hope to rise above this acrimonious dispute.

It is commonly asserted that science deals with the coexistences and the sequences of phenomena. And such coexistences and sequences are often spoken of as spatial and temporal relations. To make matters worse, philosophical 
tradition complicated and befogged the whole question of the nature of relations through the setting given by the HumeKant controversy. Are relations given as immediately as are qualities? Or are they contributed subjectively by an active and creative mind? Are they fictions? Do they apply to things-in-themselves? This intermixture of psychological and epistemological problems was thrust into philosophy in a bewildering way. It took over a century to realize that sensuous spatial and temporal order is the pattern in which qualitative sense-data are arranged and that the pattern is as empirical and as significant as are the qualities. It is undoubtedly true that experience deepens and develops the pattern more than it does the qualities, but it does this quite empirically. The general drift of thought has been toward a wiser empiricism in which relations are admitted to be given integrally with the terms. ${ }^{1}$ The critical realist would add to this recognition the admission of a higher level in which judgments of comparison are achieved. The first level contains continuities; the second level involves ideal relations. In contrast to these two types in consciousness, he would put the actual connections of physical things.

The critical realist believes that science has knowledge of the connections of things and does not deal with phenomena. He must, therefore, distinguish between experienced relations and the connections which they indicate. Reality has for him, as it were, two stories, the subjective (which is only a peculiar phase of the objective, characteristic of organisms) and the vast underlying and far stretching sweep of the physical world. And let it be remembered that for him the continuity of the world is spatial or gravitational. It is characteristic of him that he likes this word continuity better than the traditional term unity. $\mathrm{He}$ is a mental pluralist at the same time that he is a physical monist. Minds get their continuity through nature in which they are immersed and of which they are peculiar, differential parts.

The terminology of a philosopher should always be inter1 Cf. Critical Realism, Ch. 6. 
preted in terms of his system. Nearly every word by itself is equivocal. Thus monism means one thing in a naturalistic system and something quite different in a spiritualistic one. The same is true of the term pluralism. Materialistic pluralism is but another expression for an Eleatic atomism of the type presented by Democritus. Such atoms are supposed to have only external relations with one another. They do not modify one another to form a novel whole. Spiritualistic pluralism is preferably called monadism, and holds that the universe is spiritual at heart and consists of a multiplicity of self-sufficient entities of the nature of souls or minds.

While pluralism has always in the past had the connotation of a multiplicity of independent beings, whether material or spiritual, monism has usually had for its context the problem of the relation of the physical to the psychical. - Its contrast term was dualism. Haeckel's name is in Germany associated with a naturalistic type of monism which asserts that the psychical is from the very first level of evolution an integral part of the physical world. A more idealistic type of monism brings them together but inclines to make the psychical the more dominant factor of the pair. We think of Spinoza and Schelling in this connection.

But, in the Anglo-American philosophy of to-day, monism has taken on a new meaning. It is identified with absolute idealism; and this form of idealism maintains that the parts are subordinate to the whole. It holds that relations are so internal that the terms by themselves have little, if any, reality. We shall have much to say of this theory of relations in later sections of this chapter. We shall see that it is an exaggeration. At this point, I wish to call attention to a fundamental feature of this absolute idealism, viz., its denial of the reality of time and change as meaningful for this final reality. This position has been christened absolutism by its opponents and described as cherishing a "block universe," that is, one made once and for all. It is in opposition to this static and changeless conception of the world that the so-called new pluralism has been launched. Stress 
is laid upon change, activity and process. The universe is conceived as internally plastic and flexible. Time is of the very nature of reality.

It is clear that this new pluralism is opposed to Eleaticism whether in the whole or in the part. It is anti-absolutistic and anti-atomistic. It is to be distinguished from both the monism and the pluralism of the older persuasions. There is in it the modern note of emphasis upon adjustment and growth. It is also less abstract and general and more concrete, empirical and distributive. There is the sense of human presence and participation in an actual process. It tells us what kind of a world we have.

When, therefore, the evolutionary naturalist calls himself a physical monist, he is opposing speculative Eleatic atomism equally with supernaturalism. It is the spatial continuity of the world which he has in mind. But within this basic continuity there may be many sorts of additional connections, some of them very loose, flexible and creative. With regard to such evolved and localized connections which are such pregnant features of society the evolutionary naturalist is an empiricist. Hence with much that the new pluralism maintains, he is in agreement. Only he is a physical realist and a naturalist withal. The earth is our mother and the radiant sun our father, though we have passed into the new temporal dimension of consciousness and knowledge. The truth is that the majority of the old terms are outworn. To declare what evolutionary naturalism is, specifically, is the whole purpose of the present work.

Within experience there are many kinds of relations, and so we must consider the term as generic. Each species has, also, its concrete instances. Thus I can note the spatial relations of sensible things, the order of numbers in a series, the similarities of things, their differences, etc. In ordinary language, we speak of spatial relations between things, of temporal relations between events, of causal relations, of relations of identity and difference, of quantitative relations, social relations between persons, etc. It is obvious, then, that a large part of human knowledge is concerned with 
relations or based upon them. We wish to know where a thing is, the order of certain changes, the relations of the parts to one another, its class. Thus a very large share of human knowledge consists of propositions in which the term relation may be made to appear as the important element. We classify things by putting similar things together, logically not literally; we explain events by finding their antecedents; we locate things by measuring their temporal and spatial relations. The category of relation appears to be omnipresent.

But many relations divide as much as they connect. Thus space and time separate things and events as markedly as they relate them. Why is it that the idea of uniting comes so easily to mind instead of the idea of separating? I think that there can be but one answer to this query. The human mind is primarily interested in seeing how things stand to one another, in trying to bring them together into a system for thought. It relates, compares and classifies, thus supplementing those continuities, such as the spatial and temporal, which are more passively given. And those characters of the perceptual field which can serve as fulcrums for this activity are called the data of the relation. Thus I compare two books with respect to color. The two respective colors are the data, while the books are the terms of the relation. Our cognitive interest uses all the material available as bases for knowledge about things. And such knowledge is comparative in its very nature.

The Category of Relation and the Method of Knowledge.-The logician and the psychologist well know that things are never left in isolation. The mind plays about things. It notices their shape, size, relative position, color. But these qualities are interpreted through comparison. The comparison does not create the quality but rather develops it. It acquires additional meaning by the process, something which extends it without falsifying it. We could not handle the world if we had to apprehend its parts separately as through a peep-hole. The basis of all reasoning is the dis- 
crimination of identities and differences. Thus the mind is constantly relating things, bringing them together mentally, for the purpose of answering the inquiries which arise.

Popular knowledge consists in the main of the perception and recognition of concrete things, their rough classification, and a few general rules in regard to their mutual behavior. Even to the making of this degree of knowledge certain mental operations are necessary. There must be discrimination, analysis, synthesis, and some measure of abstractive construction. It will be remembered that we have maintained that empirical objects are constructs in which the past is united to the present and the future. How the thing has behaved and how we expect it to behave are equally parts of its content. The physical thing is the point of reference for the properties which are called to our mind. It is this thing which has done this and which we expect will do that in the future.

To the adult, then, the world presents itself as a spatial and temporal continuum. Things and events are in an order of other things and events. Hence, the idea of connection is, as it were, forced upon us by the very coordinated material of presentation. I see this book to the right of that book, this typewriter on the top of the table, this picture on the wall. I experience this event before that event and after that other event. These species of order are abstracted from the content of perception, given names, and conceptualized. Such orders are founded upon instances of sensible continuity, ways of passing from one thing to another. Such continuities are as much material of knowledge of the physical world as are the qualities more definitely assigned to particular things. They concern the real connections of things and events. Spatial and temporal relations are continuities in terms of which we can pass step by step from one thing to another, no matter how widely they may be separated. They represent the unity in the many, the togetherness of the differentiated field. A naturalistic monism stresses spatial and temporal continuity in place of the mystical unity imparted by some underlying substance. 
Within this field of spatially and temporally continuous objects, the mind passes back and forth to compare, interpret and classify. The result is the possession of classes of objects having marks in common though separated by distance. These logical relations abstract from position in space and time. They are therefore often called ideal relations. Among these ideal relations are comparative size, similarity in color, shape, texture, etc. We speak of the relations of similarity, difference, equality, inequality. Why are they called relations? Are they not rather facts that certain things are equal or unequal in size, like or unlike in color? The relating is something adventitious which supervenes upon the things by reason of the interest and capacity of the human mind. The minds brings them together ideally or mentally, not physically. It shifts the attention from the one to the other, and institutes a comparison. The physical things are clearly not changed by this relating. It is not a physical connection.

It is clear that we are in danger of being misled by an analogy. The mind relates things in its own peculiar way by bringing data together before the attention. This mental relation is analogous to physical connection. It is not surprising that both kinds of connection secure a common term. But, in the interest of clear thinking, it is better to adopt a terminology which indicates the difference between physical connection and mental secondary connection. I say secondary connection because comparison presupposes sensuous data of which perceptual spatial and temporal continuities are clear instances. I shall therefore try to speak of physical connection, sensible continuities, and ideal relations.

The Connections of Things.-Before examining the logic of ideal relations let us dig more deeply into the nature of real relations or connections. The prior discussion of the naturalistic solution of "the One and the Many" has prepared the way for our thesis, that things are really delimitations, or differentiations, in an extended reality; they are 
material sub-systems which can be considered for themselves. As parts, they are as real as the whole of which they are parts. Yet such differentiations in no way deny the essential dynamic continuity of the physical realm. Things affect one another. They are coordinate and interactive. We can, therefore, always distinguish two factors which are yet actually inseparable: the particular material system and its environment. The setting of a thing is its physical connections.

Investigation always proceeds along these complementary lines. The object must be studied by means of all relevant methods. Any fact which will throw light upon it must be interrogated. It must be dissected, weighed, examined. But its physical setting also must be determined. The fitness of its environment must be comprehended. One of the best instances of this supplementary approach is found in biology. A plant is studied histologically and physiologically, and, at the same time, other investigators devote their attention to ecology, to the character of the environment. The result is the combination of the two converging lines of research to the comprehension of a system within a system.

It is evident that we must use the distinction between knowledge and being upon which we laid so much stress in the more distinctly epistemological chapters. The attainment of knowledge involves the rational use of sensory material for the discovery of facts, the construction of hypotheses, the piecing together of results. The mind works like a shuttle to weave knowledge from all available sources. It glides from this subject to that, from internal structure to external conditions. But this process of comparison and interpretation supervenes upon being. Existents are determinate and are in determinate connections.

Physical connections divide into two main groups, the spatial and the temporal. On the one hand, the scientist seeks to comprehend the structure of the sub-system he is investigating, its parts and their relative positions, its place in the larger system of the world; on the other hand, he tries to see one change pass into the next in a cumulative way 
until the final stages of the historical growth are grasped in the light of the continuous steps which preceded. To drive these two dimensions of existence abreast in knowledge is the ideal of the modern scientist with his evolutionary way of approach.

Sensible continuities appear in consciousness as signs and clues to physical connections. That we can note the spatial and temporal order of things and events is an undeniable empirical fact, and this apprehension furnishes the material for genuine knowledge about physical reality. In science, these impressionistic apprehensions are developed by means of measurement with suitable centers of reference. But it is obvious that these sensible continuities are the material of knowledge and cannot be identified with the physical connections they symbolize. Geometrical plotting of positions, significant as it is, is but preliminary to an estimation of the actual dynamic tensions playing upon a particular object. Thus Kepler's laws were explained only after Newton had developed his theory of universal gravitation. Sensible distances, positions and directions are but the senuous substitute in consciousness for the dynamic and determinate connections of physical being.

Traditional Metaphysical Terms.-It has been customary to consider the character and reality of relations from the abstract standpoint of particular types of philosophy. Much of this discussion is irrelevant to physical realism, and yet it may pay us to glance at the traditional positions.

First of all, we should note that the most virulent controversies have been waged between the proponents of different forms of what for want of a better name we must call idealism. Monadists have fought less bigoted pluralists who admitted a measure of continuity, while both have arrayed themseves against idealistic monists who saw no significant reality short of an all-engulfing absolute. We can afford to glance at these antagonistic systems in only the briefest fashion, and then only for the purpose of bringing evolutionary naturalism into relief. 
Monadism asserts that being consists of selves as substances which are literally discontinuous. The dogma that substances are self-sufficient and essentially isolated was characteristic of scholastic tradition. Spinoza, reacting reflectively upon the Cartesian philosophy, defended a monism of one supreme substance of which mind and matter are but attributes. Leibniz rejected this monism and developed his monadism. In this he was moving toward dynamism as against a static view. We must, however, criticize his inference that the physical world is unextended. While we would distinguish between mathematical space and physical reality, we are not forced to conclude that physical reality consists of inextended points. It is the dynamic connection of things which makes space a valid category of our knowledge. Probably Leibniz, the scientist, was misled at this point by Leibniz, the logician. In accordance with the thought of the day, he conceived a substance as a logical subject which included all the predicates assigned to it. It is true that he suggested the possibility of relational judgments, but the subject-predicate type dominated his thought. There were, undoubtedly, theological motives, as well, in his monadism. The monadic soul is a very familiar Christian conception.

Monadism has had its advocates in modern times. ${ }^{2}$ As nearly as I can grasp its motivation, it is twofold, logical and epistemological. On the one hand is the fact that consciousnesses do not overlap. The isolation of consciousness regarded as a substance impels the thinker in the direction of discontinuity. Even transeunt causality, the influence of one thing upon another, tends to be denied. The logical motive appears in the tendency to think of all objects of judgment as things having predicates. We shall have much to say of this later when we shall try to show that physical connections can be as much objects of judgments as are things.

It is interesting to note that philosophers who, like Leibniz and Bergson, approach their ontology from psychology are inclined to attack the objective validity of spatial dis-

2 Particularly Renouvier and James Ward. 
tinctions. $^{3}$ I am unable to see in monadism anything but a false conception of individuality, a view which identifies individuality wth isolation and ignores its conditions. It is tainted by subjective idealism and the too free use of analogy.

Idealistic monism, or absolutism, has already been briefly considered. It is a form of idealism which draws its strength from various sources. One source, the contradictoriness of the fundamental categories in terms of which we think the world, the argument of this book has continuously attacked. Building upon the self-contradictoriness of space and time, the absolutist is led to seek a principle which will take him within sight of what alone is real. This principle he finds in the ideal of self-consistency. But the absolutist has already built upon an idealistic epistemology. And this principle is to the realist simply a logical principle of thought. It is our intellectual nature to be unable to think contradictory propositions together to affirm them at the same time. Reality is determinate, and it is our logical ideal to have our thoughts about it self-consistent. Another principle which the absolutist employs is that there are degrees of reality. This principle also would be challenged by the critical realist. The evolutionary naturalist does not doubt that there are levels of integration in nature, but levels of reality is quite another, and very questionable, category which accompanies an unepistemological use of the distinction between appearance and reality."

The divergence between absolutism and critical realism comes to a head on the metaphysical side in the theory of individuality and the theory of relations as so internal that they destroy the reality of the terms. The absolutist asserts that the principle of individuality can be satisfied only in

3 Mitchell has pointed out this common attitude very well in his Studies in Bergson's Philosophy. Cf. p. 39, note: "Leibniz is properly regarded as the first modern spiritualist.... Bergson has no such clear and unambiguous conception of matter.... but there are passages in Bergson which might almost have been written by Leibniz himself." For a further consideration of this point, see Ch. XIV.

- Reality does not seem to me to be a relative category. 
the world whole. This the critical realist denies as based on false assumptions. He will maintain that the whole is not something additional to its parts. Parts and whole are inseparable; the whole is the parts organized together. And individuality exists only where there is in nature itself such an organization of parts into a functional whole. The relating by my mind of objects for the purpose of comparison does not make an individual. Such objects are members of a comparison, and what I am compelled to concern myself with is the properties of the objects rather than the objects themselves. Comparison works upon contents.

Finally, there is no good empirical reason for the assertion that reality as a whole constitutes an individual. Certainly there is no adequate ground for thinking the world after biological analogies. An individual is an achievement within the world furthered by wide-spread conditions of temperature and chemical properties and is therefore an exception. The limited inclusiveness of individuality would seem, then, to be an empirical fact which philosophy must recognize.

All forms of empiricism-whether idealistic or realistic - have tended toward a measure of pluralism. Pluralism, in contrast to monadism, admits continuity in the world ; but, in contrast to absolutism, denies that parts are swallowed up or that individuals are transcended in a mysterious whole. I presume that no one has argued the case against absolutism from the empiricist standpoint more vigorously and exhaustively than William James. With much of his argument I would agree; yet I am convinced that he could have handled the case more clearly still had he made the preliminary distinctions the critical realist is able to make.

Ideal, or Logical, Relations. - The impression left upon the student of contemporary treatments of relations is apt to be that of dialectic abstraction. One feels that the symbolism has come between the concrete data and their analysis. Suppose the data are symbolized as A R B. The very perceptual distinctness of the letters favors the suggestion 
that $R$ is an entity separate from the terms $A$ and $B$. The relation becomes an entity coordinate with the terms. It must be remembered that space separates as well as unites. This confusion between formula and meaning has often occurred.

The literature which has grown up about the discussion of relations is vast in extent and I shall not here attempt to cover it. What I shall try to do is simply to give my own conclusions and some justification of them.

First of all, the theory of relations has very little significance for epistemology because knowledge is a function of the knowing organism and does not imply a peculiar cognitive relation between subject and external object. The object is selected by the organism. Much of the stress upon the externality of relations has been the product of epistemological motives. The critical realist believes that his analysis removes these motives and puts the question of relations back in its proper place as a purely empirical question.

Logical relations are to be distinguished from sensible continuities and physical connections. Royce's definition of such relations seems to me essentially adequate. "In contrast with qualities," he writes, "the relations in which any object stands are characters that are viewed as belonging to it when it is considered with explicit reference to, that is, as in ideal or real company with another object, or with several other objects. To be viewed as a father is to be viewed with explicit reference to a child of whom one is father. To be equal is to possess a character that belongs to an object only when it exists along with another object to which it is equal; and so on."5

Logicians have discovered different types of logical relations. The basis for the discovery of these is empirical inspection. Thus every relation is found to have its inverse. If a book is on the table, the table is under the book. Again, relations are divided according to the number of things in the complex as dyadic, triadic, tetradic, etc. For instance,

- Royce, Encyclopedia of the Philosophical Sciences, p. 96. 
a gift implies a giver, the person to whom something is given and the gift itself.

Relations can be classified as symmetrical, non-symmetrical, transitive and intransitive. Thus symmetrical relations permit conversion. If $\mathrm{A}$ is like $\mathrm{B}, \mathrm{B}$ is like $\mathrm{A}$. Nonsymmetrical relations cannot be converted in this fashion. If $\mathrm{A}$ occurs before $\mathrm{B}, \mathrm{B}$ cannot be said to occur before $\mathrm{A}$. This is the very characteristic of the temporal order. Transitive relations deal with the passage from the relations between two couples to a relation between the extremes of these sets of couples. Thus if $\mathrm{A}$ is larger than $\mathrm{B}$ and $\mathrm{B}$ is larger than $\mathrm{C}, \mathrm{A}$ is larger than $\mathrm{C}$. These empirical groupings of relations constitute the supplementation which has of late years been added to the Aristotelian logic of classes. It is pointed out that subsumption involves a transitive relation as in the dictum of the first figure.

So far, so good. There is practically complete agreement upon this logical classification of relations. Relations are obviously relevant to their terms. But the logical problem was befogged with metaphysical implications. All relations were assumed to be the same. Ideal relations due to comparison were heaped together with sensible continuities and physical connections, and then the question was propounded in this fashion, Are relations internal or external? This question arose out of philosophical divergencies rather than out of a study of concrete instances of relations. Bradley is in large measure responsible for the heated form of the controversy because of the use he made of his dialectic in Appearance and Reality to reduce categories to appearances. The realist countered. If internal relations are those which modify the terms, external relations are those which do not, so that the terms can enter the relation without change.

The present drift is decidedly toward the admission of both internal and external relations. Thus mathematical points are conceptual entities independent of their particular position in the series. Yet they are identical apart from their order. On the other hand, the relations between chem- 
ical elements and the parts of living organisms are judged to be internal, because the terms are not the same apart from these relations. Such, we may say, is the rough empirical drift of opinion.

Let us first ignore the dialectic presentation of the problem. There are three types of relations: (1) sensible continuities, (2) relations of comparison between contents, and (3) physical connections.

It is generally admitted now that sensible continuities hold between sensible qualities. Both are characters of the sensible continuum. But these characters are neither passive nor active just because they are characters. It is absurd, therefore, to speak of them as internal or external. They are compresent with their terms. They are relevant to their terms. They have their own character and function which is that of being relations. To make them terms is to ignore their character and status. It is to take away from a continuity that which is unique about it. Abstract symbolism of the form A R B has ignored the concrete situation. $\mathrm{R}$ has seemed to be a distinct thing which must somehow be related to $A$ and to $B$ by new relations, and so on indefinitely. The whole problem is artificial.

Let us pass next to a study of relations due to comparison. We shall find a good point of departure in Taylor's exposition: "Put quite simply the problem is as follows: Things stand in a variety of relations to one another, and what we commonly call the qualities of each are dependent on $(a)$ its modes of relation to other things, $(b)$ its relations to our percipient organism. Again, the various qualities of one thing stand in relation among themselves. To begin with, they all exhibit the relations of identity and difference." The reader will note that the first class of relations are real connections, while the second class are products of comparisons.

We have already decided that our developed knowledge of physical systems is logically divisible into elements called properties. The data of sense are means to such critical

- Taylor, Elements of Metaphysics, p. 140. 
knowledge, although, at the level of common-sense realism, they are often taken to be aspects of physical things in their own right. These data are, as Taylor points out, functions of the actual changing continuities of parts of the physical realm as these parts impinge upon the sense-organs. The effects in the sensitive organism give clues for the study of the real relations of things to one another and thence to their nature as revealed in their interactions.

But suppose that we have attained a fair amount of knowledge of particular things by means of the logic and technique of investigation. We can, then, proceed to compare the various properties of one thing with the various properties of other things. This means that the specific knowledge about things is separable from the process of its attainment. For the attainment of further knowledge we may go on to institute comparisons between things as known. To take an easy example, I may compare a boy with his father. The boy $(\mathrm{W})$ is shorter than his father $(\mathrm{R})$. This is what is called an asymmetrical relation. We are able to make a judgment about these two realities as related to each other by our thought. Such a relating by our thought is not a physical relating. It is an indirect relating through the elements compresent in the mind as knowledge about them. It is by virtue of this compresence or real mental relation that the ideal relation is achieved. How shall we interpret the resultant judgment?

I take it as obvious that the definite character of each term is the basis of the comparison; and the comparison cannot be veracious if the process changes the terms. It is beside the point to call attention to color contrasts and the modifications which result, for the modifications precede the judgmental process. Let us call the terms between which the comparison is instituted the fundamenta relationis. Thus the size of the boy is the fundamentum in his case, and the size of the father the other fundamentum. We must assume that these sizes are known. The resultant comparative judgment gives knowledge of each term with reference to the other. The direction is either from boy to man or from 
man to boy. The boy is shorter than the father, and the father is taller than the boy. Similar judgments are those of equality in length, or mass, or weight, those of similarity of structure, shape, color, those of difference in this feature or that. Such judgments are valid judgments about specific parts of reality. What do they give knowledge about- relations or bodies?

Logical Considerations.-I shall take as my point of departure the statement made by a defender of mathematical logic who sees in it a Copernican revolution in philosophy. Russell claims that the belief, or unconscious conviction, that all propositions are of the subject-predicate form-in other words, that every fact consists in something having a quality -has rendered most philosophers incapable of giving any account of the world of science and of daily life. This is a grave charge and demands investigation.

What Russell calls relational judgments have usually been denominated comparative judgments. "If we say 'this thing is bigger than that'," writes Russell, "we are not assigning a mere quality of 'this' but a relation of 'this' and 'that'. We might express the same fact by saying 'that thing is smaller than this' where grammatically the subject is changed. Thus propositions stating that two things have a certain relation have a different form from subjectpredicate propositions, and the failure to perceive this difference or to allow for it has been the source of many errors in traditional metaphysics." Now if our own analysis be correct, we have in such a case an instance of a judgment attaching to a complex subject, a judgment due to the compresence of two objects in a single object of attention. Hence, the knowledge given is of a kind different from that resulting from the study of any one part taken singly. Yet it seems to me hardly correct to say that we have knowledge of a relation. Take, for instance, the proposition, " $\mathrm{A}$ is to the right of B." Such a proposition implies a complex object of attention in which $\mathrm{A}, \mathrm{B}$ and their relative position can be discriminated. The proposition involves a compre- 
hension of the system, and this comprehension implies various equally valid propositions. If interest focuses on $\mathrm{A}$, we say that $A$ is to the right of $B$; if on $B$, we say that $B$ is to the left of A; if on the spatial relation between them, we may say that the distance is so many inches and the line between them at right angles to another line. The knowledge of the system thus gives knowledge of all the parts.

Language forms have often played the uncritical thinker false. We speak of a relation of similarity between things, say such thinkers, therefore there must be a real relation called similarity between them. What we really do is to bring objects into a system and then note their character in the light of some query. If we still wish to call the products of such comparison, relations, we should speak of them as logical relations. They are relations between contents as contents, not sensible continuities nor physical continuities. They are predicates which the mind attaches to contents which are brought before it. Identity is such a predicate, so is similarity, equality, inequality. Objects can be arranged either mentally or physically in series corresponding to these predicates. Such comparisons help to give knowledge about the respective physical realities. The judgments of comparison are valid of reality because they are grounded in the determinate nature of things compared.

The objective reality of classes may be briefly considered at this point. It is obvious that we must hold that the members of the class are numerically distinct and that the grouping of them is the work of the mind. Platonic realism is a misinterpretation. Take the class horse. The various horses are existent physically, while the connotation is clearly mental. But we must add that the connotation is knowledge of the horse, knowledge of the determinate nature of every horse. Royce seems to have been very much bothered by this problem of the element of necessity and the element of contingency in a concept "That a particular physical or psychical relation, such as that of father and child, should be present in the world, is as empirical a fact as the existence of colors or tones. That there should be physical objects to 
classify, this again is a matter of experience. And furthermore every classification of real or of ideal objects is determined in any special instance, by a norm or principle which we voluntarily choose. And in so far classifications are arbitrary, and may be said to be 'creations' or 'constructions." "I I would make the point that, in natural classifications, the norm is the product of careful study of the objects which are seen to be similar. It is the result of mental activity but it assuredly is not arbitrary.

The fault with much of past dialectic on the subject has been its inherent tendency to abstraction and neglect of the empirical instances under examination. Thus in the field of mathematics the advocates of external relations have probably had the best of the argument; while in biology and sociology, where dynamic interaction is a marked feature, the advocates of internal relations have been more successful. Now critical realism points out that there is a prime difference between these two fields. The locus of the one is the field of mental essences; the locus of the other is existence. Neo-realism has helped us better to understand logical thinking which deals with concepts. It has stood for analysis and structure. But its epistemology led it to mistake logical distinctness for an existential pluralism of an Eleatic type.

Logical monism has been a feature of objective idealism. Underlying it has been the assumption that concepts are, or can be made to be, creative. Implication supposedly is an existential relation. A, for example, implies non-A. But, to the critical realist, this principle of formal logic has its locus only in the minds of individuals and has no bearing upon the connections in the physical world. The critical realist is an empiricist and experimentalist and cannot take a dialectic of concepts as a means of insight into reality. The whole thing seems to him artificial. You only get out of your concepts what is already in them.

Another assumption of logical monism is that, when two terms are related, a new whole is formed which is essentially

${ }^{7}$ Encyclopedia of the Philosophical Sciences, p. 120. 
different from the original terms. Empirically, there is much truth in this principle. The fault is that it is misused by being pushed too far. The monist maintains that the whole engulfs the parts so that it becomes something distinct from them. He reifies the whole and makes it a thing transcending the parts. Thus the State is not so much an institutional organization of citizens as a something above and beyond them. The tendency of the logical monist is to ignore the parts and to regard all judgments as bearing upon the whole. But this view ignores the actual facts. The truth is that we can make true judgments about both the whole and the parts. We can say that the heart is above the diaphragm just as we can say that the organism tends to act as a whole. Asymmetrical relations, such as $\mathrm{H}$ is above $\mathrm{D}$, clearly hold only between parts and yet tell us in a measure what kind of a whole we have by indicating its structure.

Finally, logical monism has expressed the absolute idealist's desire to bind the whole world into one by means of the cognitive relation between the supreme mind and its objects. A cognitive unity was to replace the spatial continuity which experience indicates. It was a grandiose effort motivated by the religious view of the world. Critical realism undermines it by the proof that there is no cognitive relation even in the case of finite minds. Knowledge is a conditioned function and not a semi-physical connection uniting subject and object.

A Summary.-A summary may assist the reader to gather together the results of our argument. We have distinguished between sensible continuities, physical connections and logical comparison. These distinctions, together with the definite epistemology which has gone with them, have enabled us to steer clear of customary simplifications.

In continuities the relation is given with the terms and is a characteristic and relevant union of them. To make the relation a concept is to make it an entity which must be related to the terms by comparison; and this is to falsify the actual situation. It is always best to bear in mind the 
concrete instance. We have terms in relation and not terms and a relation.

If sense offers the material out of which the mind builds knowledge, knowledge, itself, demands the power to relate contents before the mind's eye. Contentual objects become compresent in comparison to form a peculiar whole in which the parts retain their characters. Such a synthesis is a psychological fact which every one can verify for himself. Did the synthesis involve a change in the parts comparison would defeat its own purpose. The contents are the terms of the comparison, the fundamenta relationis, and the predicates very obviously apply to these terms and not to the total object of the attention. We may say that this content is identical with that, or similar to it, or greater than it, in accordance with the problem in hand. The very nature of the predicate involves this duality. It is clearly absurd to talk of the total object of attention as being similar to, or identical with, or greater than. I am unable to see in all this anything but an empirical problem of logic and psychology. The customary dialectic strikes me as quite gratuitous and irrelevant.

In all series, then, we have continuities. And these continuities may be the object of judgment. It is only then, I would say, that we have relational judgments, that is, judgments dealing with relations. In comparisons we are primarily concerned with the relata. These are compresent in the mind. This compresence changes them only accidentally as in the case of colors and is not meant to change them. And in the case of concepts I do not believe that the relata are always changed. In this field, then, we do have external relations, or, better, an external relating. But the advocates of external relations at large have not really had this in mind. Like the advocates of internal relations, they went at the question wholesale.

It is for the scientist to tell us of the nature of real connections; and he is beginning to assert that many of these involve the change of the terms as they previously existed. This is the so-called creative synthesis upon which the evo- 
lutionary naturalist builds so largely as against the Eleatic atomist. But there is nothing in this definitely localizable, creative synthesis which points to the cherished notion of the objective idealist that the universe is an individual. There is discontinuity as well as continuity in our world. We must be more empirical in our appreciation of relations. There are degrees of internality, and complete externality is of the nature of a limit. Individuality is an achievement in the world and requires its setting. The new pluralism is in the right of it. 


\section{CHAPTER XI.}

MOTION, FORCE AND ACTIVITY.

$\mathrm{N}$ the present chapter, I shall examine certain categories I which we very naturally associate. It is my purpose not to summarize the conclusions of the sciences and present their technical definitions but rather to examine the terms and relate them to their foundation in human experience and to their significance for knowledge. The philosopher of these post-Hegelian days has relinquished the rôle of dictator or teacher to the sciences. He realizes, with becoming modesty, that knowledge arises from creative immersion in the data of a discipline and that he seldom has time or training to make a contribution. The philosopher is primarily concerned with implications and assumptions of a very general nature.

Motion as a category has always been of interest to the philosopher because of Zeno's paradoxes. This ancient worthy helped to drive home to the thinker the necessity of conceptual analysis. Motion seems to include synthetically space, time and change. In our day Eleaticism has been attacked by the intuitionalist Bergson in one way and by the mathematical rationalist Russell in quite a different fashion. Again, motion has been brought sharply to the front by the theory of relativity as formulated by Einstein. Is motion necessarily relative?. And are spatial and temporal measurements variable with the system of coordinates chosen? Finally, motion as a category of our knowledge of nature is peculiarly interesting because it has played, and still plays, 
an important rôle in the descriptive interpretation of the physical world. Does all change involve motion even if not reducible to it as in the mechanical theory? It is no wonder that the philosopher cannot desist from reflection about motion. He is drawn to it as irresistably as the moth to the flame, and the parallel may not stop without the singeing.

I shall follow philosophical usage and employ the term force to cover the dynamical aspect of reality. So used, it calls to mind both force as a technical term of mechanics for a measurable quantity and energy as a capacity for doing work and, at the same time, suggests the question of the dynamic nature of physical reality, of that whose processes are describable in these scientific terms. The critical realist is forced by his epistemology to raise this further question. Unlike the idealist, he cannot dismiss such ideas as quanta, tensions, electrons, fields of force, etc. as mere ideational shorthand. For him there are in them both symbolization and knowledge. The philosopher follows the scientist from geometry to kinematics, thence to dynamics and energetics, from the study of mathematical space to physics, chemistry and biology ; and, surely, as he does so, his sense of the substantiality and active functioning of physical things as parts and as organized wholes increases.

But change seems to be too passive a term. The mind seeks for a source and cause of change, for its origin in reality. Force and activity are terms which suggest themselves in this connection. But what do they indicate? Are they interpretative categories which arise from the objective data of science? Or are they projected into nature from the self? Do we add our own sense of agency to the knowledge which we have of things? These questions demand careful consideration.

As a matter of method, we shall begin with the analysis of motion and pass to force and activity only after having laid a descriptive foundation of this sort. We shall adopt our usual genetic method and distinguish between sensible motion, the conceptual idea of motion, and motion as a real 
dynamic change in nature. In its attempt to understand the physical world, science uses the category of motion as the essential framework of its thought. Any attempt to prove the idea of motion to be self-contradictory is an attack upon motion as a valid category of knowledge.

An Application of the Genetic Method.-The psychologist tells us that there are two ways of experiencing motion. "In one," writes Pillsbury, "we know merely that an object has moved; in the other, the object is seen to move. The difference is shown by the second hand and the minute hand of the watch; one can be seen to move, the other we know to move only because it changes its position between observations." ${ }_{1}$ The watch is the stock example but in nature we can contrast the movement of the sun with the flight of a bird. There is an immediate difference between perceiving a thing move and knowing that it has moved.

After-images are essential to the perception of motion. If the hand is moved across the field of vision, it will be noticed that there is a streak behind it that persists for a brief time. The motion is perceived on the basis of this image. The experience of motion involves a mental synthesis. There is, also, much that is inferential in the ascription of the motion experienced. Very often it is referred to the wrong object. This fact indicates that it cannot be an intuition of a quality in the object itself. There are many illusions which bear upon this point and bring out the primitiveness of the sense of motion as against its location. "If the reader will touch his forehead with his forefinger kept motionless," writes James, "and then rotate the head so that the skin of the forehead passes beneath the finger's tip, he will have an irresistible sensation of the latter being itself in motion in the opposite direction to the head." ${ }^{2}$ At first motion is a feeling or sense of change which spreads over the entire field and infects it. Knowledge, that is clarification and distinction, enters gradually to bring about the proper reference. But such knowledge does not always

1 Pillsbury, Essentials af Psychology, p. 171.

2 James, Principles of Psychology, Vol. 11, p. 172. 
possess a clue sufficient to interpret the situation. In such cases we have what are called illusions. "We know in all these cases," writes James, "what really happens, but the conditions are unusual, so our primitive sensation persists unchecked. So it does when the clouds float by the moon. We know the moon is still; but we see it move even faster than the clouds." Another fact is sufficiently important to justify mention. The sense of motion is so delicate that it is impossible to derive it from a sense of position which is usually less delicate. The sense of something moving is even prior to the sense of succession. There is an obvious biological reason for this endowment. No doubt every one has observed how things which move unexpectedly attract attention.

From these facts and well-grounded theories we may conclude that the perception of motion is an experience which has a very primitive foundation in the psychophysical organism, that it is widened and rendered more precise by the gradual increase of ability to discriminate positions. When the adult sees a thing move, he has a sense of motion qualifying a more or less definite appreciation of relative positions.

Inferred motion, also, requires psychological analysis. The fact of any such kind of motion is a judged alteration of position in a thing. A single perception cannot give the data on which to build inferred motion. But since there is no sufficient reason to impugn memory, we account for a judged change of position by motion of the sort perceived. But, in so doing, we at the same time intellectualize perceived motion. Let it be remembered that in perceived motion there is a continuous change of position.

$A$ Return to Space and Time.-When we analyze the thought of motion we discover that it involves a peculiar correlation of space and time. As regards space, it is an ordered change of relative position; as regards time, it is an order of moments corresponding to these positions. The orderly change of position is a series of events. But we 
must add to space and time as correspondent orders this primary sense of transition to get the true experience of motion. Motion is for common sense a behavior of things, and this behavior appears in space and time characters.

The fundamental difference between mathematics and science consists in the fact that mathematics is a science of order as such, whereas science concerns itself with an external world. Sometimes mathematical physicists have come perilously near to forgetting this basic distinction. Thus pure mechanics has been taken for physics. But the student of mechanics should never forget the abstractions he has made and the conventions he has allowed himself. Let it be granted that it is his purpose to describe motions in nature. Yet he does so with the aid of concepts which must not be reified. He can treat a large body as a mathematical point in which mass is concentrated but he must not forget that this treatment is a convention for the purpose of handling his material.

This problem has been pretty well fought out. The mechanics of Boscovitch and the vortices of Kelvin are no longer seriously taken as adequate knowledge about matter. Matter is the stuff about which all the empirical sciences are trying to gain information.

But while mathematics as such is not a physical science, it is a fundamental aid to physical science. It is a science of order, and nature is a realm which possesses order as we have shown by our epistemology. Thus there is a natural correlation between mathematical order and physical order, the genetic basis of which we studied in our consideration of space and time. Nature geometrizes in its own fashion under the play of its own forces. Mathematics, on the other hand, develops under the creative play of the human mind. It has a richness of content to-day which cannot be explained by a slavish imitation of nature. Mathematics is an art which gives sweep to the abstract imagination. It is an historical product. In the jargon of philosophy, it is a science of subsistence rather than of existence.

Let us recall, also, that mathematical space and mathe- 
matical time are constructions which must not be reified. They are subsistences and natural tools of human thought. Real space we have seen to be the dynamic continuity of the physical realm, and real time to be the changes which occur there. These changes may be agglutinative and involve the increase of potential energy as in all kinds of orthogenetic evolution whether of atoms or organisms, or they may be dispersive as in the kinetic theory of heat. But mathematical time means a peculiar order and a measurable lapse or time distance.

We have argued that knowledge is seen to diverge from being and is not a mere copy of it. In knowledge, we relate the present to the past and predict the future; in being, only what is $i s$. This situation must be borne in mind in the case of motion. We must distinguish between physical motion and mathematical motion though admitting a correspondence. That a body was in a certain place at a certain time is knowledge about the body. That motion can be best described mathematically as a correlation of position and moments is the affair of mathematics.

It may be well to refer briefly to the theory of relativity. Personally I doubt whether the theory has far-reaching metaphysical implications, tremendously important as it is for physics. Assuredly I reached the idea of real time as change in nature apart from the relativity theory. And my conclusion brings real time and real space together. And surely philosophy had long ago outgrown Newtonian absolute space and time as receptacles for things and events. I quite agree, therefore, with Broad's view of the matterand Broad is an ardent admirer of Einstein - when he writes as follows: "So far, then, from Einstein's way of looking at things being a piece of speculative metaphysics, it is a resolute attempt to be as empirical as possible. It is the consistent application of the principle, enunciated ad nauseam by earlier physicists but never really carried to its logical conclusion, that we can and do know nothing but relative motion."3 The physicist must have an axis of

3 Broad, The Hibbert Journal, April, 1920, p. 439. 
reference, and there is nothing absolute about any axis he may adopt. I would, however, call attention to the fact that in our own case we know that we initiate motion, as in walking, and that something similar to this takes place in explosions. We must not confuse the kinematic description of motion with the activity itself. To say that I can consider the earth as moving in the case of my walking just as much as myself as moving is to ignore additional information.

Simultaneity is an experience in consciousness. But we have no guarantee that two external events are simultaneous; and events which are given in consciousness as not simultaneous may have been so, as in the case of thunder and lightning. The critical realist is not troubled by these facts. How then shall we define simultaneity for the external world? Does the statement "simultaneous events are those which happen at the same time" really mean that we can conceive a class of events existent with, say, my present thought? To the philosopher, time is not an entity Only the events themselves are real. ${ }^{4}$

But though I can conceive such a class of events, it is another thing to apply my concept and determine what events are actually simultaneous. To do this is the task of the physicist. The dating of events is an operation which involves technique. Einstein points out that it requires a stipulation. $^{5}$ And this stipulation involves measurement. And it can easily be shown that this measurement varies with the system of coordinates to which it is referred. What is simultaneous to one system will not be simultaneous to another system.

It is clear that Einstein's theory brings home the fact that experienced time order is, just like any other datum, a function of conditions. We are very much aware of this for spatial order, for we see how shape changes as we approach or depart from an object. To have driven home the corresponding fact for time is his honor. Knowledge

4 Cf. Russell, Scientific Method in Philosophy, p. 117.

${ }^{5}$ Einstein, Relativity, p. 28. 
is a construction based upon the use of data. We cannot intuit a privileged point of reference as Newton tended to suppose. What we do need is a system for transforming measurements from one system of coordinates to another moving uniformly with that or even, as in his general theory, moving in other relative ways.

Into a discussion of the more general theory of relativity and its application to gravitation I do not feel myself competent to enter. That is as yet an affair for physicists and astronomers. The following points are of peculiar interest to the philosopher: (1) that the geometrical properties of space are not independent, but are determined by matter; (2) that the universe is finite and probably non-Euclidian. Both of these conclusions are in harmony with our own views. For us spatial reality is distinct from mathematical space. But, as a philosopher, let me frankly admit that philosophy has no special source of information and could not tell by mere analysis whether real space were homoloidal or not, whether the physical universe were finite or infinite. By himself, the philosopher would not have either the data or the technique.

Relativists describe events by means of the space-time continuum of four dimensions. In itself this device is not novel. But the time dimension has a different value from the Newtonian because of its dependence upon the axis of reference. The result is that the time dimension is a variable when a transition is made from one system to another. But I think that we should bear in mind that in all this we are concerned with descriptive knowledge of external events.

Does it follow from the theory of relativity that we can conceive only relative motion? I do not think that it does, though at times Einstein seems to imply this view. Let us approach the point in an historical way. While the geocentric astronomy dominated thought, the earth was held to be an absolute point of reference. It was at rest and all moving bodies should be referred to it. If we accept a stagnant ether, it will take the place of the earth as an absolute reference. The empirical fact is that we cannot 
use the ether in measurement because there is no way of getting at it. The ether carries light but does not emit it. Hence it cannot be perceived. But perception is not the sole test of being. That which is implied by what is perceived must also be considered to exist.

Again, purely conceptual motion can be referred to an axis of reference which is also conceptual and postulated to be absolute. When we think of the stagnant ether as a background of motion we are thinking in this fashion. What holds for the subsistential realm, however, does not necessarily hold for the physical world. Experience, alone, decides what our situation actually is.

Zeno's Paradoxes.-We hinted at the beginning of the chapter that Zeno's paradoxes still disturb philosophy. Both Bergson and Russell have plumed themselves on meeting them by a shrewder treatment, Russell by analysis and Bergson by intuition.

Zeno's paradoxes serve the purpose of forcing the thinker to define his terms and state his assumptions. Let us examine his proof that the moving arrow is at rest. "You have an idea that the arrow flies through space. But in order to reach its destination, it must pass over a series of points in space; hence it must successively occupy these different points. Now to occupy a point of space at a given moment means to be at rest and its movement is but illusory." Is it the assumption that the moving body occupies positions in the sense of resting in them? And what are positions or points? Are they extramental realities with which moving bodies enter into relation? Or are they points of cognitive reference?

We will remind ourselves that mathematical space must not be reified. Locations of things, on the other hand, are cases of preliminary knowledge about them. And the same is true of those flying locations or snapshots which attempt to tell us where a thing was at a certain time. It is obvious that a moving body never occupies points; for points are elements in the mental system which correspond to the real 
process of motion. The real motion is projected into the medium of consciousness and there secures a conservation and extension which serves as the basis of the descriptive knowledge that concerns kinematics.

The paradox of common-sense realism displays itself again. We rest in the perceptual fact and surround the moving thing with predicates of power. We feel that something dynamic is occurring out there. And yet, when we come to analyze the content of perception we can discover nothing but change of place of a sensibly continuous kind. We should not forget, however, that we can know the motion of an object in terms of its possible effects. It is only in this empirical way that we obtain those quantities which we call energy. If motion is an actual condition out there, we can never hope to intuit it as such. We can only gain knowledge through data of various sorts.

In his construction of motion the mathematician abstracts from the knowledge of the physicist and concerns himself with the attempt to think motion as change of place in time without contradiction. This description naturally uses mathematical space and time. Conceptual continuity is substituted for sensible continuity.

What the mathematician tries to do, therefore, is to describe motion in terms of spatial and temporal order. What the physicist wishes to do is to study the moving body, the antecedents of its motion, its energy, etc. The physicist's aim is furthered by the mathematician's analyses and technique.

Bergson has been extremely sceptical as to whether the mathematician could so conceptualize motion that he could escape a cinematographic version of it as an intermittent process. I believe that Russell has shown that the modern mathematician has attained this descriptive goal. "The solution," writes Russell, "lies in the theory of continuous series: we find it hard to avoid supposing that, when the arrow is in flight, there is a next position occupied at the next moment; but in fact there is no next position and no next moment, and when once this is imaginatively realized, 
the difficulty is seen to disappear."' Let it also be remembered that rest consists in being in the same position at all the instants throughout a certain finite period, however short; it does not consist simply in a body's being where it is at a given instant. Thus I am quite unconvinced that the intellect is at fault.

It would seem unwise not to examine Bergson's treatment. The idea of mobility as an intuition gained from an intense inspection of consciousness plays a large part in his metaphysics. He is a modern Heraclitean who stresses internal relations and the absoluteness of change. He is skeptical of the value of concepts. He wishes to penetrate to what is immediately given and believes that he finds a flux. Personally, I find both recurrence and change. The intellect seems to me to illumine experience. I presume the reason why I find his anti-intellectualism distasteful is that it is directed against a type of intellectualism which has had little currency in America and England. I hesitate to accuse him of holding that a concept of change must be a changing concept, but his statements sometimes suggest such an interpretation.

It is difficult to follow Bergson's treatment of motion. With his attack upon a snapshot view of motion which leaves out the transition which is the heart of motion one can of course most heartily agree. But he seems in the main to be dealing with the experiential elements of the idea of motion rather than with the completed idea. In the notable study of motion in Time and Free Will, he analyzes the idea into two elements, homogeneous space and a qualitative act. "Space contains only parts of space, and at whatever point of space we consider the moving body, we shall get only a position. If consciousness is aware of anything more than positions, the reason is that it keeps the successive positions in mind and synthesizes them." Now we have so far a matter of the psychology of motion and I think that there is nothing novel in his position. But

${ }^{6}$ Russell, Scientific Method in Philosophy, p. 174.

7 Op. cit., p. 110. 
exactly what is Bergson concerning himself with? The sensible experience of motion? The mathematical concept of motion? The behavior of the objective physical thing? $\mathrm{He}$ asserts that the second element of motion, the act of synthesis, has no reality apart from consciousness. It is a quality or an intensity. But has homogeneous space, the second element, any external existence either? The critical realist would certainly say that it has not.

Bergson's solution of the Eleatic paradoxes consists in the claim that they confuse motion with the path traversed. There is undoubtedly a measure of truth in this contention. And assuredly motion is other than the path traversed. Motion is a kind of change. It is a change of position which corresponds to a period of time. But motion as a physical event cannot be exhausted by kinematics. It is a case of behavior implying energetics. In short, the critical realist finds that both Russell and Bergson supplement one another but that both stop short of the further problems which physical realism raises. It is to these that we now turn.

The Movement versus the Path Traversed.-Real time is change, and change is thinkable only in the temporal order of succession. This temporal order is always connected in our experience with a sense of duration. This indicates that each process has a speed which is as characteristic of it as the order of succession itself. By kinetic time, science measures those quantities which it calls velocities, accelerations, etc. That one process takes longer to occur than another is genuine knowledge of it. But there is clearly nothing intuitional in such knowledge.

Real motion seems to be the behavior of a body as expressive of energy changes. This behavior is projected into consciousness on the background of other bodies. Hence, as Einstein has seen, the location and description of it must be relative. Gross motions are visible, that is, can be detected by the eye. But science informs us that all sorts and degrees of motion are occurring in bodies which are not translated. There are molecular motions, atomic mo- 
tions, intra-atomic motions. In fact, science has tended to correlate all change with motion. But motion is not necessarily of that free, isolated kind that the older mechanical view universalized. And we must remember that motion is only the behavior of things and their parts; it is not a peculiar kind of entity.

Kinematics is an abstract science which studies the paths traced by moving bodies and the ratio between space and time as measurable quantities, ratios which come under such heads as velocities and accelerations. So far as there are repetitions, predictions can be made. To know that a certain comet will appear in the sky again after so many decades is knowledge about the behavior of the comet in its system of forces.

But when we pass from kinematics to dynamics, we meet the further question of the origin, character and energy of the moving body. We are brought face to face with causality and force. Contractions of my muscles cause my body to move. A shell moves because of the explosion of powder. New knowledge enters to supplement kinematics. There is something differential and specific. The difference between gravitational energy and these more localized kinds lies here. And, as nearly as I can make out, it is the universality of gravitation which makes it a proper subject for kinematics.

From the dynamic point of view a moving body does not occupy positions in an Eleatic sense because it is in motion and it would require more than a point to stop it. In other words, mechanics gives us knowledge about the behavior of bodies with respect to the acquirement, possession and relinquishment of the conditions known as being in motion. And it is well known that mechanics began with the study of molar bodies and worked out its ideas and laws from them. It is to-day being realized that such bodies are complexes and that these laws may need reinterpretation and refinement as being derived rather than primary. What is mass? What is inertia? Are these ultimates or variables? 
And surely we must not take inertia to be an innate quality and assume that matter is literally inert and inactive.

Typical Problems.-It has taken time to form adequate ideas on all these subjects. An historical approach is extremely illuminating. We see geniuses like Aristotle and Archimedes groping over what is now clear to us. In his Mechanical Problems Aristotle asks question after question. Why is it that a balance moves more easily without a weight upon it than with one? How is it that, if you place a heavy axe on a piece of wood and put a heavy weight on the top of it, it does not cleave the wood to any considerable extent; whereas, if you lift the axe and strike the wood with it, it does split it, although the axe when it strikes the blow has much less weight upon it than when it is placed on the wood and pressing on it?

Take, again, the controversy over the concept of force. The majority of philosophers have stressed its psychological nature. Have we a right to objectify this experience? Mach asserts that the concept of force is a survival of fetishism. Kirckhoff takes the wiser position of ignoring the metaphysical problem and pointing out what science can do. "I propose as the problem of mechanics," he writes, "to describe the motions which occur in nature, and, forsooth, to describe them completely and in the simplest way. I will further add that it should deal only with this, to state what the phenomena are, not to determine their causes." To the critical realist, this means that the scientist concerns himself with the specific knowledge experience mediates.

The ancients went on the supposition that motion would naturally slacken with time; Aristotle's difficulties on this score are notorious. When we consider this problem, we are straightway led to ask why this assumption seemed so natural. The answer is that bodies on the earth do actually stop sooner or later. The reason for such stoppage was not investigated and understood in mechanical terms. The consequence was that the axiom of scholastic mechanics founded on the naive view was discovered by the Coperni- 
cans to be inadequate. This contrast has been admirably brought out by Painlevé as follows: "For the scholastics, there was no such thing as acquired velocity. When one separated a material element in movement from all other bodies the element would immediately stop. According to the Copernicans, on the contrary, it would guard its velocity in magnitude, direction and sense." Thus the scholastics believed that neighboring bodies contribute its velocity to a material element at each instant; while the Copernicansin this followed by Newton-held that neighboring bodies only modify the acquired velocity of the element. Now this latter conclusion has justified itself by its ability to explain occurrences and has latterly become an integral part of the principle of the conservation of energy.

From the time of Hume, at least, impact has presented a problem. When one billiard ball strikes another, the second ball moves. Such motion is a fact both kinematic and kinetic. The capacity of the second ball has increased by a definite amount which is called its kinetic energy. We see nothing new about the ball and yet it behaves differently and can do work. What has happened? We say that it has acquired energy. But energy is not something which can be seen. It is indicated by effects and measured by them. We have, in other words, knowledge about the increase of energy but not intuition of it. The paradox of commonsense realism again confronts us. A moving body is somehow different from a body at rest; and yet we cannot see anything about it which gives it this power. We perceive the motion and learn by experience that a moving body can do things which a body at rest cannot. No peculiar sensedatum gives us insight into the change.

Now the scientist has relinquished the intuitional ideal of common sense and is satisfied to gain what knowledge he can of behavior, preferably in a quantitative way. The critical realist points out that he follows the only path to knowledge. Crude perception deals only with gross effects and reveals very little about an object. It requires analysis and, as it were, burrowing into the parts and their relations, 
before elasticity, compressibility and kinetic energy are in any measure understood. They are then seen to be resultants of internal structures, tensions and responses. Knowledge we have, but never the intuition of which naive realism dreams.

Sometimes energy has been thought of as an entity which can be released in quanta and wander off freely as a peculiar stuff. The transformation of energy was then conceived as the transformation of this stuff into stuff of another kind. It is doubtful whether there is free energy of this sort. Energy seems always to be connected with matter, ponderable or imponderable, as a condition of tension or release. In matter, potential energy of an internal sort seems to be a condition of organization. Chemical systems contain an immense amount of potential energy. This seems to indicate a dynamic structural union in which new wholes are obtained. Undoubtedly we have to do with internal relations which elicit new properties. And yet we are clearly confined to a knowledge which is necessarily so little revelatory of aught but structure, composition, behavior under different conditions and quantities of various sorts that it baffles the metaphysician who cannot but wish to penetrate somehow into the heart of the object in a more intuitive way. The knowledge mediated by sense-data and intelligence falls far short of a complete revelation. But he who grasps the nature and conditions of external knowledge is not likely to have a crude idea of physical reality. He who simply equates the knowledge gained by the ordinary physical sciences with being and does not realize that it is only such knowledge as can be gained in this way is led to dualism. In short, knowledge may be valid and yet not exhaust reality.

Motion and Force.-As I use it, force is admittedly a vague and treacherous word. We are warned by many critical scientists to avoid it altogether except as a technical term in mechanics. And assuredly they are right in so far as they wish to warn us against the multiplication of peculiar kinds of forces as explanatory causes. An explanatory 
cause must be antecedent conditions and processes in nature as known, and force as a thing-in-itself cannot be such an explanatory cause.

But when we dig a little deeper into the situation, we find that, while force and matter in their untechnical sense have no explanatory relevance in science, they indicate the realist's conviction that being is other than the contents of knowledge, that physical things are substantial and have a determinate nature which must express itself in what occurs. Back of these terms, the sense of objective determination lies. Our sense-data and our concepts have no obvious physical efficacy, but we are convinced that processes out there are rooted in something massive and efficient. Of this dynamic agency we can, as Hume pointed out, gain no intuition. ${ }^{8}$ Our knowledge is essentially descriptive and cannot, from its nature, setting and material, introduce us into the mills of physical reality. Knowledge is pale and symbolic as compared with the processes which occur.

Yet the very affirmation of existence, when combined with the specific knowledge which our minds working ingeniously on data can achieve, leads us inevitably to realize that existents are full and not empty, and that this fulness of existence is effective and behavioristically meaningful. To be is to be something, and to be something is to make a difference to other things, to repel them, to attract them, to combine with them creatively, all of which terms are after all descriptive and not intuitions of peculiar forces. The critical realist knows that physical reality is existent in its own right and that knowledge merely records as best it may what goes on. How could we affirm the existence of and claim knowledge of what had no nature in its own right? It would be absurd to assert the existence of a thing which was nothing and claim knowledge of what was nothing. The modern realist opposes the positivist who asserts that he has no concern with existence.

We must recognize, therefore, that the object of knowl-

${ }^{8} \mathrm{We}$ are quite able to avoid naive anthropomorphism. Cf. Soddy, Matter and Energy, p. 20. 
edge is no mere passive entity but a dynamic and structurally organized stuff. To be is to count for something, to play a part in what goes on, to make a difference. In a broad way, activity, or force, is a category which grows out of the data of knowledge. It is not that we have an intuition of productive agency or that we reify our motor sensations. Rather is it that we realize that change is rooted in the very nature of things and expressive of them.

The Dynamic versus the Inert.-Idealism has always found its metaphysical strength in modern times through the assumption that activity is a category of spirit and not of the physical world. Both Leibniz and Berkeley argue from this premise. What shall we say of it?

The critical realist points out that he does not expectas Berkeley apparently did-to find a quality called activity in his sense-data. "All our ideas, sensations, notions, or the things which we perceive, by whatsoever names they may be distinguished, are visibly inactive-there is nothing of power or Agency included in them. So that one idea or object of thought cannot produce or make any alteration in another. To be satisfied of the truth of this, there is nothing else requisite but a bare observation of our ideas." " But these data of knowledge force us to develop the category of activity and apply it to physical nature. It is not that we intuit activity out there but that we are obliged by our data to postulate it as a characteristic of things. Clearly it is not a distinctive quality which can be reproduced in our ideas but a mode of behavior which is the opposite of passivity and inertness. To condemn data for not containing that which from their nature they cannot contain is the mistake of spiritualistic activism. The critical realist expects less from knowledge for he knows its nature and conditions. If activity is an objective category, it must grow out of the material offered to observation. Subjective or experienced activity must, of course, harmonize with activity as a category of physical science but they need not be identical.

- Berkeley, Principles of Human Knowwledge, Sec. 25. 
The point is this, because the content of our knowledge is passive, it does not follow that the object of our knowledge is. Does a concept of activity need to be itself active? Activity as an objective category is a concept and not a feeling of activity to be intuited and read into things. It expresses a kind of behavior. Yet the history of metaphysics is full of the easy assumption that only the will is active and that nature must be interpreted in analogy with the active and conscious self.

Mechanics is apt to be dominated by what may be called a mathematical rationalism. The physical world is equated with certain abstract concepts. Thus it is well known that the older physics thought of the ultimate particles of matter in terms of inertia. Inertia was exalted into an absolute and innate character of the stuff of reality. But we realize now that inertia is a behavior concept valuable for mechanics but having its obvious limitations. In the other sciences to-day such terms as adjustment, mobile equilibrium, interaction, stress, tension and energy are employed. These are dynamic terms. Physical reality is quite clearly not inert and passive. It is mobile and replete with tendencies.

Early reflection was too largely a transcription of the gross data of perception. It was the motion of masses which was stressed. I cannot help feeling that the sense of passive bulk was largely introjective. Mass was thought of as that which had to be lifted and moved. Much has been said in philosophy since Hume's day about the danger of reading muscle sensations of effort into nature. The opposite is surely also true. We must not read into nature a sense of resistance and of gross lethargy.

It is from the more concrete sciences that modern dynamic ideas spring. Experimental physics, chemistry, biology and psychology, all are flooded with the appreciation of tension, adjustment, equilibrium, growth, interdependence. We do not literally intuit activity in nature but we intellectually grasp it as that which alone comprehends organization and change. Reality is active in the sense that things get done, that unions are formed, that new properties arise. 
Matter is no longer thought of as the passive potentiality of Aristotle which receives but does not control. Nor is it an inert stuff buffeted about by other inert masses mysteriously in motion. No; the physical world can be considered the source of ideas, as it can be adjudged the locus of evolution. We cannot permit Berkeley to wave it aside so lightly in his desire for a proof of theism; we cannot permit without a protest the assertion that our notion of activity is gained wholly by observation of ourselves, that in attributing activity to inanimate objects we really endow them with the sort of activity which we perceive in ourselves, and that, in fact, there is no activity save soul activity. ${ }^{10}$

A certain element of what some may call agnosticism must be cheerfully admitted. Knowledge is a groping human affair. It is gleaned by a painstaking interrogation, correlation and analysis of sense-data. But such sense-data must have their limitations as conveyers of being. There is necessarily something so intimate, something so inseparable from the very stuff of being in its activity that it is not surprising that sense-data cannot transfer it in a direct fashion but can only give knowledge of the "powers" of things through results of a structural and quantitative sort. The critical realist must always contend against that supranaturalistic and intuitionalistic view of knowledge which makes it like an all-seeing eye searching into the depths of being. The knowledge which man is achieving is wonderful, and the more so, the more we realize how it must be deciphered from the code of data which things arouse in us. That sense-data, causally conditioned by the mechanism of sense, can furnish the material to the mind of so much information is matter for congratulation. And a false ideal should not be allowed to belittle this actual knowledge. Just as man has had to outgrow unmeaning visions of absolute perfection before he could see human conduct aright, so must he see the absurdity of the immediate and undimmed inspection of the energies of being. What we call the ob-

${ }^{10}$ Cf. Calkins, The Persistent Problems of Philosophy, p. 81. 
jective category of activity or dynamism is, like all realistic categories, founded upon the pattern of experience.

The Significance of Activity-Experiences. - Berkeley's idea of mental activity is clearly naive and unanalytic. "I find," he writes, "I can excite ideas in my mind at pleasure, and vary and shift the scene as oft as I think fit. It is no more than willing, and straightway this or that idea arises in my fancy; and by the same power it is obliterated and makes way for another. This making and unmaking of ideas doth very properly denominate the mind active." 11 Hume very properly points out that we are not aware of any creative fiat or power. We simply discover that, on the whole, ideas arise according to certain principles. We are recipients of ideas rather than their obvious creators so far as the conscious self is concerned. The activity must be assigned to the brain-mind, and so becomes strictly of the same type as that with which physical science is concerned.

Of recent years there have been many penetrative discussions of activity. James Ward, Stout, Bradley, Angell, Laird, Perry, Bergson and William James have added to our understanding of the problem. It seems pretty clear that we must relinquish any special element which may be called an activity-feeling. Rather is activity an empirical experience of a complex sort just as the experience of passivity is.

When we examine our experience to discover the various types or qualitative degrees of the sense of activity, we find (1) bare activity, the feeling of change, of something doing: (2) changes in which there is a sense of direction as in striving and desiring; (3) the experience of assent or choice in which we appear to ourselves to decide the course of events to a certain extent by our fiat; (4) the maintenance of a choice or purpose in the face of obstacles. It is in the last type of experience that we have the fullest sense of activity, and, be it noted, it is not a special sensory element but a Gestaltqualität. Thus James: "Those factors in those relations are what we mean by activity-situations;

${ }^{11}$ Principles of Human Knoweledge, Sec, 28. 
and to the possible enumeration and accumulation of their circumstances and ingredients there would seem to be no natural bound." There can, I take it, be little exception to the empirical conclusion he draws: "The experiencer of such a situation possesses all that the idea contains. He feels the tendency, the obstacle, the will, the strain, the triumph, or the passive giving-up, just as he feels the time, the space, the swiftness or intensity, the movement, the weight and color, the pain and pleasure, the complexity, or whatever remaining characters the situation may involve. He goes through all that can be imagined where activity is supposed."

But James goes farther and makes the following assertion in the mode of Leibniz: "If we suppose activities to go on outside of our experience it is in forms like these that we must suppose them, or else give them some other name; for the word activity has no imaginable content whatever save these experiences of process, abstraction, striving, strain or release, ultimate qualia as they are of the life given us to be known." ${ }^{12}$ What shall we say to this claim that experienced activity of this personal and subjective type is the only adequate basis for the concept of activity?

Suppose that we assert that the flow of consciousness is an essential part of the effort of the brain-mind to adjust itself and to carry out its desires. The experience of activity should, then, reflect the objective activity of the brain of which it is an expression and a peculiar part. But to say that it is all that is actively going on seems to me not to do justice to the facts. The actual operations seem to me to be primarily operations of the brain-mind which are, as it were, illuminated and furthered by consciousness. The flood of sensations which color success and failure are less essential than idealists suppose. To objectify them naively is at this day and age impossible. Activity as a category applicable to nature is not identical with the experience of activity, though it does not conflict with it.

The complex contents of the experience of activity are clues to the objective operations of the organism. We

12 James, A Pluralistic Universe, p. 376. 
realize that such operations include hesitation, inhibition, release, dominance, etc. Complex adjustments are made, new stimuli interpreted, impulses checked or released. It is clear that subjective activity reflects and harmonizes with objective activity at this high evolutionary level. But is there any just reason why we should read into lower levels data of this sort? Only if there is sufficient reason to universalize consciousness. And of that I am not able to convince myself. Nature is active in the sense of operating and responding, but only the complex functioning of the nervous system is of a sort to find veracious reflection in the subjective experience of activity. 


\section{CHAPTER XII.}

\section{UNIFORMITY AND CAUSALITY.}

T $\mathrm{HE}$ category of causality has clearly been hovering in the background for the greater part of our work. It is time to give it our serious study. It has, indeed, been diffcult not to refer to it explicitly in connection with change, motion, properties, physical connections and force. Do we not think of all changes as caused and not merely occurring? And is not force usually conceived as the very agent of change, as that which necessitates and compels events into being? Change arises in reality and is not loosely connected with it by some temporal ordinate. It is surprisingly easy to build up a mythology about causation, but it seems in these days equally easy to commit the opposite mistake of making it a merely logical relation.

Our first task was to analyze the preliminary categories of order and organization, space, time, change and thinghood, which furnish the framework of our thought and knowledge of the physical world. Yet we could not shut our eyes to the insistant demand for a connective category moulded on these and expressive of the dynamic processes and connections of reality. We never believe these days that changes appear by mere hazard without essential antecedents, without, as we say, a cause or reason in the nature of things. A change must be imbedded in a matrix and be a function of processes. Changes are changes of things, of parts of reality, and so must express their nature. To ask for causes is obviously to seek to give a change a setting. 
This demand for the removal of changes from their isolation as brute facts and to see them in their actual relations is expressed in various terms which are seldom sharply differentiated. We say that we seek the reason for changes, the law of changes, the ground, the cause, the why. At other times we content ourselves with saying that we seek regularities in nature. It is evident that there is need of distinctions. We shall apply our theory of knowledge and draw a contrast between the actual process in nature and the form of our knowledge of it. In this way we can do justice to the uniqueness of every event and at the same time point out the value of those formulations which are in terms of universals and which, as the foundation of inference, enable us to pass back and forth from present to past and from past to future. In short we can show the truth in both the realistic and the logical theory of causation. Also, it will not surprise us to find that man begins with the discovery of strands of uniformity in events and only slowly penetrates to a thorough knowledge of the whole system undergoing change.

A Genetic Study.-The category of causality has, like the other categories, grown out of our every-day experience. Our own more personal experience as sufferers and doers has been fused with the relations which we perceive around us. Hence there has been both validity and mythology in our crude ideas of causality. We feel ourselves to be stable, persistent things set down in the midst of other things. We are organisms operating in an environment. This environment of other things we can change and shape in some degree and we experience likewise its effect upan 11s. It is our constant experience, then, that things "cause," lead to, induce changes in other things. In our thought we connect the coming of a modification in one thing with the action upon it of another. Hence reflection finds the category to hand and has only to analyze and criticize it, rid it of unjustified ingredients or associations, and place it in its proper relation to the other categories similarly purified and ana- 
lyzed. Thus it is evident that causality involves space, time, thinghood, properties and change. Things interact in space and their properties change in time.

Roughly speaking, changes are more or less internal or more or less induced by the action of external things upon the particular thing in question. In our own experience this contrast appears clearly in the difference between voluntary and involuntary attention. In the one case, the stimulus elicits our attention; in the other, a train of thought leads to observation. It seems that the more of growth and cumulative change there is, the greater the amount of internal change. Individuality and self-direction are based upon this inner momentum. I call attention to it at this point because the principle is so important for the comprehension of biological and human facts. The germ plasm mutates internally and gives rise to new species either dispersively or orthogenetically. The thinker works out a plan and puts it into execution. In neither case do external forces explain the facts. But, of course, I would be the last to deny relations and to drop into monadism. The environment is all the time stimulating the organism and the thinker must know the external factors of the situation. Nevertheless, this distinction will have bearing upon the question of free-will in that it militates against any dead-level mechanicalism. There is both continuity and discontinuity in nature and, rightly interpreted, these do not conflict.

The primitive view of the nature and range of the interaction between things was naturally less critical than that of to-day and accepted possibilities which are no longer considered tenable. For instance, magic dealt with and affirmed sympathetic influences that a wider experience and a more sceptical understanding have shown to be nonexistent. We may say, then, that science has represented this growth of a zealous spirit of examination into the exact reach and conditions of the interaction between things. It was soon seen that distance insulated things, that a relation approaching contact was necessary. Mere similarity and past contiguity were found to be ineffective. Such relations con- 
nected things in the mind but not in the external world. As these facts were realized, causality took itself to the context of physical science. All that could not be brought into this system was soon regarded as supernatural and mythical.

We have pointed out that man thinks of himself as simply one thing among others, acting upon them and being acted upon in return. In this vague empirical situation we must agree with Ward's conclusion: "Activity and passivity, doing and undergoing, are at least prima facie facts of experience, connecting subjective changes with objective changes and objective changes with subjective changes. It is prima facie certain that, within limits, I-determine the course of external things, and that this within limits determines me. Such immediate experience of activity and passivity may be the source of myth, but it is not itself mythical." 2 We find that just such an outlook is made primary by Dewey in his contribution to the volume entitled Creative Intelligence. When we put this statement into our terminology, it means that we (embodied selves) bring about changes in other things by the action of our bodies which are under our control and that other things bring about changes in our bodies and thence in our consciousness. The facts of the case are quite undeniable but they raise the question of agency.

The Idea of Agency.-Activity and volition go together in human experience. But volition aims at accomplishing definite effects. There has therefore been the tendency to think of causes as actively intending the effect. But while this may be in part true in the case of human beingsthough the total process is seldom analyzed-it does not follow that we can universalize it. Physics concerns itself with our actual knowledge of the physical world, and it can find only regularities; but we should remember that physics

${ }^{1}$ In the chapter on "Physical Connections and Relations," we were led to agree with this discovery of science. Ideal relations must not be confused with physical connections.

2 Ward, Naturalism and Agnosticism, Vol. 11, p. 238. 
does not deal with what is peculiar about organic things. It may also be that self-knowledge supplements the knowledge gained by the physical sciences.

There is a harmless and a harmful meaning to the term agency. Let us look at the harmless meaning first. We have seen that the human being views himself as ipitiating a line of bodily conduct (how he does so he does not know) and in this manner bringing about changes. A definite order of changes arises and he is convinced from experience again that these changes would not have occurred apart from the movements of his body and that his body would not have behaved in that specific fashion had it not been for his fiat. It does not mean that he has any intuition why they and not other effects follow the fiat and the action of the body. Experience alone has told him what to expect. Hume drove this fact home to the reflective human consciousness once for all. Man possesses no deductive, a priori knowledge of what effects follow what antecedent.

For our present purposes we can quite disregard the ethical and legal distinction between responsible and irresponsible agents. We wish simply to find the empirical ingredients of agency; and the essential point seems to be an assignment of a thing as the initiator of a series of changes. But we are led back to the distinction between internal change and external change. Things which cannot develop changes and so be the beginner of a series do not deserve the name of agent. It is clear, however, that this distinction is relative and one of degree. When we try to discover why a person acted as he did when he did, we soon discover that he is responding to a situation. Absolute and unconditional initiation seems meaningless because untrue to experience. The flaw in the customary theological idea of agency in a First Cause is the neglect of the matrix within which agency is always found. A human agent is not a first cause but one who acts creatively and differentially. I presume that it comes finally to this point, that there is no one absolute time series as was formerly supposed but that there are many series of changes loosely located 
together and not having much to do with each other. Once more we see the priority of space for the unity of the world. Philosophers have suggested this possibility before but seldom have developed it.

There is always something arbitrary in stopping at any one point in a causal series. Why did an earthquake start at this point in the ocean floor? Because it was the weakest place? But why did it come to be the weakest place? Why did President Wilson act thus and so at the Peace Conference? Because he had certain aims. But why did he have these aims? The two series of questions are parallel. But we must remember that we are dealing with different kinds of things.

Because man is a highly organized individual having new properties, he is more capable of initiating series than are other things. I believe that much of the controversy about free-will has represented a vague sensing of this qualitative difference. It is the kind of causality, not the absence of causality, which is in question.

To-day we believe that only conscious things feel that they initiate changes and that only man has the sense of planning them beforehand in accordance with his past experience. We may say, then, that in the primary meaning of the term all physical bodies are agents because they affect other things. This does not mean that they are active in the human sense, that they consciously initiate and maintain lines of conduct, nor does it mean that any mysterious, productive power is seen to go out of them.

I presume that the false idea of agency is that which Hume attacked, that is, an intuition, either in ourselves or in other things, of a literally productive force which is seen to bring change about. We are confined to the course of events as these reveal themselves to us in our sense-presentations; and, at this stage of analysis, it goes without saying that we cannot penetrate to the springs of change in nature itself, nor, if we could, would we likely be confronted by a productive force spinning out changes from itself. The whole idea of productive power rests probably, as Hume 
saw, upon a misinterpretation of the kinesthetic sensations. It is a vague projection of our sense of effort while overcoming obstacles. So much for any intuition of power in the external world. But how about ourselves? Well, it is an admitted conclusion of psychology to-day that we have no innervation-feeling. Hume was ahead of his time in this respect as in so much else. But we must warn the reader that it does not follow that our mental processes are ineffective because we cannot intuit in them any productive power. Since we cannot intuit any productive power anywhere, consciousness is not an exception.

The Discovery of Causal Uniformities. - Man early noticed regularities in nature. His own actions had regular consequences, for instance. The investigator of primitive religion informs us that in ritual man sought to force the gods to do things he desired done. The situation was, then, of this character: if a man wished to accomplish certain ends, he adopted well-known means. But being more or less capricious, he changed his ends, wanting this thing one day and something else, perhaps, the day after; and he thought of nature as full of spirits capricious in like manner. Because nature was the sporting-ground of spirits he did not expect overmuch regularity. Yet uniformities there were, and other events were marvels and miracles.

Gradually man came to conceive of nature as a complex of physical things behaving according to their native-structure and capacities. The result was the rise of what is usually called the mechanical idea of nature, the idea, namely, that things affect one another by contact. The cruder form of the mechanical interpretation pictured the world as composed of hard particles striking against one another. The modern form is harder to portray because it is less positive in its specific content. Yet it is clear that the development was along naturalistic lines and postulated the self-sufficiency of material substance, the significance of spatial relations, the importance of structure, and the vital reality of interaction. 
With the growth of critical observation, regularities were everywhere discoverable. It was found that certain conditions always led to certain results. Weights could always be raised by levers in accordance with definite laws. Eclipses occurred with conspicuous uniformity. Death followed the administering of substances called poisons. Chemical elements reacted in specific and recurrent ways. Nature was a realm of repetitions. The methods of testing presumed regularities were formulated by working scientists and found their way into books on logic. These methods enable the scientist to unravel strands of uniformity and to formulate them as empirical laws. The next step is to explain these empirical laws by a close study of the particular system under change. Thus the empirical law of sequence is that A (the entrance of a diphtheria germ into the organism) is the necessary antecedent of $B$ (that peculiar type of sickness). These empirical laws are usually spoken of as causal uniformities. Around them and their necessity philosophical controversy has raged for centuries.

Now Hume has shown that all we empirically have in such cases of causal uniformity is a sequence established by experience. We are not able to reason out a particular sequence a priori nor establish it beforehand. His conclusion is that experience does actually present us with data which the most critical investigation reveals to be such that, if the first had not been, the second would never have occurred. From this analysis comes his definition of an empirical cause as "an object, followed by another, and where all the objects similar to the first are followed by objects similar to the second." Let us examine Hume's doctrine.

When do we have an empirical causal law? Surely the fact that $B$ follows $A$ is not enough. We can divide events at one moment, and all the events after this moment follow those before. In causal uniformity we are seeking more than this characteristic of the time-order. ${ }^{3}$ We are seeking particular strands of connection. We are trying to find out

${ }^{3}$ Mere dating has little to do with causal connection. 
how things affect one another. In other words, we must not separate causal laws from the principle of interaction. The scientist manipulates physical factors to see what follows. The introduction of a crystal of alum into an alum solution of a certain saturation is followed by the crystallization of the whole solution. We easily discover that many physical factors are indifferent to this process of change. Given the alum solution and the introduction of the crystal, the result ensues. Now we should not call this sequence a mere association of ideas. It is a sequence within perception, and it concerns a physical system in change. What testing tries to establish is that $\mathrm{B}$ occurs only when definite conditions are fulfilled. If such a connection is established for past experience, we expect it to occur under exactly similar conditions in the future. What is the character of this expectation: What Hume showed was that we could perceive no necessity in the sequence itself which would enable us to regard the expectation as founded upon an iron-bound intuition of an undeniable union of the terms. An analogy will make us understand the sort of union which he has in mind. In geometry, we perceive a connection between the equality of the sides of a triangle and the equality of the angles. Here we have a relation dealing with what may be called concepts. that is, with contentual objects intuited by the mind. The necessity here is an intellectual necessity like that which binds us when two premises of a valid syllogism are given. Is it not true that in causal uniformity we perceive nothing like this logical necessity? We do not see why the effect should follow.

The Postulate of Uniformity.-While attempts are still made to discover a logical necessity in causal uniformity, they have not been markedly successful. For instance, it seems absurd to the physical realist to assert that a law is an operative cause bringing about the result; for is not a natural law simply a formulation giving knowledge about the actual changing system? All we can say is that, if the law holds for the future, we can predict what will take 
place. The future is something upon which the law, which is a cognitive formulation, has no hold. For that matter, a law has no more hold upon the present since it is a mental content. A similar reply must be made to those who seek to reduce causal uniformity to the principle of ground and consequent. The principle of ground and consequent is a logical principle and has no concern with processes of temporal change. The one is irrelevant to the other, and it is absurd to belittle a causal process by saying that it is an imperfect expression of this logical relation. Yet it is easy to see that those who look upon time as unreal and reality a timeless system would naturally be inclined to regard the causal relation as mere appearance. Our stand with respect to the preliminary categories precludes the adoption of any such device.

On the other hand, it is impossible to follow Mill and hold that the uniformity of nature is an inference from particular uniformities. It is true that the general principle of uniformity is suggested by the experience of various particular uniformities in the past, but the proof of the continuance of particular uniformities demands the acceptance of the general principle. But if we cannot prove the general principle by the particulars, it must remain a postulate logically, an assumption for which we take the risk.

But why do we make this postulate either in its particular form or in its general form? To say that we tend to universalize the sequences that come under our notice because we have that sort of make-up is true so far as it goes, but it does not go far enough. Are there any deeper principles at work?

I seem to find this deeper principle in the belief that change expresses the nature of that which changes, that a change is not adventitious and, as it were, tacked on from outside, but something which grows out of the very heart of that which changes. But, if so, the change throws light upon the nature of the changing system; it is the kind of a system to produce this change as an end-term. Grant this interpretation, and it follows that the, very same conditions 
will lead to the very same effect as often as repeated. The empirical question will simply become, To what extent is nature repetitious? Do the same conditions recur? And, of course, this question can be answered by investigation.

But it may be replied that we have no certainty that the same determinate nature will not express itself differently at different times. Why cannot the world be a capricious and lawless world? So far as I can see we have no absolute guarantee against such a supposition, yet we should note what the supposition involves. It implies that changes are adventitious and accidental, that they are not so much changes of things as changes to things. For such a view, changes would not be the expressions of processes rooted in systems of reality but rather the capricious and unconnected origination of novelties. Change would be mere change, a coming and going without rhyme or reason.

Implications of this Interpretation.-What a thing has once done under known conditions we expect it to do again under the same conditions. That this is the way the mind works is undoubted. Let us now see why it has been led to universalize in this manner. Here we have a psychological question.

Mere association plays its part in this expectation. It takes an effort to think of something else happening instead of what did actually happen. We feel that such a substitution is arbitrary and artificial.

In the second place, the increasing discovery of regularities in the past all through nature reenforces the natural expectation and makes still more feeble any attempted substitution.

In the third place, we discover that things act in accordance with their known constitution. I do not mean that we can $a$ priori deduce types of action from known constitutions but that we can reason by analogy from given instances to like instances. If a certain type of thing acts in a given way, we find that we reason correctly to future actions of like things. This empirical fact suggests to the 
mind that constitution has something to do with what occurs. In other words, we are led to supplement the first two motives by the principle we have already stressed, that change expresses the nature of that which changes. The demands of reason thus grow out of experience.

It is interesting to note that this idea of connection between changes and the constitution of systems was applied most slowly to human nature. What is called free will is primarily a denial of this principle. I mean by free will, obviously, not choice after deliberation-which is a fact of experience-but a freedom of indifference, that we could just as well do one thing as another. It is the general conviction now that character counts for something in conduct. that will is but another name for character in operation in response to the stimulation of a situation.

These supplementary motives seem to me adequate to account for that feeling of necessity which we experience in the face of a causal uniformity. If the sequence $A$ B is tested scientifically and we come to the conclusion that B has happened only after A has happened, then we feel obliged to believe that under the same conditions A will be followed by $B$. Whether such conditions will again be realized we do not always know. In the inorganic world, however, we find that we are able to reproduce the conditions through the material at hand. We can always make an alum solution and introduce a crystal. The demonstrator in chemistry can make oxygen for his class by heating manganese dioxide with sulphuric acid. In this spatial world of ours, substances exist in quantities.

There is another implication of this interpretation of the postulate of uniformity. If changes are rooted in the nature of the system in process of change, the end-term is the inevitable expression of the particular process. But, if so, the law of the change is simply the formulation of the changes in their actual order as they appear to us and are actually known. The inevitableness does not rest in the law but in the physical process. Yet the law can be the basis of a deduction, and this because it is valid of the 
system which is to undergo change. We predict in accordance with knowledge. What I mean is this: the process begins in nature, and we who have had experience of a largely similar process can anticipate the steps to come. We are spectators who have had our cue but we do not interfere with, or control, a process of real change which marches step by step according to its own inner necessity, a necessity which is a self-determination.

Kant versus Hume.-It is at this point that we can best refer to the difference between Hume and Kant. The amount of this difference has been grossly exaggerated. Kant admits that particular syntheses spring from experience. Why, then, is he so determined to assume the existence of a priori principles to press upon these and give them a formal universality? For two reasons, I take it: (1) he had begun his theory with the assignment of all connection to the understanding as an a priori function-an hypothesis which he gradually relinquished; (2) he thought of empiricism in terms of mere association and was unable to identify his sense of necessity and universality with expectation.

There is getting to be a surprising unanimity among thinkers that this controversy is outworn, but that we rest nearer to Hume that to Kant. Kant's machinery is no longer held in reverence and his self-contradictions have been pitilessly exposed. A clearer study of the process of experience has shown the part played by reflective analysis and synthesis; perceptual observation is in the service of concepts which, themselves, have arisen out of, and in responsibility to, sense-material. Logic and psychology have changed to a richer and truer empiricism in which justice is done to mental activity and to well-based concepts. And then there is the historical element in such a feeling as that of necessity. To both Kant and Hume, this recognition of the historical growth of the idea of necessity was almost completely alien. And yet it is clear to the modern thinker that the belief in regularity has increased with the discoveries 
of science. And this belief exercises constraint upon the trained individual. His theories reveal nature to him as a system of things with definite structures acting everywhere in accordance with those structures. The mechanical view of the world was a good, even though too elementary, teacher of a uniformity rooted in things. We think that we see the how of processes even though their inner springs are hidden from us. We believe that we penetrate by tested theory beneath the sensuous surface and at least see with the mind's eye the wheels go round. ${ }^{4}$

Empirical Uniformities Only the Beginning of Science.The discovery of perceptual uniformities represents only the beginning of science. What science seeks is explanation. Let us consider a case of poisoning. The human organism is brought into touch with hydrocyanic acid, and a reaction takes place which ends in that condition called death. But why does death follow? What takes place in the organism? Does something take place which conflicts with normal processes? Science studies the various changes in a physical system in the light of the best knowledge that can be acquired. It seeks to find out in detail just what happens and to find instances in these happenings of minute and general regularities or laws. Such laws are entirely conceptual and refer to physical processes as constructed knowledge about them. A pump will raise water only so many feet-this is a fact to be explained. Well, science has decided that this fact is due to the specific amount of the pressure of the air which has weight. But what is weight? Weight must be connected with gravitational attraction whose law is that of inverse squares. But to what is gravitation due? What process goes on everywhere in matter? Is it mechanical or electrical? It is evident that analysis, synthesis, construction, discovery, all go on at a conceptual level in which the data of sense are used as suggestions and controls. But into the logic of science we cannot go further since our main purpose

4 It has been suggested that industrial processes have supplemented science in the nourishment of the sense of forced regularity, a regularity reflecting the nature of the system. 
is to understand the category of causality. It is clear, though, that the scientist seeks hidden, minuter, more fundamental uniformities conceived by the intellect through the aid of sense rather than grossly open to perception. Yet even in these uniformities productive power cannot be intuited.

Again, science locates uniformities within changing physical systems. It desires to find out both what is really happening and where it is happening. For popular thought, a cause does something to something else. Science, on the other hand, has realized that any effect is brought about not by the sole "power" of one agent but by a process of interaction between, and within, things. The nature of the patient is just as important as the action of the agent. A bacillus which makes one person sick may not affect another person in better health. The divergence between the popular view and the scientific is in the main due to a divergence of interest. Instead of giving attention to the whole situation and all the factors, common sense selects one factor called the cause and attributes any striking change in the patient to the "action" of this cause. Human analogy is obviously at work. We bring about the results which we desire in our surroundings by adopting means known to secure particular ends. The result is a romantic painting of nature in which actual processes are ignored. In contrast, science is realistic, and painstakingly seeks to appreciate all the factors in any change and to determine the part each plays. Once this realistic procedure is adopted, the cause can no longer be conceived as an agent which does a particular something to that upon which it externally acts. All changes are seen to occur within a system of things and to be controlled by the nature of that system. The falling of a tree, for instance, is not its "act" but the expression of the whole gravitational system of tree and earth.

It may not be amiss to call attention to this scientific purification of the idea of cause. The human basis of the idea of agency leads us to associate with the cause a sense of activity and effort. Until our attention is called to the 
characteristic, we invariably read into the thing which we regard as the active cause that feeling of effort which floods our own consciousness when we are making exertions. This animal nisus, as Hume called it, is, nevertheless, an unwarranted projection. Whatever science may mean by activity, it must not mean this feeling of effort and exertion; and the term passivity must undergo a similar purification.

Causality the Basis of Uniformity.-When an "occasion," or stimulus, throws a physical system into disequilibrium and inaugurates a process of change, we may rightly speak of the process as one of causality. In such a process something is doing, reality is making itself. Here we have a real change in which forces are at work seeking adjustment. To our eyes, the sensible appearance of the system varies until that stage is reached which we call the effect. It may even be that we witness a series of effects following one another in a definite order. Objectively, or in nature itself, these effects are conditions, more or less permanent, of the changing system; subjectively, they are presentations which can be used to give us information about the objective condition. The presentations come to us in a temporal order and we judge the conditions to follow each other in the same order.

This analysis enables us to meet dialectical objections which have been urged against the category of causality. In such objections there has always been a tendency to confuse causality with causal uniformity. Causal uniformity is the selection of interesting landmarks and the recognition that these marks come in an invariable order. A precedes B. As Mach and others have pointed out, such causal uniformity can be accepted as a law of the order of changes in a particular strand of nature while the popular notion of a "cause" is altogether rejected.

The majority of conventional objections to causal uniformity and causality play upon the category of time. Thus it is maintained that the temporal order of the events $A$ and $B$ in a causal uniformity involves a discontinuity. But 
surely this is not so. A and B are continuous through intermediaries which make them confluent. Let us admit that any event has arbitrary limits. Human knowledge is selective, but it is not for that reason falsifying. As for the causal process itself, there can be no gaps of empty time because time is nothing separate from the process. Real time is change, and time as a category is knowledge about the order and duration of such real change. Again, it is maintained that the effect controls the cause as much as the cause the effect. But surely such a statement is untrue. The temporal order of events is a definite one and has an irreversible direction; the causal series is asymmetrical. Finally, it is true that if you know the law of a repetitious causal process, you can work inferentially in both directions. If $B$ occurs, you can infer $A$; if $A$ occurs you can infer $B$, provided, of course, that no adventitious physical factor intervenes to modify the causal system. If a man dies with certain symptoms, you can infer poisoning by arsenic. But the taking of arsenic along with an antidote will not be followed by death. In this sense, laws are hypothetical. They tell us what will happen if certain conditions are fulfilled in nature. They are knowledge about the process of causal change in a physical system.

Let us next examine the theory that causality involves an indefinite regress, an imputation which many have regarded as indicating a fundamental defect in the category. Professor Taylor has stated the argument so clearly that we cannot do better than quote his account: "The same reasons lead us to demand a cause $A$ for any event $B$, and to find that cause in an assemblage of antecedent events, requires that $\mathrm{A}$ should be similarly determined by another assemblage of antecedent events, and that this cause of $A$ should itself have its own antecedent cause, and so on indefinitely. Thus the causal principle, logically applied, never yields an intelligible explanation of any event. Instead of exhibiting the transition A-B as the logical expression of a coherent principle, it refers us for the explanation of this transition to a previous instance of the same kind of 
transition, and then to another, and so forth without end."'s We must distinguish two features of this challenge. I see no reason to deny an indefinite regress of changes in nature ; but this temporal character of the world is not in itself an explanation why some particular event has occurred. Empirical uniformities represent only the beginning of science. What the scientist undertakes to do is to study the system in change from $A$ to $B$ to discover what occurs within those limits. For instance, we should not think of trying to explain why the taking of poison leads to death by finding an event $\mathrm{C}$ which precedes the act. A detective might have this interest but not the physiologist. The latter desires to investigate and theorize over the changes in the body between event $A$ and event $B$. The objection appears to be based on a misunderstanding of the function of empirical uniformities in the economy of science.

The Category of Causality a Deepening of Time and Change.-Space and time are preliminary categories of order. Valid as they are, they need deepening by the empirical growth of other categories to give them fuller content. Thus we suggested that space is the mould into which such categories as structure and organization fit. The physical world is spatial, and this spatial realm is known in terms of such categories as mass, energy, structure and organization. Much of the detailed knowledge of the special sciences falls into these further categories and thence into space.

But our world is both spatial and temporal. It is a field of change as well as of coexistence. Reality is spatial, and this spatial reality changes. Such changes are not, however, mere unconnected events. They are outgrowths of the adjustments and equilibria of physical systems. And it is this realization of the internal relation of particular changes to that which changes which is called causal necessity. Such causal necessity is usually contrasted with what is called logical or inferential necessity. Let us examine the problems indicated by this contrast.

- Taylor, Elements of Metaphysics, p. 177. 
Hume pointed out once for all that an event B cannot be inferred immediately from an event A. But if inference is to take place from the past to the future, we must assume the principle of the constancy of nature which expresses itself as follows: granted a tested uniformity of events in the past, the same uniformity will characterize the future under similar conditions. But we surely ask ourselves the reason for our tendency to accept this principle. It is clearly a postulate or assertion. Out of what does it arise? Some may hold that it expresses a pragmatic situation. In order to handle the world and adjust means to ends, we must work with this faith. There is a large measure of truth in this position but not all the truth.

It seems to me that we believe in a necessity in nature. It is not that laws govern nature, but that the changes in nature grow out of that which is changing, and that we can see no reason why things which are similar to those in the past should not respond in the same way. Of course this implies that we believe that we know things, that we can again and again recognize similar things and that the changes which come from them are expressions of them and therefore knowledge of these changes is knowledge of nature. It must be remembered that for us time as mere lapse has no dynamic reality and therefore cannot account for difference of behavior. He who denies causal necessity must go further and assert that nature is a complete flux which changes in a capricious fashion, that a stone can become a man and a tree a rock, etc. He must deny that things have a specific nature. Now all our knowledge is against such a position, and it seems to be a mere tour de force. Therefore we must grant a causal necessity in nature itself and regard the inductive principle as an implication of it.

There are two doctrines much held about which, in conclusion, I must say something, although I have touched upon them slightly in other places. First, there is often confusion between a law of events and the actual process of causation. Let it be grasped that a law is a formulation giving human knowledge of a certain type of behavior. It 
is always abstract and hypothetical. All it permits us to assert is that, when certain conditions are given so that the essentials of type $A$ are realized, we have a right to expect the effect B. There are always slight differences and variations because there is never complete repetition in nature. Predictability is relative to the appearance of repetition in nature; and this repetition is a matter of degree. The less of individuality there is and the more our treatment is statistical, the more of repetition will reveal itself. In the laws formulated for inorganic nature both these conditions are present and, accordingly, we have in that field more of repetition.

But predictability is identical with logical necessity. Those who are opposed to necessity in nature usually identify it with logical necessity and attack it through the absence of predictability in human conduct. Such is, on the whole, Bergson's method. But we would point out that we are able to lay down large, general rules for people we know intimately, and that, when these rules are falsified by their conduct, we are able to explain this falsification very easily by lack of knowledge of the situation which actually confronted them and by the assumption of a certain measure of deception in their past conduct. Since we do not know ourselves completely, we should hesitate to believe that we know other people adequately. Rules must be based upon knowledge, and it is impossible to get as satisfactory knowledge of individuals as of lower things because of their greater complexity and change through growth. Time enters into their very makeup. In the second place, causal necessity is not identical with logical necessity and predictability. Much of the debate about free-will has been due to the inability to make this distinction. As applied to the self, causal necessity means self-expression in response to given situations and conflicts with nothing that is valuable in human personality. I believe that there is creativeness and novelty in human self-expression but that this novelty should not be disconnected from the past. But we shall have more to say about that in the next chapter. Berg- 
son's emphases have been stimulating, but all his insights can be admitted by a genuinely evolutionary naturalism.

Let us come to our second point. Many idealists have attempted to interpret all of nature in terms of the self. To the evolutionary naturalist there is both truth and falsity in such an attempt. To say, for example, that purpose is the clue to necessity in nature is misleading. A purpose is but the response of a man's nature to a situation with which he is confronted. The ultimate factor is, then, what we have called the nature of the thing. This factor is present in all reality but decidedly varies-as our knowledge shows -at the various levels of evolution. There is evolutionary discontinuity in nature as well as continuity, and this fact involves kinds of causality. Frankly, it seems to me rather absurd to speak of magnets desiring iron or the fall of a stone as completing an intention. Assuredly, man is a part of nature, but his differences from inorganic nature must not be overlooked.

It would seem that common sense adhered to a profound insight when it associated causality with interaction. Causality can no more be separated from space than it can be from time. It is not a purely temporal category. Its locus is the one real world to which all our knowledge ultimately has reference. 


\section{CHAPTER XIII.}

\section{POTENTIALITY, NECESSITY AND NOVELTY.}

$\mathrm{N}$ the present chapter we shall attempt to apply the results of our systematic analysis of the primary categories to those secondary, and, as it were, derived categories which have been the No Man's Land of thinkers. What is the validity of such a category as potentiality? Aristotle made much of it; so did the Thomists; and it would seem that the pragmatists consider knowledge to be always forward-looking and concerned with the possibilities which lie open to the intelligent man. On the other hand, the majority of thinkers have refused to give this category the objective standing assigned to actuality. "It is," writes Ward, "worthless in so far as it throws no light on the process which it indicates." I think that the majority of us, again, have felt intense dissatisfaction with Mill's designation of matter as the permanent possibility of sensation. Reality is clearly more than possibility.

And much the same query arises with respect to chance, necessity and probability. Are these categories more subjective and relative than are space, time, structure and causality? The problem is extremely interesting.

The two master generalizations of the nineteenth century were conservation and evolution. In the broad sense, conservation means that there is an invariant character to physical reality, that energy, or the power of doing work, is not consumed or lost in an absolute sense. Let us grant that this generalization has not been proven in any final 
sense. It yet remains strongly indicated and distinctly appeals to the reason. Evolution is but another term for change or the variable character of specific things. We must rid the term of any finalism and be ready to admit that any change is the function of conditions. But it seems clear empirically that conditions on this planet have temporarily, at least, been favorable to a process of cumulative change leading from units of a lower to units of a higher order. The word higher is purely logical in this connection and not valuative. I mean that the higher order implies and includes the lower order. The molecule includes the atom; the colloidal substance includes the molecule; the cell includes the colloidal substance; and the organism includes cells and organs. I would not, however, speak of one animal type as being higher than another in this fashion. They are, rather, divergent and specialized lines. But questions are indicated here which 1 must postpone.

There has been much misapplication of the concept of conservation in the effort to make it protector against change. Thus people demand the conservation of values, of institutions, of personality. This seems to me a grave mistake. All specific objects are products of change and are relative to conditions. They are inseparable from those conditions which are, again, variables. That which is born will also die. That which has come to pass will perish. Conservation, as an objective category, and change are supplementary and not contradictory. The ladder of evolved forms teaches the lesson that novelty may be added to novelty to produce novelties of higher orders. And the fact of death equally teaches that the reverse direction may be taken with giddy speed until the wonderful structure with its capacities of thought and action falls apart into dust. Yet nature is not bankrupt. It has been hard for man to admit this impersonal $\mathrm{ebb}$ and flow of what to him is valuable.

While, at first glance, it may seem foolhardy to treat many elusive categories in the compass of a single chapter, second thought suggests that many of these categories imply one another and arise out of the same situation. They are 
categories of knowledge and apply to judgments rather than to things. Their status and reference are logical and psychological rather than ontological. Again, chance, necessity, freedom, possibility, impossibility, probability, certainty, potentiality are largely relative terms bearing upon one another. The analysis of any one of them illumines the others. Is chance the absence of necessity? And, if so, what is necessity? Is freedom the opposite of necessity? And does it mean chance? Does novelty involve discontinuity? In what sense, if any, can a novelty be said to be potentially present before its actual appearance? Such questions as these reveal how intimately these secondary categories are intertwined.

It may not be amiss to point out that these secondary categories have played a stellar rôle in philosophy just because they are practical human categories involved in conduct. Man must act in accordance with his knowledge, and he must predict that which has not yet occurred. Theology with its personalistic scheme of reality reenforced this natural emphasis and gave it a cosmic setting. Our task is to reduce these pretensions and so to interpret these secondary categories as to harmonize them with science. I believe that it can be done by pointing out their universe of discourse and limitations.

The critical realist, while asserting that knowledge is a comprehension of reality, points out that it is not identical with reality. In this way he is able to avoid that reification of laws and essences to which the scholastic realist fell a victim. Laws are not in nature, nor do they control nature. The status of propositions is subjective. If there is an invariant character and an orderliness in nature a study of the data will reveal it. But we need no assumption of ghostly laws regnant over the physical realm. This point we made in our study of causality, but it is well to recall it. Even the neo-realist has been too much inclined to a scholastic Platonism. 
Novelty and Potentiality. - The apparent conflict between changelessness and change was early noticed by Greek thinkers. It is notorious that the Eleatics opposed themselves to the followers of Heraclitus, and that this fundamental opposition supplied the basis for the quarrels of later schools. That the opposition still plays a part in modern thought is apparent from the following quotation: "Yet even science through most of its history has been little interested in time as such, and it has usually got away from the mere temporality of things as fast and as far as possible. It has been interested in 'unchanging laws of nature' -laws which, for the most part, to be sure, relate to temporal sequences but are themselves conceived as things into which the tooth of time cannot bite." ${ }^{1}$ The increasing recognition of evolution for every level of nature shows, however, that there is no logical conflict here. As long as there is a large measure of stability in structure and behavior, our knowledge will take the form of laws. Even to the evolutionist nature is not a flux.

The problem before science and philosophy in these days is to harmonize new forms of organization, new types of behavior, new properties with the more stable and fixed background of inorganic nature. The higher the order of integration, the more striking a challenge is it to the huge mass of material which to the unimaginative eye uneventfully surrounds it. Yet completer knowledge is undermining the flat dualisms of the past. Inorganic matter is a far more active, subtle and responsive stuff than the brickbat atomism of the past supposed. It lends itself to mobile integrations which under the hand of time may lead to tremendous novelties. The physicist may have been able to ignore time; the geologist, the biologist and the sociologist cannot. What has been done has been done slowly. And yet it is undeniable that human civilization has evolved from a world which contained no indications of it. The human mind looks before and after and tries to connect rationally what seems so alien and different.

${ }^{1}$ A. O. Lovejoy, Bergson and Romantic Evolutionism, p. 13. 
Aristotle was the first thinker clearly to use the category of potency or potentiality to mediate between being and becoming. He was handicapped by his intellectual inheritance. $\mathrm{He}$ seems to have been unable to believe that nature is experimental and creative. What is to be must already exist in some sense. Its guiding idea must be operative. Let us note his application of the category in accordance with his epistemology and his metaphysics, and then point out its significance for the modern evolutionist.

We may say that Aristotle thinks of Form, which is the unchangeable and necessary, as the goal of becoming. In this relation we have his theory of final and formal causation as against material and efficient. "Becoming consists in this, that some matter takes on a definite Form. This Form must therefore be posited before each case of Becoming as the aim and end thereof.... The fact of Becoming, in other words, is inexplicable unless it be true that before anything came to be there was a Form which itself had not come to be." 2 That which becomes must become out of that which is since it cannot arise out of non-being; yet that which is must be different from that which it becomes. There remains the compromise that it is potentially what it is to become. That whose very nature it is to be potential is matter, while that whose nature it is to be actual and changeless is Form. From the intimate and unique union of these two kinds of reality he seeks to explain the empirical world of substances.

Modern evolutionary naturalism breaks completely with Aristotelianism. It discards both ruling Forms and passive matter. In this it is in line with the whole movement of modern science. The flaw in Aristotelianism was twofold: it reified universals and believed in final causality. And, of course, these two points went together. To the critical realist, the physical realm is the locus of efficient causality, and novelty results from processes of integration. The process is creative. It is conditioned but unguided from 2 Zeller, Aristotle and the Earlier Peripatetics, Vol. 1, p. 340. 
outside. Forms would be but ghosts with no clear function to perform.

It follows that potentiality is a reflective category. It is ex post facto for the past and predictive for the future. It does not indicate any mysterious power which leads to a specific unfolding. It is but a shorthand expression for the genetic continuity of a past process, an assertion of causal determinism. Only in so far as it tends to ignore the importance of the actual conditions and the intermediate steps is it fallacious. To recognize its sphere is not to detract from it but to appreciate it properly.

Judgment has a temporal freedom that does not hold for actuality. We can say that certain results would follow if certain conditions were given and yet know that these conditions will not be given. Possibility is always hypothetical and subjective. Critical realism can do justice to this play of the mind. Now it seems to me that the category of potentiality is a category which stands, as it were, midway between actuality and possibility. It is a recognition that what comes to pass is a function of actual factors but that each factor has its own nature. It is the combination which accounts for any actual process. Thus a person is in his youth potentially many things. This means that one set of circumstances brought to bear upon him would lead to his becoming a journalist, another set to his becoming a business man, another set to his becoming an artist. The recognition of this dependence of the future upon many factors is mental. And that alone is possible which is in line with the potentiality of the interacting factors. It seems to me that the pluralist must feel kindly to this category. It means that a thing is greater than its actual relations; that, however internal connections are, they do not exhaust the terms. Another way, perhaps, of putting the same thing is that potentiality is a protest against the irrevocableness of time. Time throws the dice. Potentiality is a many-sided category. It fits into prediction. It expresses determinism. It calls attention to what is usually called the contingency of events. The more you isolate a thing spatially and temporally, the 
more you have mere potentiality. We shall return to this category.

Possibility and Impossibility.-Possibility and impossibility are obviously categories which reflect the distinction between knowledge and the object of knowledge. What is is. It is, strictly speaking, neither possible nor impossible. These are essentially deductive categories expressive of the status of knowledge. To say that a thing or event is impossible is to express an inference from the knowledge we possess. It is to exclude the event or thing from actuality. To say that it is possible is not to include it but to deny that it must be excluded.

Since Hume's day it is pretty well admitted that our ideas of the possible and the impossible are laid in experience. Another mode of striking the same note is to point out that a priori all things are possible because there are no guides and tests. Even Kant was forced to admit that particular causal uniformities were given to the mind rather than laid down by it. The mind is by no means a dictatorial lawgiver whose demand is obsequiously obeyed by reality.

When I say that a priori all things are possible, I do not wish to be misunderstood. If reality has a structure or order, all things are not possible. For instance, one thing cannot be to the right and to the left of another thing at the same time. But with this qualification, I believe the principle holds. Yet experience, alone, presents us with the specific character of reality.

Possibility and impossibility are categories of judgment. And I think that it is easy to show that they arise in our minds as the deductive, systematic organization of knowledge increases. There are two levels for these categories, although these levels shade into each other. Hume did justice to the first or more empirical level. Our expectations, our view of what is possible and what is impossible, reflect our past experience. There is a surprisingly small amount of deduction in such empirical judgments. The native of a hot country might say that the solidification of 
water is impossible. The citizen of a competitive and individualistic country might hold that private profit was the sole possible motive in industry. The natural impulse is to hold that what has not occurred cannot occur.

But it is only when the sense of logical conflict comes to the surface that the idea of possibility secures its most significant contrast with the idea of impossibility. The rise of water in a suction-pump beyond thirty-four feet is impossible because it conflicts with a system of tested and precise knowledge about atmospheric weight. Admit the one, and you cannot at the same time admit the other. The judgment of impossibility involves the appreciation of such disharmonies between tested systems and particular suppositions. Possibility, on the other hand, reflects harmony and consistency. Ordinary experience consists of masses of remembered material little organized by theoretical explanations, and for that reason it is often hard to say just what is and what is not possible. In a field organized by science, it is usually easy to distinguish between the possible and the impossible. Perpetual motion is impossible. Why? Because it conflicts with the accepted principles of thermodynamics. The deductive element is clear. We build up generalizations and work out their implications. Yet it must always be remembered that deductions are no stronger than the generalizations upon which they are based, and that, therefore, our judgments as to what is possible and what impossible may be false.

It is natural, again, to distinguish between what is in general possible and what is possible under specific conditions. Thus it is theoretically possible to establish an intelligent democracy which will elect able men and develop constructive policies. Is it possible under conditions of pecuniary materialism with newspapers controlled by advertisers and devoted to gossip? Again, an engineer may be confronted with the problem of building a dam. The job is theoretically possible; is it actually possible? As our knowledge passes from indefiniteness to definiteness, we have the categories of the expected or probable, the 
improbable or merely possible, and the impossible. This condition of knowledge is reflected in the disjunctive form of judgment. A chemist who is making an experiment may assert that the product of the reaction will be either A or B or C. These are for him the possible, and other products are impossible. Suppose the experiment to have been carried through; a causal uniformity is established and the judgment passes from the disjunctive to the categorical.

I think that it is obvious that possibility is a category whose conditions are largely psychological. The standard varies from person to person and from group to group. What is possible to one may be impossible to another. Thus to me with my view of the identity of mind and brain, spirits are impossible. To Sir Oliver Lodge they are not only possible but highly probable. We may say, then, that possibility differs from a mere play of the imagination because belief exercises consorship. It narrows down the ideas entertained to those which do not conflict with known facts. But this censorship is very variable.

Probability versus Certainty.-By its very nature science cannot be satisfied with possibility. It wants to know what is, what has been, and what will be. But just because knowledge is mediate and inferential, this ideal cannot always be attained. Especially is this the case with the future. We may point out, moreover, that science seldom concerns itself with individual events. It interests itself more in the study of types and principles.

The category of probability has a definite context in science. It applies to propositions about events and not to the events themselves. "What do we really mean by probability?" asks Couturat. "In the first place, it cannot be concerned, whatever may be said to the contrary, with the probability of an event, for an event is essentially particular and determinate; it happens or it does not happen.... Probability can be nothing else than the quality of certain judgments which we pass upon events in order to predict or conjecture them. But of what judgments? If it is a 
question of a judgment passed on a particular event it is once again fully determined; it can, therefore, only be true or false. The epithet 'probable' can only be applied to a judgment which may be true in certain cases and false in certain others. But such a general or indeterminate judgment, which holds good indifferently of any case of a series is nothing else than a propositional function." 3 The truth is that in the calculation of probabilities we make an assumption that several events are simultaneously possible. This assumption is an expression of two things: (1) our ignorance of the exact combination of factors leading to the coming event; and (2) the belief that in a series one combination will come up as often as another.

It is rather remarkable that a scientist should forget this context for probability. But it certainly seems, as Holt has pointed out, that Professor Henderson in his argument for teleology in nature has committed it. Henderson wished to prove that the elements and their properties were unique and together formed an ensemble which could not have come by chance. "There is, in truth," he writes, "not one chance in countless millions of millions that the many unique properties of carbon, hydrogen and oxygen, and especially of their stable compounds water and carbonic acid,.... should simultaneously occur in the three elements otherwise than through the operation of a natural law which somehow connects them together." The scholastic assumption of an externally operating natural law should be noted. But the main point is that he has ignored the context of chance as giving probability. Holt's comment is so relevant to the point we are making that I shall quote it: "The least situation in which chance can be spoken of is: two (or more) causal sequences, and an observing computing organism; further, the causal sequences are relatively independent, but they are about to interact, or meet ; further, the observer knows this but owing to the relative apartness of the causes he is able to deduce or predict only very imperfectly some features of the ex-

3 Couturat, Encyclopedia of the Philosophical Sciences, p. 152. 
pected interaction: these unpredictable features he declares to be 'subject to chance." ",

A categorical judgment makes a definite assertion about some part of reality. This type of judgment is the ideal of science. A problematic judgment contains within itself both the assertion and the attitude taken toward it. "It may rain," means that raining is an event about which I am not certain but that there are some indications favorable to it as an inference. Modality is subjective. An apodeictic judgment can be analyzed in a similar fashion. The must is inferential. Again, laws are general and hypothetical. They state that, if certain conditions occur, they will be followed by certain consequences. Also, that this relation has happened in the past.

Certainty is clearly an attitude taken toward a judgment. Certainty and certitude are the opposite of doubt and opinion. Certitude is a stable assent of the mind to a judgment. It is more easily obtained in judgments of perception than in judgments of theory. The facts of observation of the scientist are close to perception and are easily tested.

Subjective Chance versus Objective Chance.-The above treatment of probability furnishes a good introduction to the distinction between subjective chance and tychism or objective chance. We are led back to a consideration of causality.

There are many closely associated terms in this connection which must yet be distinguished. In their interpretation of events, people commonly speak of fate, luck and chance. They use these terms chiefly when they have in mind some event which affects themselves or others favorably or unfavorably. It is the relation of the event to human beings which is stressed. The element of valuation

4 Holt, "Professor Henderson's 'Fitness' and the Locus of Concepts"; Journal of Philosophy, Psychology and Scientific Methods, Vol. XVII, No. 14. It is interesting to note that Holt apparently repudiates much of his Concept of Consciousness. 
comes out clearly in the idea of luck. In fate and chance, externality and lack of control are the dominant elements.

Well, we must admit that an individual is only a small part of the world and has surprisingly little control of events. If the political and physical environments are favorable and stable, the individual can do much and lead a fairly happy life. The Great War has driven home to the present generation how helpless the masses of the people are before a cataclysm. To some, events are disastrous; to others, they are not unfavorable. This is the minimum meaning of lucky and unlucky. And so far as these words are used descriptively and empirically they are terms expressing instrumental value. Things break right for some people, indifferently well for others, and badly for still others. We must, however, be on our guard against exaggeration and against mythology. The activity of a person has very much to do his with his career. With stable conditions and ability, a healthy person is to-day able to control his fate. But after all the range of such mastery is limited and, in the large, we must remember that a person's capacities are not of his making. The individual is a specific organism whose structure and constitution has resulted from past activities. But human beings do not, as a rule, demand very much from life after their romantic period is over. The capacity for adjustment and acceptance is very large.

Poetry and religion have surrounded the idea of fate with mythological implications. Strictly speaking, fate is simply a factual term, a designation of what happens. History presents the fate of nations; biography, the fate of conspicuous individuals. But the old animistic outlook still lingers. Man tends to think of his life as planned beforehand. In this sense, fate is a product of early man's helplessness and his anthropomorphism. It assumes some shadowy being which predetermines events, which overrides and uses resistance. The Semitic religions have contained this outlook to an abnormal degree. The Greeks, likewise, pictured something, more ancient and mightier than Zeus, which decreed what must happen. 
There seems no reason to continue this anthropomorphism which makes events a mere rehearsal of an established plan. It is impossible to take causality seriously and hold such a view at the same time. We have taken time seriously as a process of change and, by so doing, have attacked the intellectual element in fate. The emotional element remains. So long as man feels helpless, he will have a sense of a larger whole determining his destiny. He will feel passive and fatalistic. As yet, the occidental world has confidence in what it can do and so feels active and ereative.

Subjective chance admits objective determinism. We have seen this to be the case in the calculation of probabilities. We have, again, probability as a mode of our judgment when the knowledge is insufficient to base certain prediction upon. And this may be due to (1) the number of the factors, (2) the variation in the situation, or (3) the variability of an important factor. The last reason bulks very large in the behavior of human individuals. Thus Fabre could predict what a mason-wasp would do under certain circumstances because instinct is orderly and limited, but he could not predict what children might do if experimented upon. It follows from our whole discussion that subjective chance is largely irrelevant to any theory of real causality. It concerns our cognitive position.

Objective chance is a theory of causality in nature; and offers itself as a denial of what is vaguely called objective necessity. We have clearly to do here with relative terms.

Tychism seems to be a protest against the exaggeration of a particular type of determinism. Too often science has lapsed into a scholastic realism which thought of laws as governing nature. The critical realist agrees heartily with the tychist so far as he protests against any such logical anthropomorphism. Again, I find in much of current tychism a protest against a dead-level mechanical view of nature which does not take evolution and novelty seriously. The behavior of man cannot be described in terms of mechanics. It is absurd and unempirical to ignore the fact that his behavior involves the application of past 
experience to the situation which now confronts him. And this situation is inseparable from his interests and selections. The situation confronting a lower animal is not, and cannot be, the situation confronting a human being. In other words, a situation is a selected aspect of the environment.

The new pluralism sympathizes with the tychist in his opposition to a block universe, on the one hand, and to logical determinism on the other hand. But when it comes to the positive teaching of tychism the matter is altered. I would put the case thus. With one interpretation, tychism does not contradict determinism as I understand it. With another interpretation, it does. On the whole, I am inclined to treat tychism as a valuable protest against absurd interpretations of objective necessity.

Philosophers who approach nature from the standpoint of analogy interpret the behavior of atoms and electronsso far as they give these terms external validity-as responses similar to the response of an individual to a novel situation. There must be choice. And is not choice an instance of spontaneity? After choice is made habit ensues. Henceforth, there is routine and the mechanical.

My chief objection is that such an argument from analogy does not take evolution seriously enough. I grant that habit implies a preceding novel adjustment, but I very much doubt that there is enough similarity between the response of an atom to its environment and the adjustment of an organism to make the application of the same terms meaningful. I grant you that there is an identity, but there is also a difference. The identity lies in the fact that all response is an expression of the nature of that which responds; but is not the constitution and capacity of the organism very different from the much more limited constitution of the element? To employ a physicist's expression, there are degrees of freedom in the one case not characteristic of the other. I do not believe that it is justifiable to extend the locus of the term habit. I feel much the same toward such categories as impulses and will. I 
know that the speculatively inclined Leibnizian will not agree with me.

Let us, then, shift the venue of the question to human activity. Does our experience reveal indeterminate spontaneity and genuine caprice? I am not quite certain what the tychist postulates. I do not wish to caricature his position and make him advocate freedom of indifference. My chief quarrel with him is his tendency to misstate the position of the critical determinist. For instance, I find it difficult to distinguish Bergson's idea of free-will from relative self-determination. Once we have turned our back upon fatalism, predestination, a mere spectator-like self moored to an organism and such outgrown fantasies, much of the meaning of the historic controversy about free will has evaporated. The problem modern thought is engaged upon is the discovery of what kind of a creature the human self is. That it is complex and more or less divided against itself appears evident. Such freedom as it has is a positive character. It is the ability to control its surroundings, to realize its aims. And such freedom is obviously relative.

Positive freedom is very evident in moments of decision when we deliberate and do not act from habit. ${ }^{5}$ Then we apply all our intellectual capacities to the task confronting us. But is such freedom revealed as caprice? Surely not. "Our personality shoots, grows and ripens without ceasing. Each of its movements is something new added to what was before. We may go further: it is not only something new, but something unforeseeable. Doubtless, my present state is explained by what was in me and by what was acting on me a moment ago. In analyzing it I should find no other elements. But even a superhuman intelligence would not have been able to foresee the simple indivisible form which gives to these purely abstract elements their concrete organization." 6 The conclusion of this quotation does not have much meaning for me. Doubtless it is in line with Bergson's

${ }^{5}$ I agree with Bosanquet that freedom is not most strongly felt in choice. We feel most free when we are carrying through plans.

- Bergson, Creative Evolution, p. 6. 
almost mystical emphasis upon internal relations in consciousness. The new pluralist does not apply the hypothesis of a super-human intelligence. It seems to him rather meaningless outside of the domain of mechanism with its definite assumptions and data. The significant question is, Of what would complete knowledge of a person consist? Is a person stable enough to be the object of complete knowledge? The nature of this kind of object is the fundamental question. Is not knowledge- even self-knowledge-largely retrospective? Yet if I could know exactly what the situation was which confronted an individual, what his valuations and desires were, what his courage was, etc., I could foretell his conduct. Assuredly the general line of it. Why? Because these are the actual data of his own decision. As soon as these become stable in deliberation, the choice is fixed.

Bergson has done excellent psychological work in criticizing the mechanical conception of motives as fixed things pushing from behind. Motives are responses of a changing self and constantly alter. Personality is a process and not a static thing. And yet we must not go to the other extreme and ignore the conservative aspect of the self. Character, habit and heredity indicate the element of continuous identity. More acutely here than anywhere else do we meet with the union of novelty and permanence. Growth implies organization and intimate accumulation, an active harmony of the new and the old. The old meets and welcomes the new. We must grasp the fact that internal relations do not involve a complete alteration of the past. There is something phenomenalistic and superficial about a kaleidoscopic view of the self. It does not sense the limits to change. Under normal conditions, change is always secondary to permanence.

Again, there has always been much sentimentalizing about the self. An ideal self is often set up and contrasted with a baser self. The thinker must realize that these are but parts of the one complex self. This ethical dualism is usually attached to the traditional soul-body dualism. Self- 
deception gets in its deadly work. We must remember that the objective self is an object of mediate knowledge and that there is never complete knowledge of it. The total self is complex, and only part of it is expressed at any one time. In spite of its many exaggerations, Freudianism has driven this fact home to the modern thinker. The self which dominates consciousness is not the whole of the complex self.

I do believe that on many of these problems philosophy is approaching more of an agreement than is usually supposed. The decay of outgrown assumptions accounts for much of this convergence of opinion. With the withering of supernaturalism, the setting of problems has become much more concrete and empirical. This is peculiarly the case with the problem of freedom. Freedom is now more naturally conceived as a positive characteristic of the whole person. It means abilty to control factors in the environment and to realize ends. It is a term which applies here and now to activities in concrete situations. It designates a kind of behavior.

The traditional method of approach began with an entity called will and asked whether this was free. Free from what? And what is this entity with which we are so greatly concerned. There was much of the ghostlike about this will. Its relation to concrete personality was unclear. Now the whole bio-psychological approach to the self has changed all this. It is seen that the will is a function of a developing complex of instinct and experience. We do not believe in and do not want a mysterious will alien to us and issuing its decrees like shots from a pistol. The self is a process of adjustment and growth. In consciousness the individual is on the inside of this process and an effective part of it. Free will should mean only what concrete freedom means.

Has the contrast between free will and causal determinism much meaning to-day, once we relinquish freedom of indifference? I do not see that it has. Any intelligible sort of free will is but a protest against a false sort of 
determinism. Like vitalism, it is a protest against inadequate views. There are those who make heredity too rigid a thing rather than a set of tendencies and general capacities which are modifiable within degrees. There are those who make the individual the passive victim of economic conditions. The metaphysical determinist replies that the degree and kind of freedom an individual or a group has is a question of fact. Freedom implies causal activity and relations.

Much of the misunderstanding of causal determinism has been due to a disregard of the importance of time. It has not sufficiently been realized that time is nothing apart from change. That personality is a process and that the same situation in a literal sense can, therefore, never recur has not been appreciated. Misleading words have also played their part. If I tell a person that he could not help doing what he did at a certain time in the past, I am suggesting that he was struggling against factors seeking to control him and that he was conquered; whereas he was undoubtedly choosing happily and hopefully. All the determinist should point out is that choice is the expression of the self of the time in the situation of the time. He does not mean that the individual would act that way again now that he is a wiser man. Nor does he mean that the act was necessarily the expression of the best in the man. The pathos of action is often that potentiality conflicts with actuality. We may say also that in this conflict lies the significance of repentance and conversion. Few actions are the function of all the resources of an individual. It is quite correct to say of men that their potentiality is greater than their action. But a potentiality which is never expressed in any degree is a myth.

The traditional doctrine of free will was also pointed against epiphenomenalism. It was a protest against the crude idea that a man's actions were the function of purely mechanical changes in the organism and in the environment. Such epiphenomenalism assumed a dualism between mind and body with which the evolutionary naturalist has no 
sympathy. There are levels of activity and behavior in nature. Mind is a physical category.

We may conclude that the old, deductive, mechanical necessitarianism which thought of man as a machine and consciousness as a mere psychic illumination has received a shrewd blow. The various sciences are becoming more autonomous, that is, more empirical, and are refusing dictation from anything but their material. The categories are enlarging and becoming more flexible. Man is still regarded as a part of nature-that is the fundamental thesis of naturalism-but his specific abilities are not ignored. Naturalism has at last decided to take evolution seriously. Just because the critical realist distinguishes between knowledge and its object, he can harmonize all that is valid in both determinism and tychism. As against logical determinism, he points out that laws are not external realities governing events. As against tychism, he asserts that spontaneity can only mean an activity relative to and affected by a situation. And such activity at once expresses that which is and modifies it.

How Shall We Conceive Necessity? - Necessity for Spinoza was the same as true freedom. Was this a play upon words? Clearly, if we are to avoid a paradox we must find out what we mean by necessity. The discussion in the previous section should help us.

To be determined by one's own nature is to be free. Such determination is self-expression which is the same as freedom. But things are not so simple. Even if we are not pushed from outside as a culprit is by a policeman, we are often divided against ourselves. The individual is solicited by various ideas which are incompatible. The victory of one idea is never complete. The vanquished element is rebellious. The truth is that the past thought too much in terms of substances of a simple nature. The categories of to-day are those of process and complexity. As we have already seen, modern pluralism is a revolt against a false conception of unity, a conception which thinks of the whole 
as above and controlling the parts. Spinoza's was a mystical, logical substantialism. The evolutionary naturalist has knowledge of an external world knit loosely together and permitting localized developments and novel activities in the parts. Both space and time are more empirically conceived.

It follows that freedom is a category which permits degrees and that it expresses knowledge of the part played by one thing among other things. While not limited to man, it has for him a deeper meaning because of his greater abilities and his fuller knowledge of himself. Man has wants and desires, and is led to measure his freedom by the extent to which his environment cooperates or can be made to cooperate with him to their fulfilment. This freedom has a transverse reference to the setting of his action. The opposite of freedom is bafflement and frustration; and these lead to the emotional attitude of fatalism.

The common denominator, so to speak, of the various levels of causality from the atom to man is a physical system actively changing. Hence it is obvious that causal necessity concerns every level and does not differentiate them. Freedom, on the other hand, is a category with degrees and expresses specific knowledge of specific things. It is nonsense to talk of the whole universe as being free unless we think of it as a single person. Freedom has to do with the success or failure of a part within a larger whole. The causal determinist of evolutionary, pluralistic persuasion is clearly a believer in interaction and differentiation. He grants activity and power to the individual. In all this he keeps close to the facts. In short there is no conflict between freedom and causal necessity.

Descartes and Kant are historically to blame for the prevalent association of determinism with the reign of mechanical laws. But what was an excusable fault with them is inexcusable to-day. It is one of the merits of the pragmatist that he has stressed the objective validity of biological and psychological categories. But because of his idealistic inheritance and poor epistemology, he did not always do justice to the inorganic which is man's cosmic 
setting. There was at times something comic and boyish about his lighthearted humanism.

To return to our main argument. From the principle of causal necessity as I have interpreted it, no theory as to the method of change in any system can be deduced nor should the creative activity of any object be denied. The causal determinist can champion invention and the creative power of intelligence with an even more assured conscience than can the indeterminist. But I feel certain that this fact is being realized and that the old controversies are on the point of disappearance. Causal determinism is pragmatically harmless. $^{7}$

The category of necessity is essentially retrospective and cognitional. For this reason appeal from it to the sense of free activity in conduct is quite irrelevant, all the more so that there is no intellectual conflict. When B follows a set of conditions $\mathrm{A}$ and tests show a genuine relation, we are led to maintain that B necessarily follows from A. This "necessarily" expresses our conviction of an inner relation of change to that which changes. But it is nonsensical to conclude that the changing system must feel necessitated. It is in thinking that we feel the necessity. But those who make the false interpretation argue that our sense of freedom in action disproves causal necessity. It does not, because there is nothing in the general theory of determinism which implies that we should have any other experience than we do.

At the risk of being tedious, let me draw together the threads of my argument. First, any physical system in process of change determines its changes. Let us call this self-determination. Such self-determination has no logical connection with any specific theory of the mode and manner of change. Only empirical investigation can throw light upon this latter problem. And the facts indicate that there are different kinds of processes in nature. Second, the feeling of causal necessity is subjective and retrospective.

7 It is quite evident that James saw this, for he argued finally only for novelty. Historical idealism took much the stand of Spinoza but was, like him, unjust to time and space, novelty and pluralism. 
It should not be projected into the process of which we are gaining knowledge. In free action we have a characteristic sense of relevant transition. There is a sense of accepted and even willed unfolding or direction. I believe that Professor Alexander has named this experience enjoyed determination. The opposite of it is a sense of compulsion. Third, the feeling of necessity, of which Hume made so much, in no wise conflicts with our experience of activity and freedom. The same action that we feel free and active in doing will retrospectively appear to follow from our character and the situation in which we were. In action the self is the character or personality. There is no sense of control by it as something external to the self. Or, to the extent that this is the case, we are divided against ourselves. Finally, causal processes often lead to novelty, to new combinations, to new wholes having new properties. We must separate causality and repetition. It follows from all this that causal determinism is perfectly harmonizable with empirical freedom and self-realization and that both are opposed to fatalism and predestination.

Freedom is a category expressive of the ability of man to plan and to dominate. At its highest level it implies thought and judgment. For this reason it is right to say that only the good man attains the highest degree of freedom. The more man masters himself and his environment the freer will he be. Freedom is at once a transverse and a temporal category. And it is always relative to situation and aims. When individuals ask whether they are free or necessitated, they have reference to the fact of success or its absence. And the empirical answer must be that they are sometimes free and sometimes not. Let us note that there is just as much causality in the one case as the other, so that causality, itself, cannot be the distinguishing mark. It is equally clear that freedom as a category has most meaning where there are creatures who make plans and try to carry them out. It is not that physical things are completely unfree, for they participate in the result and are never passive. It is rather that the internal situa- 
tion of conscious beings begets contrasts which were previously non-existent. How far down in the scale of evolution these conditions are found is a question for the comparative psychologist. Evolutionary naturalism does not ignore man's peculiar abilities since it takes time and evolution seriously.

A Fresh Return to Potentiality.-Early in the present chapter, we offered a suggestion as to the correct meaning of potentiality. We saw that it was a complex category connected with causality. It stood, as it were, midway between possibility and actuality. It is that upon which possibility must be based to make it more than a mere play of the imagination. It stands for a recognition of the complex nature of things and of the fact that things are capable of various expressions according to the conditions brought to bear upon them. It means that what occurs is always a selection, that other events would have occurred had other combinations arisen.

Potentiality is, thus, a category which the pluralist must always emphasize. It stands for the significance and richness of content of terms. What, for example, would I have been like without a university education? Would not certain sides of my nature have been partially dormant? Potentiality signifies that terms are not reducible to their relations without a remainder. I do not wish to be misunderstood. Relations in nature are not external, but they are additional and changeable. Potentiality does not mean an inactive core at the center of the term but it points to new modes of action under different conditions. It signifies that individuality is cumulative, complex and charged; that it is not exhausted by any one response but is ready to express itself again and again and variably. Potentiality goes with such categories as organization and cumulation. The shallowness of mechanistic naturalism has revealed itself in its inability to concede potentiality and variability. Nature was all surface as it were.

But this larger meaning of potentiality implies a nar- 
rower meaning, that of causal continuity. In this sense, potentiality signifies that the final result of an actual process is the natural and legitimate expression of the changing system. False potentiality ignores creative activity and holds that the result was already there in some sense at the beginning. It is an attempt to belittle the significance of time and change. It is a yearning for continuity overdoing itself. Both absolutists and mechanists have been guilty of the false use of potentiality. The reason for this is not far to seek. Both were opposed to novelty and sought to interpret it as concealed repetition, as an unveiling of what already was. The believer in false potentiality loves such a term as the implicit.

It is somewhat surprising to find that many advocates of novelty still interpret the principle of continuity in such a way as to furnish a support for the false notion of potentiality. This question comes to a crisis in the problem of the appearance of consciousness. Let us examine James's interpretation of the famous passage in Tyndall's Belfast Address in which he claimed to find in matter the "promise and potency of every form and quality of life." James regards this as an appeal to continuity and comments as follows: "We ought, therefore, ourselves sincerely to try every possible mode of conceiving the dawn of consciousness so that it may not appear equivalent to the irruption into the universe of a new nature, non-existent until then.... Merely to call the consciousness 'nascent' will not serve our turn... The fact is that discontinuity comes in if a new nature comes in at all.... And consciousness, however little, is an illegitimate birth in any philosophy that starts without it, and yet professes to explain all fact by continuous evolution."8

I shall argue in the next chapter that consciousness is not a new stuff in any metaphysical sense and that awareness and cognition are functions of the structure of consciousness and the activity of the organism. But while psychical contents are inseparable from cerebral states and

8 James, Principles of Psychology, p. 149. 
are a literal part of their nature, they are novel just as these states are novel. They cannot be deduced nor foreseen. They are new just as mental capacities are new. Much, therefore, depends upon what James means by a new "nature." We must postpone the subtleties of this point to the discussion of mind and body.

There remains the logical question. Does continuity imply mere sameness? Does the principle imply that the future is like the past and that change can only be repetitions? Surely not. Our whole argument has been against that. And the facts of science and of human life are as clearly against any such interpretation. I conclude that continuity can demand only genetic relationship, the absence of causal breaks. It has no right to go further and assert complete logical identity of the sort that comes out in the formerly popular postulate that the effect must be like the cause. As a matter of fact, the effect should not be like the cause, although it should be relevant to it. ${ }^{9}$

The idea of continuity is often of a sensuous rather than of a logical type. Thus the visible confluence of the parts of a spectrum in which adjacent likeness yet permits marked differences between widely separated parts is sometimes cited as an example. But evolution deals with cumulative change and with new wholes rising on the intimate combination of recoverable, yet for the time changed, parts. Shall we say that such a progression involves discontinuity? If we mean by discontinuity novelty, yes. But if this novelty grows necessarily out of the situation, is there not also the essential of continuity? Otherwise, continuity means identity and the postulate conflicts with the obvious fact of change. Let us apply this conclusion to the problem indicated by Tyndall and interpreted by James.

That human behavior and structure is new in the world, cannot, surely, be doubted by the evolutionist. What is postulated is that these capacities and activities and organizations can be shown to have grown step by step from preceding stages. It is genetic relationship which is held in

- Cf. Bosanquet, The Principles of Individuality and Value, Vol. 1, Lecture 3. 
mind. But human consciousness is intertwined functionally with these capacities and activities. It must therefore be as new as they, for it is not a sterile and passive stuff which has no organic relevance to the life of the organism. Any empirical theory of consciousness makes it correlative, not to the atoms into which the dead brain can be disintegrated, but to functional nerve-systems. Why, then, should the existence of consciousness at a particular stage of evolution and its non-existence at low levels be any more of a challenge to the principle of continuity than the corresponding contrast between organic behavior of an intelligent sort and mere physicochemical process? Primarily, I presume, because the uncritical mind works up a contrast between an unorganized matter alien to consciousness and this new thing called consciousness, and can detect no bridge from one to the other. Such a change becomes a miracle and genetic relevance intuitively excluded. But after we have once relinquished naive pictures of a material stuff known to be alien to consciousness in its very heart-a view which reflects what may be called natural dualism-we perceive that the thinker can just as well argue backward and say that the physical system which contains consciousness must have grown out of a type of reality capable of bringing it to birth. I believe that consciousness is an irruption so far as its novelty is concerned but not as regards its genetic matrix and conditions. $\mathrm{He}$ who denies this assertion of essential continuity must maintain that only consciousness can produce consciousness. But to this thesis it can rightly be rejoined that consciousness is not a productive stuff which is seen to reproduce itself endlesssly, that consciousness is a complex of contents ever coming and going as seemingly free gifts, and that both the significance of consciousness and its occurrence appear to be bound up with the brain, a reality which is more than consciousness though not alien to it. But we are in danger of forgetting that we are analyzing only the category of potentiality. In our later discussion of the mind-body-consciousness problem we shall be in a better position to gather all the necessary threads of thought together. 


\section{CHAPTER XIV.}

EVOLUTIONARY NATURALISM AND THE MIND-BODY PROBLEM.

No problem is more crucial for a naturalistic view of 1 the world than the mind-body problem. There are many biologists who look with equanimity upon a mechanistic interpretation of life, and yet regard the location of mind and consciousness in the physical world as impossible. The categories of psychology, they assert, are incompatible with those of physical nature. "That matter and mind are incommensurables," writes one, "seems to my judgment so obvious that it needs no argument and risks no serious denial."1 It is undoubted that this problem is, as Bergson contends, the most formidable problem that humanity can face. Upon the correct solution of it so much depends. Man cannot know himself unless he has an answer to the question whether he is literally, and in all respects, a child of this earth, or has a dual nature which unites him by one of its parts with that which transcends the visible world.

It is clear that the critical naturalist feels himself on his mettle when he approaches this fundamental problem. No assumptions must be left hidden and unanalyzed. No terms must be allowed to remain undefined. No one must be permitted to talk about incommensurables in a loose way, as though the terms of the comparison were intuitively given. Here, if anywhere, is a problem which is reflective to its very roots.

1 Professor D'arcy Thompson, Life and Finite Individuality, p. 30. 
The traditional formulations and solutions-if such they may be called - of the mind-body problem have been due to ideas of a very general nature. They have reflected assumptions which for various reasons-to be understood only historically - have dominated the thought of past epochs. The conventional attitudes taken by the majority of scientists and philosophers were based upon past speculation and were expressive of a period antedating the rise of the biological and the social sciences. They were pre-Darwinian. I find, even, that many scientists are not aware of what strides toward union with biology psychology has taken in the last decade. I do not hesitate to assert that, to-day, the gap between psychology and biology is no greater than that between bio-chemistry and biology. The time has arrived for a new inventory and a revaluation of the situation. Philosophy must throw away old conceptions and begin anew. It is this that evolutionary naturalism, with the aid of critical realism, is seeking to do.

On the whole, it was taken for granted, in the past, that mind and body are existentially separate. The body was assimilated to the inorganic level and the mind was conceived purely introspectively and mystically. The question of their relation was thus inevitably formulated in a dualistic fashion as that of the causal interplay, or absence of causal interplay, of these incommensurables.

But this usual assumption of existential separateness is too fundamental to be allowed to pass unchallenged. Thus far in our investigations we have seen no good reason for the assumption -indeed, quite the reverse has been the case. For instance, our whole epistemology developed itself most naturally on a biopsychological basis. The very structure of consciousness reflected the position and adjustments of the organism. It will be remembered that the conscious self was correlated with the interested response of the organism to the objects of perception, while the content of perception was correlated with the stimuli from those objects. The whole flow of consciousness seemed naturally assignable to the organism which was thus differentially 
reacting to its environment. There must be strong reasons against such an assignment if it is not to be made. I would certainly hold that the burden of proof rests upon dualism. Are the traditional reasons, built up under the control of an inadequate epistemology, a dead-level mechanicalism and a spiritualistic idea of the self, sufficient to hold apart what appear to be united in a natural and functional whole?

The task of the present chapter will, therefore, be twofold. We must demonstrate the falsity of the premises upon which the old dualisms were founded and attack the defense offered by Bergson for his type of dualism; and we must render intellectually conceivable the presence of consciousness in the organism. It will be our effort to show that evolutionary naturalism can do justice to all the facts and so accomplish what materialism of the traditional type with its inadequate epistemology and its lack of appreciation of organization and novelty could not accomplish.

The view we shall adopt in our approach is that the mind-body problem, not being specific in the experimental sense and being entangled with all sorts of conflicting assumptions, is largely a philosophical venture. What is required is a clear analysis of the terms and of our knowledge of them. A point of view must be achieved from which the well-grounded generalizations of the physical and the mental sciences can be harmonized. It is obvious that such an achievement is impossible without an analysis of fundamental categories. The greater part of this work has already been accomplished. Our present task is to apply these results to the mind-body problem.

Such, if I mistake not, is the logical situation of the mind-body problem and the reason why philosophers must have a peculiar interest in it. But if philosophy is to be a coordinating science resting upon, and cooperative with, the special sciences, its interpretation of the problem must reflect the march of events in these sciences. It cannot isolate itself in the old romantic fashion and trust solely to the powers of dialectical speculation. Its hypotheses must spring from the pressure of the general scientific movement 
and reflect in their growth the point of view and the fertile suggestion which such pressure gives to the creative imagination. But, added to this, philosophy must contribute a clear analysis of the actual content of experience and a sharpened notion of cognition.

Traditional Solutions.-The traditional solutions of the mind-body problem have a metaphysical parentage which goes back to the early days of modern philosophy. Dualistic theories have a Cartesian flavor, while monistic speculations are tinged with Spinoza's postulation of a fundamental substance with two knowable attributes.

One of the perplexing features of the modern forms of dualism and monism is their vagueness in regard to substance. It is often difficult to determine just how far they continue to retain the Cartesian or the Spinozistic ontology. This very fact shows their weakness; they are compromises between tradition and the drift of the moment. A psychology without a soul can scarcely be said to be dualistic in the traditional sense.

It is pretty generally admitted now that Cartesian parallelism reflected the scientific situation of the time. The physical world was conceived as a huge machine operating according to the laws of mathematics. The thinkers of the time were daring enough to include the human organism in this mechanical complex. It followed that the individual's actions were, like all other motions, effects of specific conditions interpretable by the laws of mechanics. Now this conception of the body, as merged passively in the whirl of events, was made palatable by the admission that the soul was distinct and separate. The result was that science compromised with supernaturalism by means of a division of reality. Consciousness and the soul were voluntarily extruded from the physical realm.

But, as time passed, the soul lost standing; and states of consciousness alone seemed real on the mental side. The increasing de-substantializing of the mental led to its timid approach to the brain of which it was increasingly treated 
as a step-child having no authority or energy of its own. It had relinquished its rights and could not regain them. The logical consequence was naive materialism or epiphenominalism. Consciousness but repeated parrot-like the processes going on in a brain with whose activities it had nothing to do.

It is obvious that the naturalistic philosopher who is dissatisfied with this situation must strike at the assumptions underlying this whole development. Is the physical world a dead-level mechanical system? Are consciousness and mind alien to it as both religion and science have so smugly assumed? Will modern biology and psychology recognize this early grant of their domains to physics? I doubt it.

Like metaphysical parallelism, interactionism has been a dualistic theory maintaining that mind (or soul) and body are two distinct kinds of existences which yet interact in perception and volition. There is hardly less of the dualistic tradition in interactionism than in parallelism. But it is more robust and confident on the mental side. The champions of the soul refuse to make it a mere translator and shadow of the alien physical domain. I respect the interactionist for this stoutness of conviction. It will wring concessions from the scientist, though the reformulation of naturalism may not please the interactionist who has mystical yearnings.

We must distinguish the metaphysical type of interactionist who postulates two kinds of existence from the psychological type who eschews metaphysics and is chiefly interested in the question of the efficacy of consciousness. When we discuss interaction in this chapter, we shall mean the position that stresses a flat distinction between mind and body and yet holds to a causal relation between them. Such interactionists believe in the soul as something which overflows the body. They are animists and vitalists. Thus a belief in the efficacy of consciousness is not enough to label a thinker an interactionist.

The older scholastic theory of the soul made it an immaterial substance upholding mental activity. When Locke 
made this immaterial substance a permanent unknowable, he gave the soul a shrewd blow; especially so because of his cmpirical idea of personality and of personal identity. For this reason as well as for others, contemporary advocates of the soul-theory fight shy of the term substance. They speak of memory and the self. What they do affirm is the necessity for something other than the body.

Let us glance at some of the difficulties confronting metaphysical interactionism. Physical things are always spatially related, and causality in science implies this spatial background or context. But the soul acts into space rather than in space. It is interesting that, when we come to attack Bergson's defense of his position, we shall lay stress upon the validity of the spatial category. The questions of epistemology will again come to the front. The divergence with regard to space is fundamental, but there are others which develop it. First, does not interactionism imply a denial of the constancy of energy? The brain-event acts upon the soul, and the soul reacts; and so the physical system ceases to be self-contained. Secondly, the soul either acts without the need of energy or it possesses its own peculiar and spiritual kind. And yet bodily nourishment affects the activity of the mind. So does sickness. Who does not feel the essential truth of Gissing's reflections: "The very I, it is plain, consists but with a balance of my physical elements, which we call health. Even in the light beginnings of my headache, I was already not myself ; my thoughts followed no normal course, and I was aware of the abnormality. A few hours later, I was but a walking disease ; my mind-if one could use the word-had become a barrel-organ, grinding in endless repetition a bar or two of idle music." Does not the dualism seem to be an illusion due to some weakness in approach and formulation, to be confusedly verbal rather than real? Thirdly, how does the soul know when and where to act upon the brain to produce desired results? It would seem necessary to assume unconscious knowledge of the minute structure of the brain. and that by something other than the brain. We are thrown 
into the clutches of the mysterious with a vengeance. Even Bergson with his instrumentalist theory is forced to hold that brain and spirit overlap in pure perception. Fourthly, whence comes the soul? Why does it accompany organisms? Does it assist in the synthesis of these organisms. as vitalism suggests? Do souls have their embryology and development? Why are souls and bodies as fittingly connected as if both had the same heredity? Fifthly, by what right is it assumed that the brain cannot perform those functions assigned to the soul as an imperceptible thing? May it not be that the soul-body dualism of tradition operates in this conviction that there must be two things instead of one?

The modern exponent of interactionism is practically always an animist and a vitalist. Thus McDougall writes: "It is just because we have found that mental and vital processes cannot be completely described and explained in terms of mechanism that we are compelled to believe in the cooperation of some non-mechanical, teleological factor and to adopt the hypothesis of the soul."' 2 Let us bear this reason in mind. Evolutionary naturalism does not believe that the higher levels of nature are purely mechanical; it accepts critical points with resultant new properties. The struggle between animism and naturalism centers here.

But there are some thinkers who frankly identify the soul with the self as a unitary system of experiences and refuse to admit the necessity for a thing with capacities. Yet the difficulties confronting this purely experiential conception of the soul are many. Is the soul intermittent? Can it cease to be, as in sound sleep, and be reborn identical with what it was? What is the basis of retentiveness? Yet we must again admit that this empirical analysis of the soul must be recognized by naturalism. To cover the facts is one of the basic requirements of an adequate natturalism. There is much to suggest that empiricists who are dualists are so as the result of a false epistemology and a resultant underestimation of the living organism. While

${ }^{2} \mathrm{McD}$ ougall, Body and Mind, p. 365. 
animists are firm believers in the mechanical theory of the physical world, empirical interpreters of the soul are apt to be naive realists also. ${ }^{3}$

The Empirical Difference Between Interactionism and Parallelism.-When we shake our thoughts loose from the older substance-theory and ask ourselves just what the empirical difference between interactionism and parallelism is when these are taken as working hypotheses, we find that the main divergence concerns the efficacy of consciousness.

Interactionism intercalates mental states between the incoming stimulus and the outgoing motor discharge and so breaks the continuity of the physical series. Strictly speaking, this intercalation is in the brain, so that the mental state, be it image or meaning, comes between two brainevents. To those who object that an image can have no causal grip on the brain of the external or transeunt sort here implied, it is answered that transeunt causality is a mystery which must be accepted.

I have already offered a number of objections to interactionism. To these I would add the suggestion that mental states are unthinkable apart from the body of whose functions they seem to be an inseparable expression. Cannot the mental state be given a setting in the brain of such a character that its efficacy does not involve a discontinuity and action from outside? Interactionism would appear to champion a truth, but to do so clumsily just because it is dualistic.

Empirical parallelism differs from interactionism on two points. First, it asserts a temporal correlation between mental state and brain-event. Every mental state has a correspondent brain-event. Interactionism, on the contrary, regards its intercalated mental states as literally self-sufficient. There is only one mixed series instead of two parallel series. Second, parallelism holds to the inefficacy of consciousness so far as cortical events are concerned. The two series do not interact. As I have already suggested, paralSelf.

${ }^{3}$ I am referring to Laird's excellent book entitled Problems of the 
lelism would appear to champion a truth in so far as the first point is concerned-though this correlation cannot be proved in any direct fashion.

The naturalistic view which I am going to develop has as yet no successfully definitive name. It holds to the effective presence of consciousness as a natural ingredient of functioning cortical systems. In one place in my writings I have called it the unity-theory; but that expression calls attention to only one side of the position, viz., the denial of the traditional dualism. ${ }^{4}$ From another angle, it can be designated a critical development of the double-aspect theory, a development founded on critical realism. There is complexity in the brain itself. It is a double-knowledge theory expressive of this unique complexity.

Why Has Mind Been Excluded from the Organism?In our brief study of the historical development of parallelism, we saw some of the reasons why mind has been excluded from the organism. We must now examine them more analytically.

The first reason may be called epistemological. The physical world is the object of scientific knowledge, while consciousness is the seat and means of knowledge of it. This contrast is readily taken to be an ontological contrast. I presume that this interpretation is made easier by the tendency to assume that the very stuff of the physical world is given in perception and in valid conception. Scientific realism takes the form of an intellectual intuition of the very substance of physical things. Not all scientists are as naive as this but many are. Thus a naive epistemology is the inevitable generator of a naive dualism. Two different realms seem spread out before the comparing gaze of man. Hence, to say that the organism has anything in common with consciousness is like saying that black is white. The difference is held to be inspectional in type.

The dualism suggested in this fashion is supplemented by a logical motive. The categories which develop in our

4 The Essentials of Philosophy, Ch. 22. 
knowledge of the physical world are in many respects not identical with those which characterize consciousness. I presume that the one striking exception generally admitted is time; and Bergson denies even this identity. For him the physical world contains simultaneity only, while true time is a mark of mind. Hence these two generic objects of thought cannot be identical. Consciousness is not simply the physical world, and the physical world is not simply consciousness. It is natural, then, for the logical motive which shows a disparity to be interpreted along the lines of prepossessions awakened by the epistemological motive. It is forgotten that there are other possible existential relations besides simple identity.

The third motive may be called methodological. There has been a working dualism growing out of the data of the sciences. This has meant an ignoring of questions of the nature of consciousness as not relevant to the content of knowledge. The scientist's cognitive interest was in the physical world and not in consciousness; and in the world known through the data of observation he could find nothing which reminded him of consciousness as he understood that term. The point is a somewhat subtle one and to some extent involves the first motive. Consciousness was often conceived as something which could be perceived if it were in the physical world. By naive realists-or at least intuitionalists of a conceptual sort-the physical world was thought of as something directly intuitable; and the tendency was to assume that consciousness, also, was something of like possibility; why could not consciousness be perceived if it were there? Need I point out that the critical realist affirms that this whole argument has no validity? The physical world cannot be intuited, for what we intuit is the content of perception; and the recognition of this situation makes it absurd to seek to perceive consciousness as an object in the sense that the physical existent was supposedly perceived. Even were consciousness in the physical existent, it could not be perceived in the naive sense, for no part of the existent is intuited in this sense. 
But still another methodological motive was at work in the science of the past. Let me put the situation in the following way. Most of us, I imagine, would be inclined to say that there is neither mind nor consciousness in inorganic nature. But science was for many years an investigation of inorganic masses. Only lately have the natural sciences gained a fair measure of autonomy and self-confidence enough to suggest new categories. And if the dominant sciences were physical and chemical and dealt below the level of the organism, it is not strange that the category of mind did not appear as involved in the data and their necessary interpretation. The absence of mind as a category is just what we should expect. And since evolution was not taken seriously, the conclusion drawn was that all phases of nature could be understood without the idea of mind. As we shall later see, behaviorism is unwittingly raising the question whether this be so.

A sort of pragmatic dualism grew, then, out of the stage in which science was. Scientists did not feel that mind and consciousness were relevant to the physical world as they knew it. Reinforce this methodological motive by the epistemological and the logical motives discussed above, and the strength of dualism can be appreciated. Yet, on the other hand, it is not without significance that scientists, when speculative, endow matter with the potentiality of life and mind.

New Tendencies in Science.-Within the last two decades, new tendencies of a genuine interest to philosophy have been declaring themselves. These are, (1) a questioning of the adequacy of the laws of mechanics for any field of nature except that of molar masses; (2) the increased recognition of the empirical autonomy of the various sciences; (3) the admission of creative synthesis in nature with accompanying critical points and new properties; (4) the rise of behaviorism as a physical science bringing human conduct into the physical world.

The implications of these tendencies are fairly obvious, 
yet it will be some time before they are frankly acknowledged. I want to suggest particularly their bearing upon the idea of continuity. The emphasis previously was upor sameness. New could not come out of the old. Identity precluded differences. But has not this point of view weakened? Genetic continuity seems to us to unite striking differences. We are confronted with pluses. Chemical properties are not the same as physical properties. There is a further plus when we examine the functioning of organic tissues. The older properties are transcended and included. And behaviorism is suggesting that a still more synthetic level is reached in the nervously controlled action of the whole organism.

Evolution seems, therefore, to contain two equally real elements. There is genetic continuity, and there is novelty. Such change is a critical growth within reality. Who has a right to say a priori how great a novelty may arise and so set limits to the possibilities of nature? The extent to which this recognition of evolutionary synthesis has come to the front of late is surprising. It means the frank admission of novelty without an appeal to a superphysical agent. But if we accept the effectiveness of new organization, the rather abstract and dialectical choice between mechanism and vitalism becomes a fallacy of incomplete disjunction. A richer and more empirical approach to biology has opened before us. $^{5}$

If totality and self-regulation appear as undeniable features of the economy of the organism, they must be recognized as such. This relevance of data to categories and of categories to data is the foundation of the true logic of science. There need be no fear that this empirical autonomy of the sciences will involve disorder. Out of it will come a truer appreciation of the working and genetic possibilities of nature than could be fostered by a rigid and doctrinaire mechanicalism.

5 Though many of Lodge's criticisms of the speculative naturalism of Haeckel are just, his own suggestions are full of a belief in discontinuity of a dualistic type. It would be difficult to connect his view of life with biological investigations. See his Life and Matter. 
Lastly, the development of psychology has led to an increased recognition of its biological foundation. If the behavior of an organism is empirically different from that of an inorganic body, this difference must be admitted. Again, there are obvious differences of capacity in the organic realm. Psychology but confirms the rough conclusions of every-day life when it points out differences of capacity in the animal world.

The Thesis of Evolutionary Naturalism.-The evolutionary naturalist desires to throw off the spell of outgrown categories and points of view and to do justice to new tendencies. The thesis which best accords with this ideal is as follows: The living organism, when properly and adequately conceived, includes consciousness and is the sole source of that differential behavior which distinguishes it from less integrated bodies. Or, to put the thesis from another angle. I shall maintain that the traditional mindbody problem resulted in large measure from false conceptions of both mind and body. There are delicate analyses to be made and false contrasts to be avoided. And for this necessary work an adequate epistemology is absolutely essential. Nevertheless, a correct sense of the lie of the land is fundamental. And I think that I reflect the contemporary drift when I assert that it is a good methodological principle not to assume a dualism unless there is no help for it. In the main, traditional statements sinned against this principle because they started with two substances, or realities. It will be remembered that Locke hesitatingly suggested that one substance might be enough.

My queries will, then, be as follows: Is not the organism the object of reference of all the knowledge about it gained by the various observational and experimental sciences, including behaviorism? Do not the contributions of these sciences supplement each other? And is there anything in this tested knowledge which forces us to exclude consciousness from the organism? Finally, what should we mean by mind? Is it the same as consciousness, or is it something 
bound up with consciousness and manifesting itself in consciousness but yet not merely consciousness? These are not easy questions, but they have the virtue of being fairly specific. If we can answer them in accordance with the drift indicated, the traditional mind-body problem will disappear, to be replaced by such empirical questions as concern the genesis of types of behavior, the varying capacities they reveal, the nature, status and rôle of consciousness.

Mind as a Physical Category.-Let us disregard the complex yet relatively unanalyzed notion of mind usually present in psychologies and systems of philosophy, and see what categories have arisen in connection with the observed behavior of man and the other animals.

The behavior of organisms is interpreted largely as a function of the nervous system. And there are easily distinguished types, or levels, of nervous action and its correlated behavior. Reflex action is stereotyped and seems to involve a particular nervous group, little controlled by the whole nervous economy. Instinctive action is much more complex and orders many stimuli, together and in succession. It involves the coordination of a series of actions which are in themselves partially reflex; and yet there is more of plasticity and totality in it. Instinctive action shades into intelligent behavior in which there is "learning by the past," selection, and even planning. Such behavior displays intelligence. This ability to meet situations in a non-mechanical way through the capacities of the nervous system is the empirical fact which behaviorism stresses. And behaviorism is as much a physical science as is chemistry.

It is becoming customary to speak of intelligent behavior, and to regard mind as a term for the internal processes of the organism which find expression in the overt characteristics of bodily action as examined over a reactive period. Where we have these internal processes we have mind. The recognition of this situation is often expressed by saying that we know what mind does or how mind functions, but 
that we do not know mind itself. But this form of statement implies that mind is a substantive thing not revealed in its conduct. It also assumes an ideal of knowledge which we have attacked all through this book. And, besides, is it not truer to the empirical facts, and simpler, to say that in instances of intelligent behavior we know how the organism behaves and that, until the contrary is proved, the conditions of this behavior must be assigned to the organism? Is there anything in the facts which demands the assumption of two objects of knowledge? My conclusion is that knowledge of what mind does is really knowledge about the organism. The burden of proof rests upon dualism.

If, then, we use mind as a physical category, we should mean by it the nervous processes which find expression in intelligent conduct. The mind is the brain as known in its functioning. It is the brain in its integrative capacities. All the physical sciences give knowledge about the brain, but they do not give the same knowledge. Their propositions are supplementary rather than identical. One of the tasks of evolutionary naturalism is to show how they can be harmonized when once evolution is taken seriously.

It is well to let the behaviorist speak for himself. "The differences among the various sciences," writes Watson, "now are only those necessitated by the division of labor. Until psychology recognizes this and discards everything which cannot be stated in the universal terms of science, she does not deserve her place in the sun. Behavior psychology does make this attempt for the first time. It has been called physiology, muscle-twitch psychology and biology, but if it helps us to throw off the shackles of the present-day conventional psychology and teaches us to face the human being as he is and to deal frankly with him, what name it is given will not be a matter of much consequence." Now it has been customary to think of physiology as covering the objective study of the organism. It is important, therefore, to grasp the difference between it and behavior psychology. "Physiology teaches us concerning the

- Watson, Psychology, Preface, vii. 
functions of the special organs. For purposes of experimentation and exposition, the heart, liver, lungs, circulation, respiration, and other organs are isolated, and they are discussed as though they functioned in an isolated way.... It is not meant to assume that physiologists deal wholly with organs in isolation. Certain combined processes are studied, such as metabolism, digestion, effects of poisons, etc., but nowhere in physiology do we get the organism, as it were. put back together again and tested in relation to its environment as a whole.... Physiology tells us nothing of man's capacity to form and retain habits, nor of the complexity of man's habit organization."'

With the positive side of this outlook I have complete sympathy-as I think most American psychologists and philosophers have. It is with the tendency either to ignore or to deny consciousness that the divergence comes. But I do think that the knowledge of the individual gained in accordance with these methods should be stressed. It is man's organization and ability which is studied. It is in the theory of implicit language habits that behaviorism is as yet weakest. With the attack upon any transcendentalist notion of thought and with the aim to connect thought with bodily integration and adjustment we can express our essential agreement. Thinking arises upon and is always subtly connected with moods, bodily attitudes and tendencies. I would not isolate the cortex, and yet I do believe that there is a level of process which involves the activity of higher nervous centers. The organism is, as it were, thrown back upon itself in these delayed responses.

The bearing of this approach upon the mind-body problem is readily seen. The science of behaviorism establishes mind as a physical category growing out of the data of observation, and so far there is no mind-body problem.

Suggestions in Favor of Evolutionary Naturalism.-But while there is no mind-body problem in the traditional sense, when this method of approach is adopted, the nature and

' Ibid., pp. 19-21. See also pp. 324-327. 
origin of this non-mechanical behavior becomes itself a subject of inquiry, all the more acute because specific. As long as the abstract, mechanical ideal of explanation, an explanation by reduction, ruled thought, the postulate maintained was that organic behavior could be reduced to a complex series of purely positional, or unintegrated, motions. A physical system was assumed to be nothing but the sum of its parts and their external relations. Organization counted for little. But to-day this postulate has been weakened by the growth of the biological sciences. It is, to say the least, just as possible that a system is more than an external sum of parts, that it is an organization in which the whole exerts a control over the parts, that the resultant is a function of the system.

But if these new tendencies are accepted, their implications must be worked out. The implication which I have constantly stressed is the forced admission of levels of causality in nature expressive of organization or creative synthesis. In other words, the empirical data force the thinker to construct categories corresponding to them, categories continuous with the old, and yet obviously striking a new note. Thus the mental level in nature is the level of intelligent behavior-of which, of course, there are degrees. Mental processes are brain-processes, and these control and express themselves in behavior.

Added Knowledge About the Organism.-The behavior of individuals must be enlarged to include gesture, facial expression and language. Such data of observation are peculiar because they are interpreted by the observer as symbols of inner states of consciousness to which he cannot otherwise penetrate. This act of interpretation is instinctive in its foundation and carefully cultivated because of its value. We should note, further, that there is an agreement between the overt behavior of the organism and the meanings of these symbols of expression and language. My friend says that he is going to the Campus, and I find that his body moves in that direction. 
Overt behavior consists of the movement of the whole body or of part in response to a situation. This second kind of behavior, on the contrary, is not a physical adaptation like an animal's serial actions, but is social in its intention. It is essentially a communication. Let us see what it communicates. But first let us note that these words and gestures and facial expressions are symbols to us because we know, or think that we know, what they mean. Their meaning is, therefore, a part of the objective datum. A shake of the head means the feeling and idea we have when we say no.

The second series of behavior-data offers us a knowledge of the mental states of the individual who is communicating with us. Note that I say knowledge and not participation in. What we do is sympathetically to reproduce the mental state of our communicant, that is, we produce the meaning of the symbol. In the case of gesture and expression, this production is a trained reaction in which we sense an identity between our experience and that of the other person. We may call this a sufficient identity of content - with which alone we are concerned. In the case of words, we understand a man's statement and say that we know what he means or feels.

This added knowledge of the organism gives us an increased grip on mind. We said that for the physical sciences mind as a category covered the character of the nervous processes which control and find their expression in overt behavior. But now in these data of behavior which are interpreted as symbols we gain knowledge of ideas and feelings which, combined as desires and plans, precede behavior as apparent control of it. We are led into a deeper knowledge of mind. But a knowledge which raises perplexing questions.

The Epistemological Situation. We must be careful to keep the epistemological situation clear if we are to thread our way through the coming difficulties. Let it be remembered, first of all, that all knowledge arises and exists only 
in the consciousness of individuals. The other point to remember is that there are at least two general kinds of knowledge of external objects of the human type: (1) information about things and processes founded on the study of the pattern and qualitative differences of sensedata, and (2) knowledge of the contents of other minds through the interpretation of symbols. It is the first kind of knowledge which behaviorism stresses, thus limiting itself to this kind of knowledge. Traditional psychology stresses the knowledge which the individual knower can have of his own mental processes and admits the knowledge of the contents of other minds. Whether this added knowledge helps the behaviorist is a question which he alone can answer. But it must be emphatically stated that there is no conflict and that the behaviorist who denies consciousness is talking nonsense. It should be remarked that most of those who speak in this fashion are animal psychologists for whom, naturally, knowledge of content has little meaning. They do not converse with white rats.

I do not believe that knowledge of other minds is based upon analogy in the ordinary meaning of that word. Thus I would criticize the following passage from Bergson: "To know with scientific certainty that a particular being is conscious, we should have to enter into it, coincide with it, be it. It is literally impossible for you to prove, either by experience or by reasoning, that $\mathrm{I}$, who am speaking to you at this moment, am a conscious being. I may be an ingeniously constructed natural automaton, going, coming, discoursing; the very words I am speaking to affirm that I am conscious may be being pronounced unconsciously. Yet you will agree that though it is not impossible that I am an unconscious automaton, it is very improbable. Between us there is an evident external resemblance; and from that external resemblance you conclude by analogy there is an internal likeness."8 In the first place, such an automaton would be but another person since it would have all the characteristics. You would be assuming the difference of

8 Bergson, Mind-Energy, p. 9. 
indiscernibles. In short, you would be making the hypothesis that an organism is an automaton. But a still more cogent objection is to point out that our knowledge of other minds is not based upon analogy. It is an interpretation of symbols. And this interpretation has an instinctive foundation though tested unremittingly. When you use certain words, I interpret you as having the same meanings in your mind that they suggest to me. How constant this testing of knowledge is! It rests upon the correlation of behavior and meaning. It is an experimental time process. The old idea of escape from solipsism through passive analogy of structure was quite superficial. To the critical realist this point is important because the idealist will still ask him the question how he knows there are other minds. It is no more difficult to know other minds than to know physical things. But in both cases knowledge is mediate and not intuitional. To make consciousness a hidden thing which cannot be known is to do it injustice.

Since Bergson is to-day in many ways the most formidable opponent of naturalism, it behooves us to criticize his argument against the capacity of the brain to produce ideas. This argument is an attempt to show that the realist who believes in the cerebral soul necessarily contradicts himself. We shall point out that Bergson makes assumptions which the critical realist rejects. These are two in number: (1) that the realist must be agnostic, and (2) that a part of reality cannot have even a partial independence of the whole. Our epistemology has been directed against the first thesis and, in our discussion of relations, we denied the second.

I shall content myself with calling attention to the various assertions made by Bergson to the effect that the content of perception throws no light upon external reality and that the category of space is invalid beyond experience. "But realism," he writes, "holds that the lines of separation which we draw in the field of presentation are artificial or relative; it supposes that beneath presentations there is a system of reciprocal actions and entangled potentialities; 
in short, it defines the object not by its entry into our presentation, but by its solidarity with the whole of reality supposed to be unknowable." 9 Again, "In front of the hidden background which he assumes to be reality itself, and where everything must be implied in everything, since it is behind space...." 10 Once more, "He forgets that he had placed his reservoir outside of the world of idea, and not within it, out of space and not within it." 11 Passages like these could be multiplied. It is clear that he believes that the realist cannot maintain the validity of the categories which we have been examining so carefully in this book. In this he is at one with spiritualists from the time of Leibniz. As clear-headed a writer as Parker shows the same bias. $^{12}$ All idealists have an aversion to space.

But what shall we say of the doctrine that a physical thing has not even a relative independence? Surely it is pure dogma. It is our old friend internal relations so interpreted as to make the part dissolve into the whole. Had Bergson, Bosanquet and Bradley taken the category of space with its attendant categories of organization, structure and position more seriously they would have seen the absurdity of this facile subsumption of the part. ${ }^{13}$ I conclude that Bergson has not proven the self-contradictoriness of the cerebral soul.

The critical realist holds, then, that we possess two kinds of knowledge of another's mind, and that these supplement one another. The first one is knowledge of intelligent behavior gained through observation. This is knowledge of mind as a physical category and is studied by behaviorism. There is, second, knowledge of content through assertion of identity. These are what I meant when I called my position

9 Ibid., p. 244.

10 Ibid., p. 247.

11 Ibid., p. 249.

12 Parker, Self and Nature, Ch. 7.

13 Bosanquet's assumption that existential judgments imply some such phrase as, "Reality is such that at or in S it is P," is to the critical realist unwarranted. The object of judgment is specifically the thing which is affirmed and referred to. See, however, Life and Finite Individuality, p. 80. 
the double-knowledge theory. It should be noted that, in our own case, consciousness is given while the first kind of knowledge remains the same. The brain as a whole is always only known while consciousness is intuited, using that expression roughly in the Bergsonian sense.

The Relation Between Consciousness and Brain.-Mind has been an ambiguous term felt somehow to cover cerebral capacities, subjective operations and the changing content of consciousness; and as long as consciousness was thought of as alien to the organism qua physical thing, mental operations tended to be loosened from the body in sympathy with it. Not until consciousness is seen to be included in the brain will the term mind cease to be ambiguous and the age-old problem vanish in the more adequate conception of the living organism.

What, then, is the relation of consciousness to the brain? And how can we insert it into those cerebral processes which control intelligent behavior? Can mind as a category of physical science coalesce with mind as an appreciation of what takes place in consciousness-recollection, reasoning, valuing, planning-into a deeper knowledge about the content and operations of the brain?

There are, then, for the critical realist cortical processes which control and find expression in behavior; and there are conscious processes which apparently have a similar relation to behavior. We can only have information about the cortical processes, while we can either experience (in the case of ourselves) or know (in the case of others) conscious processes. How shall we conceive the relation between these two?

Empirical parallelism stresses what may be called a temporal correlation. The events in one series are temporally correlated with the events in the other series. Historically, this empirical correlation has passed through two stages and is just entering upon a third. The first stage may be called psychophysical correlation. This formulation was characteristic of the time when the brain was 
dogmatically conceived as a kinetic mechanism. The correlation could be only temporal because the two series did not have even a common form. What in consciousness could correspond to an atomic movement? The second stage may be designated psychophysiological correlation. It stressed the correlation of mental states with complex physiological processes. It was in theory a psychochemical correlation.

The third stage has been entered upon comparatively recently. To select a term appropriate to it is not altogether easy. Let us call it a psychofunctional correlation. It emphasizes the fact that the nervous system has functional sets and that a pulse of consciousness should be correlated with such an activity. We conceive mind as an activity and believe that it is to be assigned to the complex neural process which mediates behavior. How complicated and yet how well integrated such total responses are almost passes conception. "A simple eye-band coordination," writes Watson. "the picking up of a pin from the ground, brings about a well-ordered and integrated response of the organism as a whole." In thinking proper we have to do with neural processes of a higher level involving activities of comparison, abstraction and rearrangement. These, also, have a setting or organic solidarity. Gland and muscle action must accompany them as integral supports. But I do not think that, as yet, the psychologist of behavioristic persuasion has penetrated to them. The experimental psychologist of the older tradition has gone farther in his analysis of the higher mental processes.

Thus temporal correlation of the traditional sort is being replaced by a formal and functional correspondence. There is an agreement of method in the two processes which points to their merging in a whole. Corresponding to association is the connection of the neuronic groups; corresponding to the compresence of sense-data and images in perception is the cofunctioning of various subsystems. Corresponding to meanings is some sort of summation. These correspondences have not been traced in detail but they seem to me 
clearly to point to the significance of such categorics as integration and solidarity. The whole is not the sum of its parts. The whole has, as it were, a being of its own. The evolutionary naturalist must be logical and take organization seriously. A whole both controls its parts and is controlled by them. The first fact enables us to escape mechanism; the second fact holds us to naturalism. We shall have more to say about the causal status of organization in the next chapter.

We have endeavored to prove that there is no sufficient reason to exclude consciousness from the brain. To this we have added the significant fact that there is an agreement of method between neural activity and consciousness. This principle has been much used by psychologists in the past in order to infer from psychosis to neurosis. Often the psychology of neurologists has been faulty and has misled them. Often, again, psychologists have been too submissive to the mechanistic prejudices of neurologists. McDougall's otherwise excellent work has seemed to me injured by this tendency.

Critical realism undermines natural dualism with its vague assumption that we possess an intuition of the very stuff of the physical world, an intuition which makes the presence of consciousness almost a logical contradiction. The inability of ordinary scientific realism to account for consciousness is ably pointed out by Bergson: "Hypnotized, so to speak, by the void which our mental power of abstraction is creating, we accept the suggestion that some, I know not what, marvellous significance is inherent in the mere motion of material points in space, that is to say, in an impoverished perception.... Because, by rubbing extensive presentations against one another, you have blotted out the qualities which differentiated them in perception, you have not thereby advanced one step towards a reality which you assumed to be tension, not extension, and consequently more real as it is more inextensive."14 Only critical realism frees the naturalist from the dilemma which Bergson points out.

14 Bergson, Mind-Energy, p. 252. 
The contest between Bergson's spiritualism, which has given so much aid and comfort to the supernaturalists of this generation, and evolutionary naturalism turns out to be epistemological in its foundation.

It should be pointed out that it is impossible to pass from knowledge of neural structure to any specific psychical content. But why should we expect such an impossible inference. Our knowledge of neural states is too indefinite. But we can pass from behavior to psychical contents and the ultimate reason is their existential connection. The mind is not hidden just because it is an effective part of the organism.

We have knowledge of the brain but no intuition of the stuff of the brain, that is, no vision of what physically is. Consciousness, on the other hand, is a term for data open to inspection and analysis. Of it, alone, do we have acquaintance. It follows that the setting of consciousness in the brain cannot be given in the same way that the psychical is given. In other words, by the very nature of the case we are precluded from witnessing the ontological linkage of consciousness with the being of the cerebral processes. The situation is unique. Only in consciousness does nature know itself. The world as idea is in the brain.

The Nature and Function of Consciousness. - Interactionism of the traditional type makes of consciousness a self-existent substance which externally and, therefore, mechanically acts upon the neural processes. Descartes's crude theory gave place to a mystical, because unintelligible, idea that consciousness affects the neurones at their synapses by heightening or lowering resistance to the passage of a nervous current. But such an operation reminds one of Clerk Maxwell's sorting demon. It is too external. And there is, moreover, too much solidarity in any action. We must relinquish a ghostlike or puppet consciousness.

The efficacy of consciousness must be relative to its nature and its function. There are those who can conceive of the physical as having. efficacy only if it is a form of energy. But we mist remember that energy, as used in 
physical science, is a term for certain quantities in our knowledge. It is quite proper to speak of mental energy, for, on our theory, it is identical with neural energy. Psychiatrists often characterize those whose personality tends to dissociate as lacking in mental energy. Yet in these cases we are not thinking of the psychical as such but of the psychical in its setting. We must recognize, however, that consciousness is a part of mental activity and involves energy changes. It is a character of the neural system in action. It is quite clearly not something which can act by impact. To understand its function we must comprehend the properties of the system within which it exists.

Could the mental operations of learning, foresight and reasoning be performed apart from the assistance of the psychical? It is this question which puts us on the track of the function and efficacy of consciousness. To answer the question we must study variable adjustments and cases of planned action. Now it seems clear that in conscious behavior we lean on the past and are guided by data. Responses are tentative and experimental. The act is constructed as we proceed and in a quite obviously nonmechanical fashion. As all psychologists point out, this progressive organization has a selective or teleological character. Furthermore, the situation as a whole must be interpreted by meanings which guide response. This typewriter means something on which I can write this manuscript. Human behavior is conscious behaviour. We look before and after. Our responses are guided by experience. But this surely implies that mental behavior would be impossible without the psychical.

We come at this point to the interpretation of modern pragmatism. Like evolutionary naturalism, of which it is a form, it holds to the creative power of intelligence. It is directed against epiphenomenalism. It affirms that man is an effective agent whose thinking and planning brings about physical changes which would otherwise not have arisen. With pragmatism's rejection of epiphenomenalism I wholeheartedly agree. The general outlook of instrumentalist 
pragmatism is essentially veracious and sane. ${ }^{15}$ But I hold that its opposition to espistemological dualism is based upon a misunderstanding. I take it that it is seeking to interpret conscious behavior much as I do. Percepts and concepts are stimuli to responses and guide those responses. To secure the right stimulus is the function of consciousness. We must remember that the pragmatist does not use the term stimulus as the physiological psychologist does as something which irritates the organism. The stimulus to conscious behavior is an interpreted situation. Now to the critical realist, this stimulus which guides response is a part of the individual's field of consciousness. And it must be considered a character of the causal process at the cortical level. I ask the pragmatist to realize that the critical realist who is developing an evolutionary naturalism is not defending a dualistic theory of mind and a mechanical interactionism. Mind is an internal process of interpretation and adjustment characteristic of the human organism. Once woo the pragmatist from naive realism and the two camps can combine. Or, to put the situation still more exactly, once convince the pragmatist that epistemological dualism of the critical realist's type is a really new outlook which does not conflict with his insights, and American philosophy will be the gainer.

In deliberation we have a conscious process of survey, selection and combination. Ideas are led to their consequences and judged by them. And our decision certainly takes the form of a plan which guides our behavior and without which our actions would be quite different. Hence our natural belief that this conscious process counts for something, that, without it, this type and level of behavior would be impossible. But how can we conceive the method

15 "Never, surely," writes Lovejoy, "did a sillier or more selfstultifying idea enter the human mind, than the idea that thinking as such-that is to say, remembering, planning, reasoning, forecasting -is a vast irrelevancy, having no part in the causation of man's behavior or in the shaping of his fortunes-a mysterious redundancy in a cosmos which would follow precisely the same course without it." The Journal of Philosophy, Psychology and Scientific Methods, Vol. XVII, No. 23. 
of operation of consciousness? My theory is that we must relinquish, once for all, outworn notions of cerebral action. Mental abilities are the results of biological mutation and are the witnesses to types of causal action in the brain, not found elsewhere at lower levels. There is a mode of action of the brain corresponding to reasoning, to memory, to purpose, to foresight. To this thesis behaviorism must, of course, assent. But I would go further and assert that these types of action imply consciousness and cannot be carried through without it. The psychical is a natural ingredient of the brain at these levels and its function is to aid in the solution of problems by the cues it affords. Consciousness literally assists the brain to meet new situations. We must grasp this presence of consciousness in a non-dualistic way. It does not act mechanically from outside as the older interactionism thought. It is a functional character of the causal process itself. ${ }^{16}$ We must enlarge our conception of the physical. We must grasp the fact that consciousness is inseparable from the level of intelligent activity. Planned action involves a changing system of great complexity in which the past is called upon and the future suggested. On the motor side, there is selection and ordering of habits of action. To put my suggestion bluntly, it is just because consciousness is not a second substance outside the brain but a variant within it that it can act as the focus and instrument of functional adjustment. Thus out of an apparent dualism we have achieved the conception of a more adequate monism which accepts the internal differentiation of the organized and functioning reality we call the brain. Consciousness is, as it were the eye of the brain. Intelligent integrations of the brain need consciousness to guide them. In thinking, planning and desiring -in all those conscious processes which we call activities-we are on the inside of the brain and at its focal level of operation. Here objective and subjective activity meet.

Advantages of This Theory.-If consciousness is at once the conditioned expression of the brain and the instrument

${ }^{10}$ Cf. Critical Realism, p. 244. 
through which operations such as discrimination and anticipation are carried on, we can readily meet the traditional objections to the efficacy of consciousness for these assume a dualistic interactionism.

In the first place, energy and its measurement applies to the whole cortical system. It is knowledge about the brain. Interactionism at least tends to make consciousness a substantial system external to the cortex and, for that reason, is confronted with the principles of science which assert that the physical world is a closed universe.

In the next place, our view takes the sensori-motor process as a unit and holds that cortical integration of which consciousness is an element is always genetically continuous with a motor pattern of the brain. In other words, cortical integrations arise in one system with motor tracts. This means that ideas are from birth immersed in neural processes which have motor extensions. Ideas and motor tendencies are always on the same circuit. A dominant idea means a dominant cortical system, and such a system possesses its genetically developed roots. Behavior is a growth from instinctive tendencies to action; and it is within such instinctive functioning that conscious action appears. A purpose is, thus, a part of an active system which has its trained expression. Hence, in the brain itself, purposive idea and motor expression are only stages in a continuous neural process. Or, to speak even more exactly, the integration of the idea is at the same time the integration of its motor prolongation. But because only the idea is given to us we are prone to erect a dualism and to ask how the idea by itself-which we forget is an abstraction from its ontological setting-can produce what follows.

We are forced to conclude that the relation of consciousness to the brain is internal and unique. It is a relation which can be understood in some measure only when a correct knowledge about the brain's method of action is added to a proper conception of consciousness. Only then can we, as it were, see consciousness as immersed in, and continuous with, brain-systems in action. Had not M. Berg- 
son been led astray by his sharp antitheses between space and time, spirit and matter, freedom and determinism, I feel certain that he would have reached a position similar to ours. I enlarge the conception of the brain to include the mind; he narrows the brain to a purely motor complex and so excludes the mind. The divergence of policy reflects a different analysis of the categories and a different understanding of the physical world. For him, matter is inert and time has no grip upon it. For me, matter is active and capable of high levels of organization and accumulation. $\mathrm{He}$ is a Cartesian for the physical world in order to spurn its helplessness and inadequacy. I attack Cartesianism at its source. Yet while I differ from him so fundamentally, I recognize to the full what an inspiration to philosophy his work has been. His mind is subtle, mobile, concrete and daring. I have attacked his position so constantly because I am persuaded that the choice lies between his romantic, anti-intellectualistic, overly speculative spiritualism and evolutionary naturalism.

Consciousness and Mind. - It has been our admitted purpose to achieve an adequate idea of mind which will harmonize the conclusions of behaviorism with those of the more traditional psychology.

If mind is a physical category standing for the abilities and trained capacities of the organism when viewed in its behavior, then objective psychology gains valid knowledge of mind. But if consciousness is at once the expression and guide of mind, changes in contents should indicate the mental processes as well. An act of comparison is a process in which contents are brought synthetically together; and such an act is the function of some interest. The self is a witness and participant. It does not witness all that is going on in the organism, as both behaviorist and Freudian have shown, but it participates in the more reflective levels of activity. The brain as mind is a more or less integrated system of propensities and interests which respond to the situation in which the individual is placed. 
And such interests must not be thought of as physiological in any sense that excludes discriminative appreciation. They are neurological systems whose urgencies are inclusive of mental contents.

Consciousness must be connected psychophysically with neural processes of some reach. Attention, itself, can be understood only as a forward movement or passage in which the cerebral activity makes its path. What we must seek to do is to deepen our conception of the brain as at once activity and content. It is sensori-motor, idea-motor; it is a stream of tendencies lit up by consciousness. The brain is synthetic because it is active. It is a more or less unitary process controlled by the neuronic system which is functionally uppermost. It is hard to describe what the reflective mind feels, that personality is like the deep heaving sea with its currents and counter-currents. It is the pressure of this complex, internal immensity that we call interest. Back of interest is the dominant drive or set of the organism.

Our conclusion is that consciousness is a feature of mind but by no means the whole of mind. It is too evanescent and passive, too little self-explanatory, to be so considered. It is relative to an organism and to that organism's activities.

If the arguments of this chapter stand firm, we have established the thesis that the living organism, when properly and adequately conceived, includes consciousness as a characteristic, internal feature of the functioning, neuronic system. It is a quality of a novel whole, and is as novel as the synthetic whole of which it is an expression. I have frequently called it a variant to bring out its existential correlation with a complex process. The field of experience of any one time is a psychical structure which corresponds to the activity of the organism. This correspondence we have tried to explain in connection with perception as a neurally mediated activity.

When I conclude that any psychical fact is a quality of a nervous complex when functioning synthetically, I do not, 
of course, use quality in the sense of naive realism. The brain is not red when the psychical entity, red, arises in it. The use of psychical entities as the material of knowledge, while the object of perception is confused with the content of perception, gives rise to this misinterpretation of the psychical content. This problem involves the category of quality which we have discussed in an earlier chapter.

Psychical entities are not substances, but rather peculiar characteristics of neural wholes and inseparable from them. As soon as such psychical entities are thought of as selfsufficient things, dualism breaks out and they are extruded from the brain by our thought. As soon as they are conceived as more than contents, as more than they themselves reveal, as soon as they are given by themselves power to do things, they become to the deceived thinker non-physical and alien to physical reality. And it is very difficult for one to avoid these errors unless he is master of an adequate epistemology which has clearly seen the fallacy of naive realism.

Psychical entities are, then, contents which arise in the synthetic brain, and they are aids in the discrimination and correlation of objects. In terms of such contents acts of memory and anticipation clothe themselves, all this proceeding in the brain as a natural part of its adjustmental function. The brain has been underestimated in the past in behalf of a hypothetical reality postulated to perform functions rather dogmatically asserted to be impossible to a physical organ however delicate its structure. In contrast, we have argued that the brain is rightly conceived only when we supplement all the knowledge gained by the physical sciences about it by all that the mental sciences can teach. It is literally the brain-mind, the home of the psychical and of mental capacities.

Panpsychism and Materialism Are Extremes.-The evolutionary naturalist desires to combine the total information he can gather about the human organism. He knows himself to be an evolved substance of tremendous complexity whose material is that which he consumes each day in food and 
drink. He thinks, acts, adjusts himself to complex situations, ministers to his body, experiences fatigue, has sick. nesses, etc. That is the kind of a thing he is. He is all of these cooperative functions at one and the same time. And yet quite obviously the conscious self sits in the watch-tower of the brain to guide the organism's behavior.

Materialism builds its outlook upon the conclusions of the physical sciences, and, naively taking this knowledge to be exhaustive of the organism, can find no room or function for consciousness. We have tried to correct this mistake by pointing out that, in consciousness, we are on the inside of the organism, or, to speak more correctly, are a literal part of the organism. We have found, also, that mental contents function in a guiding way in those operations of discrimination and correlation which the brain performs. Our conception of the brain has been enlarged and deepened as a consequence.

Panpsychism starts from consciousness as a stuff and seeks to conceive it as fitting the demands of the physical sciences. For us, the psychical is not a distinct stuff. Much of past panpsychism was idealistic in its epistemological setting and so lightened its task. But for us panpsychism must make plausible the structure of the brain and the massive properties and relations of the physical world. Mental contents, as I am aware of them or as I introspect them, seem to me incapable of bearing this burden. The contents of consciousness are correlative to neural processes which are not found at the inorganic level. They come and go, and yet, as memory shows, they are not completely lost. They are expressions of the brain and their fading from the field of consciousness is a relative and not an absolute loss. The difference between the conscious and the unconscious must be one of degree and not of kind. And yet, because we are tied to consciousness by our very nature as conscious selves, the difference of status cannot be fully grasped by us. Past experience plays into consciousness in many and subtle ways and so must be conserved and operative. The solidarity and fulness of the cerebral soul must he 
granted but we must be on our guard against conceiving its content too literally in terms of the content of consciousness. There must be both identity and difference.

But I do not hold that mental entities must be objects of awareness to exist. Unconscious consciousness in the sense of psychical entities of which the self is not aware is to me no contradiction in terms. Awareness involves a structure within consciousness, a structure of compresence and interpretation. To avoid even the semblance of a contradiction, it is, perhaps, better to speak of the unconscious psychical. ${ }^{17}$ The origin of awareness is the origin of a complex function. It seems inseparable from the tensions and adjustments of the organism. It is an illuminative interconnection of several responses.

To the panpsychist's objection that he is unable to understand the origin of the psychical from the non-psychical, the natural reply is that the physical world is not nonpsychical in any dialectical sense. I have tried to show that the psychical is of the very texture of the functioning brain. If the psychical is novel, we have on our hands only the general question of the origin of the novel. But is not the organism with its capacities and operations novel? And why should not such a novel whole be accompanied by novel contents in the tensional adjustments involved? My own mind sees no theoretical difficulty. It does not quail before a real, though conditioned, beginning. Let him who feels otherwise show how a simple quality like red is reducible to something simpler. Frankly, it seems to me that there is novelty of an undeniable sort at every level of reality, but that here only are we on the inside, so to speak.

To conclude: the epistemology of materialism and its Categorienlehre were too naive and inadequate. Panpsychism, on the other hand, builds too exclusively upon mental contents and upon introspective psychology. It is the other extreme. Evolutionary naturalism does justice to what is factual in both. In the next chapter we shall pass to the consideration of certain general implications of evolutionary naturalism.

${ }^{17}$ For a fuller discussion of this point see Chapter III. 


\section{CHAPTER XV.}

MECHANISM, TELEOLOGY AND PURPOSE.

7 HE divergence of the newer type of naturalism from I the traditional sort has by now been pretty well indicated. Evolutionary naturalism seeks to do justice to the organic as well as to the inorganic, to the undeniable richness, purposiveness and range of human activities as well as to the vast cosmic setting in which they come to momentary flowering. It wishes to see the part in the whole and yet to assert the specificity of the part.

It is clear that the chief fault with the older naturalism was its blindness to heterogeneity and diversity. For it, a category to be true must apply to all things simultaneously. It would not recognize levels and uniqueness. It was cosmically equalitarian. Accompanying this prepossession and expressive of it was the assumption that novelty is illusory. We may say that the older naturalism was inherently antagonistic to the idea of evolution, that it gave this revolutionary theory of the nineteenth century only lip-service, that it did not overhaul its fundamental assumptions. The reason for this state of affairs has of late years become increasingly clear. The older naturalism was the expression of the mutual support given to each other by a complex of factors. It was a phase in which the science and the naturalism of the day came to an equilibrium. Mathematical rationalism, the dominance of the exact sciences, the lack of an historical sense, the dislike of design and providence, all reenforced each other to establish an orthodox view of the world. There 
was included in this a clear admonition to all supernaturalists that their outlook was scorned as absurd, romantic and childish.

Now one of the weaknesses of dogmatism is that it discourages analysis. It dwells upon large contrasts stated in sketchy ways. The natural consequence is that it is not sufficiently sensitive to the effect of changes all along the line. But it is just this deepening and enrichment of the whole foundation of naturalism which has been occurring and which, I believe, is resulting in its transformation.

The very definiteness and simplicity of traditional naturalism made its inadequacy apparent to reflection. It drove philosophy to the conclusion that there was no choice between dualism and a thorough criticism of the mechanistic interpretation of physical processes. To many dualism was repugnant and only a last resort when all else failed. And the empiricist temper revolted against the assumed deductive omnipotence of mechanistic naturalism. Hence arose a movement to analyze the various sciences to see how far they were reducible to each other. Fortunately, the sciences themselves supported philosophy in this attempt to estimate the actual empirical standing of mechanism. Thought moved into a period of inventories and self-criticism.

Two important features of this transitional period were, then, the demand for autonomy on the part of the various special sciences and the rise in philosophy of animistic and vitalistic views. It was a time of ferment and wide speculation. The old frames of thought were being cast aside. For a while, it seemed as though the pendulum would swing to the other extreme.

No situation could be more stimulating to philosophy. It is the thesis of this book that it has responded and that the broad outline of an evolutionary naturalism is making its appearance. I would not belittle the aid given by the scientists who have been reflective enough to consider these problems as they appear in their own fields. Certainly, some of the best things I have read on the topics I am about to discuss have come from scientists. They, also, are asking 
themselves whether the categories of one science are necessarily reducible to those of a supposedly more basic science. The $a$ priori nature of the older naturalism is being realized. It is seen that it was a preemption of the land by faith rather than an actual settling and development of it.

The study of the mind-body problem which we carried out in the preceding chapter should be of the greatest assistance to us in our present attempt to study mechanism, teleology, purpose and value to show their place and significance. We shall here fill in the background which we there more or less assumed. We shall argue that there are levels of causality in nature and that new properties and capacities arise with novel integrations. We shall aim to show that genetic continuity does not conflict with logical discontinuity. Fortunately, there is in this argument nothing which has not already been suggested. It has been in the air, so to speak, for many years. Creative synthesis, critical points, creative evolution, creative intelligence, organismalism, logical discontinuity are current terms which attest the growing conviction that evolution must be taken seriously. The intellectual atmosphere is saturated. My hope is that I can assist the crystallization of these ideas around a realistic, instead of around a romantic Weltanschauung.

Two Mistakes of the Past.-It is rather difficult to find a satisfactory term for that outlook upon the world which is dominated by man's sense of his own life. Yet the animus of mechanical views is largely directed against this uncritical extension of will, purpose and caprice. The scientist is convinced that spirits and souls furnish no intelligible explanation of events. Let us call this first mode of explanation animism. Nature is levelled up to man, and psychological categories - substantialized and scarcely understood - are appealed to indiscriminately as means of accounting for what happens in nature. This mode of explanation is the essence of supernaturalism.

The animistic outlook upon nature clearly reflects a lack of detailed knowledge of the kind which is gained through a 
study of sense-data. There is no thought of laws nor of inevitable processes. Man's knowledge of himself is of the slightest. Impulse and caprice arise mysteriously to the surface and pass into action. Read in the light of this superficial knowledge of himself, the world becomes a realm of arbitrary action.

Let us remember that this stage was inevitable. The savage was chiefly concerned with the purposes and senti. ments of his fellows, with his shrewdly inquisitive thought of their feelings and purposes. Little wonder is it that he carried this carefully nurtured knowledge and attitude over to the larger world! It is for this reason that the social categories bulk so large in primitive religion. A world of law and conditioned change was not conceivable at this stage. As James Ward points out, "We are adepts at this (personal) kind of knowledge before we have even begun to acquire the positive, constructive, mechanical knowledge by which we conceptually summarize the world." I do not think, however, that Ward interprets this contrast correctly. His epistemological idealism stands in his way.

But was not this interpretation of the rest of nature in terms of an active self too one-sided? It is to this conclusion that science has slowly but surely led us. Animism is the interpretation of the whole in terms of a peculiar part. It is the regarding as typical what we have reason to believe is not typical. From an evolutionary standpoint, it is to level up the whole of nature to man. Furthermore, as man, himself, has been studied, the not-self has encroached upon him. Nature has absorbed the body. Even the psychologist has become skeptical of spirits and souls as agents. They seem to him round squares, wholes without parts, creative energies which need no fuel. ${ }^{1}$ Animism, as we saw, has been giving way to a naturalistic interpretation of mind which cuts loose from the ghost-soul. We may say that psychology has undermined and corrected animism. Were the physical sciences to realize this fact, they would be less fearful of it. The question of the efficacy of consciousness

${ }^{1}$ Cf. Marvin, Philosophical Review, Vol. XXVII, p. 621. 
and purpose has been localized. Physics and chemistry have won their autonomy and can pursue their investigations in peace.

It is curious that the mechanical view of nature committed the reverse mistake. While animism wanted to level up, mechanicalism wanted to level down. We have noted how inevitable the mistake of animism was. It universalized man's awareness of his own activity and connected it with a ghost-like agency. The experience was real ; the theory was fallacious. Now science first paid attention to the very general properties of things, properties known through sensedata. Its categories were expressive of this material. It was at one and the same time naively realistic and mathematically descriptive. The result was what might have been expected, a preliminary survey taken too seriously. It was inorganic nature that was chiefly studied, and even it was known superficially. In fact, it is only recently that physics and chemistry have really got an insight into the internal structure and working of substances.

My argument is that the growth of the sciences has been furnishing the corrective to the old-fashioned mechanicalism much as modern philosophy and psychology have corrected animism. The critical naturalist of the present seeks to locate mind and consciousness in nature by recognizing their uniqueness and spatial limitations. He desires to harmonize categories instead of confusing them or opposing them. And he believes that evolution and critical realism enable him to accomplish this desirable task. Evolution, because of the admission of levels in nature; critical realism, because of its recognition of two kinds of knowledge. Every objective science must gain its knowledge by means of the use of sense-data. Yet, in the case of man, this knowledge should not contradict the more direct knowledge which man has of himself as a conscious organism. On the other hand, man has no right to universalize his direct knowledge of himself. If he does so, he refuses to take evolution seriously and commits the same sort of mistake mechanistic naturalism did. 
Let us now apply this mode of approach to the current controversies.

The Controversy between Mechanism and Vitalism.There are three possible ways of approach to the controversy between vitalists and mechanists: (1) the historical, (2) the pragmatic, and (3) the systematic or logical. In what follows I shall stress the logical aspects. But a few words should be said concerning the other modes of approach.

Historically, vitalism has existed largely as a protest against the rather cavalier mechanism of past epochs. Very often science tended to oversimplify its subject-matter and to rest satisfied with vague generalizations and promises. I cannot say that I blame science very much, but there was an element of pretence and dogmatism in this attitude. Still one must grant that science kept on working and doing its best. Now vitalism was often the expression of dissatisfaction with premature explanations. It pointed out difficulties and issued challenges. It cannot be denied, therefore, that vitalism has fulfilled a useful function historically. This was the negative function of protest. But, of course, scientists and philosophers who are not vitalists can perform this same office. Thus men like J. S. Haldane and W. E. Ritter, who would not call themselves vitalists, can challenge the adequacy of physics and chemistry, as these are ordinarily understood, as means of explaining biological processes. ${ }^{2}$

But mechanism performed a more positive function. It was a principle encouraging detailed experimentation bearing upon spatial structure and chemical constitution. This aspect of the question appears quite clearly both in the history of the various sciences which have contributed to our present knowledge of the organism and in the belief in what Jennings calls experimental determinism. The mechanist is constantly on the outlook for correlations between factors. He tries to analyze complexes and to find analogies in the inorganic realm. This persistent search for differences that

2 Cf. Haldane, Organism and Environment, and his contribution to the symposium: "Are Physical, Biological and Psychological Categories Irreducible?" 
make a difference has slowly opened up to view processes and correlations which at one time seemed inexplicable. One of the best illustrations of this conquest is the discovery of the rôle of the ductless glands in the economy of the organism.

Pragmatically, the vast majority of scientists favor what they call the mechanistic view of organisms because they associate it with the strenuous effort to study all the conditions and factors of a process. They think of the vitalist as one who is somewhat hopeless of solving biological problems in this bit-by-bit fashion and, accordingly, falls back on romantic speculation. Perhaps this way of contrasting the two positions is not quite fair, but there is no doubt of its existence and influence. Is not the vitalist constantly faced by the temptation to appeal to a vital force or entelechy to account for results which apparently surpass the powers of matter as revealed in the laboratory? There is more than a touch of impatience in vitalism.

But the historical and the pragmatic approaches to this controversy are insufficient. While it is clear that mechanism has somewhat the best of the debate on both counts, such an unanalytic treatment is philosophically unsatisfactory. We who have seen how completely philosophy and psychology have floundered with respect to the mind-body problem will not be surprised to find the situation paralleled in biology. After all, it is largely the same problem. The truth of the matter is that the working categories of the sciences are not sufficiently plastic and variable to cover their data. And scientists are apt to be more rigid in their speculation than in their detailed investigation. Mechanism and vitalism have mainly been contrasts of that large, vague, semi-sentimental sort that reflects points of view. There has not been enough definition and analysis.

Let me linger a moment upon a general contrast between vitalism and mechanism which was made much of in a recent symposium. $^{3}$ Mechanism was identified with determinism and vitalism with dualism. Is it not obvious that these

${ }^{3}$ The Philosophical Review, November, 1918. 
positions are not strict antitheses of each other? The dualist may be a determinist. But there is this truth about it, I think, that the vitalist is always a dualist and the mechanist a believer in the self-sufficiency of the physical realm. Now let me frankly admit that I am a mechanist if this is all that is meant by mechanism.

There are two moments in the vitalist position: the conviction that the machine-theory-as they usually designate mechanism-is inadequate, and the appeal to a non-physical agency. However it may be veiled by a philosophy-Kantian or otherwise-this double movement is discoverable. It is, as we have already argued, in the first moment that the validity of vitalism lies. Yet it is increasingly sharing this element with positions which are not vitalistic. Hence, it is in the second moment, in the appeal to something to account for what the machine-theory cannot explain, that we must find what is specific in vitalism.

Now it is my conviction that it is a mistaken philosophy which makes the vitalists dualists. As the physical world was ordinarily conceived by scientists they had a right to be dualists. They were simply more courageous and more speculatively inclined than the ordinary experimentalist. But I do not think that they were very original, or they would have attacked the adequacy of traditional mechanism and the exclusion of mind and consciousness from the organic level of the physical world. They have, it seems to me, not been courageous enough. Why did they accept the traditional limitations assigned to the physical? The suspicion will not down that they were idealists at heart. Driesch and Bergson assuredly are and, from his interest in psychical research, $\mathrm{I}$ infer that $\mathrm{McD}$ ougall is likewise. It is this too ready acceptance of the stereotyped view of the physical which betrays them.

The systematic aspect of the problem is coming to focus around the possibility of enlarging the conception of mechanism. Thus Mitchell, Haldane and Thompson agree that the older conceptions of mechanism were glittering generalities. "If what we call matter be energy that waxes and 
wanes, if we have to deal with ions rather than with molecules, if the material fabric of the universe be alert rather than inert, then the categories of physics and chemistry are moving toward the categories of biology.... And precisely as the categories of physics and biology have become less mechanical, they seem to me to approach, not to recede from, the categories of psychology." Again, "Recent developments of experimental physics and chemistry are profoundly changing these conceptions, and, as it seems to me, tending to bring physics and chemistry not only much closer to one another, but also much closer to biology." It is, in short, rather difficult to appraise the customary employment of the term mechanical. The purely kinetic meaning will scarcely stretch to cover all of chemistry.

Is, then, the physicochemical explanation of life necessarily the same as the machine-theory? I very much doubt it. I think that much ingenuity has been wasted in the defense of, and in the attack upon, the machine-theory. The following are two typical definitions of a machine. "In a machine, though all the parts are so compacted as normally to act in relation with one another so as to produce a certain joint result, yet each several part acts uniformly without relation to the rest in response to the forces operating upon it, whatever they may be." So writes Hobhouse." Joseph interprets a machine as an aggregate of parts acting variously one upon another. "In a mechanical explanation we start from the principle of inertia... The system, therefore, is a mere aggregate. Its behavior is nothing but the mathematical resultant of the behavior of its several parts." But when we compare these definitions with the actual working concepts of physics and chemistry we find a lack of equivalence. Chemical processes do not seem comparable to the action of the rigid parts of a machine upon one another. And I am decidedly skeptical whether the chemist deals with mere aggregates. I see no hope in this dialectical mode of approach. Driesch may tell us what a machine

4 Hobhouse, Life and Finite Individuality, p. 62.

S Joseph, Hibbert Journal, Vol. 12. 
cannot do; and Thompson can make the conception of a machine more subtle and assert that a machine, so understood, can do what Driesch says that it cannot do.

It seems to me, therefore, that the logical thing for the evolutionary naturalist to do is to study the characteristics of the organism and then ask himself whether these could be the resultant of evolutionary synthesis. Is the organism a mere aggregate of parts as the elementalist assumes? Or is it a unity in which the parts play into one another and the whole into the parts? I am persuaded that the latter is the case. ${ }^{\circ}$ The organism is not a mere aggregate. It is an organization in which there is differentiation of function.

And I very much doubt that chemistry can get along without the category of organization. Is a chemical compound a mere aggregate? Is there not an intimate synthesis involved? If so, the difference between the organism and the elementary chemical compound is one of degree and not of kind. And yet I would not belittle the gap which apparently exists.

The awakened interest in organization as a prime category of nature is one of the marked features of present thought. Genetic notions are passing downward from biology to chemistry and physics. Prof. Laurence Henderson is certainly right when he asserts that pattern or organization is not peculiar to living things. Were it, our problem would be almost insoluble. May not organization be the identity whose differences spell evolution? All through the argument of this book, we have proclaimed the reality of form. Every particular substance is an organized stuff. Evolution means that there are levels in nature, that the higher is an outgrowth of the lower, that $A$ and $B$ integrated are more than A and B separate.

The bio-chemist must be allowed to speak at this point. I cannot guarantee that my quotations will be typical, but they will at least be suggestive.

In his little book, The Origin and Nature of Life, Ben-

- Those who wish to follow the evidence in detail should read Ritter's, The Unity of the Organism. 
jamin Moore argues that colloidal chemistry has made the conception of spontaneous generation less repugnant because it implies a different kind. "The territory of this spontaneous production of life lies not at the level of bacteria, or animalculae springing forth into life in dead organic matter, but at a level of life lying deeper than anything the microscope can reveal, and possessing a lower unit than the living cell, as we form our concept of it from the tissues of higher animals and plants." 7 In this connection he formulates the Law of Complexity, that matter, so far as its energy environment will permit, tends to assume more and more complex forms in labile equilibrium. This law seems to conflict with McDougall's belief that degradation of energy is the principle of the inorganic realm and that organisms distinguish themselves by their ability to overcome this tendency. ${ }^{8}$

According to Hopkins, the life of the cell "is the expression of a particular dynamic equilibrium which obtains in the polyphasic system. Certain of the phases may be separated, mechanically or otherwise, as when we squeeze out the cell juices, and find that chemical processes still go on in them; but 'life' as we instinctively define it, is a property of the cell as a whole, because it depends upon the organization of processes, upon the equilibrium displayed by the totality of the coexisting phases." In such a quotation we sense a process which is more intimately unified than a machine can possibly be conceived as being.

One other point demands attention. The biologist must put stress upon time. Heredity and variation seem inconceivable without it. There must be accumulation and specificity. In modern chemistry we note with interest that time enters more and more largely. The more complex the colloidal arrangement, the longer it takes for a reaction to occur. And these reactions may be ordered in relation to one another.

'P. 189.

${ }^{8}$ Cf. McDougall, Body and Mind, 1st ed., p. 245.

- Nature, Vol. 92. 
Our systematic argument has involved two elements. We have tried to show that physics and chemistry are no longer crudely mechanistic, and we have argued that evolution consists of a temporally developed integration. It is obvious that these two elements support each other. The first argues to identity in a large sense between the organic and the inorganic; the second, to accumulative difference. Thus I obtain a discontinuity which does not conflict with genetic continuity. As I have argued in a previous chapter, growth implies both identity and difference. New methods arise, and yet these new methods do not, when their setting is taken into consideration, contradict the methods of lower levels. The higher levels cannot be led back to the lower without a remainder. We must take time and novelty seriously.

Is Organization Effective? - Many difficult questions come to a head in any serious study of organization. Thus the empirical differences of the sciences are marked. The naturalist studies various types of animals whose appearance and behavior differentiate them from each other. There is nothing in this subject-matter which resembles the field of the chemist. Again, the chemist has his phenomena which differ from those of the physicist. The empirical autonomy of the sciences is undeniable. Each has its methods and working concepts.

And yet these sciences interact. Usually the biological sciences have gained more from the physical sciences, though there are many instances in which the assistance has been the reverse. On the whole, the tradition has been that the scientific ideal is to reduce the biological sciences to the inorganic sciences. "In what," writes Lovejoy, would a $Z u$ rückführung of biology to chemistry or physics consist? It would consist in showing that a given organic process $\mathbf{A}$ can be subsumed under and deduced from a given generalization B of the more 'fundamental science." "10

Now I am very skeptical of such a reduction. I grant 10 Science, N. S., Vol. XXXIII, p. 611. 
that there are always elements in any process which can be understood only in terms of physics and chemistry. But is there not the setting of the process and its linkage to be accounted for? In this peculiar whole, there is control and interdependence. It is physics and chemistry, and yet not entirely the familiar physics and chemistry. As I understand him, this is the point made by Haldane. It is not that any new entity has made its appearance, but that the system has become more complex and more highly organized. It is super-chemistry if you will. Mere reduction lays stress upon analysis and forgets the reality of synthesis.

The statement that life is a chemical process is correct when it means that no strange, non-physical factor has entered and that the processes which go on in the living organism are continuous with ordinary chemical processes in the laboratory. But such a claim, true as it is, is only negative. It avoids the real problem. It can as well be said that chemical processes are nothing but physical processes because the chemical element is an evolutionary product of lesser particles. Are we not laying stress upon the material and disregarding the form? It is the organization which is novel and with which new properties must be correlated. We saw the same problem in the contrast between physiology and behaviorism. It is the action of the organism as a whole which the behaviorist studies.

Logically, we are confronted once more with our old friend discontinuity. It will be remembered that we decided that the evolutionist must hold that genetic continuity admits both identity and difference. In other words, the identity must be of a kind to permit difference. The identity, in this case, is the objective significance of organization. The differences consist in the rise of kinds and orders of organization. It is with this that we must correlate new properties.

I know of no capacity of the mind which will enable it to predict evolution. To do so, it would have to create anticipatively. The human mind discovers by empirical investigation what nature has already accomplished. It proceeds from stage to stage after nature. Only the kinetic 
atomist could expect to anticipate deductively, and that because he holds that there is no creation. Creative synthesis implies the relative autonomy of the sciences and their logical discontinuity. It encourages empiricism. Since laws are human formulations, expressive of data, it is nonsense to speak of the laws of one level as contradicting those of another. To do so is to commit the fallacy of accent; it is to disregard the setting of the law.

In support of my thesis, that organization is objectively significant, let me call attention, first, to the nature of instinct, and, second, to the method of thought. I hold that what is true of the higher levels is in its measure true of the lower levels.

That instinct is the expression of organization is the conviction of both biologists and psychologists. Thus Bergson writes as follows: "It has often been remarked that most instincts are the prolongation, or better, the achievement of the work of organization itself. Where does the activity of instinct begin? Where does that of nature end? It is impossible to say. In the metamorphoses of the larva into the nymph and into the perfect insect, metamorphoses which often require appropriate adaptations and a kind of initiative on the part of the larva, there is no sharp line of demarcation between the instinct of the animal and the organizing work of the living matter." W. M. Wheeler quotes this and adds: "Viewed in this light there is nothing surprising about the complexity and relative fixity of an instinct, for it is inseparably correlated with the structural organization, and in this we have long been familiar, both with the dependence of the complexity and fixity of parts on heredity and the modifiability of these parts during the life-cycle of the individual."11

But the evolutionary naturalist sees no need to postulate an élan vital creating organization out of recalcitrant matter. Bergson accepts a sharp break between the organic and the inorganic, whereas the evolutionary naturalist refuses to

${ }^{11}$ Quoted from Ritter, The Unity of the Organism, Vol. 2, p. 312. 
do so. ${ }^{12}$ And it is clearly this break which leads to Bergson's vitalism and to his speculative metaphysics in which matter is a degradation or lessening of tension. The evolutionary naturalist is not a finalist. $\mathrm{He}$ is a believer in the novel, in time and creative accumulation. He extends time back to the non-living and makes the distinction between the living and the non-living one of degree.

It is a commonplace of logic and psychology that thought involves the organization of experience. The solution of a problem grows out of the application of relevant ideas to the novel situation and expresses the creative synthesis which ensues. There is interrelation, selection and novelty. The past is integrated and gives birth to something relevant to the present. Is it absurd to suppose that something analogous to this occurs throughout the organism? The mind's method of working cannot be completely novel since, in our opinion, it is the method of neural integration at the cerebral level.

Our conclusion is that organization is objectively significant and causally effective. Function and structure go together at every level. Function is but the active phase of structure. In no other way can we interpret evolution and bring mind and body together. From these considerations, we are justified in regarding evolution as the active rise of new wholes with new properties. These wholes can, of course, be disintegrated-as death only too clearly showsbut the products of the disintegration are not the equivalent effectively and qualitatively of the whole. This denial of equivalence must not be interpreted to mean that there is not quantitative equivalence. Quality is not a simple function of quantity.

The Organism as a Particular Substance. - It will be remembered that, in the chapter entitled "Change, Identity and Conservation," we stressed the fact that a physical thing is the product of its history. The organism is a striking case of this cumulative integration in which the past lives

12 I have the additional right to make this statement that it was made to me by Bergson in conversation some ten years ago. 
on into the present as a structure able to function differentially. Time sinks into space, as it were. Any part of reality changes and is internally modified by this active change. The organism is an individual thing which arises step by step, each stage making possible something which before had been impossible. It is to this idea of internal packing that our ordinary concepts of space are inadequate. It is clear, however, that cumulative organization does not contradict space but deepens it.

This problem of organized packing is important. There must be creative synthesis in which new properties and capacities arise. And yet this rise of higher levels must rest upon and but carry out the potentialities of the lower levels. It is the specificity and individuality of the organism which we must stress. It is a differentiated system whose parts are specialized. What each part does is for the sake of the whole, and yet there is no reason to assume purpose in it. It is an order which presupposes the order with which chemistry concerns itself and yet goes beyond it. And it is this order, alone, which explains what happens in the system.

Let me put my argument in another way. The organism is a physical system. It is a system in which there is division of labor and interdependence. All that can be learned about it by all the sciences is true of it. All that physics can find out about it is true; the same holds of chemistry, physiology and psychology. It is simultaneously the object of all these judgments. And, yet, so far as each science has a specific point of view and technique, it cannot exhaust the reality of the organism. Valuable as each physical science is, it is too analytic and disintegrative to deal truly with such a highly evolved unity as an organism. Organization is objectively significant. It would require a superchemistry, able to take differentiation, organ-formation and division of labor into its purview, before a purely chemical interpretation of the body could be achieved.

If we take the unity of the organism seriously, it would seem to follow that chemical processes in the organism are 
not necessarily exactly like those which occur in the laboratory. The setting of a process is surely important. There would be similarity with difference. It is for the bio-chemist to tell us whether this is the case. Does oxygen act in the organism as it does outside? The facts indicate a difference.

The Light Mind Throws Upon the Organism.-If, as we have argued, mind is a physical category applicable to the organism acting as a whole, the character of mind and the structure and content of consciousness should throw light upon the internal working of the brain. The acquaintance we have with consciousness should enable us to supplement knowledge through sense-data.

Now it is generally conceded that consciousness has a specific, empirical unity expressive of the past experience of the individual and the dominating purpose. There is creative integration and functional supplementation. This unity and compresence must arise out of, and relate to, the functional unity of the brain. There must be an intimate coalescence which is contradictory to any atomistic conception of the brain. The brain must be as rich and as unified as mind and consciousness. Thus knowledge of the self forces us to relinquish the stereotyped pictures of real space which past science often encouraged. The organizing capacity of the brain-mind is revealed in percepts and concepts which sum up so much of past experience. In these, as in character, expertness and personality, there is both conservation, integration and novelty. Mental operations combine and create. And I do not hesitate to assert that it is just this that the organism does. The choice seems to me plain: either we must become dualists refusing to admit a correspondence of method between brain and mind or cease to put our conception of the brain in a strait-jacket. Mind cannot be reduced to a kinetic series.

Empirical Teleology in Biology.-When the biologist carefully studies the internal working and even the behavior of organisms he witnesses processes so ordered in relation 
to each other that the welfare of the particular organism is furthered or the survival of the species is aided. This internal economy by means of which certain processes function in relation to others as means to end may be called empirical teleology. It involves both a temporal and a spatial ordering. Each organ has its function, or functions, which assists in the working of the whole. There is interplay and interdependence. The temporal ordering appears in certain cycles and in the instincts where one act is the condition of another.

This ordering is maintained by structural and functional coordinations. And there is in it all the appearance of Zweckmässigkeit or directedness to an end. The Greek word teleology has been adopted as descriptive of this sort of ordered economy. Because this teleological economy resembles the internal order of the elements of a plan in which means are selected as conducive to an end, it is sometimes called purposive. But it would be wrong to forget that we have only an analogy between two fields which are otherwise dissimilar. We must not drop back unwarily into naive anthropomorphism.

Our knowledge about the organism as a functioning organization discloses an empirical teleology which differentiates it from inorganic things. Here we are confronted with a fact which cannot be ignored. The problem is this, Can we fit this characteristic of organic life into evolutionary naturalism?

Much of the discussion of this question has concerned itself with the problem of genesis. The pre-Darwinian argument held to a design carried out by a divine technician. Since biological knowledge was very superficial, little was known of dysteleologies and imperfections. But this Paleyism made the mistake of thinking of the organism as a machine. It was a machine made by a supernatural designer.

Darwinism challenged the assumption of design in nature by suggesting a natural genesis for what had been interpreted as design. The older argument had been as follows: There are features of the organic world which are like hu- 
man designs in certain regards, though not within man's power to achieve. Now these features cannot be accounted for by random combinations of atoms, by what is usually called chance in such literature. Hence there must be a supernatural workman who planned the structure of the organism. Darwinism was epochal in that it opened a path to genetic explanation of a naturalistic sort.

But is Darwinism adequate? That natural selection is one of the factors of evolution there is no doubt; but are there not other, and more positive, factors? Bergson is not the only one to attack the theory that slight indeterminate variations are sufficient. The empirical evidence seems to indicate both determinate and dispersed variation. The capacities of the organism must be rated higher in the biological thought of the future. The philosopher can confidently leave the matter to the biologists, certain that the barren contrasts of the past will be left behind. Design, random chance and a creative life-force are not the only possibilities. We who have stressed the objective significance of organization do not think of the organism as a product of purely random combinations. There must be cumulative determinism. To cut loose from a priori kinetic ideas of change is assuredly a prime requisite of a more empirical approach.

Does the creative purposiveness of the brain in ontogenetic adjustment throw any light upon phylogenesis? I would not belittle the analogy as long as the differences are kept in mind. There may be many stages between random aggregates and intelligent planning. There may be creative adjustments in the germs which, while not guided by ideas, are yet broadly coordinative. If function helps to determine structure, it is quite possible to conceive a non-vitalistic élan vital. The part played by organization in instinct and in intelligence may easily have its counterpart in the more obscure processes which geneticists study. To underestimate the physical world is a mistake. 
Purpose and Efficient Causality.-The traditional difficulty surrounding the inclusion of purpose in efficient causality reflected metaphysical dualism, on the one hand, and confusion in the correlation of time with space, on the other hand. Its historical origin is found in Plato's rejection of Democritean atomism. We can sympathize with both Plato and Democritus and asserts that they each saw a side of the truth.

Plato was interested in showing that mind is effective. All students of his Dialogues will remember the passage in the Phædo which concerns itself with the explanation of Socrates's conduct. "As I proceeded, I found my philosopher altogether forsaking mind or any other principle of order, but having recourse to air, and ether, and water, and other eccentricities. I might compare him to a person who began by maintaining generally that mind is the cause of the actions of Socrates, but who, when he endeavored to explain the causes of my several actions in detail, went on to show that I sit here because my body is made of bones and muscles.... But to say that I do as I do because of them, and that this is the way in which mind acts, and not from the choice of the best, is a very careless and idle mode of speaking." But how is mind related to these conditions? That is the question the ancient world did not answer.

Aristotle tried to make a compromise. "Democritus thought that an event is determined only through what preceded it; Plato thought an event determined by what shall issue from it . Aristotle sought to reconcile this antagonism, and so he attributed to matter one kind of determination and to form the other kind." ${ }^{13}$ But we have gone still more deeply to unite matter and form. By making form an objectively significant character of matter we have modified blind necessity and inoculated it with mind. Integration is a variable in nature but an effective variable; and, as we have frequently pointed out, intelligence is a function of the highest level of integration. In short, intelligence is a variable in nature. It has a specific locus and definite condi-

${ }^{13}$ Windelband, History of Ancient Philosophy, p. 265. 
tions. The flaw in the older metaphysics was to ignore this fact.

Much of the misunderstanding of purposive action is due to the confusion of real, or physical, time with mental temporal distinctions. An idea as an effective existent must be correlated with the physical present, but the same idea may have the meaning of a future event. In ordinary parlance, it is a thought of the future. Common sense is nearer the right in this than many sophisticated philosophers have been. It is not the future which guides action but the present thought whose content has the future as part of its meaning.

Objectively, behavior is purposive when it displays an ordering of action-parts in such a way as to lead to results related to the needs of the organism. Usually it is beneficial. By miscalculation or mischance, the result may be harmful. Yet the specific feature of purposive action is the ordering of action in a way adaptive to an independent nature and satisfactory to the organism.

Subjectively, or in the individual's experience, the ordering of action implies a plan in which means are correlated to an end. The plan is an internal stimulus or control of a decidedly complex sort which effectively guides the drive of the organism. Experience contains a transitive linkage of forethought and final experience. We conclude that the plan as an internal stimulus is a part of the efficient cause. Socrates stayed in Athens because of "the choice of the best." We have naturalized mind and choice and, by so doing, have healed the breach between Democritus and Plato.

Purposive action is, then, only a species of empirical teleology. The brain-mind is an organ whose function is the adjustment of the individual. To accomplish this function it requires plasticity of a high degree. There must be anticipation and flexible ordering of actions. For all this consciousness is clearly necessary. That the possibilities thus opened up would react upon the individual and lead to unprecedented modes of life was to be expected. Experi- 
ence guides, elicits and creates. Yet it must not be forgotten that mental capacities are as much products of evolution as are digestive capacities. Purpose is an expression of the empirical teleology of organic development. Consciousness is not a lyric cry in the midst of business. It is a tool without which human business cannot be carried on.

Suggestions and Implications.-In controversial literature, naturalism has been so completely identified with the reduction of the higher to the lower that it will be hard to rescue the term from opprobrium. But intellectual honesty demands that the battle be made. Man will understand himself and his life only after he sees himself as a child of nature. Romantic dreams are in the long run a source of weakness rather than of strength. They cast a veil of obscurity over the situation and undermine the intellectual virility of which man stands so much in need.

But while man is a child of nature he possesses powers and abilities not elsewhere come to fruition. The stream can rise higher than its source. Man is of nature and yet above her. It is clear that pluralism with its permission of heterogeneity comes to the rescue of evolutionary naturalism and frees it from what might otherwise be a paradox. It is the specificity of the part which justifies the statement that man is of nature and yet above her. The older naturalism tended toward cosmical equalitarianism; the newer naturalism recognizes levels and differences. It is both humanistic and naturalistic. ${ }^{14}$

The ethics of naturalism should be empirical. I admit the unreality of much of the naturalistic ethics which flourished immediately after the victory of Darwinism. The struggle for existence was much overdone. Too much emphasis was laid upon fixed instincts. Thought was elementalistic in its approach. But surely that was a fault of the

14 I take this opportunity of replying to some of the theologicallyinclined critics of my The Next Step In Religion. To their mode of thought, it seemed strange that I should hold man to be a part of nature and yet capable of loyalty to values of an ideal sort. To me, their mode of thought is typical of the perversion nourished by the dualisms of the past. 
time which has been outgrown. I have no objection to trenchant criticisms of the ethical naturalism of a transitional period; but I do object to the assumption that naturalism is logically bound to such views. Man creates, sublimes, revalues. His experience opens up new vistas for action and contemplation. Yet, as contemporary psychology is making clear, the superstructure must be reared on the instinctive foundation which he has inherited. There must be organic reverberation and warmth. How clearly this fact has been shown in esthetics! The psychologist has traced the sense of beauty to the creative synthesis of organic harmonies of subtle kinds and to their sympathetic projection or Einfühlung. To the older philosophical thinker, the sense of beauty was supposed to be a gift having no organic connection with the rest of man's endowment. How, then, could it be accounted for on naturalistic principles? So Wallace and Balfour.

I have said little about values and value judgments, preferring to treat of them more fully at a later time. It is obvious that $I$ hold that value-judgments do and must fit into the cosmos as this is revealed in knowledge. Values concern man's response to, and estimation of, things. They are always guided by knowledge though they contain other elements of a more affective and volitional nature. Though they are conditioned objectively by the nature of their objects, they are yet primarily personal and social, that is, human.

Values are usually classified as instrumental and intrinsic. Things and acts are valued as tools or means to results which are valued for their own sake. Intrinsic value is an experience and implies consciousness. Instrumental value involves two elements; one, objective causal conditioning, and the other, the intrinsic value of the result cast back upon the cause. There are, again, different kinds of intrinsic values and value-situations, such as the ethical, the economic, the vital and the esthetic.

But the pluralistic naturalist does not assign intrinsic value to the universe as a whole. Value is not for him an 
universal metaphysical category like space, time, causality and structure. The cosmos is and has its determinate nature. As man values himself and his works, he may rightly assign value to the universe which conditions them and permits them to be ; nay more, which is made of stuff which had the potential power to raise itself to self-consciousness in him. Man's life is not adventitious, though it may be transitory.

But the naturalist is skeptical of any other assignment of value to the universe. There is no central, brooding Will which has planned it all. The good is not the sun of things from which they get their warmth and inspiration. Ethical metaphysics results from a wrong ordering of categories, a neglect of their setting and context.

Once again, the pluralist escapes in a measure the contrast between optimism and pessimism. He refuses to judge things in this wholesale fashion. He is not inclined toward a hedonistic calculus, nor does he see how he could secure the data for it. Furthermore, the theodicistic motive does not exist to urge him to valuative accounting. Sizing up the situation in terms of human life, he stresses the possibilities in the way of intelligent control and betterment. Let man place his hope in those powers which raise him above the level of the ordinary causal nexus. It is in himself that he must trust. If his foolishness and his passions exceed his sanity and intelligence, he will make shipwreck of his opportunity. And after somewhat the same fashion does this, and ever will it, apply to individuals. The pluralist does not take immutable laws and Schicksal too seriously in these things.

Evolutionary naturalism does not sink man back into nature. It acknowledges all that is unique in him and vibrates as sensitively as idealism to his aspirations and passions. Its claim is that its eanvas is larger and its perspective truer. 


\section{Index}

Absolutism, 196, $240 f f$.

Activity, motion force and-, ch. XI, pp. 216-238.

Agency, the idea of, $242 \mathrm{ff}$.

Agnosticism, 32, 235.

Alexander, referred to, 281.

Angell, quoted, 90 ; referred to, 236.

Animism, 292, 322f.

Antinomies, Kants', 102, 113.

Archimedes, referred to, 229.

Aristotelianism, 147, 173f, 175, 183, 264.

Aristotle, referred to, 112, 167, $174,229,235,260,264,339$.

Aspects, of things, defined, 136.

Associationism, 18.

Atcmic, the-view of nature, $175 f f$.

Avenarius, referred to, 28.

Balfour, referred to, 342 .

Beginning, had the world a-? 121.

Behavior, of organisms, 299ff ; purposive, $340 f$.

Bergson, quoted, 113, 158, 226, $274,304,305,309,333$; referred to, 36, 59, 83, 85, 97, 151 , $170,189,203,216,224,236,259$, $263,274,275,286,288,291,295$, $305,315,327,334$.

Berkeley, quoted, 233,236 ; referred to, $27,28,31,54,64$, 126, 139, 143, 235.

Biology, 191f, empirical teleology in, 336ff.

Bosanquet, quoted, 22, 23, 77, 135 ; referred to, $134,306,274$, 284.

Boscovitch, referred to, 220 .

Bourdon, quoted, 86.

Boyle, referred to, 176.

Bradley, referred to, $99,134,207$, 236, 306.
Brain, the, and consciousness, $307 f f$.

Broad, quoted, 201.

Büchner, quoted, 8.

Cartesianism, 289, 315.

Categories, status of the, ch. IV, pp. 64-82; 78ff; development of the, 71 .

Casuality, uniformity and-, ch. XII, pp. 239-259; levels of, 302 ; the basis of uniformity, $254 f f$; a deepening of time and change, $256 f f$.

Certainty, probability vs, $268 \mathrm{ff}$.

Chance, subjective vs. objective, $270 \mathrm{ff}$.

Change, and identity and conservation, ch. VIII, pp. 145172 ; for time, 119, 154; of things, 149 ; for science, $157 \mathrm{ff}$; self-identity and, $168 f ; 241$.

Cognition, 61.

Cohen, referred to, 174

Connections, physical-and relations, ch. X, pp. 194-215; theof things, $200 \mathrm{ff}$.

Consciousness, different meanings of, 45ff; a functional expression of the brain, 58; for the psychologist, 66; the pattern within, 70 ; relation between-and the brain, 307; nature of, $286 \mathrm{ff}$; nature and function of, $310 \mathrm{ff}$; and mind, 315 ; the evolving of, 284 f.

Conservation, change, identity and, ch. VIII, pp. 145-172; principle of, 103; and evolution, $161,260$.

Content, of perception, 33, 43, 65.

Continuity, 96f, 195, 199, 284, 297.

Controls, the, 42. 


\section{INDEX-Continued}

Copy-theory, the, 31, 37f.

Couturat, quoted $268 \mathrm{f}$.

Creation, 121.

Critical realism, 20, 21f, 34, 38, 54, 77f, 195f, 204f, $233 \mathrm{f}$.

Darwinism, 4, 337f, 341.

Data, sense-as material for knowledge, 37; for science, $184 f$.

Democritus, referred to, 59,100 , 131, 174, 279.

Descartes, referred to, 59, 100 , 131, 174, 279.

Determinism, objective, 272; casual, 276f.

Divisibility, of nature, 104.

Dreisch, referred to, 327, 328f.

Dualism, epistmological, $22 \mathrm{f}$.

Dynamism, Eleaticism vs., $177 \mathrm{ff}$.

Einstein, referred to, 104, 216, $221 \mathrm{ff}$.

Eleaticism, 159, 173, 197, 215, 216, 263; vs. dynamism, $177 \mathrm{ff}$.

Elements, the Aristotelian, 174f.

Empiricism, 205; vs. psychologism, 67 ; vs. nativism, 89f.

Energy, kinetic, 230.

Epiphenomenalism, 277.

Epistemological situation, the, $303 f f$

Epistemology, of evolutionary naturalism, chs. II and III, pp. 21-63; a critical science, 66.

Eristic, in philosophy, $77 \mathrm{f}$.

Ethics, the, of naturalism, $341 \mathrm{ff}$.

Evolution, 13, 273, 284, 297, 329, 332 ; and conservation, $160 f$, 260.

Existence, and subsistence, $57 \mathrm{ff}$.

Experience, field of the individual's $66 f$; the pattern of, $67 \mathrm{ff}$; distinctions in the field of the individuals, $68 \mathrm{f}$.

Experience-in-general, Kant's, 49.

Extension, defined, 101.

Fabre, referred to, 272

Faraday, referred to, 101.

Fate, 271.

Ferrier, referred to, 70 .

Force, motion, and activity, $\mathrm{Ch}$. XI, pp. 216-238; psychological nature of, 229.
Freudianism, referred to, 276, 315.

Fullerton, quoted, 182f; referred to, 182 .

Gautama, referred to, 169.

Generation, spontaneous, 330 .

Gibson, referred to, 138.

Gissing, quoted, 291.

Haeckel, quoted, 9; referred to, 196, 297.

Haldane, quoted, 180; referred to, $325,327,332$.

Hegelianism, 74f.

Henderson, quoted, 269; referred to, $269,270,329$.

Heraclitus, referred to, 226, 263.

Hobbes, quoted, 112.

Hobhouse, quoted, $327 \mathrm{f}$.

Hodgson, referred to, $29 \mathrm{f}$.

Hoernlé, quoted, 133, 134.

Holt, quoted, $269 \mathrm{f}$.

Hopkins, quoted, 330 .

Hume, referred to, $10,28,34$, $59,64 \mathrm{f}, 69,73,89,129,149$, $169,230,236,244,246,254$, 257, 266; vs. Kant, $251 \mathrm{f}$.

M13 10 1-2 picas scott 10-28

Idealism, d, $11 \mathrm{ff}, 50$; function of, 27; objective, 11f, 65, 74ff, 134f, 212 ; subjective, 135 ; empirical, 135 ; Berkeley's, 139.

Identity, change, - and conservation, Ch. VIII, pp. 145-172; and change, $146 \mathrm{f}$; self- $168 f f$; logical, 171.

Individuality, meaning of, 164.

Infinity, 96f.

Instinct, nature of, 333.

Interactionism, 290f, 314; and parallelism, $293 f$.

Intuitionalism, 235.

James, quoted, 17, 87, 104, 106, $108,122,218,219,237,283$; referred to, 236, 237, $280,284$.

Jennings, referred to, 325 .

Joseph, quoted, 328.

Judgment, categorical, 270.

Kant, quoted, 114 ; referred to, 3 , $10,22,34,49,64 f, 72 f f, 81,85$, $87,121 \mathrm{f}, 226,279$; vs. Hume, $251 f$; his antimonies, 102 ; on time, $113 \mathrm{ff}$. 
Kantianism, 72ff.

Kelvin, referred to, 220.

Kinematics, 228.

Kirckhoff, quoted, 229.

Knowledge, nature of, 21, 28; common-sense view of, $24 f$ : object of, 34; definition of, 35 ; -about, 35f ; conditions of, 36, 39 ; content of, 37 ; Greek view of, 38 ; the grasp of, 50 ; act of, 42 ; critical, 45 ; of other minds, 52ff; as truth, 55; a function of the organisms capacities, 74; method of, $198 \mathrm{ff}$.

Land, referred to, 236.

Lechalas, referred to, 95 .

Leibniz, referred to, 84, 203, 204, 233, 237, 306.

Life, of the cell, 330 ; a chemical process?, 332.

Locke, quoted, 138; referred to, $34,59,85,139,144,171,182 \mathrm{f}$, $193,290$.

Lodge, referred to, 297.

Logical considerations, 210.

Lovejoy, quoted, 263, 312, 331.

McDougall, quoted, 292; referred to, 309, 327, 330.

McGilvary, referred to, 12.

Mach, referred to, 10, 28, 229, 254.

Marvin, referred to, 323.

Mass, $176 f$.

Materialism, 7ff; and panpsychism, $317 f f$.

Mathematics, and science, $220 \mathrm{f}$.

Matter, old idea of, 7; -and force, 8.

Maxwell, referred to, 310 .

Meanings, realistic, $125 \mathrm{f}$.

Measurement, scientific, 115, 184.

Mechanics, 234.

Mechanism, and teleology and purpose, Ch. XV, pp. 320-343; and vitalism, $325 \mathrm{ff}$; its false use of potentiality, 283 .

Meinong, quoted, 42 .

Memory, and expectation, 109.

Mental, the, definition of, 60 .

Mill, referred to, 135, 143, 249, 260.

Mind, why excluded from the organism? 294f; as a physical category, 299.
Mind-body problem, evolutionary naturalism and the -, Ch. XIV, pp. 286-319; traditional formulations of, $287 \mathrm{f}$; traditional solutions of, $289 f$.

Mitchell, quoted, 204; referred to, 327 .

Monadism, $203 f$.

Monism, epistemological, 28; the critical realists', $195 \mathrm{ff}$, idealistic, 20f; logical, 212f; 313.

Moore, Benjamin, quoted, 330 .

Moore, G. E., referred to, 133, 134.

Motion, and force and activity, Ch. XI, pp. 216-238; and force, $231 \mathrm{ff}$.

Movement, symbolical representation of, 112; vs. the path traversed, $227 f f$.

Müller, referred to, 103.

Naive realism, difficulties confronting, $133 \mathrm{f}$.

Nativism, vs., empiricism, 89.

Naturalism, requircments of an adequate, Ch. I, pp. 1-20; attacks upon, 4 ; and modern science, 5 ; objection to, 13 ; inadequacy of past, $16 f ;-$ of reduction, 17; evolutionary, 18ff; two common forms of, 6ff; idealistic criticism of, 13ff; epistemology of evolutionary, 21-63; and the mind-body problem, 286-319; blindness of older, $320 \mathrm{f}$.

Nature, and the categories, 81f; atomic view of, $175 \mathrm{ff}$.

Necessity, potentiality,-and novelty, Ch. XIII, pp. 260-286; in nature, 257; how shall we conceive-? $278 \mathrm{ff}$.

Neo-realism, referred to, 28,44 , $48,60,85$; and subsistents, 57 ; and pragmatism, 76.

Newcomb, quoted, $95 \mathrm{f}$.

Newton, referred to, $100 f, 111$, $117,176,223,230$.

Novelty, potentiality, necessity and-, Ch. XIII, pp. 260-286; and potentiality, $263 \mathrm{ff}$.

Object, of perception, 33, 42f, 65 .

Objectives, the, 42.

One, the, and the many, 162f, 200. 
Organism, the, as a particular substance, 334; added knowledge about, 302ff; the light mind throws upon the-, 336; is the resultant of its history, 168.

Painlevé, quoted, 230.

Panpsychism, 50f, 317ff ; Fechnerian, 166.

Parallelism, and interactionism, 293f ; empirical, 307.

Parker, referred to, 306.

Pearson, referred to, 10.

Perception, object of, 33, 43; content of, 33, 43.

Perry, quoted, 75 ; referred to, 63, 138, 236.

Phenomena, Kant's, 65.

Pillsbury, quoted, 218.

Planck, referred to, 104.

Plato, quoted, 339; referred to, $100,163,339$.

Platonism, referred to, 2, 211, 262.

Pluralism, 195ff, 273.

Poincaré, quoted, 95 ; referred to, 10.

Positivism, 10.

Possibility, and impossibility, $266 \mathrm{ff}$.

Potentiality, and necessity and novelty, Ch. XIII, pp. $260-286$; defined, 282ff.

Powers, and properties, $142 f$.

Pragmatism, referred to, $12,55 \mathrm{f}$; interpretation of, $311 \mathrm{f}$; and neo-realism, 76ff; and Platonism, 163.

Predictability, 258.

Present, the specious, $108 \mathrm{f}$.

Probability, vs. certainty, $268 \mathrm{ff}$.

Process, neural, 308f, 316.

Properties, things and their, $\mathrm{Ch}$. VII, pp. 124-144; defined, 136, 148; as cases of knowledge, $140 \mathrm{f}$; constant, 142 ; extra-organic foundation of scientific, 186 ; correlation between scientific properties and sensations, 186; primary and secondary, 188.

Psychology, traditional; 46, 304; of to-day, $46 \mathrm{f}, 67 \mathrm{f}$; development of, 298; behavior-, 300; and experience of motion, 218.
Purpose, mechanism, teleology and,-Ch. XV, pp. 320-343; and efficient causality, 339.

Qualitative view of the world, $147 \mathrm{f}, 174 \mathrm{f}$.

Qualities, the primary and secondary, 181ff; all sensationalare subjective and none are unreal, $189 f$.

Quantitative view of the world, $148,175 \mathrm{f}, 190 \mathrm{ff}$.

Quantities, and qualities, Ch. IX, pp. 173-193.

Radical empiricism, $28 f$.

Read, quoted, 29; referred to, $28 \mathrm{f}$.

Realism*, 12 ; non-apprehensional, 181 ; common sense, 26 ; the paradox of common sense, 137 ; Lockian, 138, 192.

Reality, for Locke, 138; for the modern thinker, 138.

Relation, the cognitive, $44 \mathrm{f}$.

Relations, physical connections and-, Ch. X, pp. 194-215.

Renouvier, referred to, 179.

Ritter, quoted, 191f ; referred to, $166,325,329$.

Roux, quoted, 180.

Royce, cuoted, 206, 211f ; referred to, $30,134,136,194,216$, 222, $224 \mathrm{f}$.

Rutherford, referred to, 179.

Saint Augustine, quoted, 105.

Scholasticism, 3.

Schopenhauer, referred to, 85 , 122.

Schelling, referred to, 196.

Science, and naturalism, $5 \mathrm{f}$; and philosophy, 2, 288f ; outlook of, $156 \mathrm{f}$; change for-, 157; new categories of, 296 ; new tendencies in, 296ff; interaction of sciences, 331; and data, 185; and mathematics, 220; and empirical uniformities, 252ff; and category of probability, $268 f$.

Scientists, and philosophy, $8 f$, $183 \mathrm{f}, 321 \mathrm{f}$.

Selection, natural, 338.

*Cf. critical realism, naive realism, neo-realism. 


\section{INDEX-Continued}

Self, the, 169f, 275f ; and notself, $70,128,129 \mathrm{ff}$.

Sense-data, as material for knowledge, 37.

Shakespeare, quoted, 111.

Shearman, referred to, 97.

Silberstein, quoted, 116, 117.

Simultaneity, 222.

Socrates, referred to, 339.

Soddy, referred to, 232 .

Soul, the, 289ff.

Space, Ch. V, pp. 83-104; a strategic category, $84,98 f$ : sensational, 86 ; perceptual, 88 ; conceptual empirical, 91f; mathematical, 93f, 224; Bergson's treatment of, 97; and time, $219 f f$.

Spaulding, referred to, 76, 85 .

Spencer, quoted, 8.

Spinoza, referred to, 196, 278, 286, 289.

Spiritualism, 15; and space, 84.

Stout, quoted, 105, 107, 111, 127, 128 ; referred to, 236.

Strong, referred to, $30 f$.

Stumpf, referred to, 89 .

Subject-self, the, 49.

Subsistence, and existence, $57 \mathrm{ff}$.

Subsistents, 23, 61 .

Substance, $138 f$.

Supernaturalism, 3, 13, 197.

Taylor, quoted, $255 \mathrm{f}$.

Teleology, mechanism,-and purpose, Ch. XV, pp. 320-343; empirical-in biology, 336ff.

Terms, explanation of, 35 ; the traditional metaphysical, $202 f f$.

Thesis of evolutionary naturalism, the, $298 f$.

Thinghood, boundaries of, 152 .

Things, and their properties, $\mathrm{Ch}$. VIII pp. 124-144; and change, 154f; as physical systems, 155; nature of physical, $126 f$; aspects and properties of, 132.

Thompson, quoted, 286 ; referred to, 327, 329.

Thought, four uses of term, 78.

Time, Ch. VI, pp. 125, 123; space and, 219ff; common or stand. ardized, 110; and causal uniformity, 254f; subjective and objective, 111 $f$; mathematical, 112 ; as a scientific category, $115 \mathrm{f}$.

Transcendence, $48 \mathrm{f}$.

Truth, the question of, $55 \mathrm{ff}$.

Tychism, $272 \mathrm{f}$.

Tyndall, referred to, 283, 284.

Uniformity, and causality, Ch. XII pp. 239-259; causal, 245: the postulate of, 247ff; and science, $252 \mathrm{ff}$.

Uniqueness, the category of, $166 f$.

Unity-theory, 294.

Universal, the, its status in knowledge, $38 \mathrm{f}$.

Values, $342 \mathrm{f}$.

Vitalism, 15, 292, 277 ; and mechanism, 325ff.

Void, the, $103 \mathrm{f}$.

Wallace, referred to, 342 .

Ward, quoted, 65f, 94, 242, 260 , 323 ; referred to, $8,11,70,90$, 203, 236.

Watson, quoted, $300 f, 308$.

Wheeler, quoted, 333.

Will, free, 250, 274, 276, 279, 281.

Windelband, quoted, 339.

Zeller, quoted, 264.

Zeno, quoted, 224; referred to, 216 ; paradoxes of, $224 \mathrm{ff}$. 



$$
\text { - }
$$






$$
\Sigma
$$




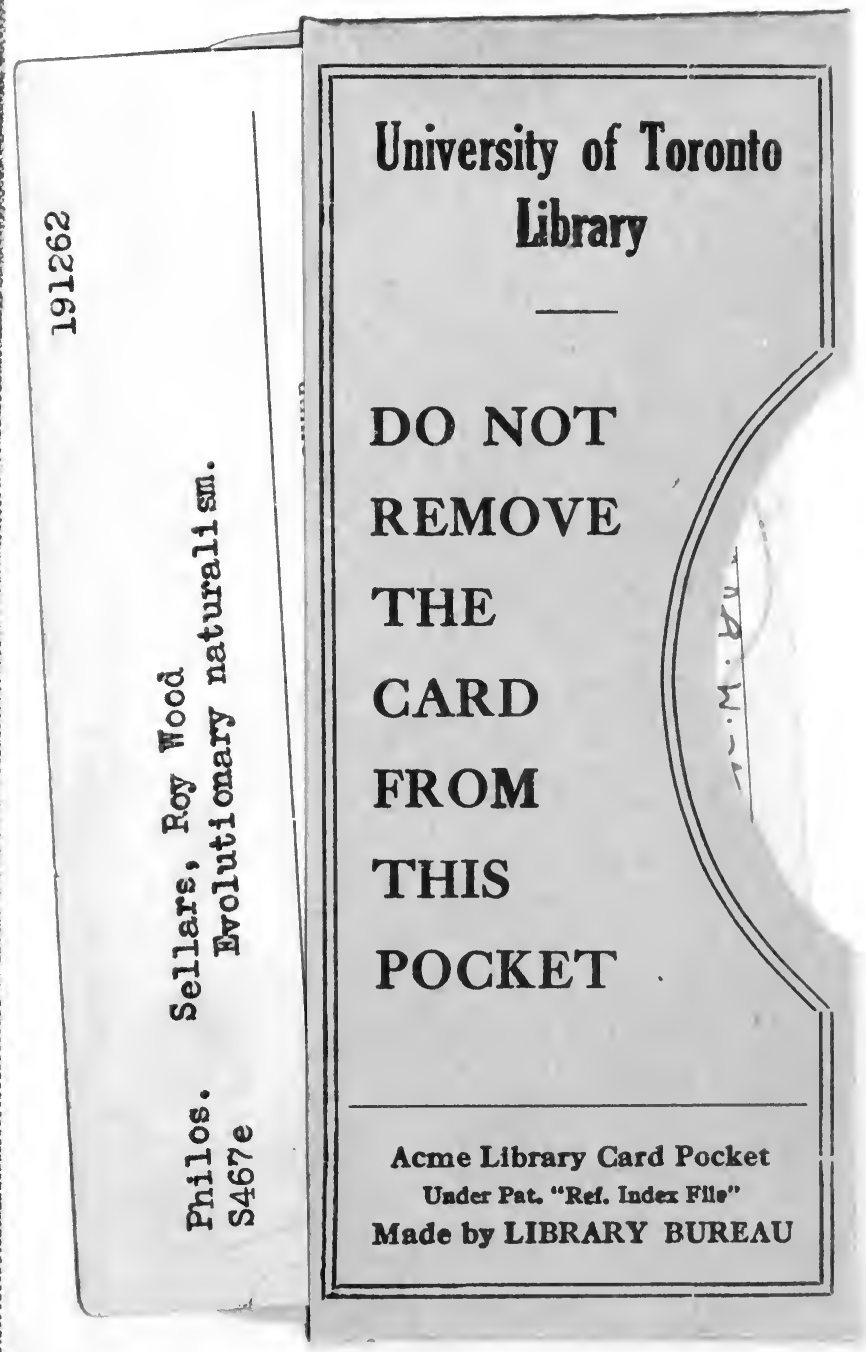


